



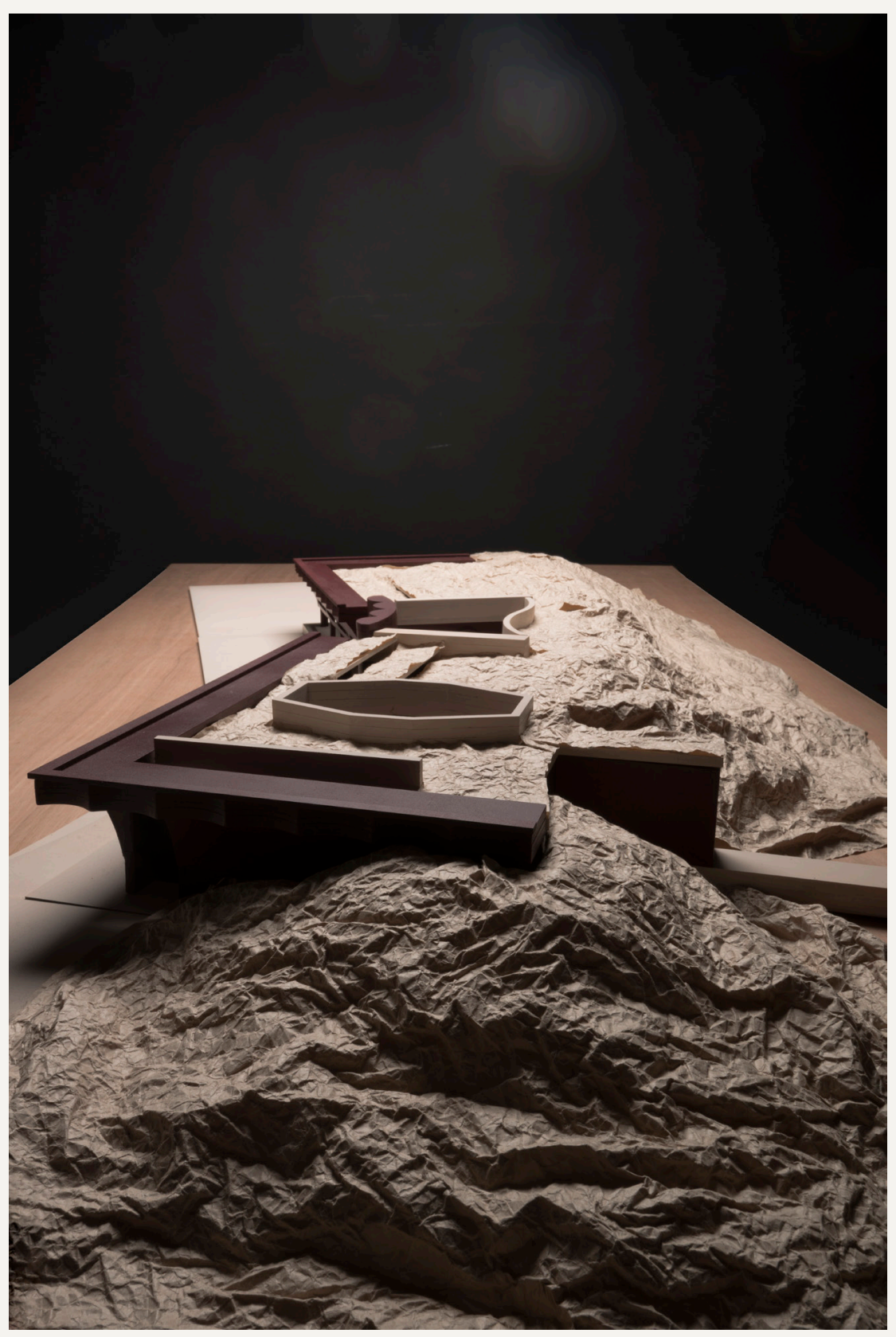

Figure 1

Buried building 


\title{
FRIENDS, ENEMIES and BUNKERS
}

\author{
Jason Tan
}

120-point thesis

submitted in partial fulfilment of the requirements for the degree of Master of Architecture (Professional).

Victoria University of Wellington

School of Architecture

2018 


\section{ABSTRACT}

A biosecurity centre on Kapiti Coast is required for checks on visitors venturing $5 \mathrm{~km}$ out to the nationally significant nature reserve, Kapiti Island. The shorefront lacks a public building connecting to Kapiti Island. The proposal for a visitors centre is the vehicle for this design-led research. This thesis experiments with architectural form in a coastal setting exploring some specific approaches to form-making.

New Zealand architects often rely on metaphors as a method for making form. For example using mountain ranges or a waka as a referent. International theorists like Pier Vitorrio Aureli argue for a more self-referential logic. Architect Ron Witte explains that a good architectural 'figure' comprises architectural references like programme, technology and form. The removal of its representational obligation gives the figure its strength. How does a good figure work without the dependence of an external referent? Can the referent be removed allowing the figure to work internally?

Derivation from earlier sources is also commonly used in making form often resulting only in the abstraction of the image. Winy Maas and Adam Caruso both acknowledge that 'novelty is nonsense'. They argue that references from the past should be used as existing knowledge and built upon. How can past sources be used for their value in knowledge rather than their use of imagery? 
This thesis is organised into a series of parts with experiments around figuration and form-making each looking at a particular use of a referent. Experiment one looks at form-making through the derivation of 'heroes'. Experiment two focuses on abstracting and using the metaphor of a waka. Experiment three explores anthropomorphic and zoomorphic figures through the architectural language developed by John Hejduk. Lastly, experiment four abandons these figures and buries the building in the site's dunes. The form and façade of the building refer to the work of several Swiss architects including Valerio Olgiati and Christian Kerez for their use of ornamentation in heavy buildings.

The outcome and implications of this design-led research address a disciplinary exploration of the referent and its use in making a form. The final design proposition extracts six formal principles used in common with works from Olgiati, Kerez and Caruso. The proposition is re-built on top of existing knowledge, offering a particular approach to form-making. 


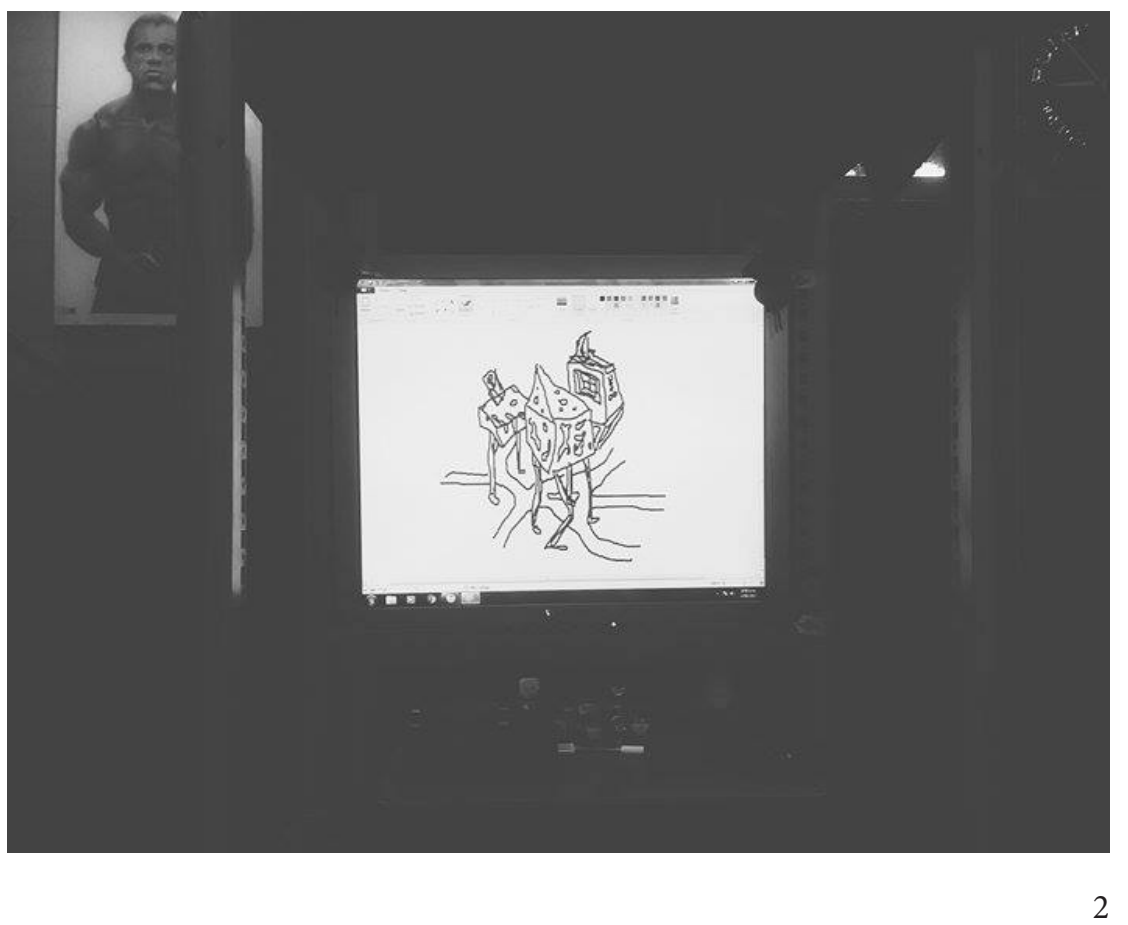




\section{PREFACE}

I am interested in what motivates form. This thesis has been an exploration of various formal strategies - from stylistic appropriation, zoomorphic cartoons, and historic references, to typological and tectonic collage.

The research tracks an arc from an obsession with imagery to a richer understanding of formal principles.

\section{$<$ Figure 2}

Cretins, MS Paint doodle at a gym in June 


\section{ACKNOWLEDGEMENTS}

Thank you to my supervisor, Dr Sam Kebbell for your honesty and guidance throughout the whole process.

My family for your patience and relentless support.

Tyler and Jesse, food scavengers and 3D printing rangers.

My cohort and stream members Callum, Elise, Joe, Ryan and Will, thank you for enduring this year with me.

Periphery, SNTS, David August and Bicep who have helped me throughout my 'four till fours'.

Finally, Rosanna who has been there from the start. 


\section{GONTENT}

Abstract vi

Preface ix

Acknowledgements $\quad \mathrm{x}$

Introduction 1

Setting the Scene $\quad 13$

Experiment One: Friends $\quad 42$

Experiment Two: The Waka Vision 59

Experiment Three: Anthropomorphism 75

Theoretical Context 95

Design Proposal 107

Discussion: Curating Architectural Principles 121

Reflection 183

$\begin{array}{ll}\text { Conclusion } & 198\end{array}$

Works Cited 202

Figure List 204

All figures with a ${ }^{*}$ symbol noted have been used in Design Review III - i.e Figure 25 * 


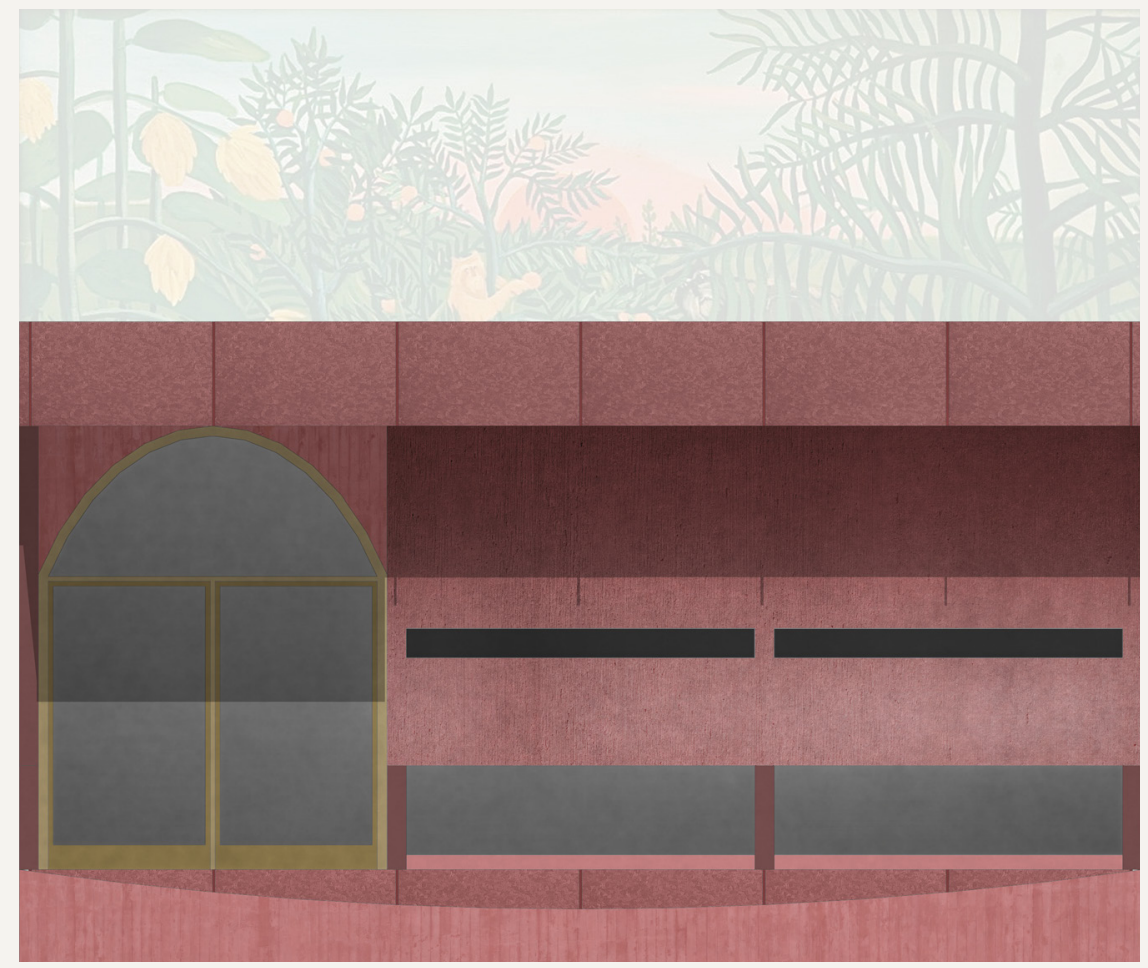

Figure 3

Elevation study 'Red bunker' 
INTRODUCTION 


\section{NEW ZEALAND FIGURES}

New Zealand architects use metaphors a lot. This is partially due to tradition with Mãori references, but coincides with the postmodern period of architecture.

Auckland-based firm Fearon Hay's TeKaitaka or 'The Cloak', completed in 2014, uses a contoured living green roof that provides shoulders from which distinctive encircling woven mesh screens can hang (see figure 4).

Wellington-based firm Studio Pacific's new control tower at the Wellington Airport, currently under construction, appears to be leaning into Wellington's prevailing northerly wind, echoing our own personal reaction to the strength of the wind (Studio Pacific, 2017) ((see figure 5)).

Lastly, the National Museum of New Zealand, Te Papa Tongarewa, which was built in the 1990s by Jasmad, now Jasmax, is a postmodern building that is designed to represent the bi-cultural relationships between the Māori and the early European settlers (see figure 6). The building is split into two distinctive parts: the North 'Māori Face' and the South 'Pākehā (European) face. Both faces have their own design attributes symbolic of their party.

The Māori face overlooks the harbour. Its bluff-like walls embrace nature, the sea, hills and the sky (Te Papa, 2017). The Pàkehā side faces the city and its gridded spaces reflect the patterns of European Settlement. Additionally, the space between which unites these faces houses the exhibition of the Treaty of Waitangi- the nation's founding document.

These projects have a certain tension to them where the architecture becomes representative of something else. The referents in these cases dictate how form is interpreted. This approach becomes a method where designs start to become only as good as their referents, relying only on their narrative and architectural symbolism.

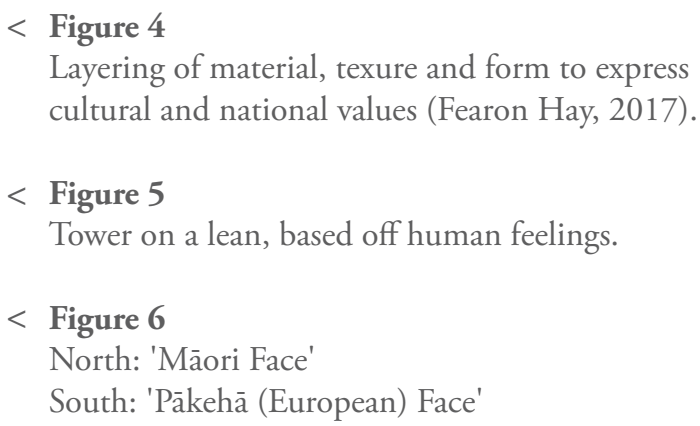




\section{RESEARCH OBJECTIVES AND PROPOSITION}

This research is driven by the current New Zealand architectural scene, where buildings are built with their own distinct style and strange, questionable forms, using representation as an end product and often as a selling device. This context sheds light on this research's objectives in a disciplinary inquiry on formmaking and figuration. This research does not aim to provide a definitive answer on how form should work or what New Zealand buildings should look like. Instead, the primary aim is to interrogate how form is made and spark a discussion on the use of representation in buildings. A secondary aim is to understand how precedents and sources work in relation to the form as an image. This thesis hypothesises that a good figure is void of representation and the use of the external referent, using only the operations of architecture to inform the design. It also hypothesises that a good figure understands and interprets architectural qualities of precedents and sources, rather than simply reappropriating the image.

To test these objectives, the research uses the bio-security centre based on Kapiti Coast as a vehicle of experimentation around form-making. The intention is that this building will anticipate its role in a future city by developing the coastline and re-activating the coastal edge, not only operating as a visitor gateway to Kapiti Island but enhancing the connection between tourists and local residents, positively affecting the Paraparaumu township. 


\section{RESEARCH METHOD- DESIGN LED RESEARCH}

Design-led research is the method used for this thesis. The process of iterative design was key in keeping a fluid design that could constantly be broken down and questioned. Relentless experimentation in design was critical for research. Design-led research opened up discussions and a series of insights that I could not have foreseen at the start of this thesis. 


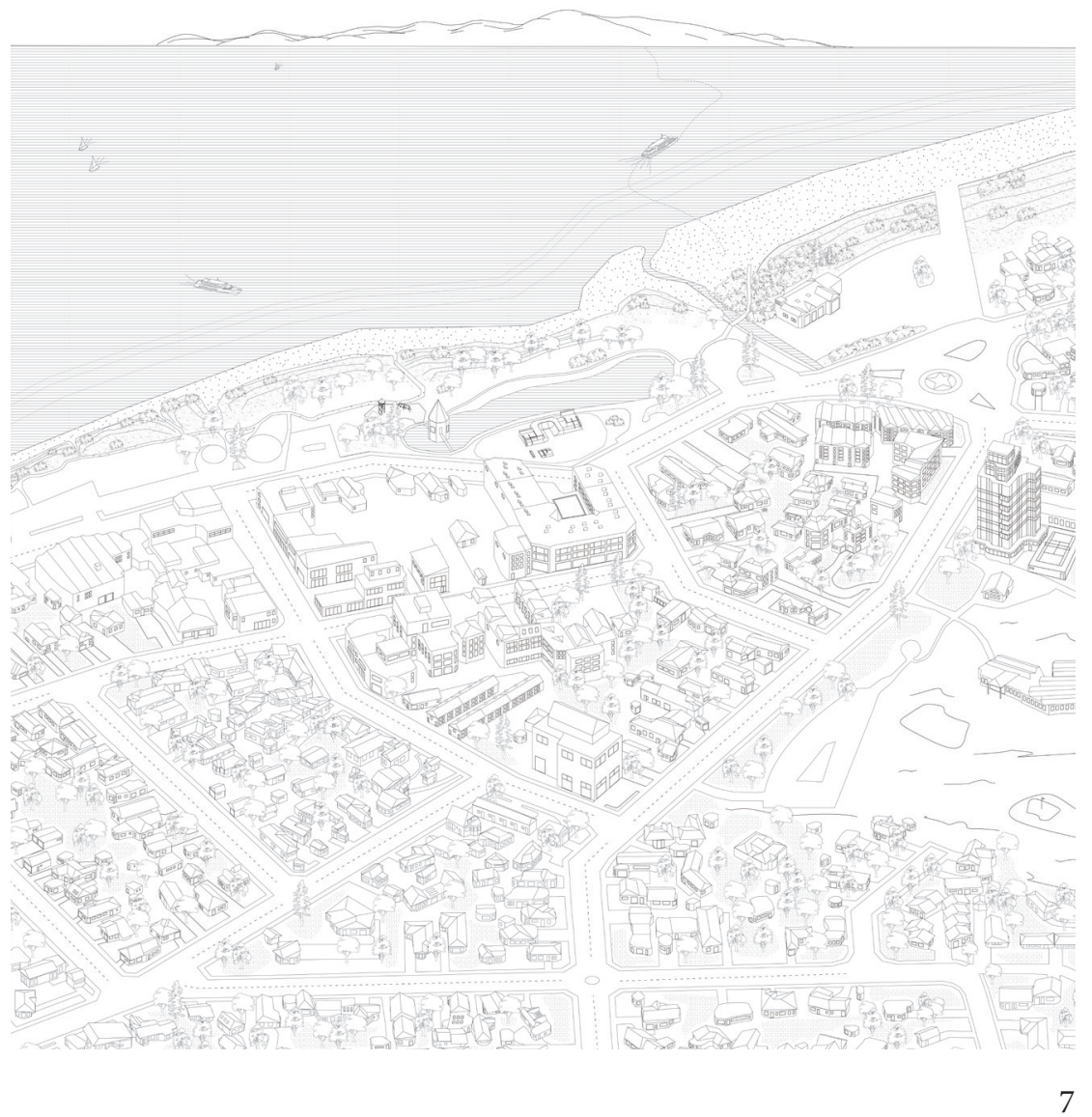




\section{SCOPE}

This thesis is based in Kapiti, on the beachfront of Paraparaumu overlooking Kapiti Island. The programme of the bio-security visitors centre prescribes the scale of the design. The research's outcome seeks to imply a level of feasibility as an addition to the current conversation around a future proposal with the local city council. The experiments will be tested and discussed with residents of Kapiti. This engagement encourages an intentionof legibility, where the public can recognise and understand the value of the design and what it can bring to the beachfront and public space.

In conjunction with this, in addressing the enquiry of formmaking and figuration, the scales shift with each testing of experiments. The initial experiment's pursuit in teasing out a certain aesthetic, image, and architectural language overrules a level of pragmatism. However, the progression through experiments sees form seized, refined and rigorously worked with to generate a scheme with greater architecture detail.

\section{$<$ Figure 7}

Existing axonometric of Paraparaumu and Maclean Park looking towards Kapiti Island 


\section{DESIGN CHRONOLOGY}

March

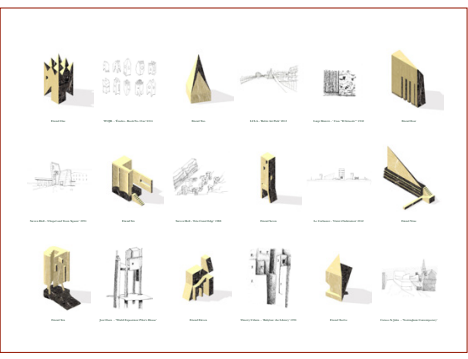

V

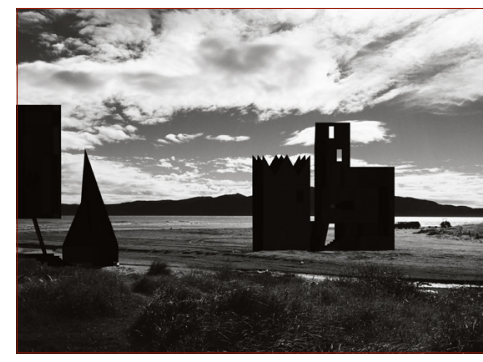

Experiment one: Friends

Exploring form through the lens of other architects and the language of John Hejduk

April - June

July - August

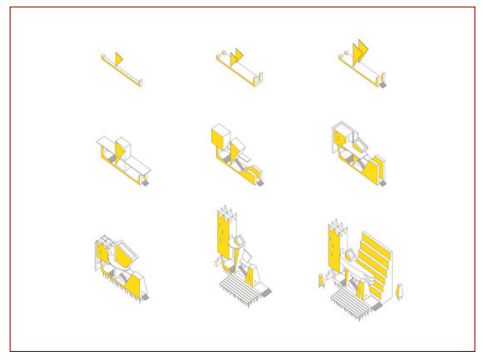

V

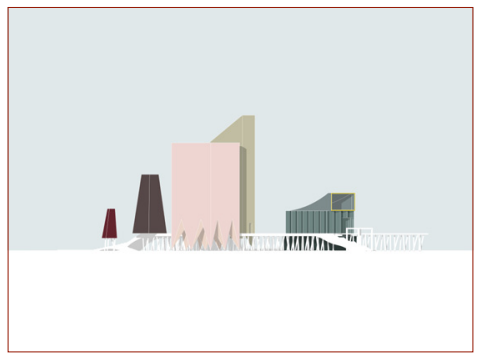

Experiment two: The Waka Viswion

Using metaphor to generate form

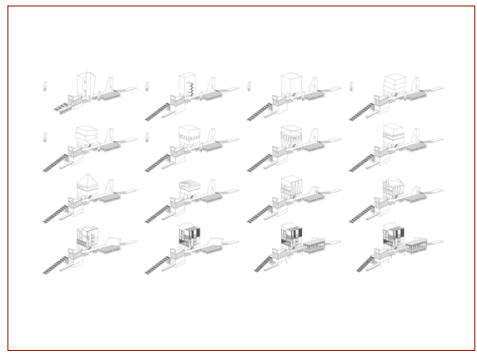

V

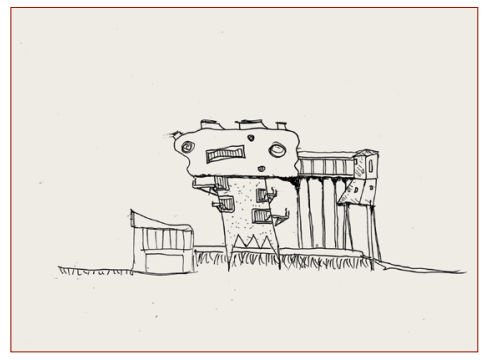

V

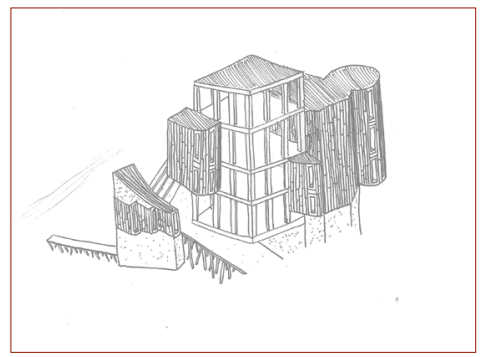

Experiment three:

Anthropomorphism

Zoomorphic and

anthropomorphic driven forms 
"Uncertainty - To find anything new in architecture, you have to be ready to give up everything you have already done so far."

September

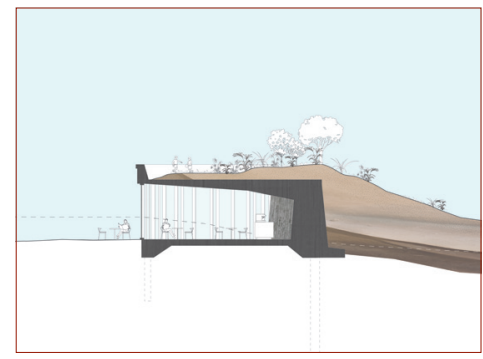

V

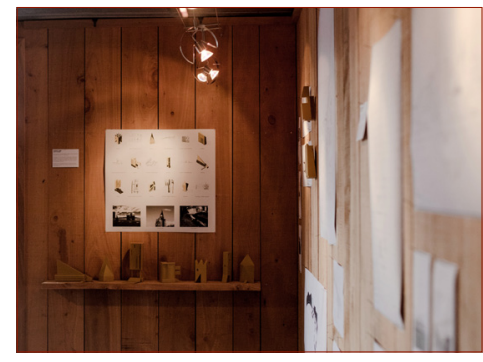

$\mathrm{V}$

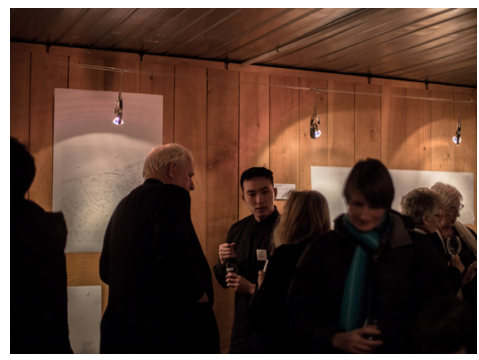

Design proposal: Bunkers

Burying form. It was at this point of the design process in which I realised I was working with form in a distorted way.

Proposal is tested with the residents of Kapiti

October

November

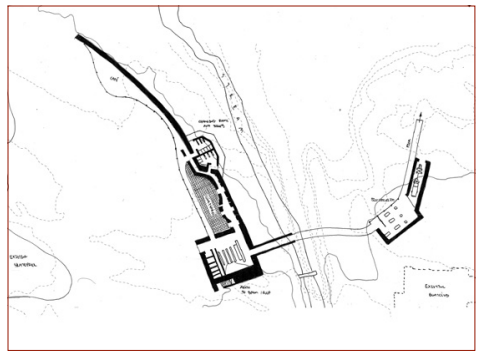

V

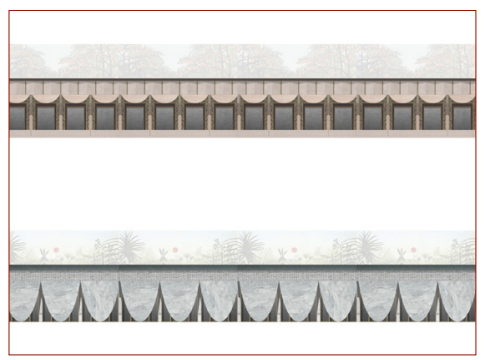

Development of proposal

Re-working the proposal and exploring the use of image and precedent

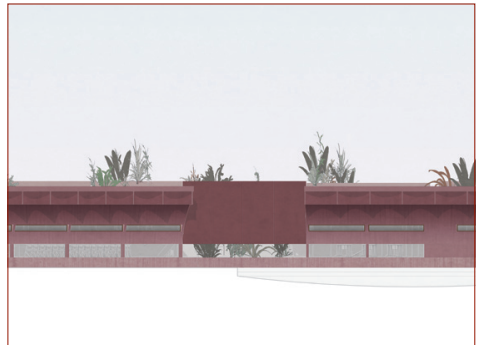

V

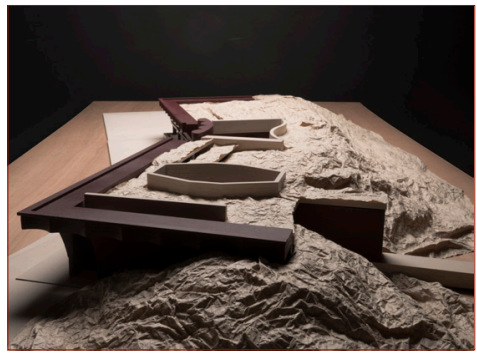

Final Review

Design principles to frame and generate form 


\section{THESIS STRUCTURE}

Part one

Part two

Part three

Part four
Setting the Scene

The scene of Kapiti Coast is observed as context for the proposed bio-security centre. This section inspects the existing surroundings and the built environment highlighting Kapiti's architectural figures and the current situation of Kapiti Island's bio-security facilities.

Experiment One

Experiment Two

Experiment Three

Each set of experiments share the same investigation into form-making. Experiment one deals with form and imagery, unrelated to site and programme. Experiment two focuses on abstracting and using the metaphor of a waka. Experiment three explores anthropomorphic and zoomorphic figures standing in the landscape.

\section{Theoretical Context \\ The Design Proposal \\ Curating Architectural Principles}

This part takes a turn from the previous experiments. Reconsideration of how form works in relation to the referent leads to the design proposal abandoning past figures. The building is buried in the site's sand dunes offering a different kind of architectural form-making. A discussion around six principles used to frame the design reflects on how form can work internally rather than externally. Dealing with precedent is also looked at in this part.

Reflections and Conclusion

The concluding part reflects on the research of this thesis and concludes on the findings around formmaking as well as the use of imagery. 


\section{Part one}

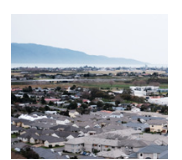

Setting the Scene

Kapiti Figures

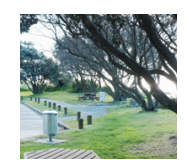

Setting the Scene

Maclean Park

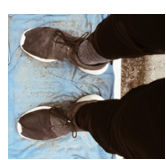

Setting the Scene

The Bio-security

\section{Part two}

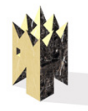

Experiment One

Friends

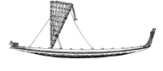

Experiment Two

The Waka Vision

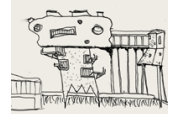

Experiment Three

Anthropomorphism

V

Part three

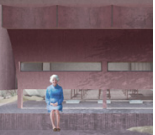

|

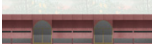

Theoretical Context

Literature and case studies

Design Proposal

Curating Architectural Principles Dissecting the Design Proposal

Part four

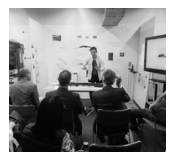

Reflections

Bridging the Gap

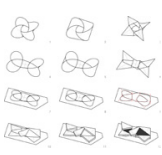

Reflections The Design Process
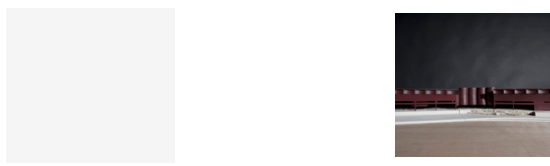

Reflections

Conclusion

The Future of the Referent and Dealing with Precedent 


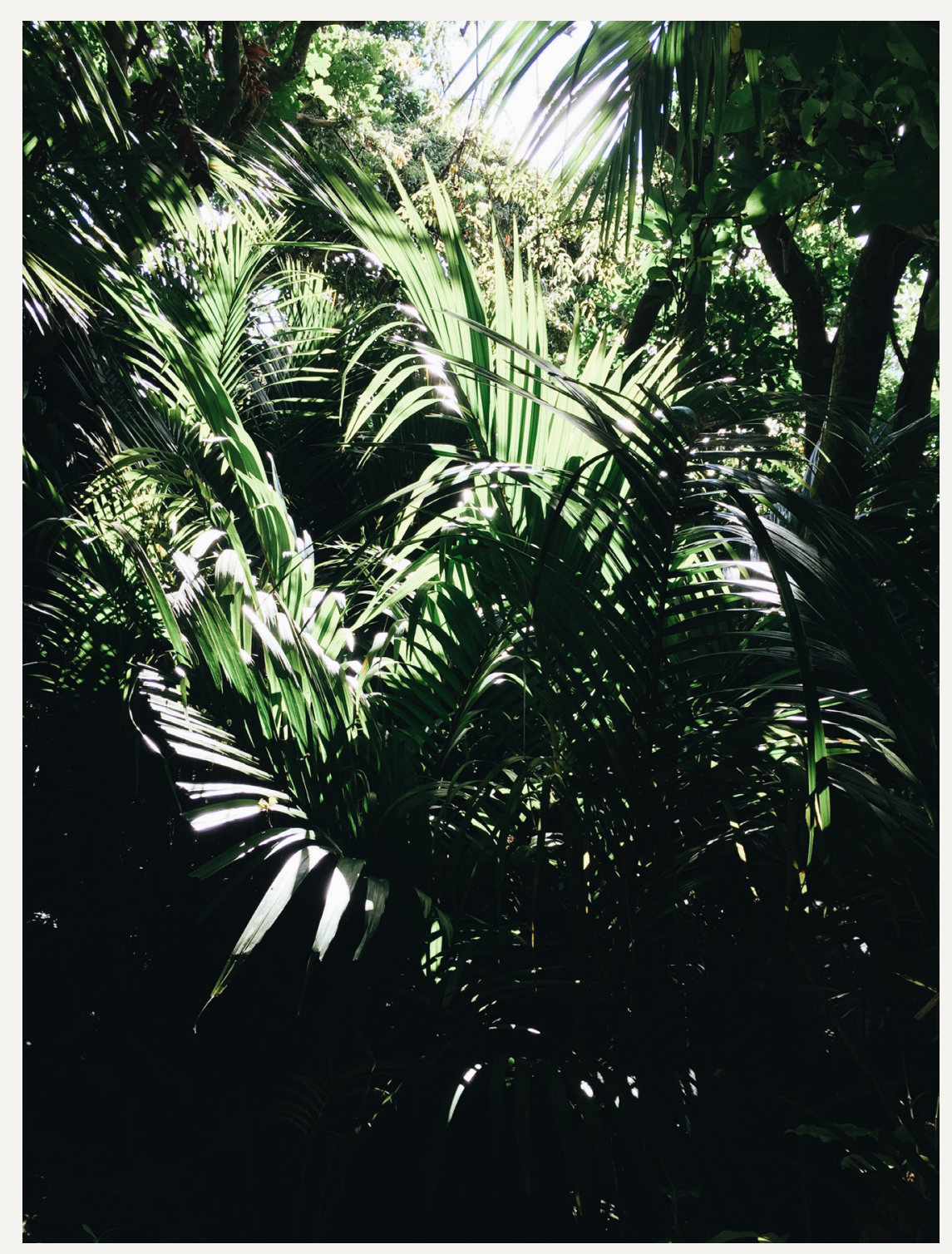

Figure 10

Kapiti Island foliage 
PART 1

SETTING THE SCENE 
Figure 12

Kapiti Coast in New Zealand

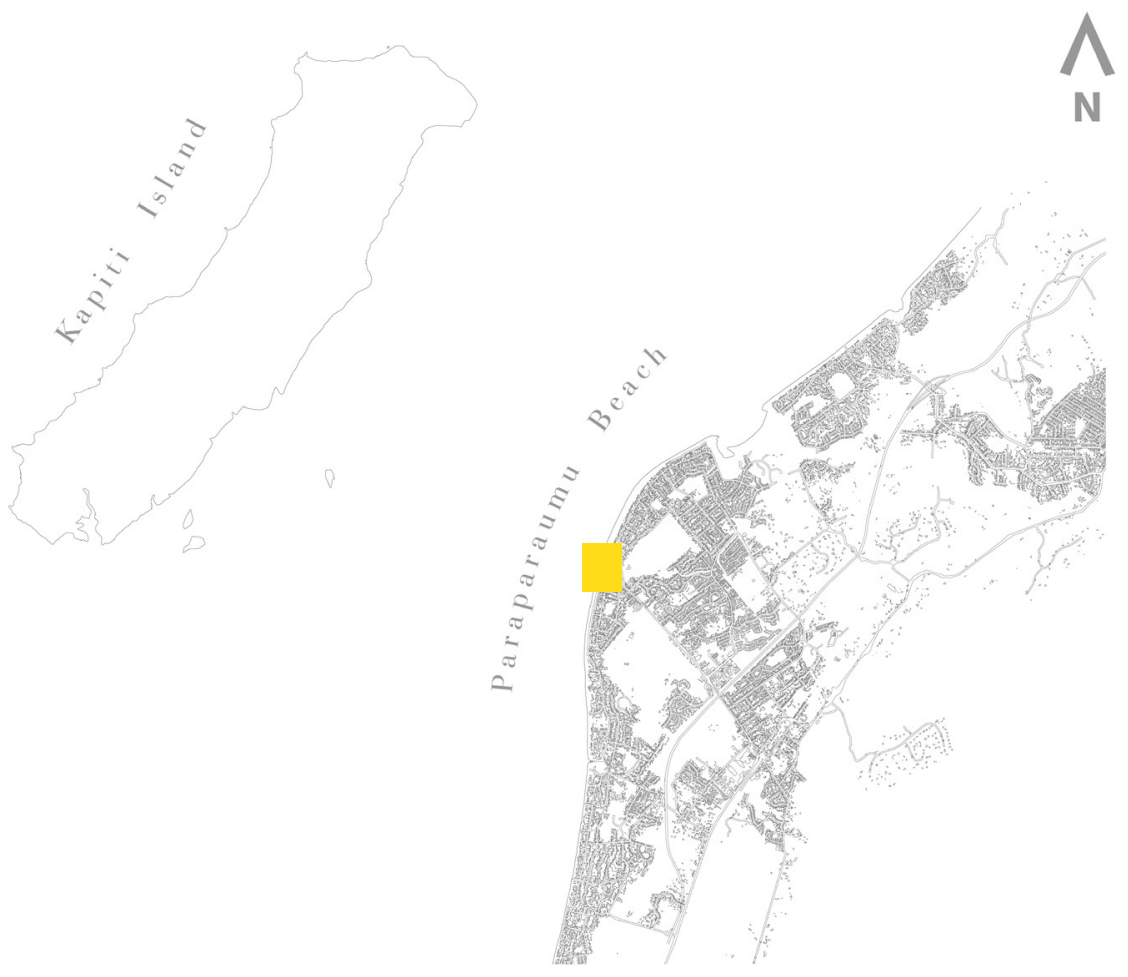

Figure 11 


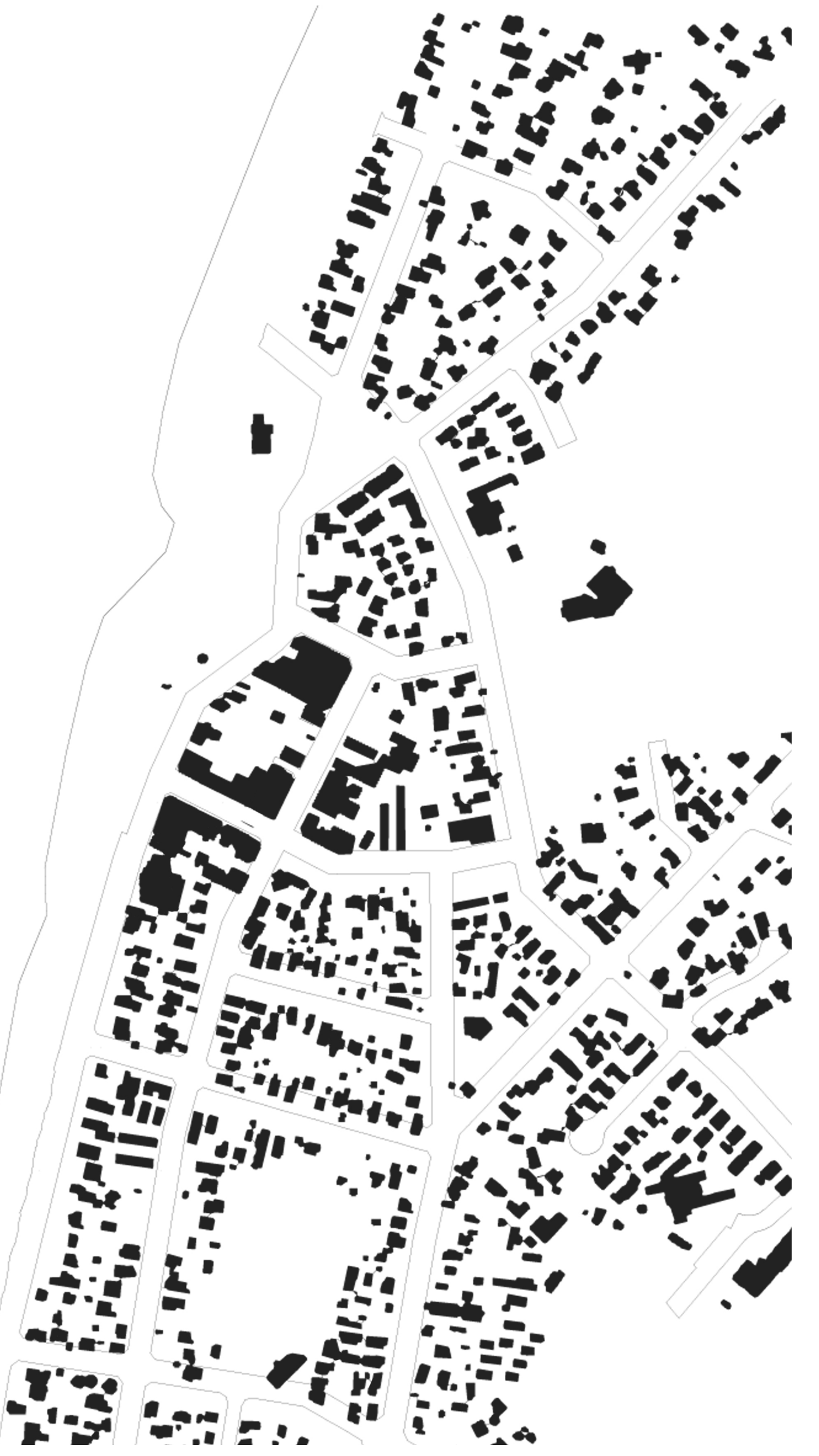

Figure 13

Figure-ground of Paraparaumu 
!

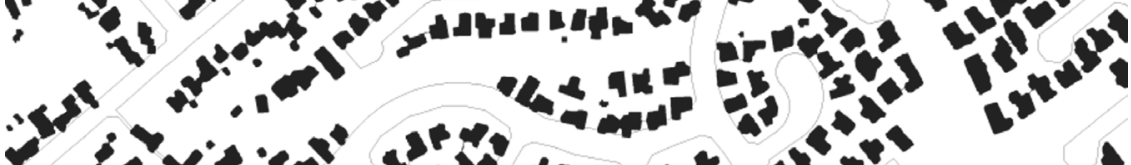

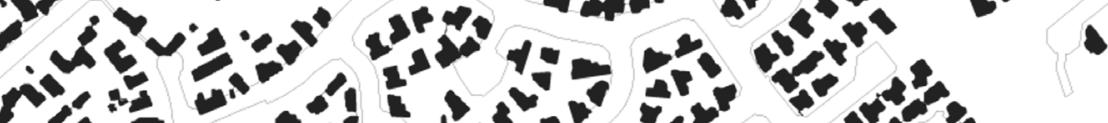

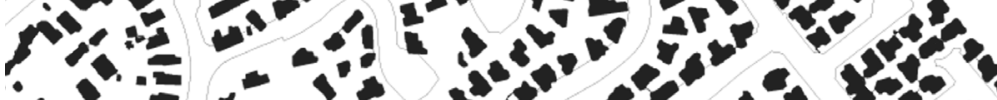

ind [1

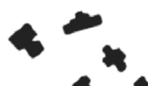

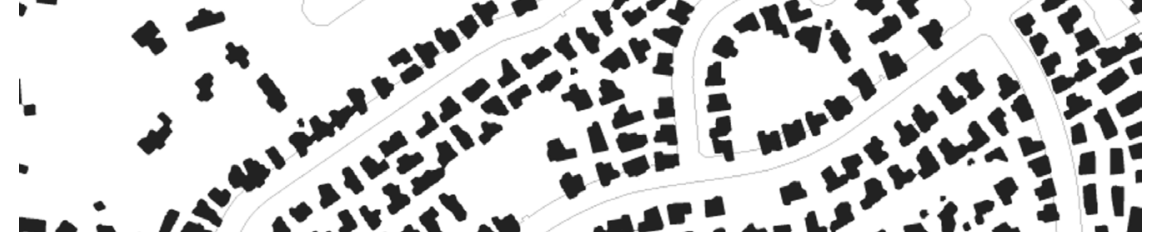
Pas

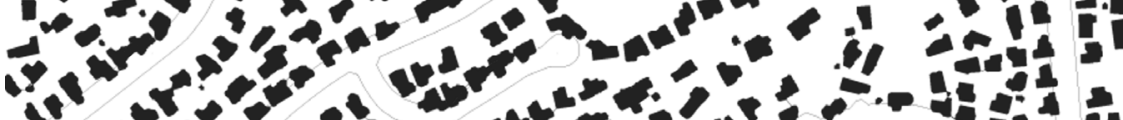

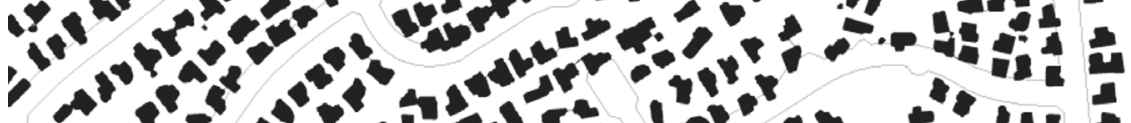

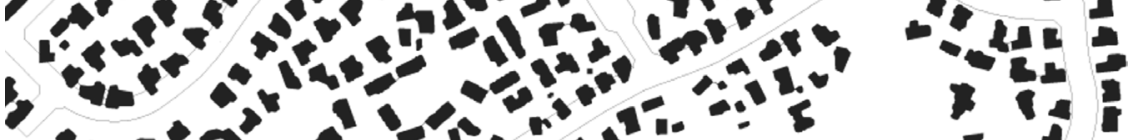
$3+3$

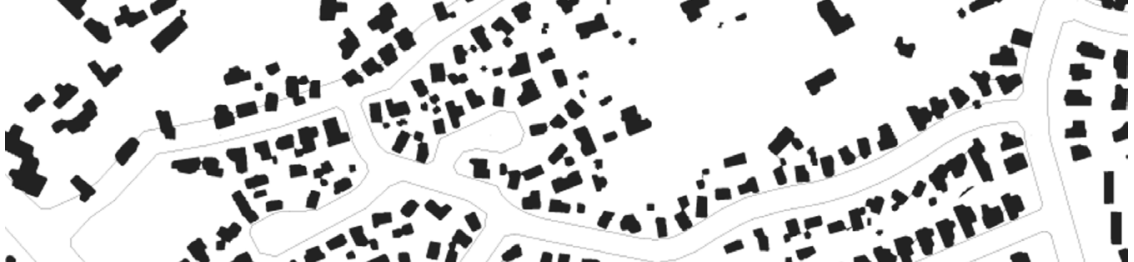

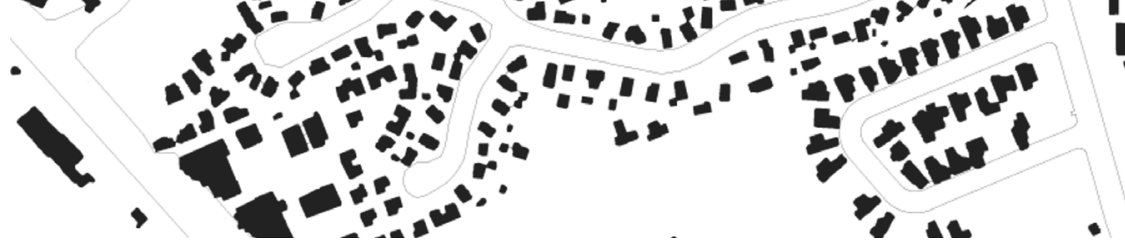

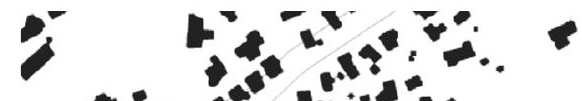

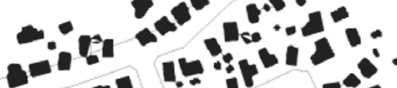

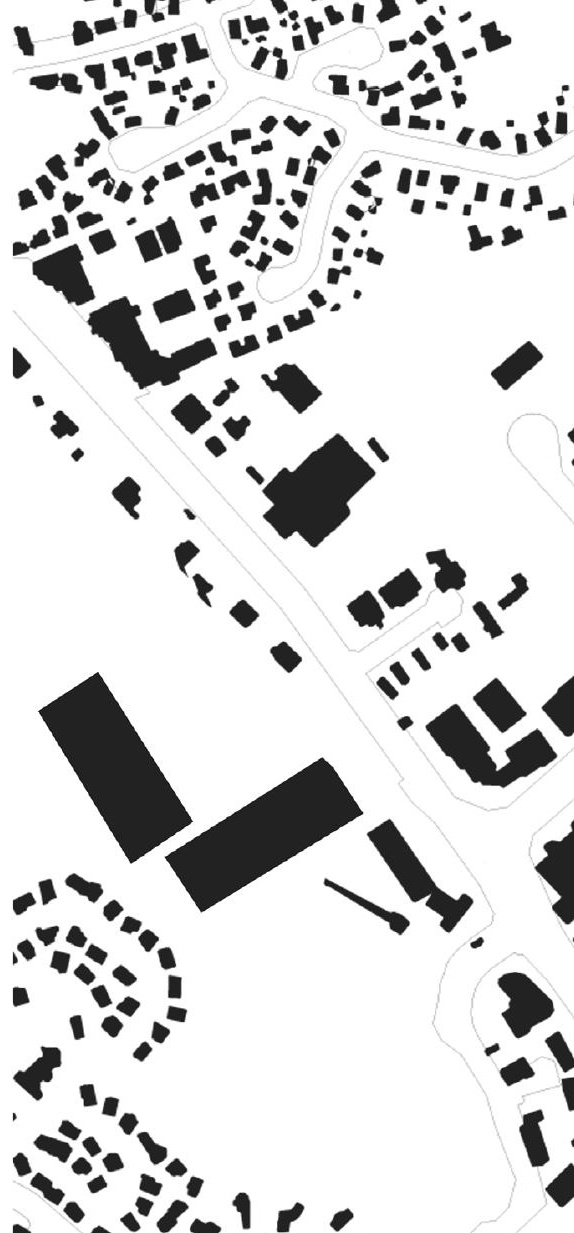

$=\operatorname{lig}_{12} 2_{0}$ 


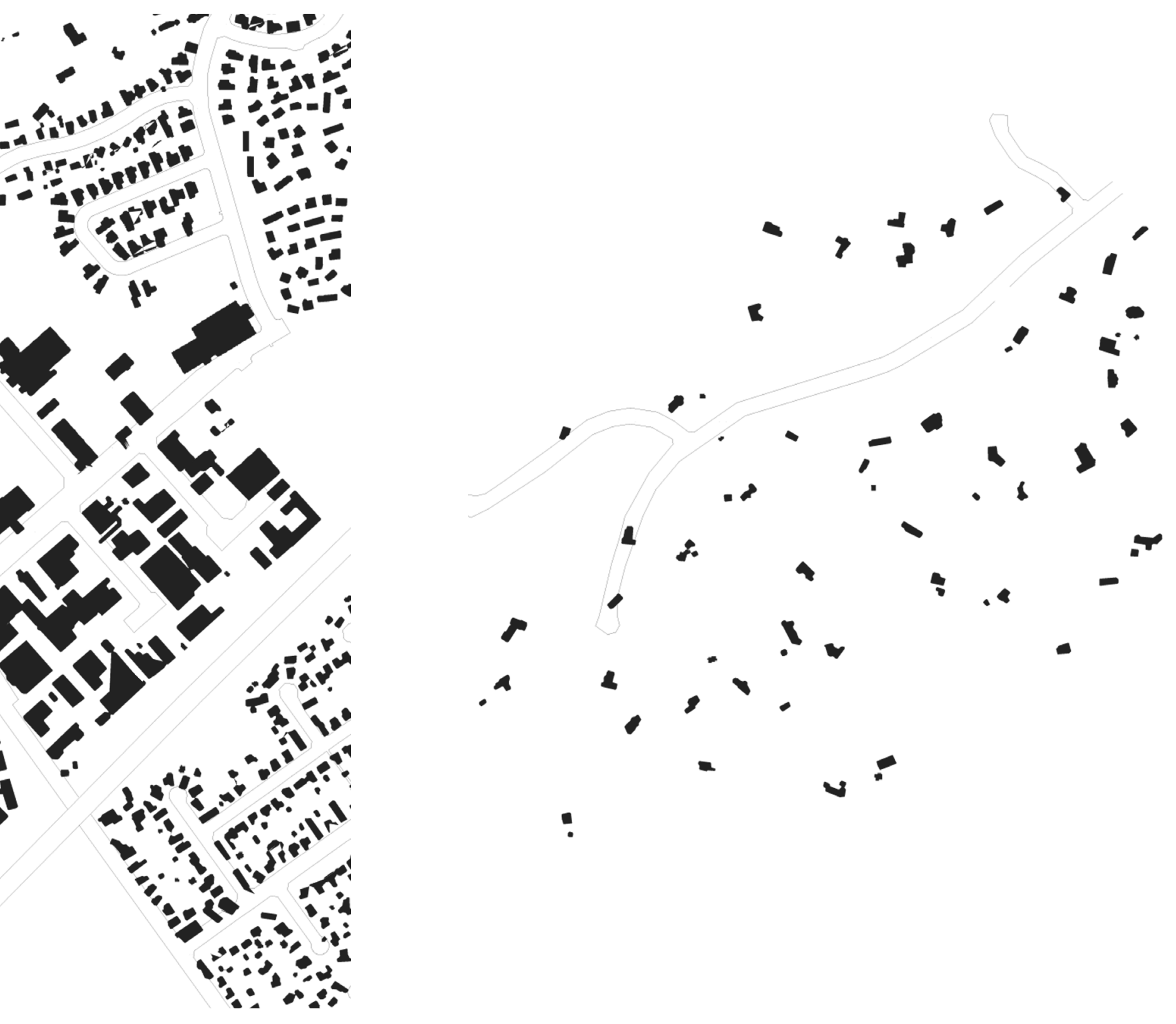



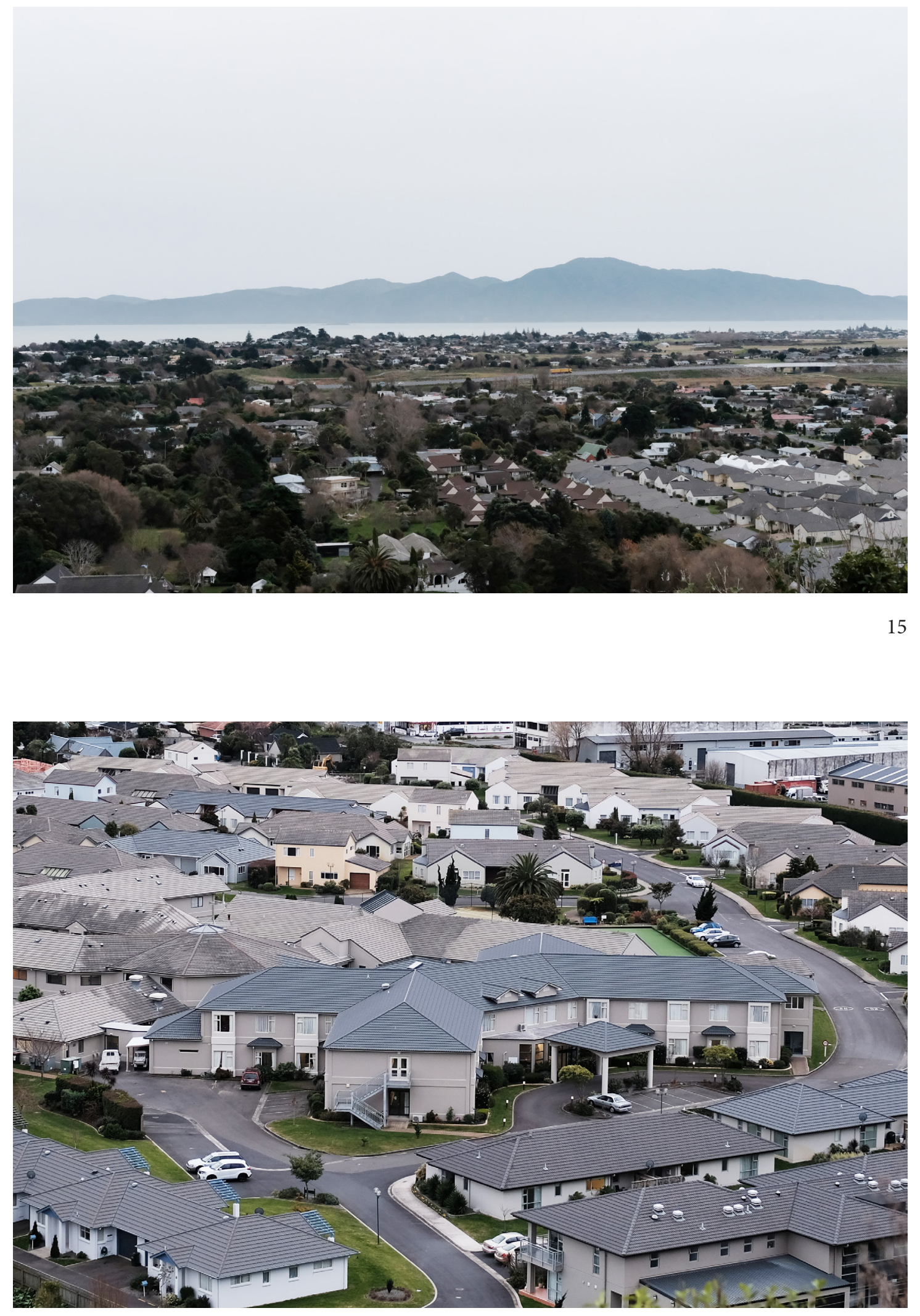


\section{KAPITI FIGURES}

The Kapiti Coast district is part of the Wellington region, consisting of 49,000 people, $11.5 \%$ of the total population for the Wellington region. The environment is dynamic, full of parks, wildlife, mountains, and the sea lined with beaches. The coast stretches $30 \mathrm{~km}$ from Paekakariki to Otaki, and is named for Kapiti Island,which stretches along the West Coast (MacLean) ((see figure 15 and 16)). Within Kapiti Coast is the town of Paraparumu with a beachfront lying opposite Kapiti Island. The environment and proximity to the capital city make this a desired lifestyle area, ideal for a relaxing escape. Data in 2013 showed $25 \%$ of Kapiti Coast's population to be over the age of 65, and between 2013 and 2028 a forecast of a 35.7\% increase in the retirement age population is predicted (Forecast). This major shift shows a demographic of the elderly looking to settle down, integrating with the urban and landscape environment.

Paraparumu's architectural scene is a mixture of residential suburban houses, beachside baches, commercial buildings, a shopping mall and a very out of place mini high-rise apartment block (see figure 17). The majority of these buildings can arguably be seen as typical homes. Most of them are kitset houses, subject to strange floorplans with kinked walls (see figure $18 \& 19)$. Materials such as corrugated metal, timber weatherboarding and solid plaster make up the aesthetic of these figures. This seems to be the trend and recognised quality that will develop and sprawl in the near future.

\footnotetext{
$<$ Figure 15

$8 \mathrm{~km}$ long Kapiti Island flanking the West

coast of Kapiti

$<$ Figure 16

Surburban figures packed together
} 


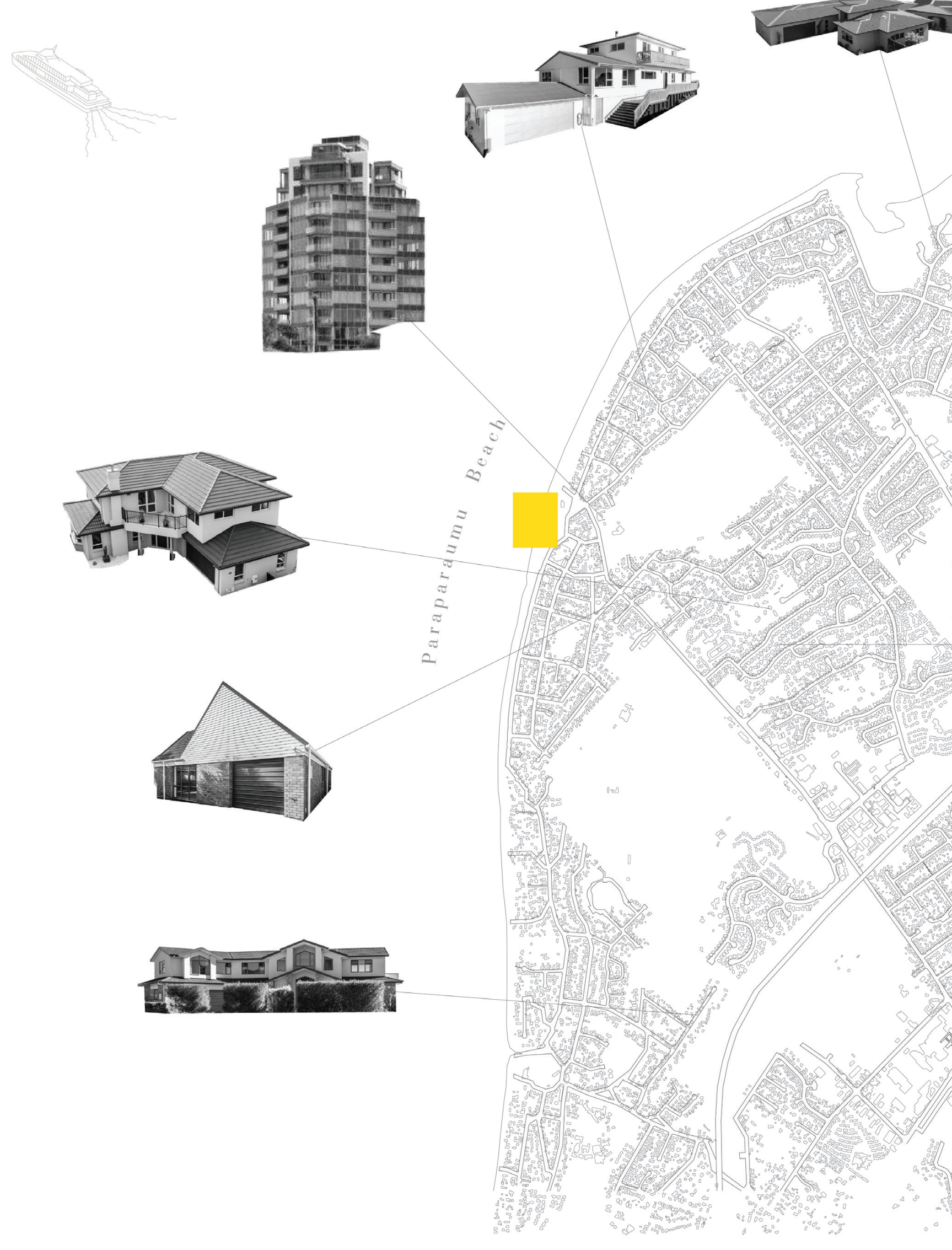




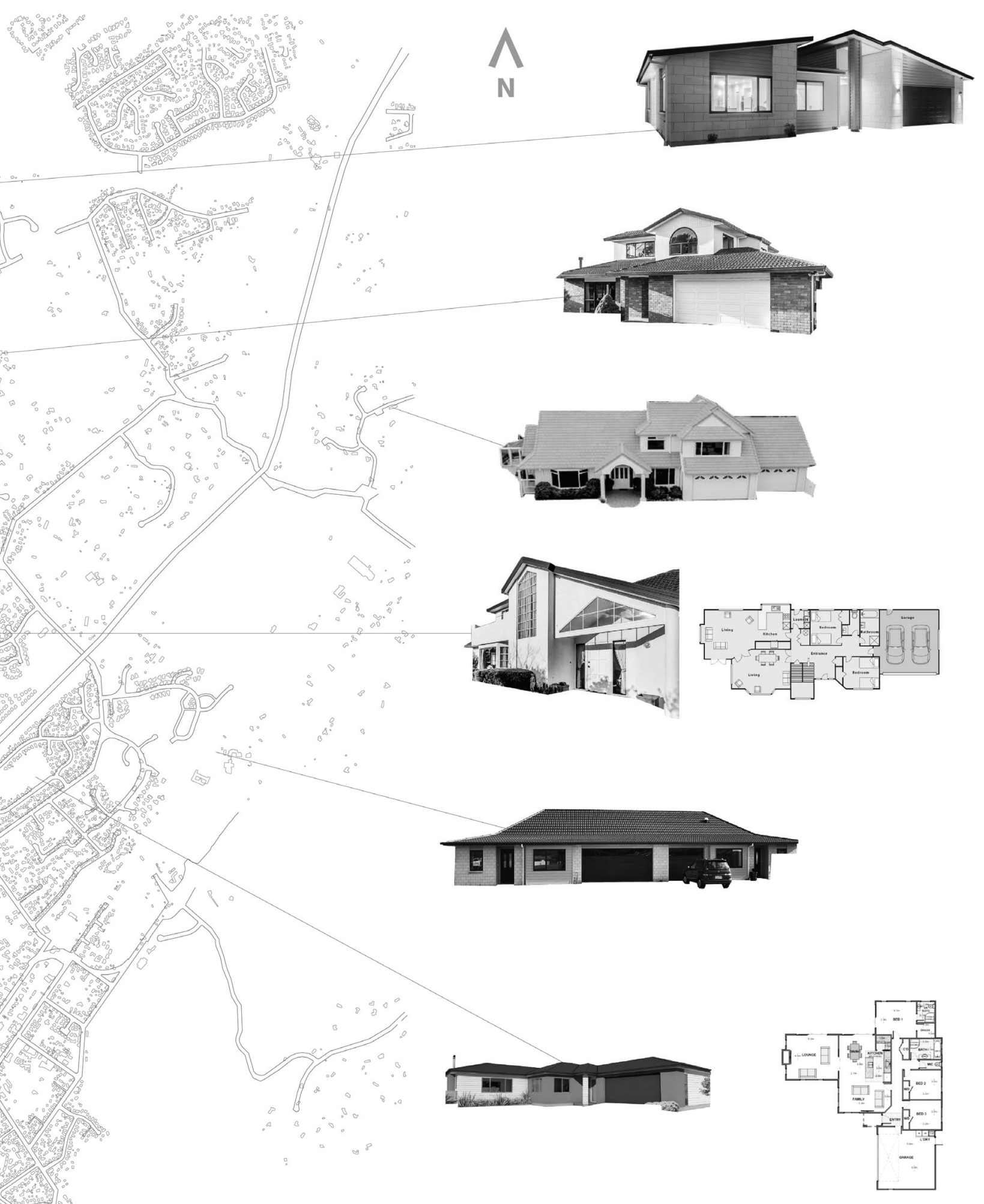




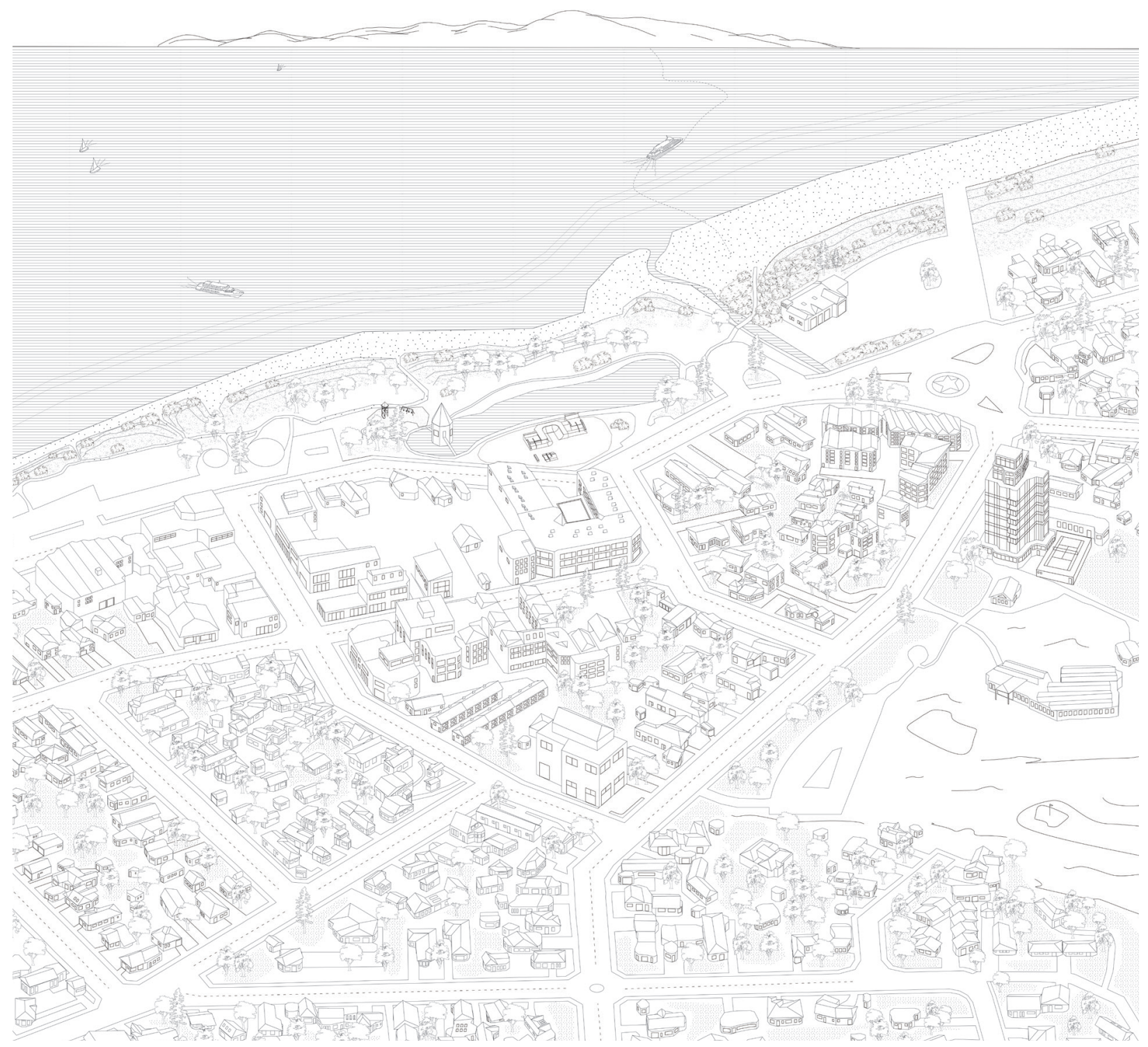

Figure 18

Orthographic perspective looking towards Kapiti Island 


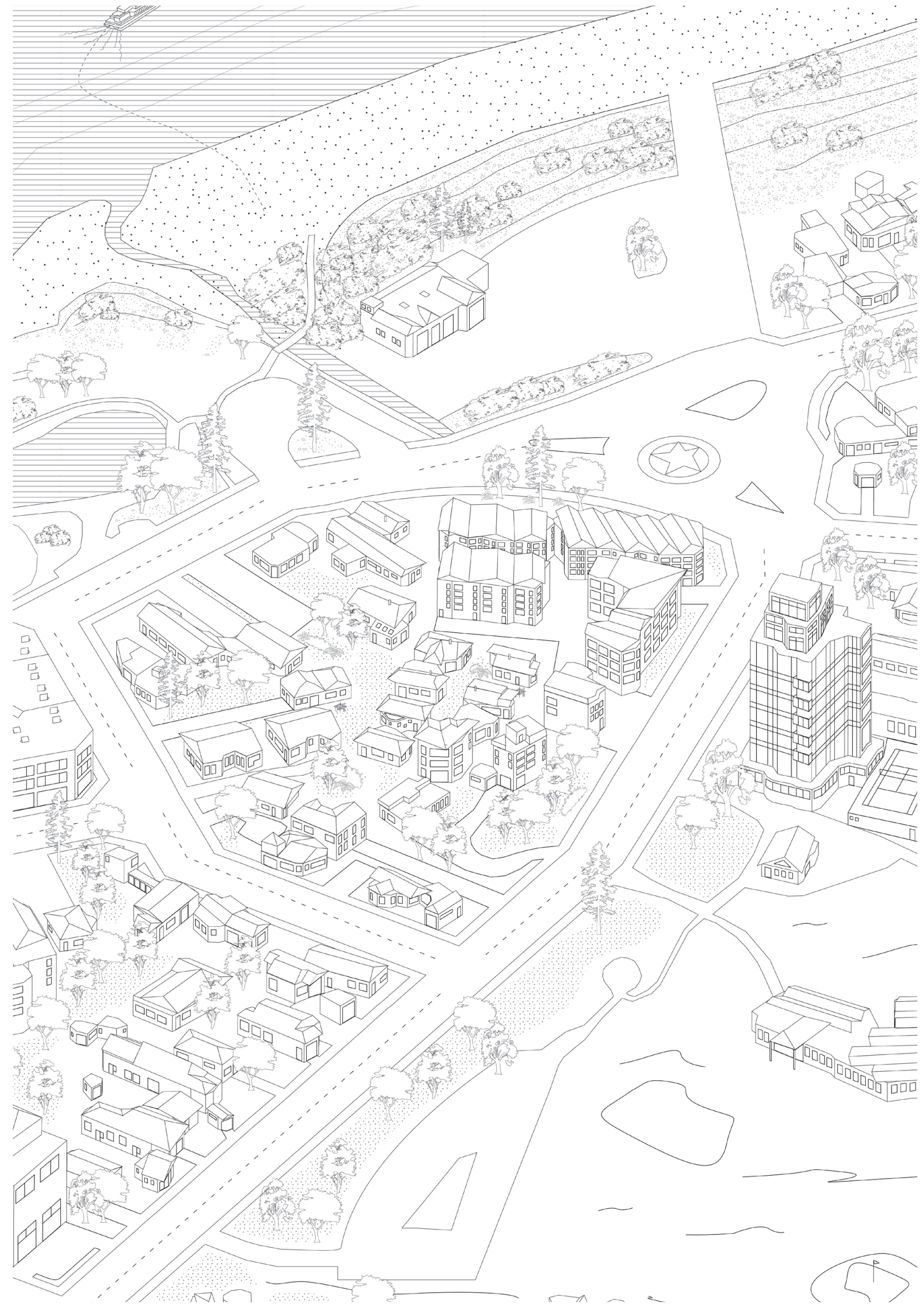

Figure 19

Orthographic perspective 
Paraparumu's public buildings also have little aesthetic appeal. Coastlands shopping mall and large convenience stores provide residents with all necessities. The shopping mall was completed in 1969 and was supposed to act as a magnet to draw people in, as malls were the only retail centres trading on Sundays. Currently there are no other notable public buildings or architectural interventions which activate and draw visitors in. No architectural setting has a strong presence either, in contrast to Napier's 1920s art deco scene. A connection between architecture and people is missing at the moment and Kapiti Island appears to be the main attraction that draws tourists and visitors into this township. Kapiti Island contains a nature reserve, which is home to a bird sanctuary of rare birds such as kākā, kōkako, takahē and hihi (DOC). The Department of Conservation recorded 7284 visitors in the year 2013, and 9505 visitors in 2016 (DOC). This figure will continue to rise as the sanctuary becomes more populated with native birds.

This proposal looks to respond to these features: the demographic of the elderly, the current architectural context and the growing number of visitors to the island.

$<$ Figure 20

Aerial view of Kapiti Island and the peninsula forming Paraparaumu Beach 


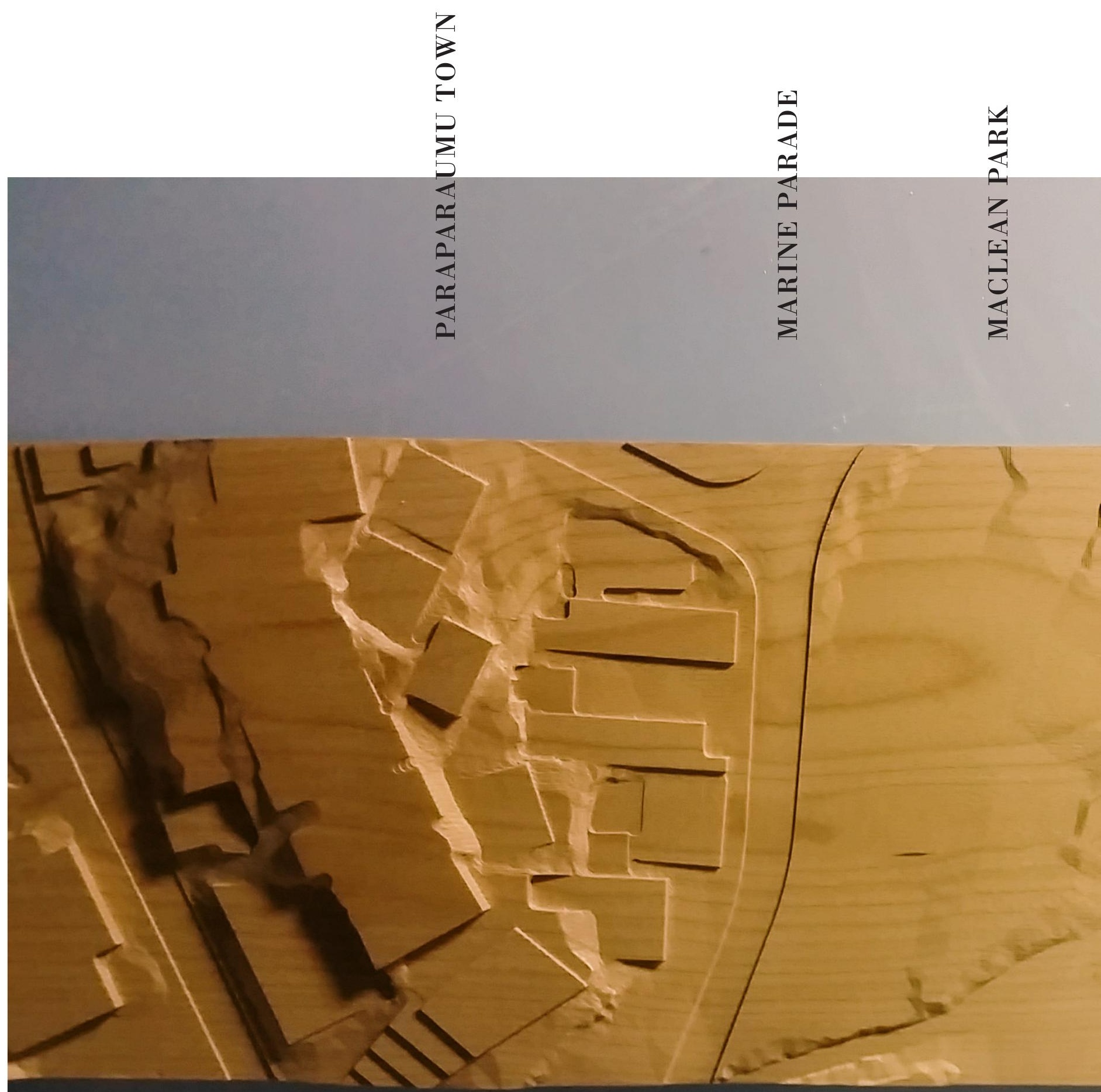




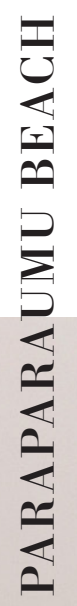

$\underset{\substack{x \\ 0}}{\mathbb{4}}$

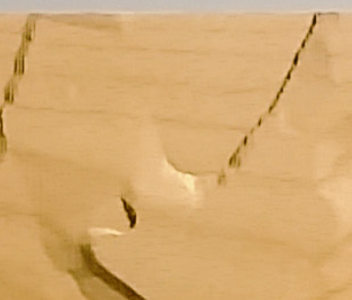

Figure 21

1:500 Longitudinal Section of MacLean Park - modelled from european white beech. 

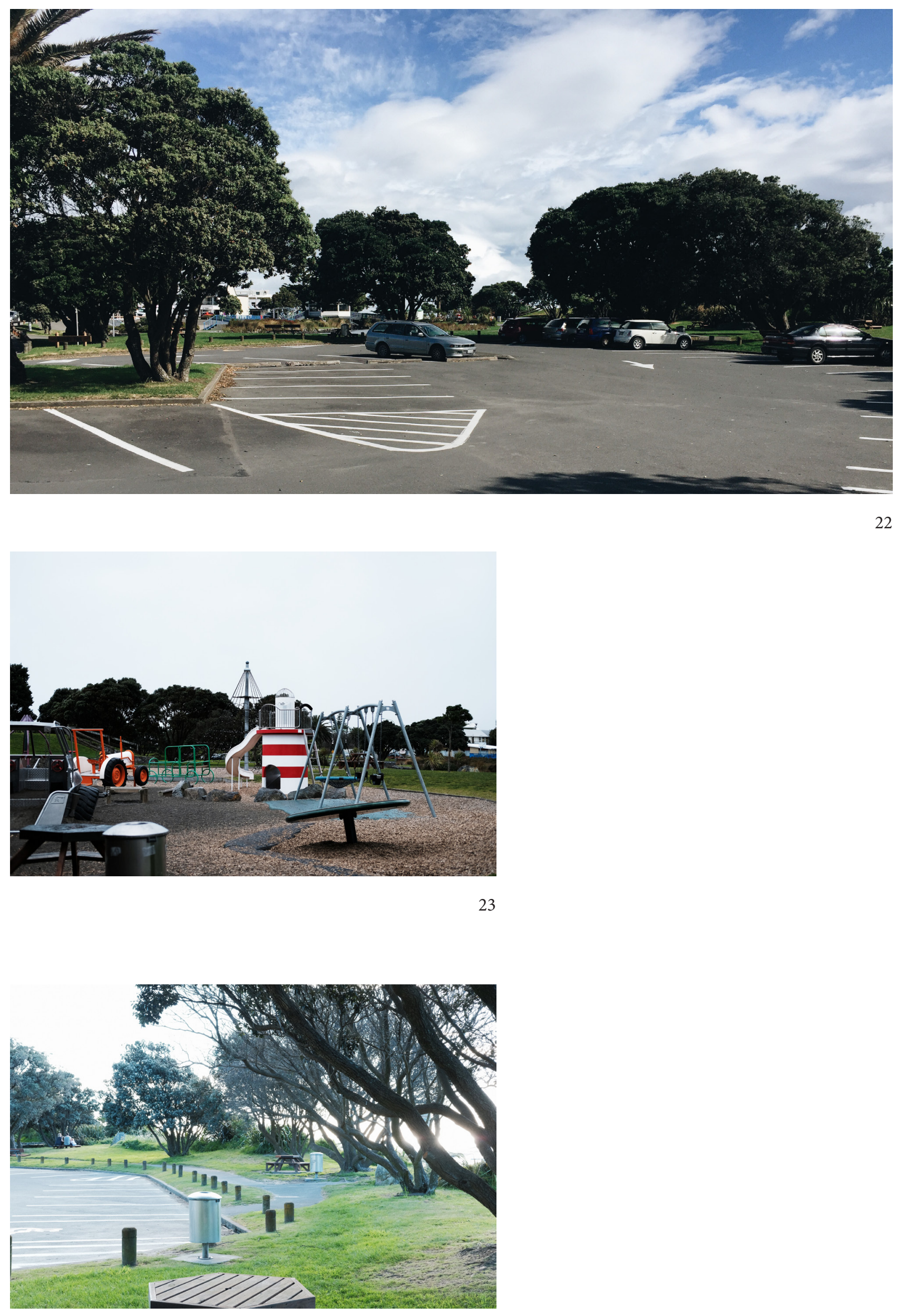


\section{MACLEAN PARK}

MacLean Park is currently the point of departure to Kapiti Island, containing a playground, unuseable pond, skate park and car parking (see figures 22, $23 \& 24$ ). Adjacent to the park is the Kapiti Boating Club (see figure 25). There are no public buildings or visitors centres within this vicinity. The bio-security procedure occurs here, and the 20 minute journey to Kapiti Island departs from this location via a boat towed by a tractor. The boat is pulled down towards the beach into the sea where it is launched, travelling $5 \mathrm{~km}$ to the island.

MacLean is the chosen site for the proposed bio-security centre. The area is in close proximity to current boating access to the sea and has car parking facilities in place. The launching of the boat works with the current course, which does not interfere with the other sections of beach designated for walking and swimming. The main weakness of this site is exposure to the winds; the trees (see figure 24) attempt to shelter park users, but are not significant enough.

MacLean Park's connection with the town allows the proposal of a public building to serve as a fitting visitors centre and gateway to the island.

\footnotetext{
$<$ Figure 22

Abundance of car parks

$<$ Figure 23

Decent sized playground

$<$ Figure 24

Line of trees in between the shorefront and the park provide some shelter
} 


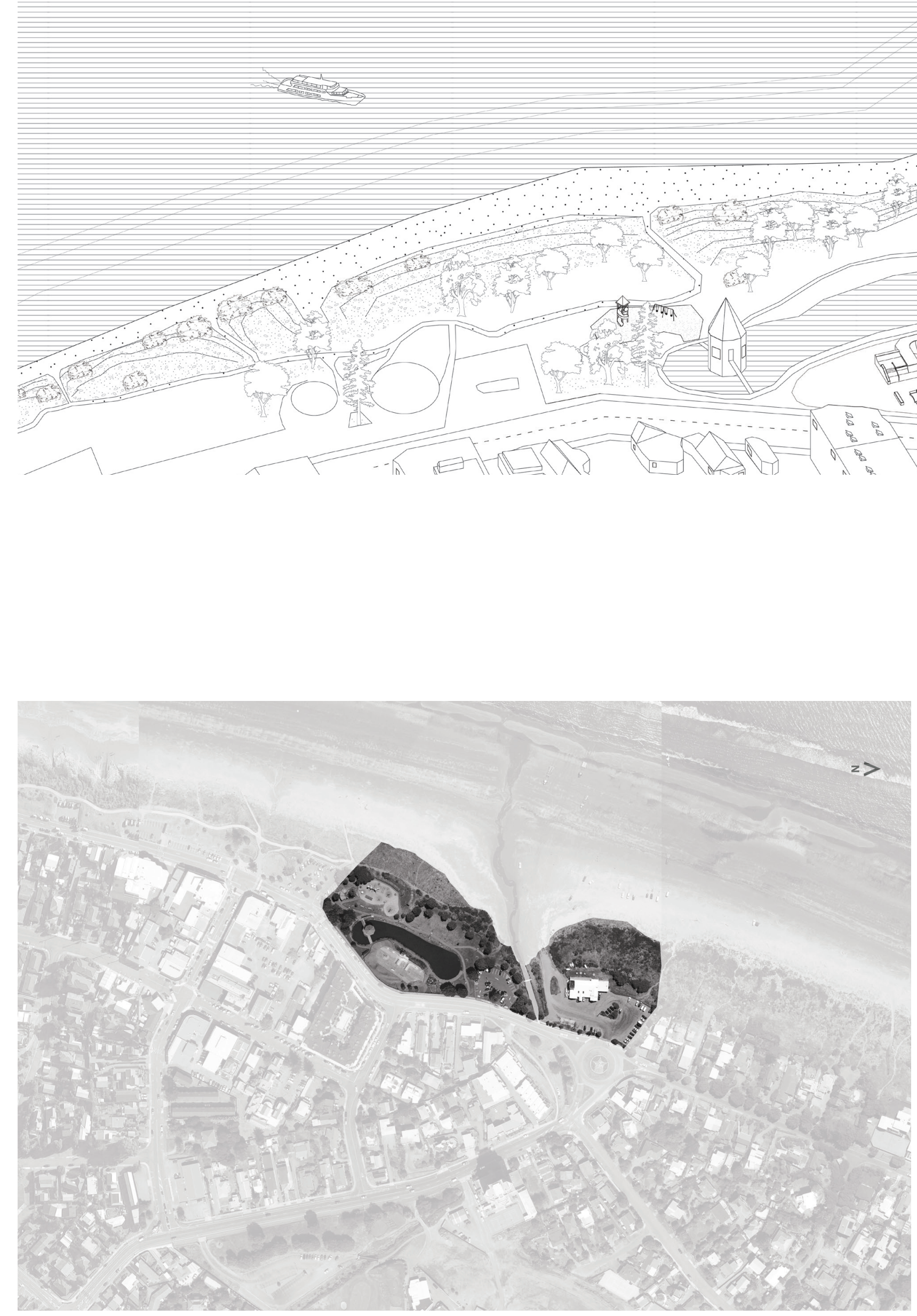

Figure 25 *

MacLean Park and Kapiti Boating Club 

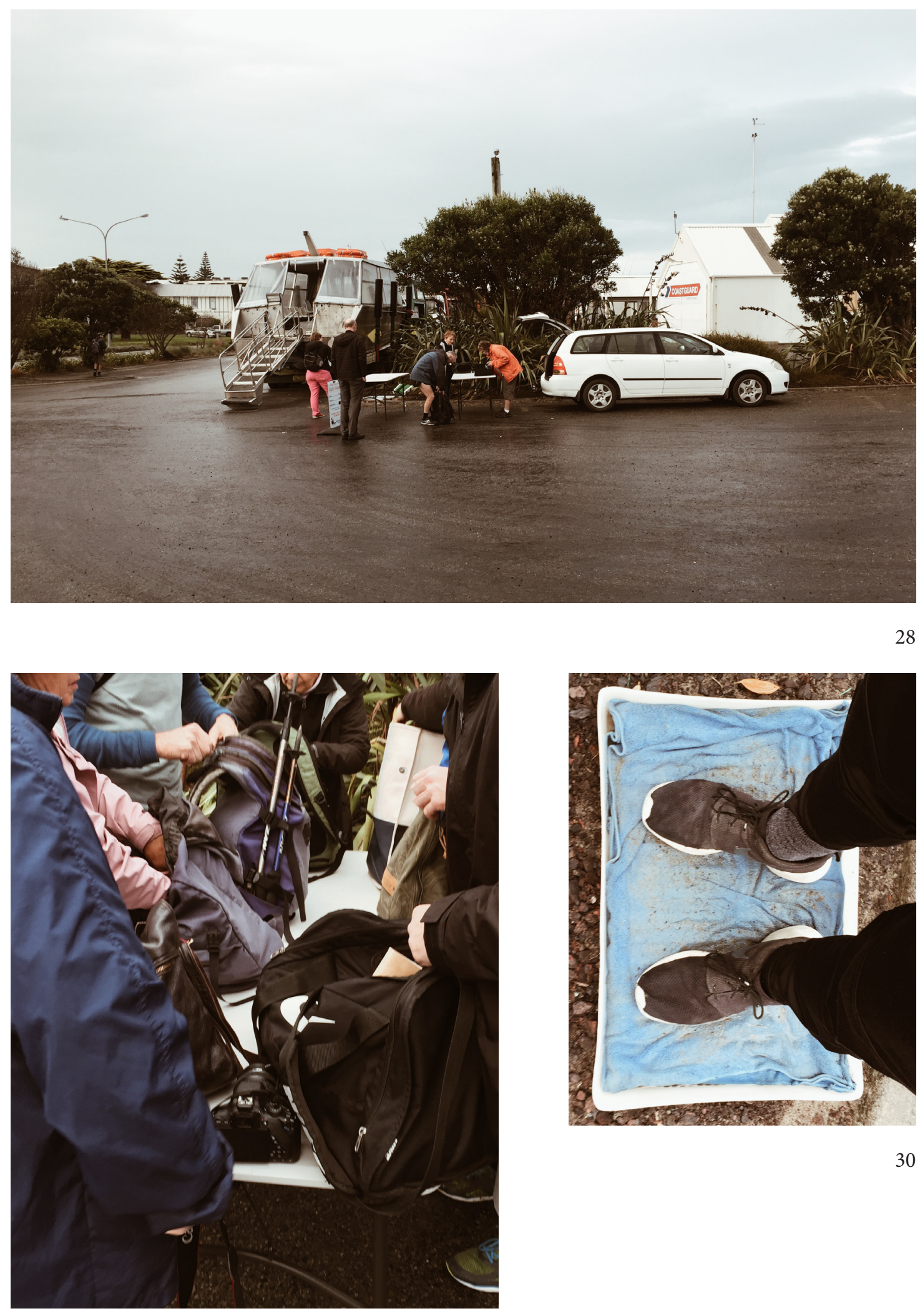


\section{THE BIO-SECURITY}

Currently, bio-security checks are carried out in a carpark in the open. Kapiti Coast Mayor K. Gurunathan says that given the dangers to the island's bio-security, the Department of Conservation should be providing a best-practice security process, "not this shameful disgrace where visitors to our island are forced to undergo bio-security checks on the tarmac in open weather" (Gurunathan 2016).

The current bio-security routine includes:

- Introduction in carpark with the Kapiti Island tour guides

- Table check of bags

- Foot scrub and disinfectant

- Load up on boat

- Safety briefing on boat

- Depart to island

$<$ Figure 28

The extent of the current bio-security facilities

$<$ Figure 29

Checking bags for seeds, insects and soils

$<$ Figure 30

Disinfecting shoes 

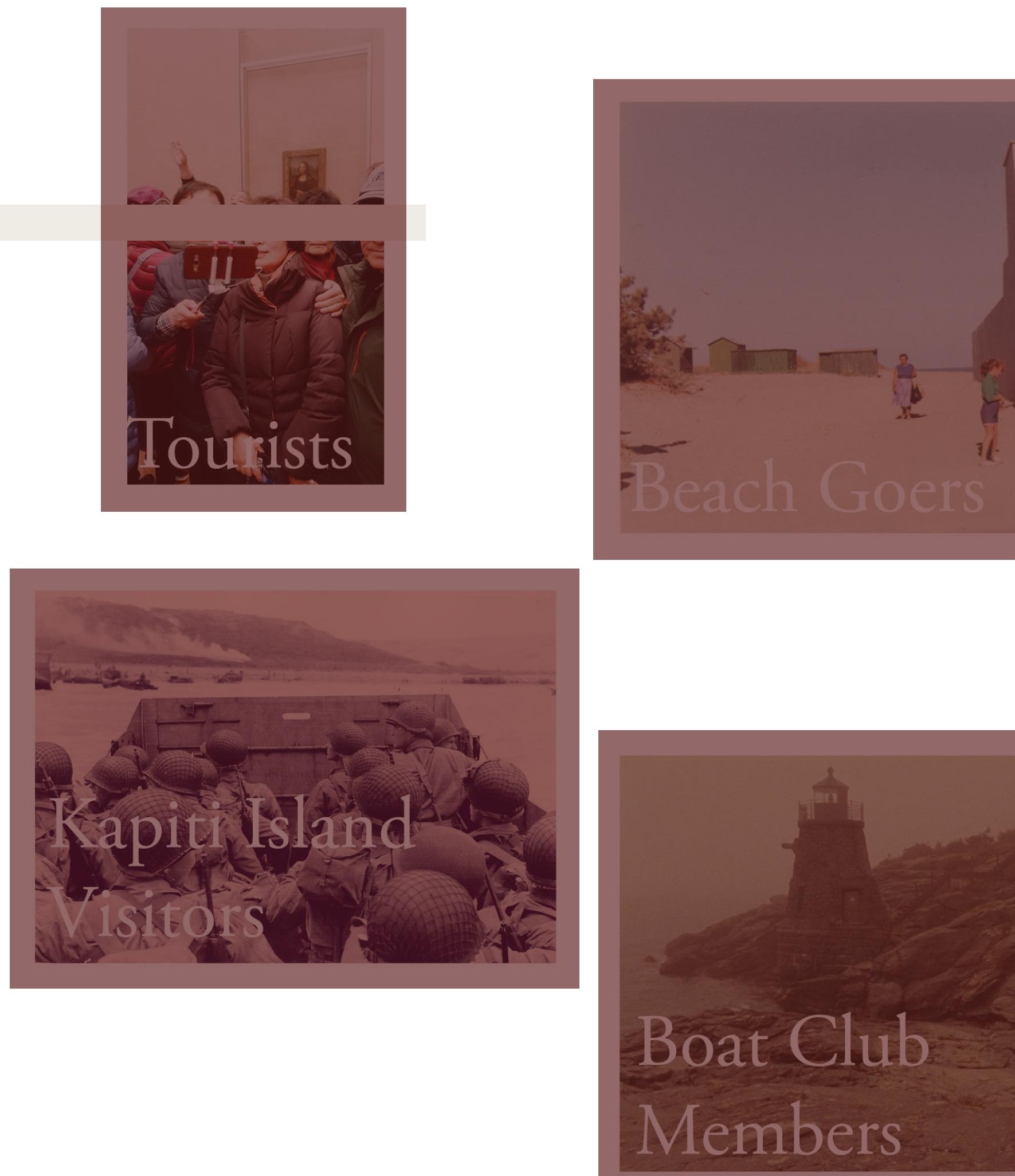

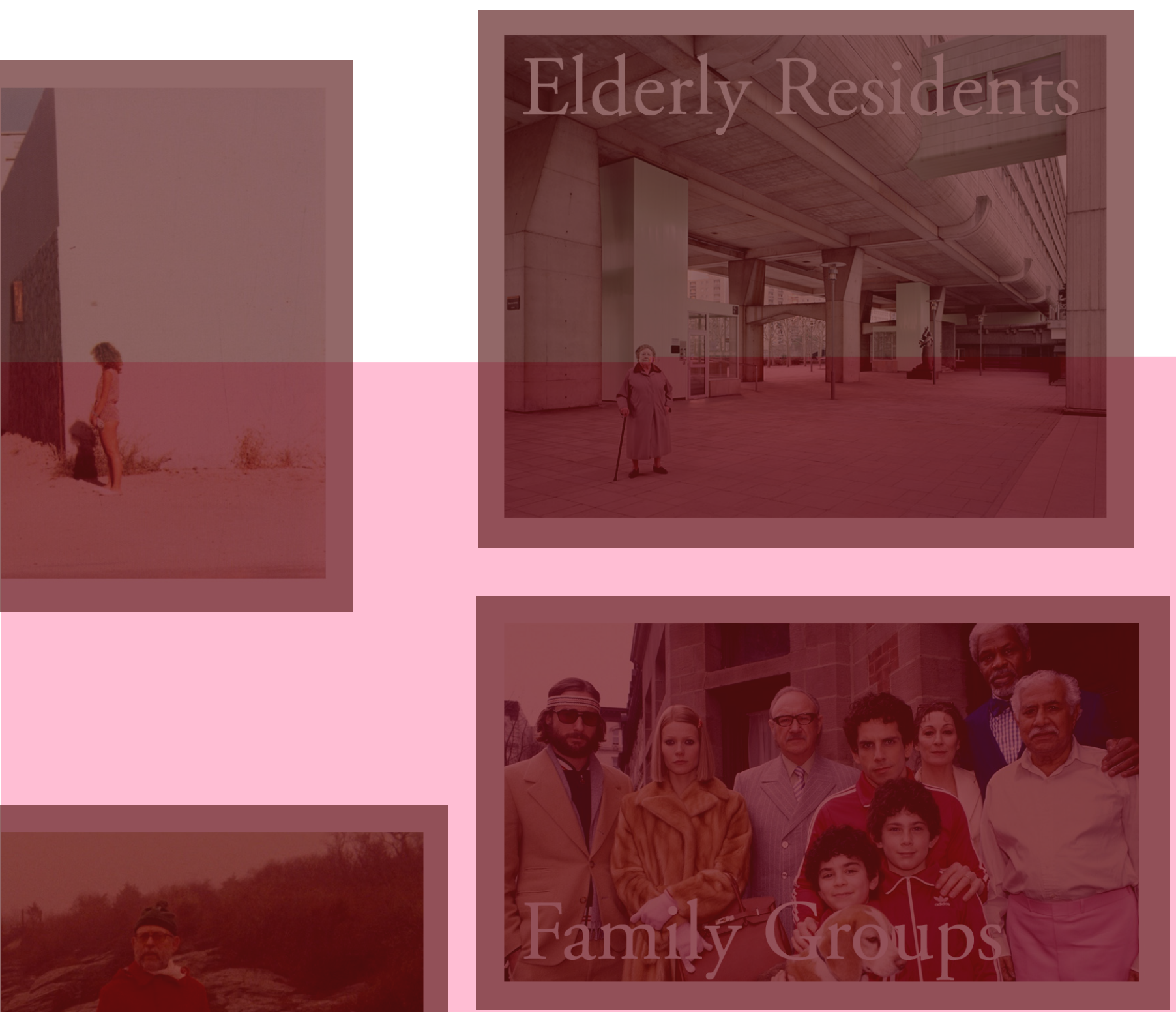

Figure 31

Types of visitors for the proposed biosecurity and visitor's centre - collage 

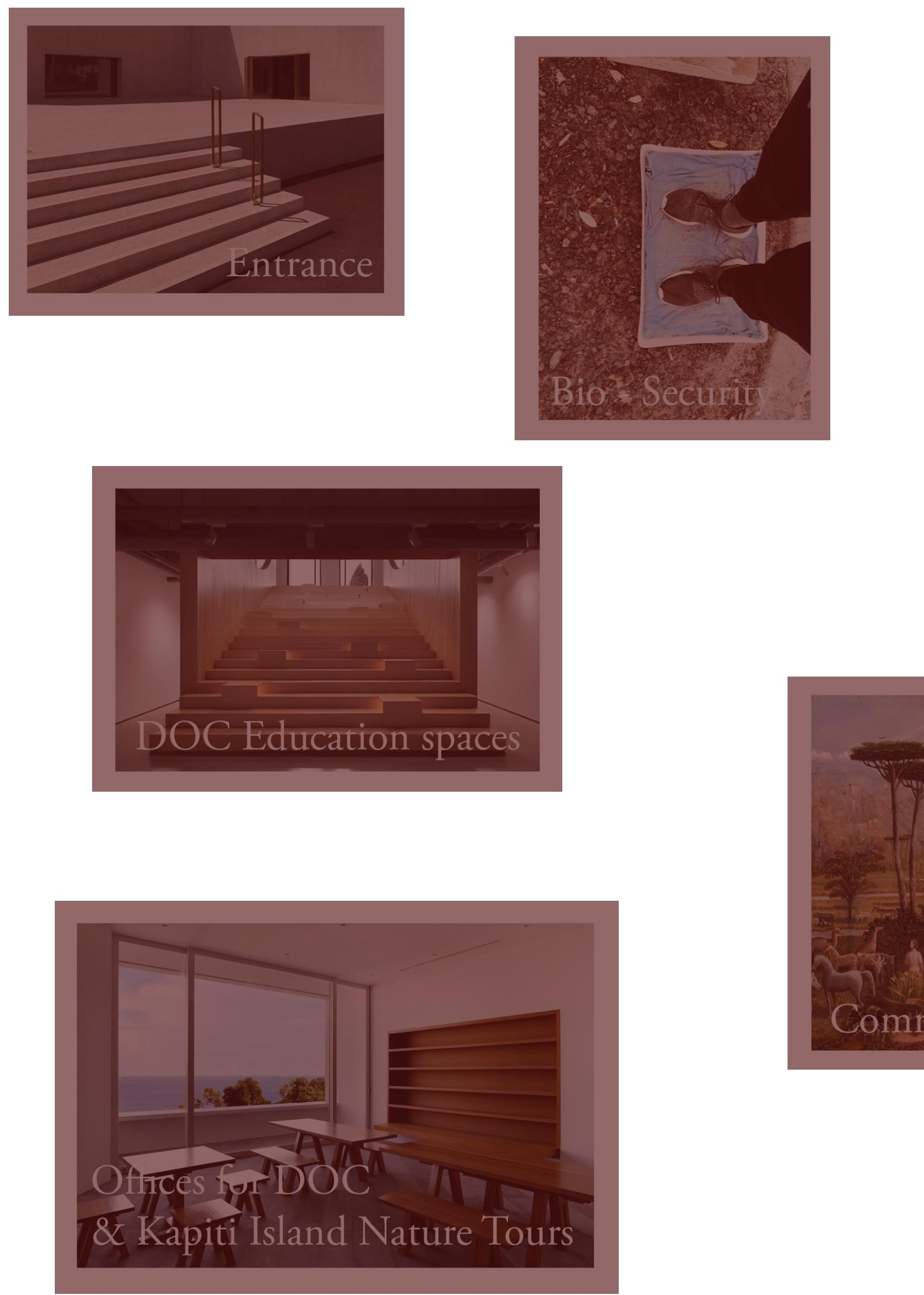

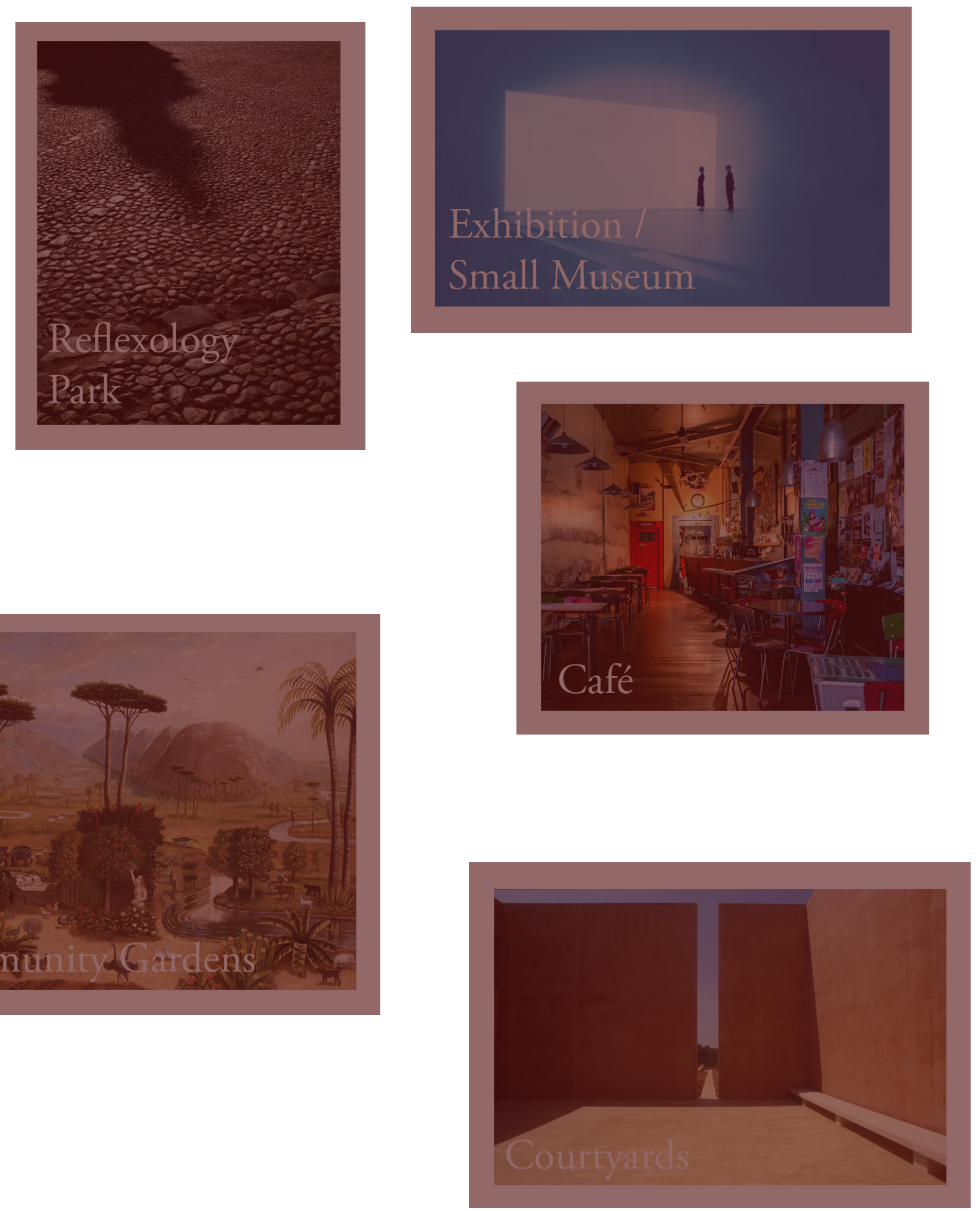

Figure 32

Types of programmes for the proposed bio-security and visitor's centre - collage 


\title{
TERRITORY
}

\begin{abstract}
"The journey towards Kapiti Island feels like entering a battlefield. The bumpy boat ride heads to a giant mass of land leering at you. The orientation of seats has you facing neighbours, yet it is too loud from the sea to actually talk. You end up sitting there as you await your destination, similar to arriving at a shorefront or parachuting off a plane into enemy territory.
\end{abstract}

This idea of arriving at the shorefront stems back to the historical days of voyaging, exploring and conquering new lands. It is different to our mode of transportation, where you immediately arrive at the heart of the city where activity happens. The quiet shorefront on the fringes of the island is where you 'sneak on' into foreign territory. The birds are the island's inhabitants, safe in their sanctuary.

The ride over feels less of a commute and more of an event. There is definitely some tension. There is something larger at stake, a project greater than you. You are merely contributing in a small way, but your actions can change things for better or for worse. We are visitors to a nature reserve that has existed for 120 years and will continue to do so for a long time. It is a territory very different to the one you left from." 


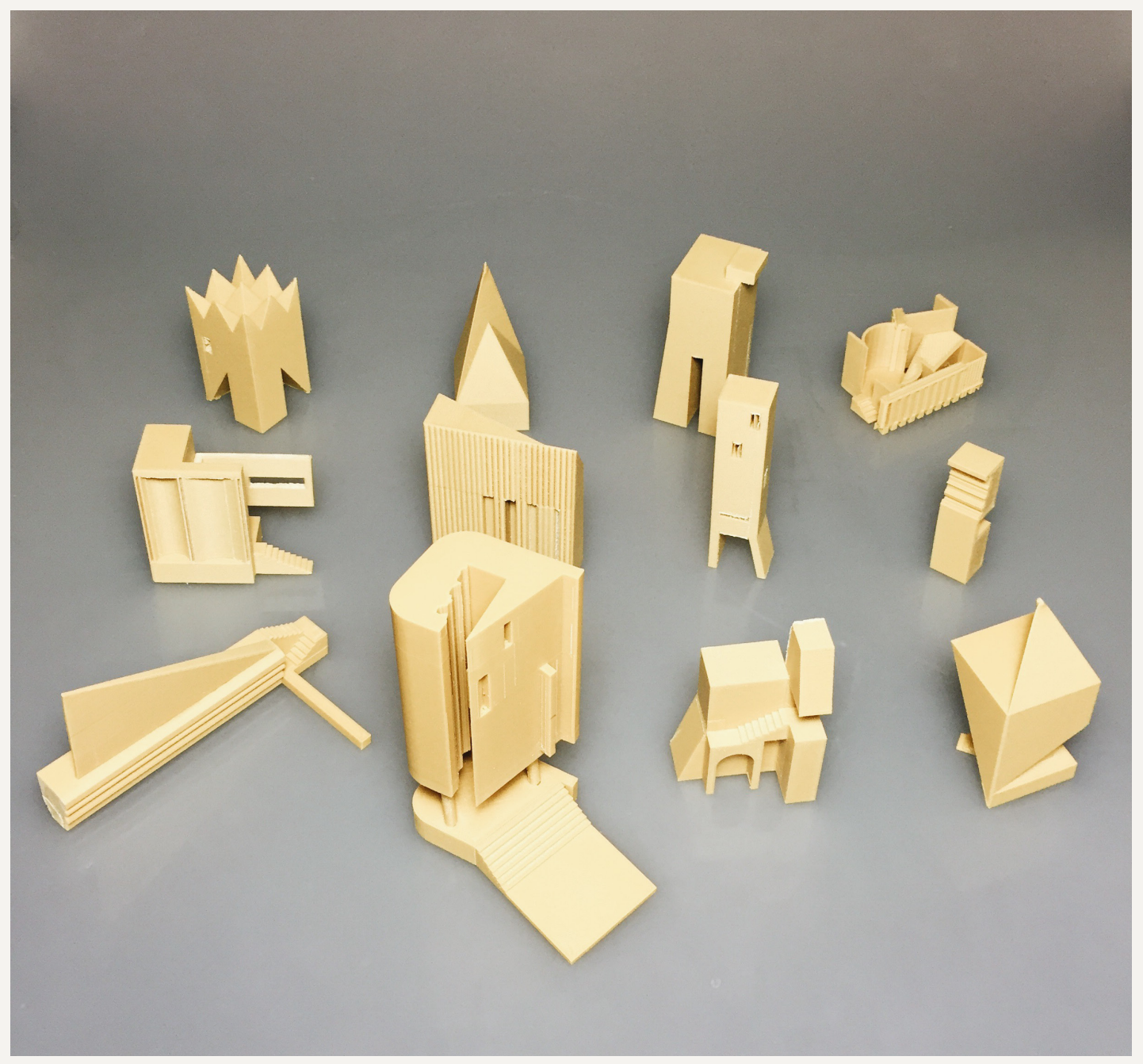

Figure 34

Friends in $3 \mathrm{D}$ printed form 
PART 2

\section{FRIENDS}

EXPERIMENT ONE 


\section{FRIENDS}

"One of the reasons why architecture is better than any art form is that it comes so close from realism to reality"

Jeffrey Kipniss, 2013

This chapter of experiments uses drawings and models based off the language of John Hejduk (see figure 35) to generate forms and figures in a playful and whimsical manner. These 'Hejdukian' figures merge and are reworked with other architectural references, like the works of Steven Holl or Caruso St John. The geometries are reassembled, collaged and re-appropriated to produce new forms that tease out a certain aesthetic for this design proposal and reveal a modus operandi, a way of making form. With each figure, architectural cues such as site and programme are not at the forefront of experimentation, but rather the form and the manipulation of image. The result can be seen as a collection of follies or pavilions. They have no clear indication of space, but they suggest a level of occupancy with stairways, windows and niches.

These Friends are seen as 'gods' and 'idols', crucial to the composition and authorship of sequential experiments. The golden and marble texture-laced representation of these models and drawings highlight the value and knowledge which is instilled within each friend, which are artefacts examined for a reinterpretation of form. 

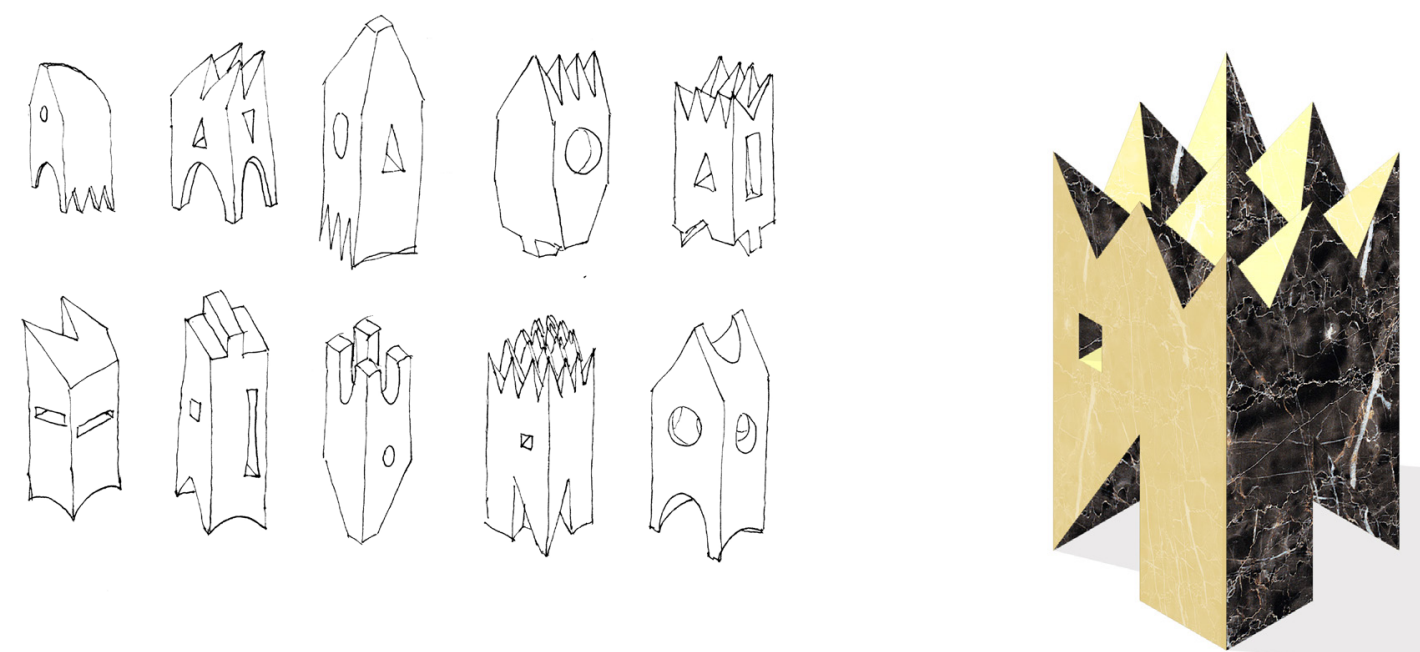

$\wedge$ Figure $36 *$ Friend One

Études - Book No. One, WOJR (2015)
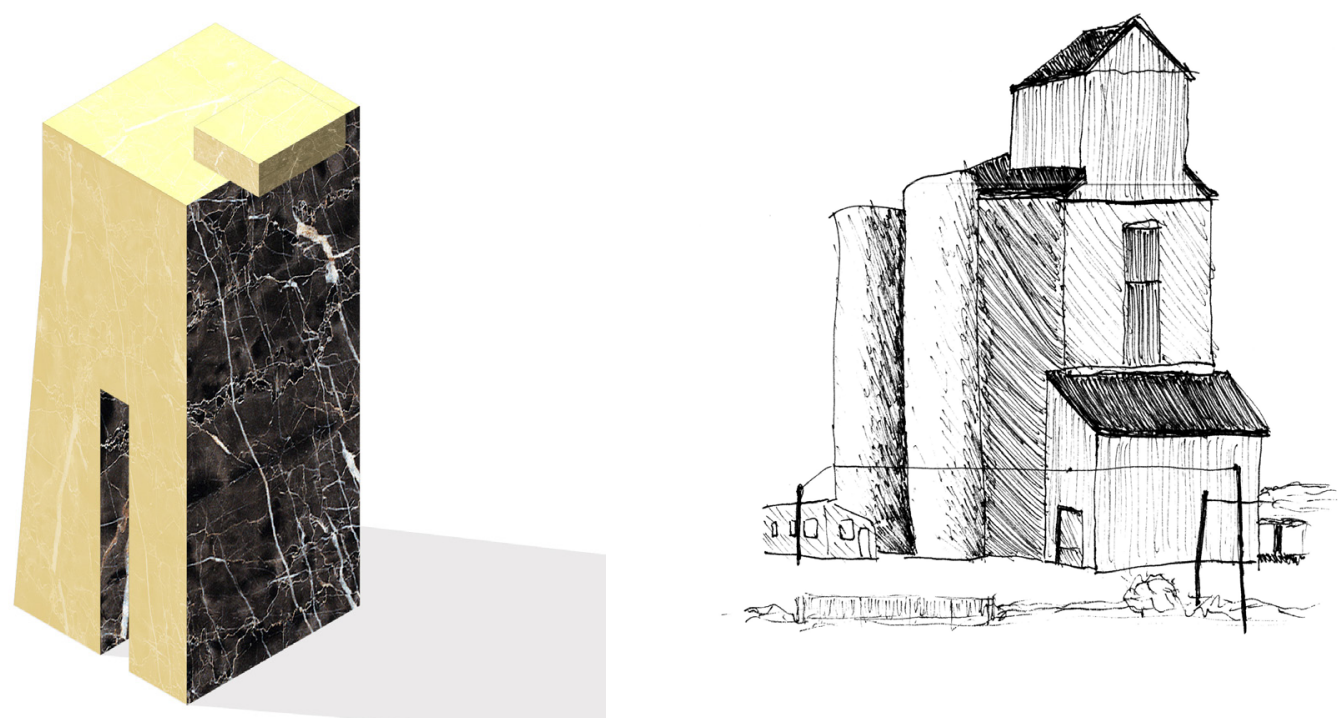

$\wedge$ Figure $37^{*}$ Friend Three

Getreidesilos, Bernd \& Hilla Becher (2006) 

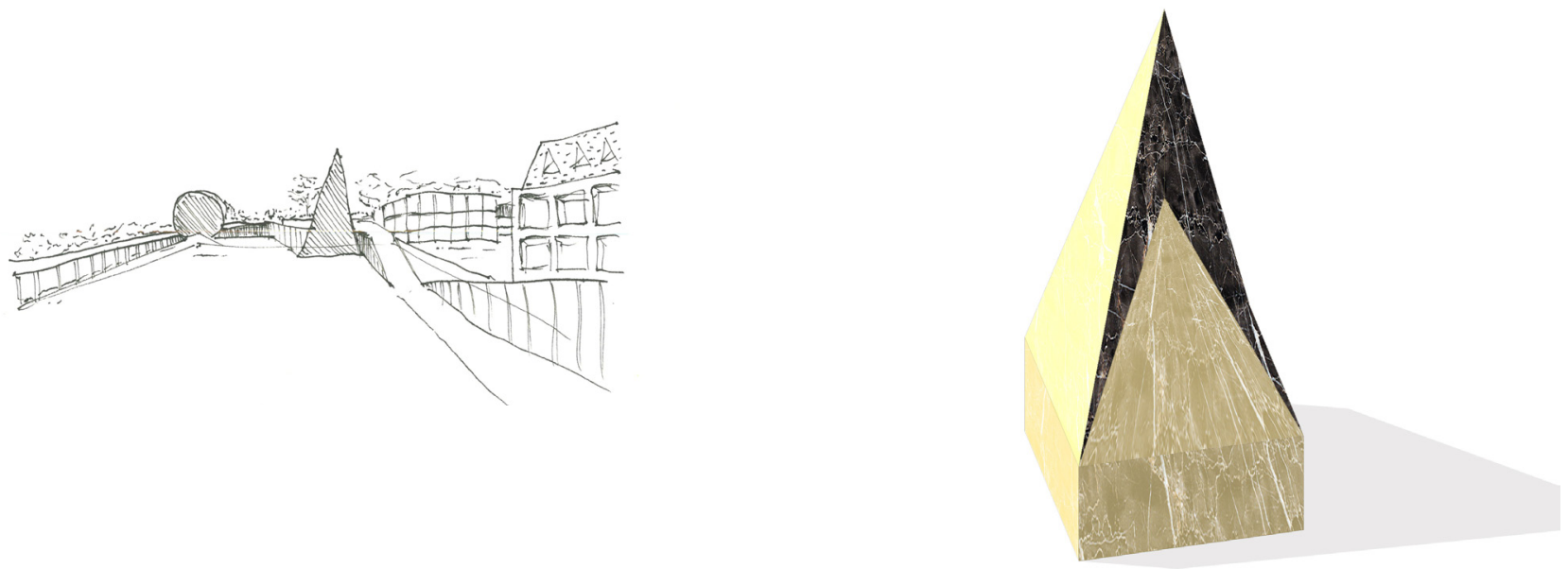

$\wedge$ Figure $38 *$ Friend Two

Baltic Art Park, LCLA (2013)
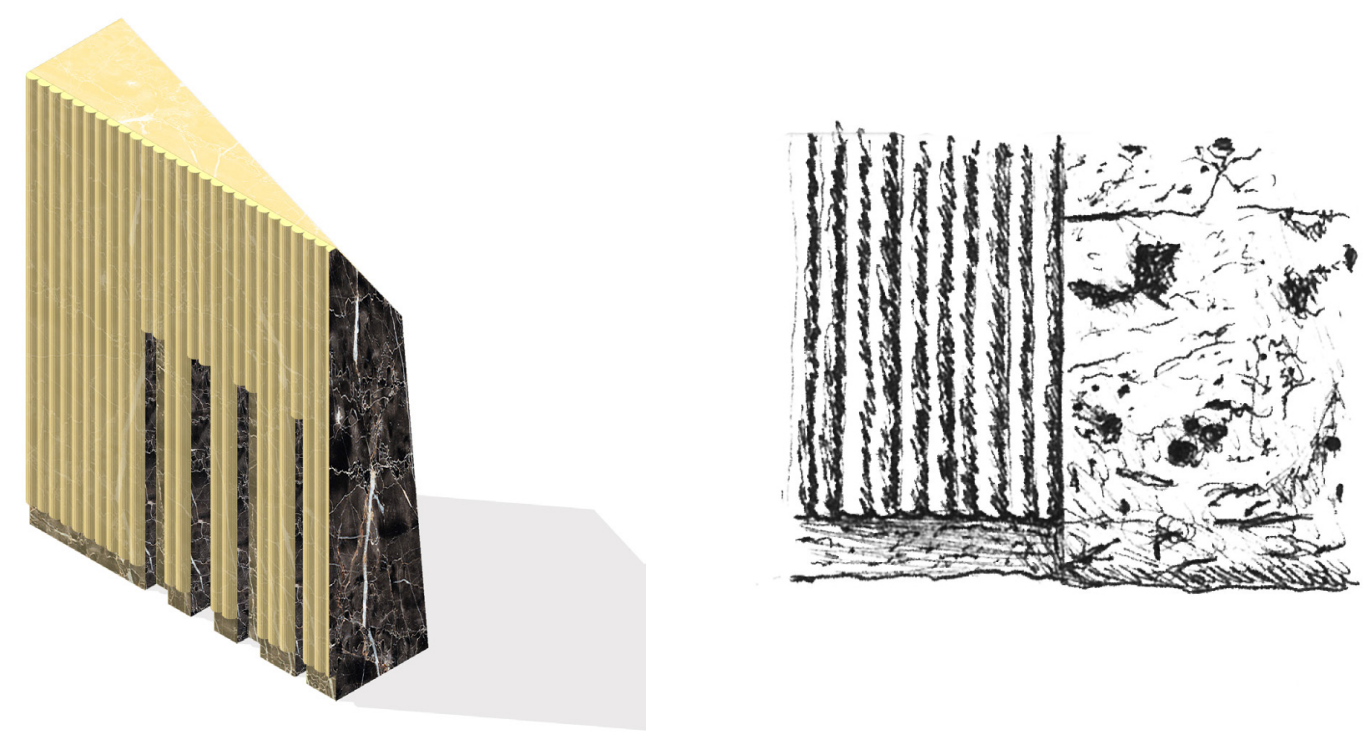

$\wedge$ Figure $39 *$ Friend Four

Casa Il Girasole, Luigi Moretti (1950) 

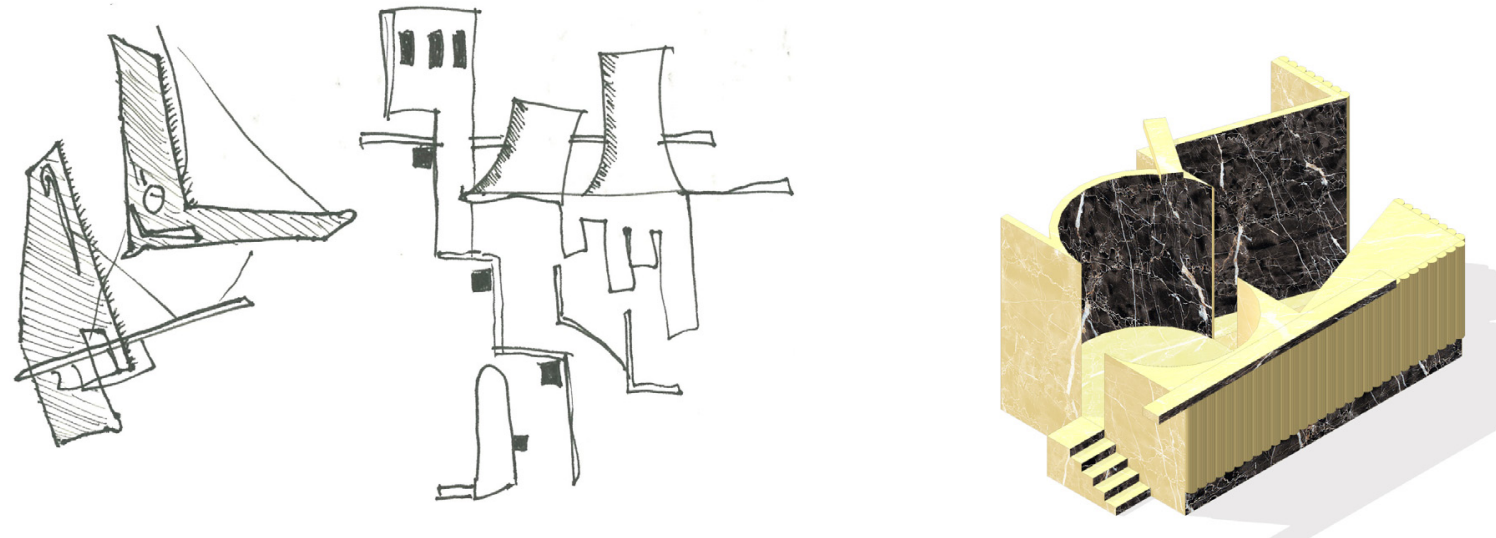

$\wedge$ Figure $40 *$ Friend Five

Left: Theatrical Pleasure Ground Istanbul, Bartlett Unit 21 Sarah Bromley (2011)

Right: Urban Theatre, Bartlett Unit 21 Will Aitken (2009)
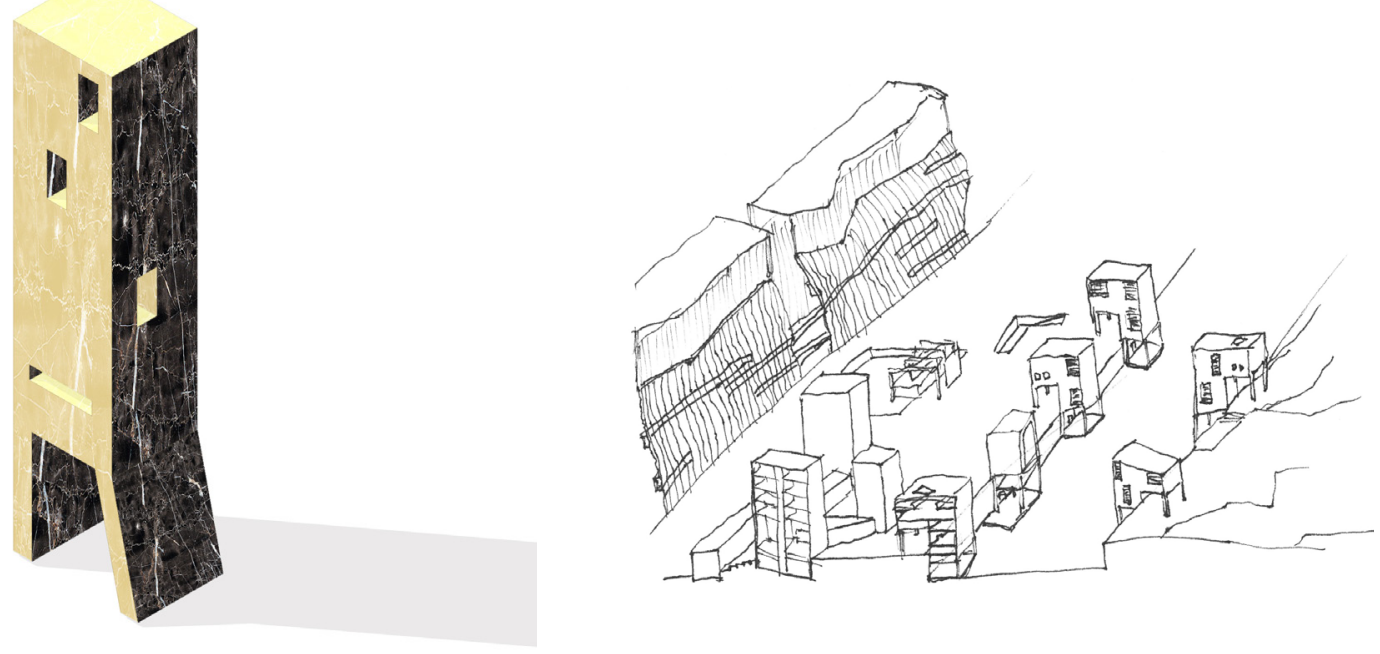

$\wedge$ Figure $41 *$ Friend Seven

Erie Canal Edge, Steven Holl (1988) 

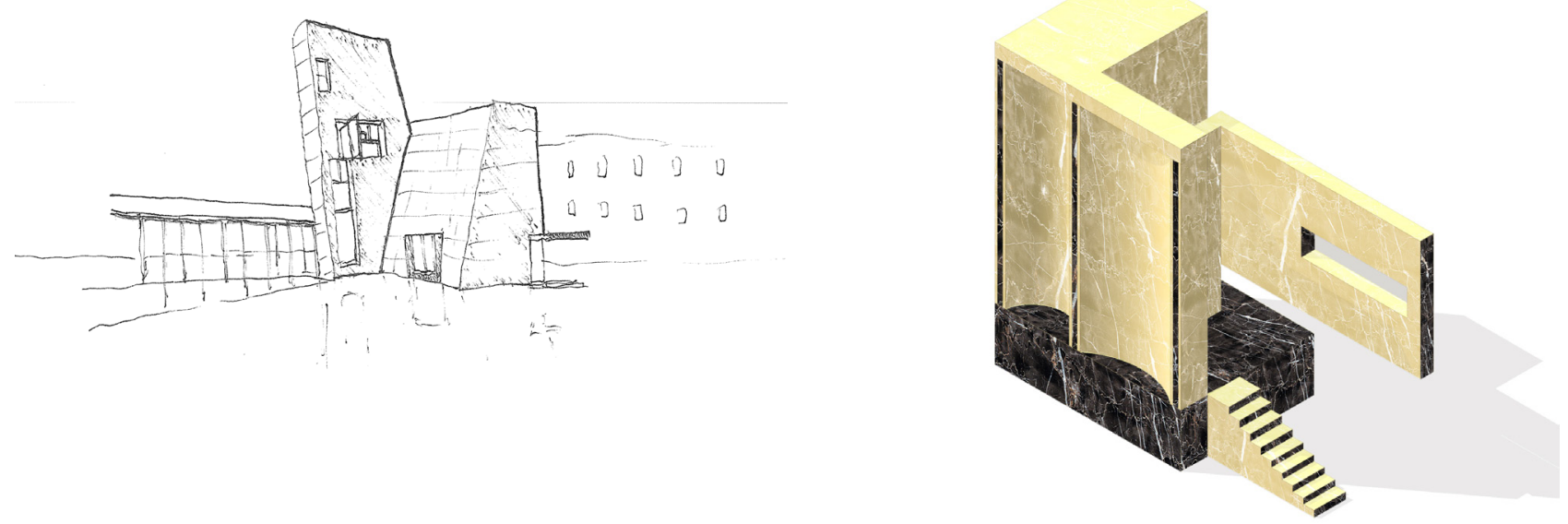

$\wedge$ Figure $42 *$ Friend Six

Chapel and Town Square, Steven Holl (1991)
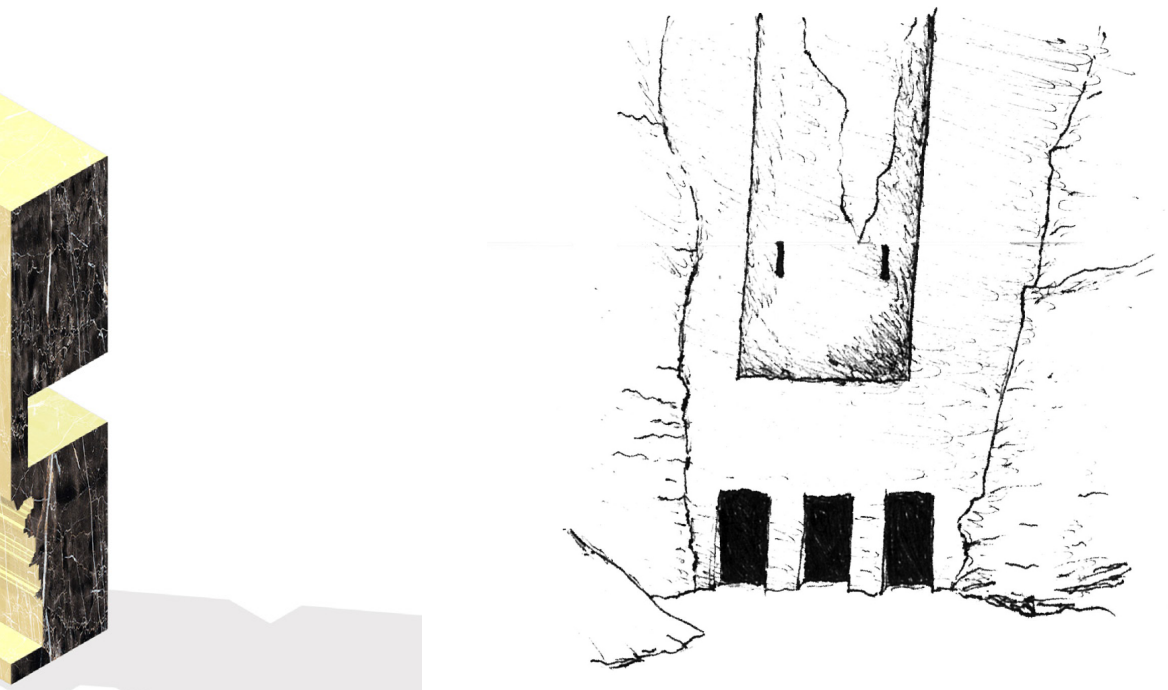

$\wedge$ Figure $43 *$ Friend Eight

Qsar el Saràb: the Citadel, Thierry Urbain (1995) 

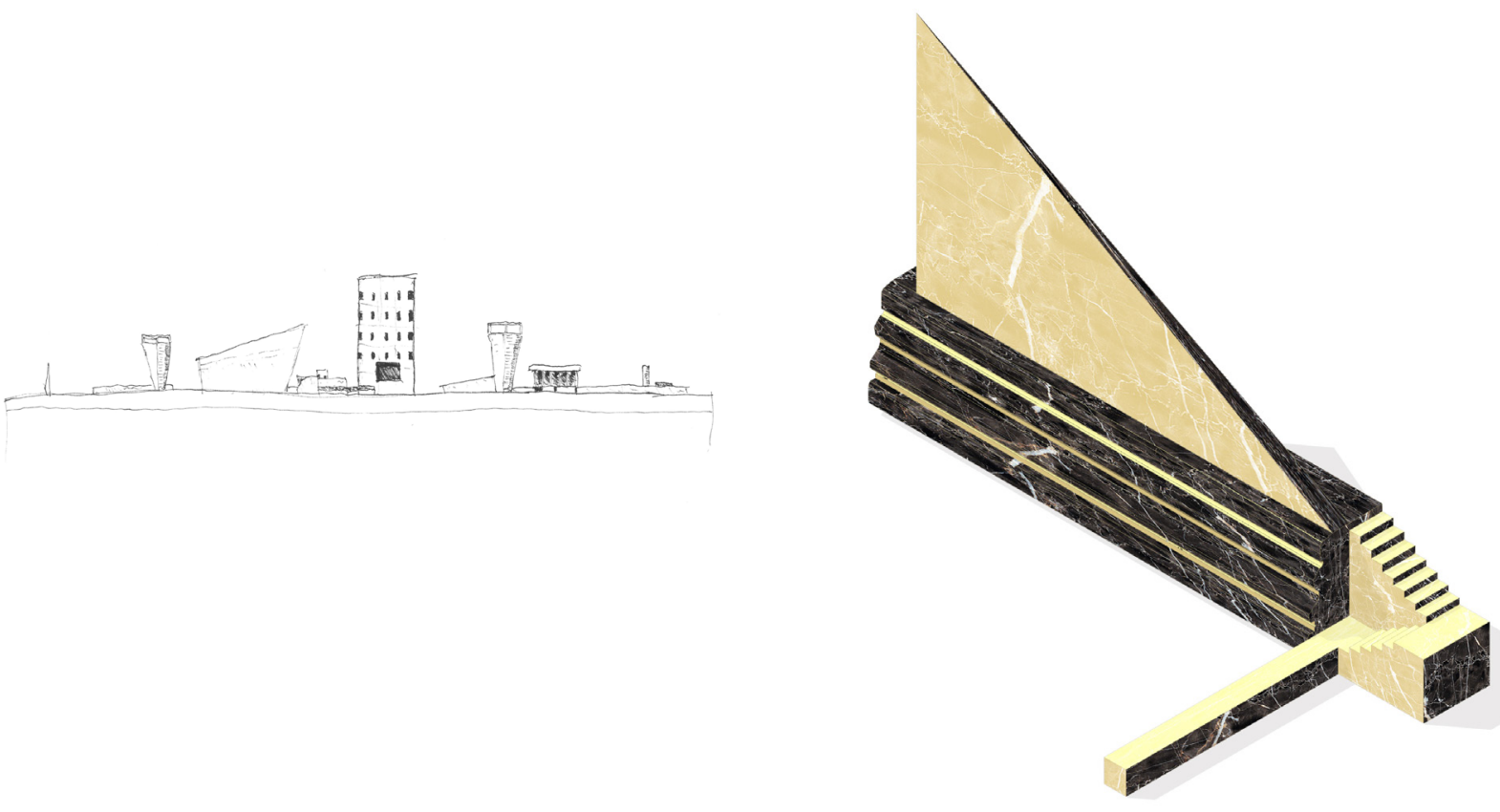

$\wedge$ Figure $44 *$ Friend Nine

Unité d'habitation, Le Corbusier (1952)
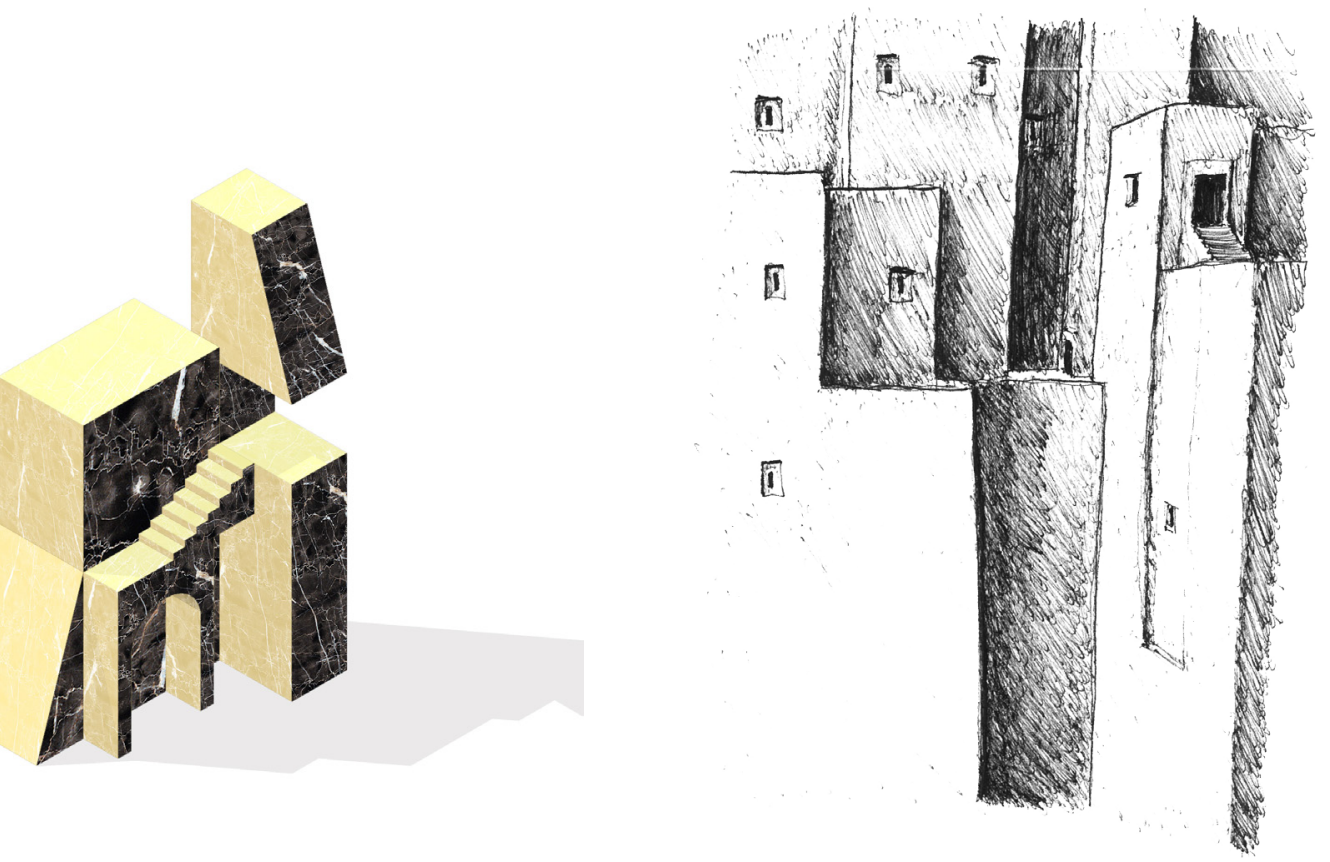

$\wedge$ Figure $45 *$ Friend Eleven

Babylon: the Library, Thierry Urbain (1991) 

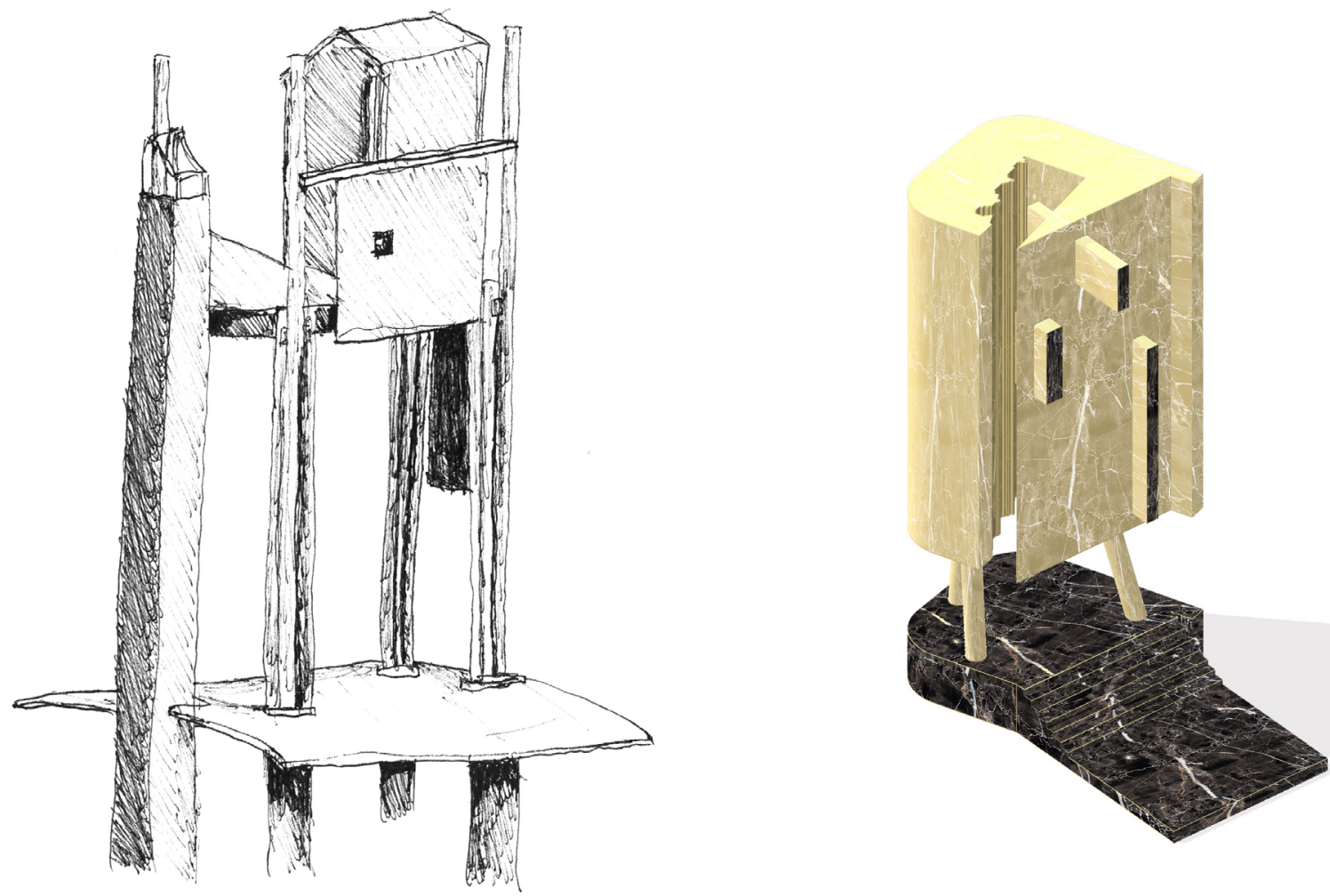

$\wedge$ Figure $46 *$ Friend Ten

World Exposition: Pilot's House, Jon Olsen (1983)
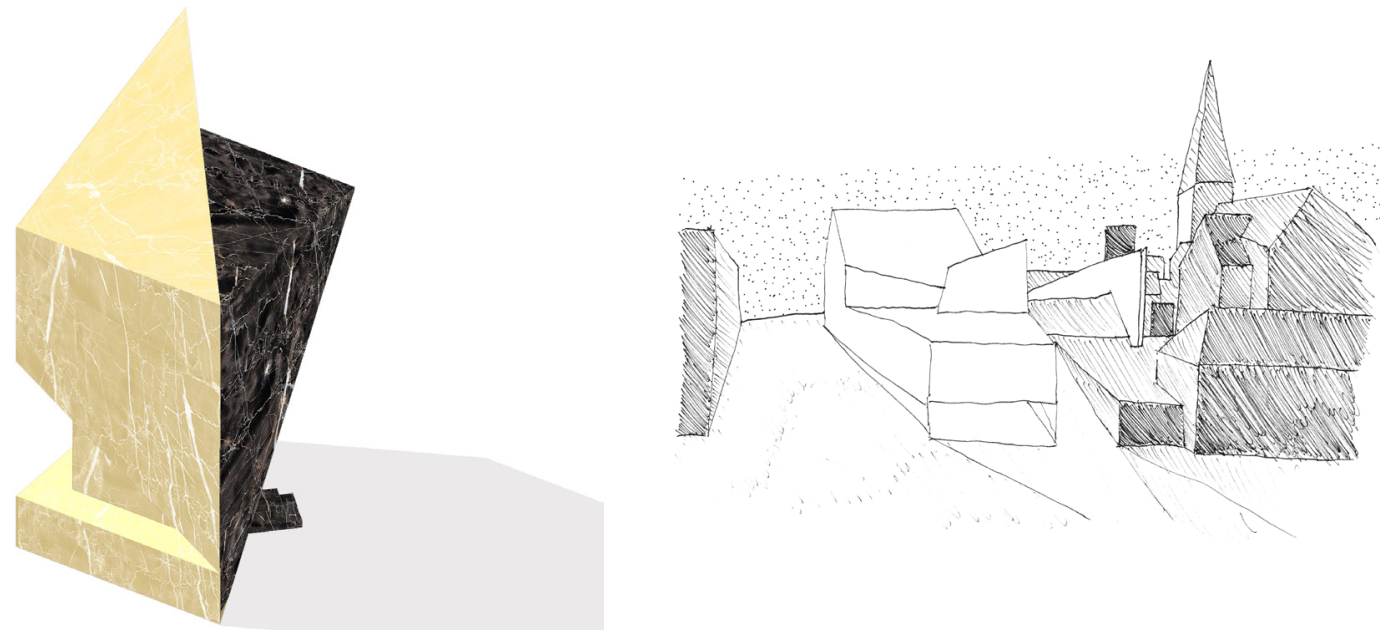

$\wedge$ Figure $47^{*}$ Friend Twelve

Nottingham Contemporary, Caruso St John (2009) 

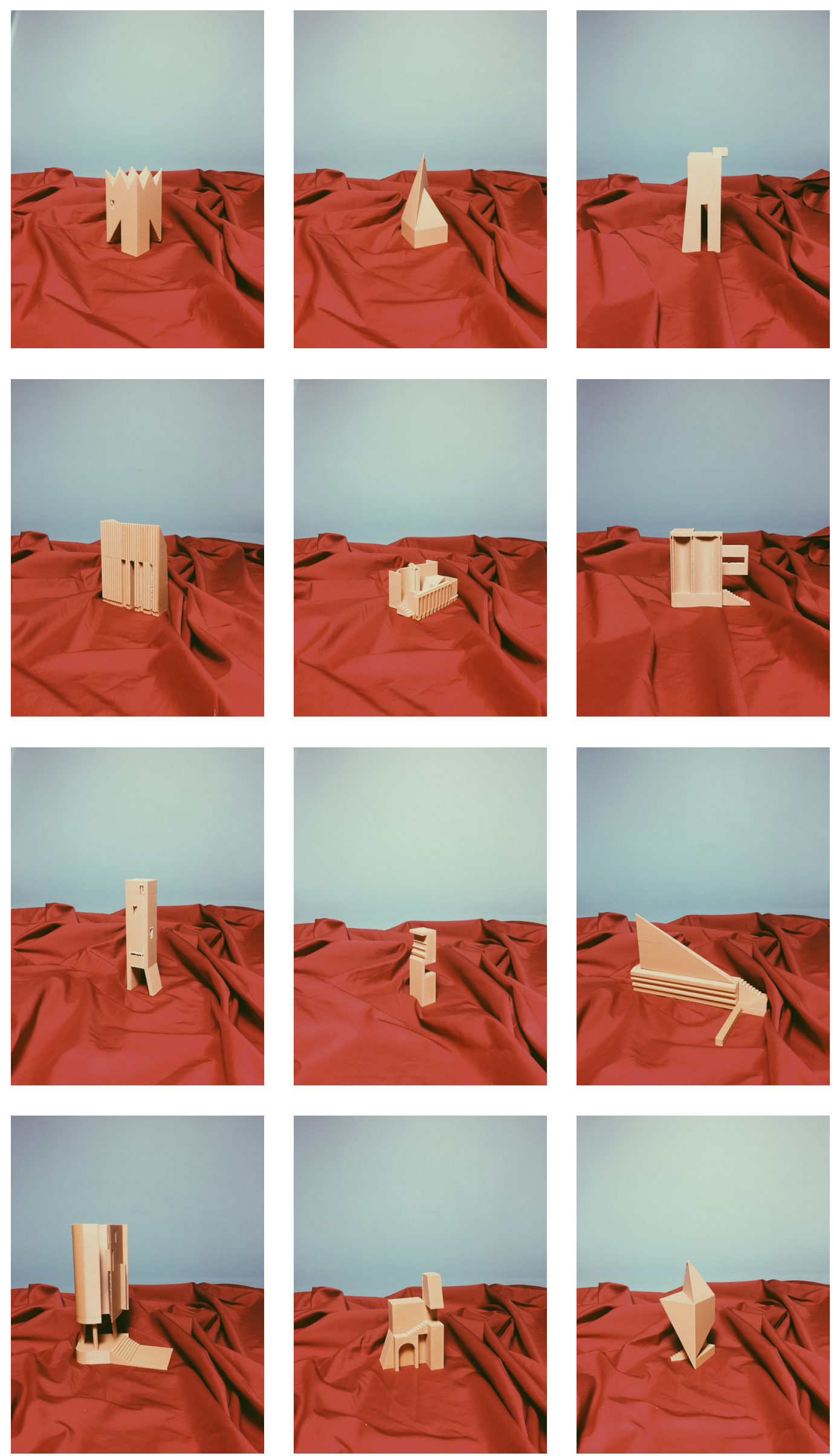

$\wedge$ Figure 48

Portaits of friends sitting on the shorefront 


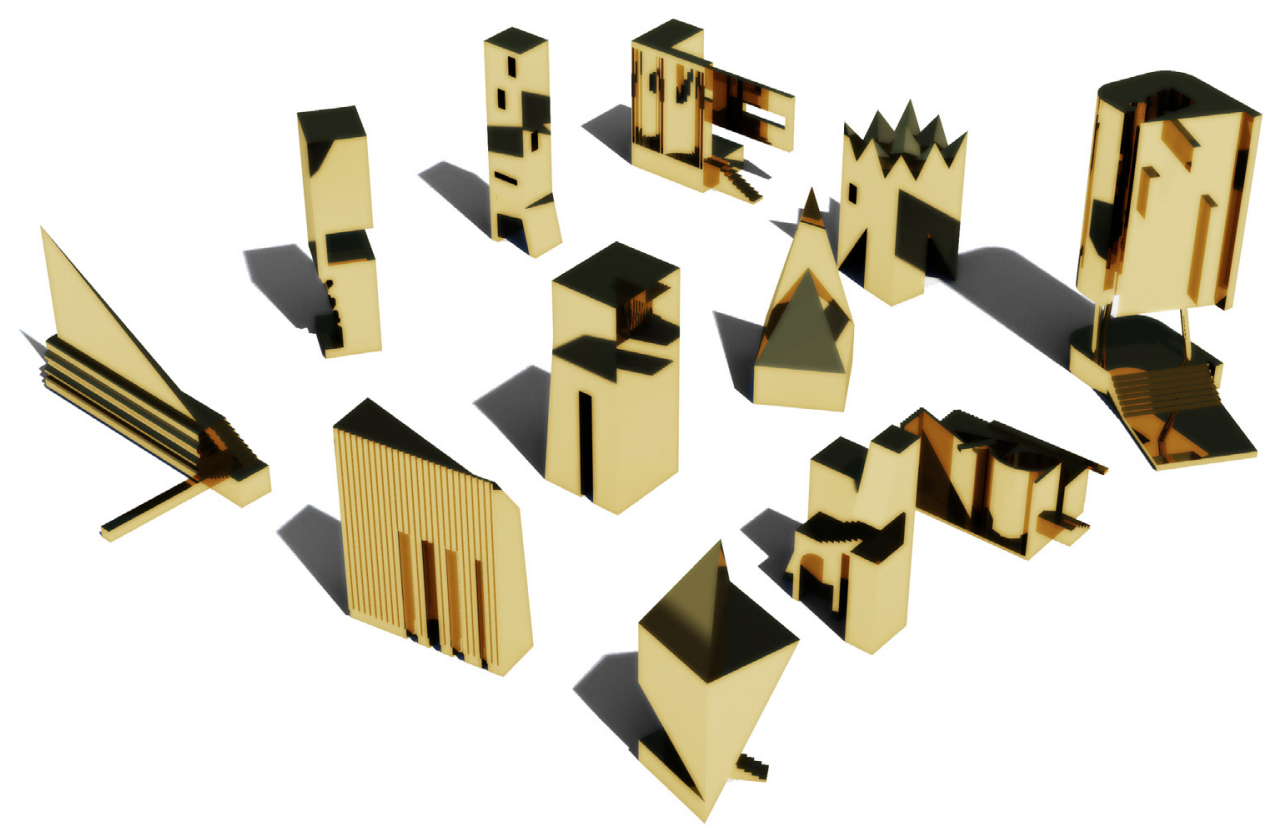

$\wedge$ Figure 49

Friends gathered

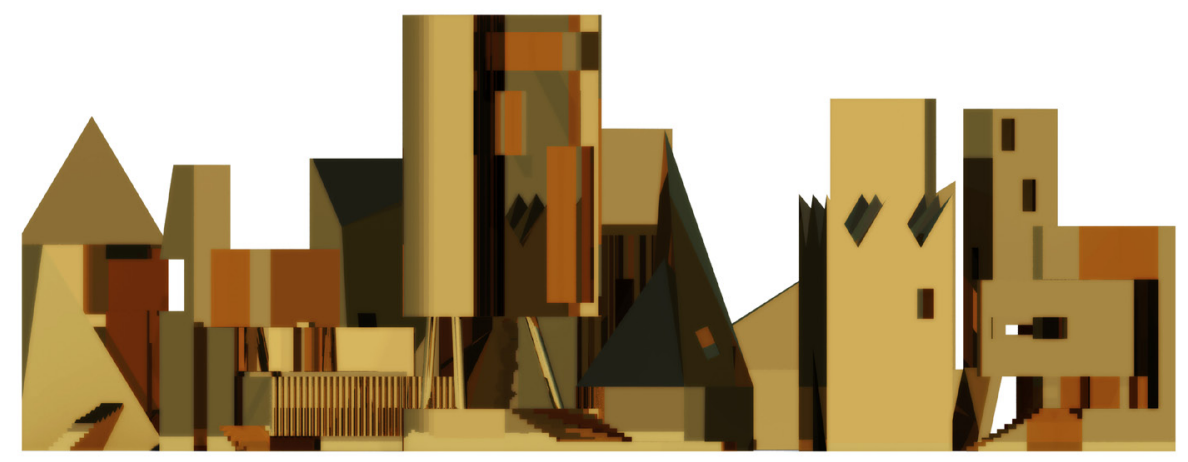

$\wedge$ Figure 50

Friends in gold 

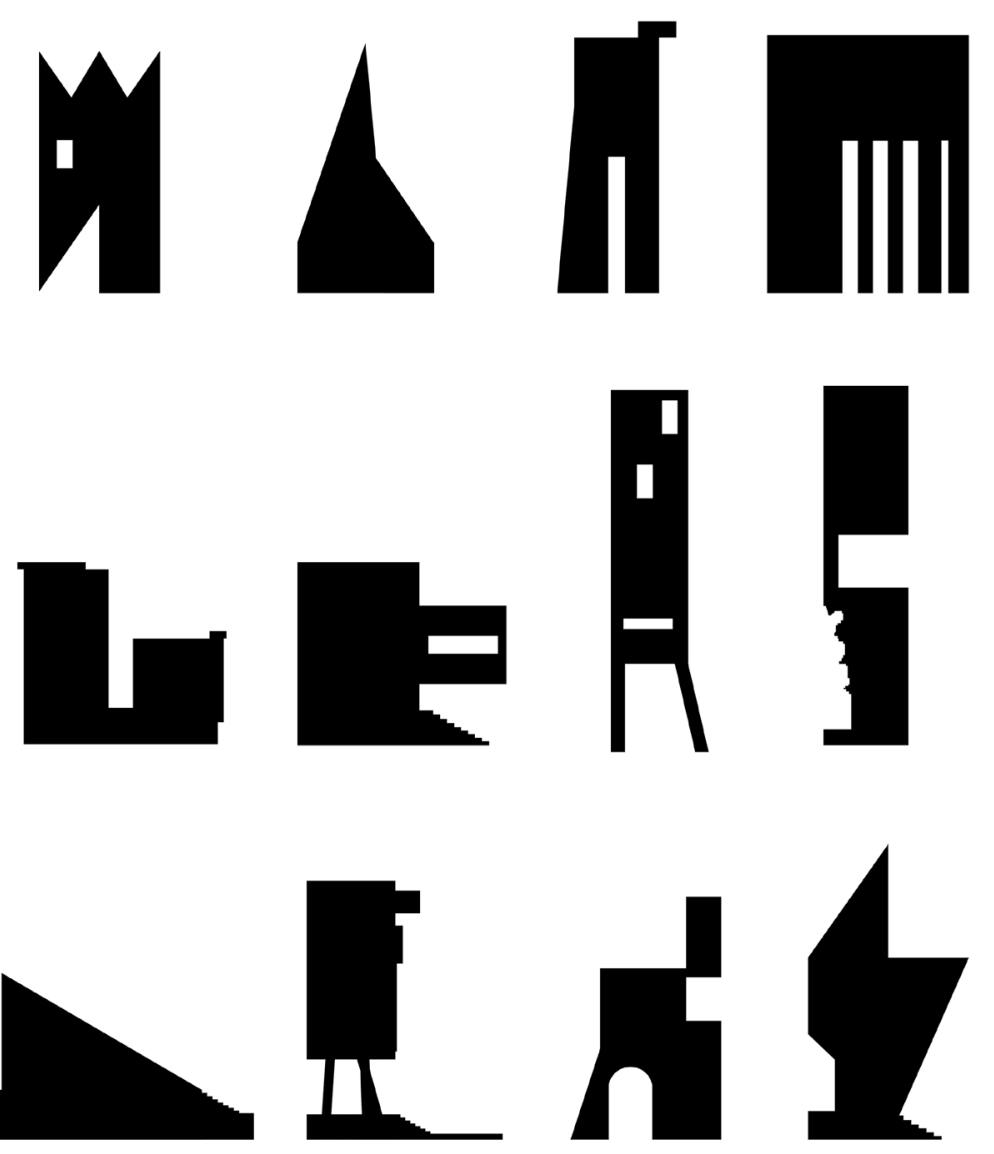


\section{FRIENDS ROAMING}

The site-less Friends are placed on site in the Paraparaumu township where they become part of the urban environment, roaming around and creating chaos and havoc. In Hejduk's Masques we encounter anthropomorphic scattered figures, likened to an Italian Maschera, each having its own character, "traveling from city to city twisting the mundane urbanism of their sites into carnivalesque narratives" (Hays). American architectural historian and professor K. Michael Hays compares Hejduk's figures to Lacan's gaze, the anxious state that comes with the awareness that one can be viewed.

"The differential play that usually takes place along the axis between viewer and the object is now internalised in the object itself and turned back on the viewer."

Friends, now associated with the township of Paraparaumu, transcend the issue of form-finding beyond aesthetical expressions. Friends, sitting in an urban context instead of floating in a 'worshipped' realm, can now begin to initiate conversations on the acceptance of the form with different viewer-subject relationships, or on the inhabitation of programme, or on materiality and other missing architectural conventions. 


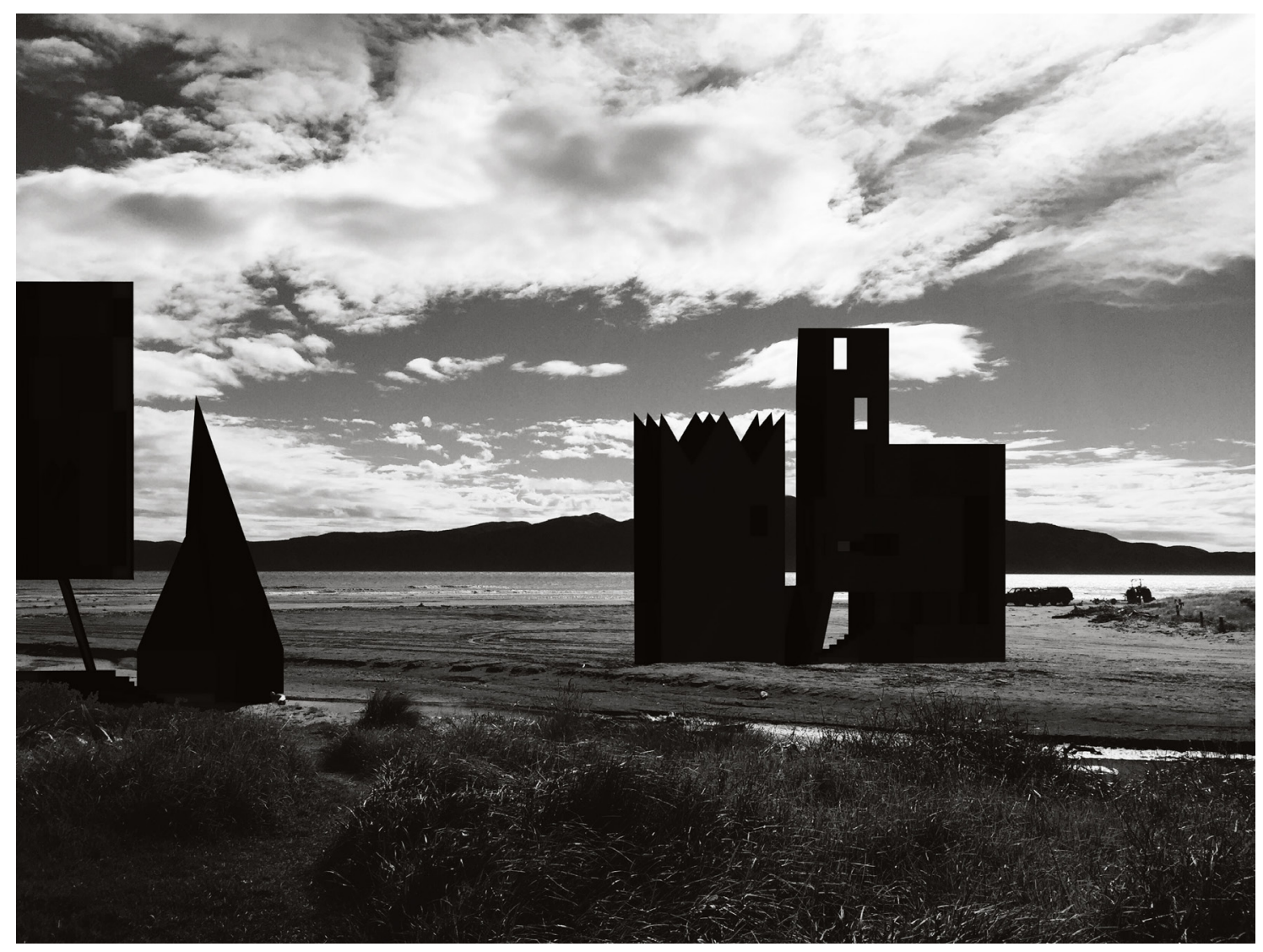

$\wedge$ Figure 52

Friends scattered on Paraparaumu Beach, blocking views towards Kapiti Islands

$>$ Figure 53

Friends grouped on the way back from Kapiti Island

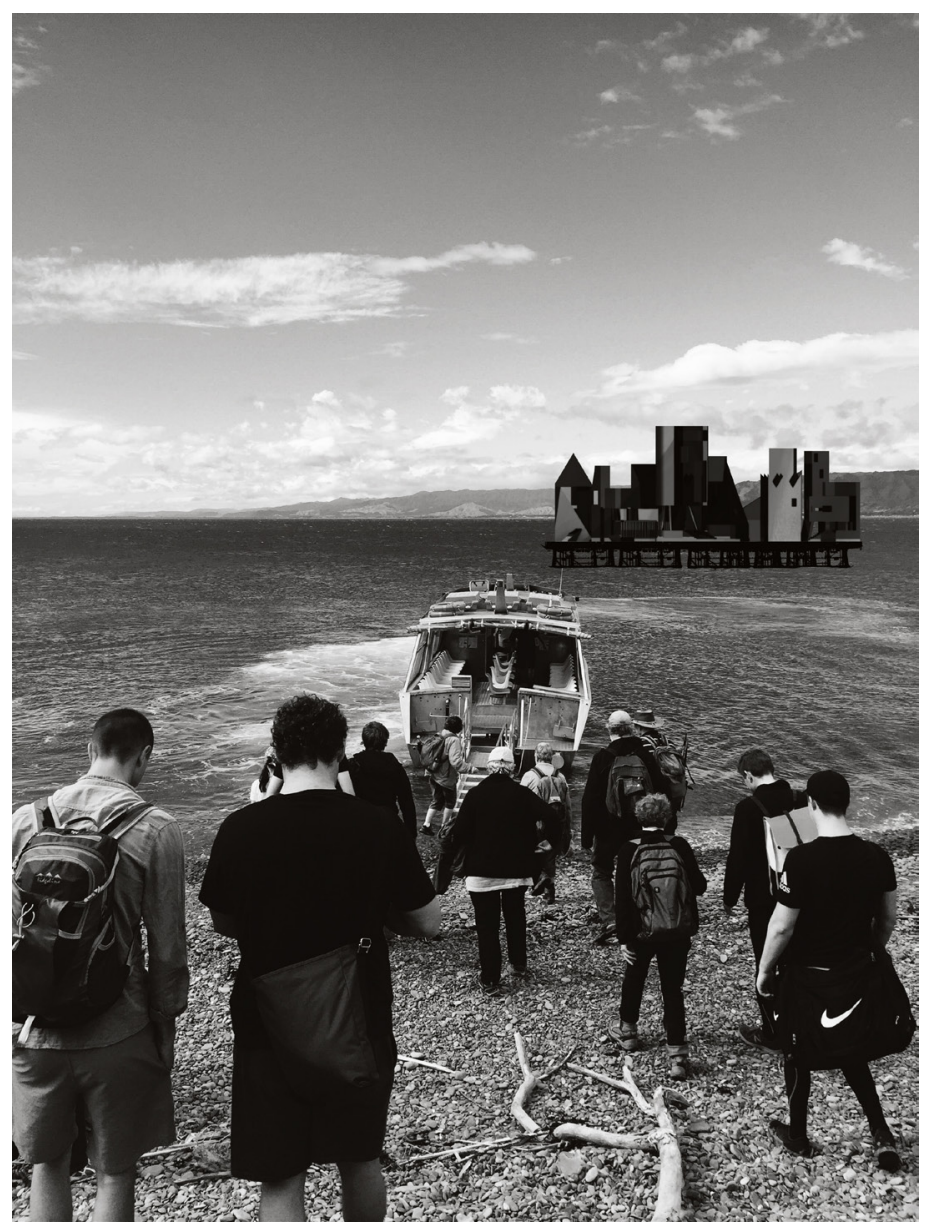




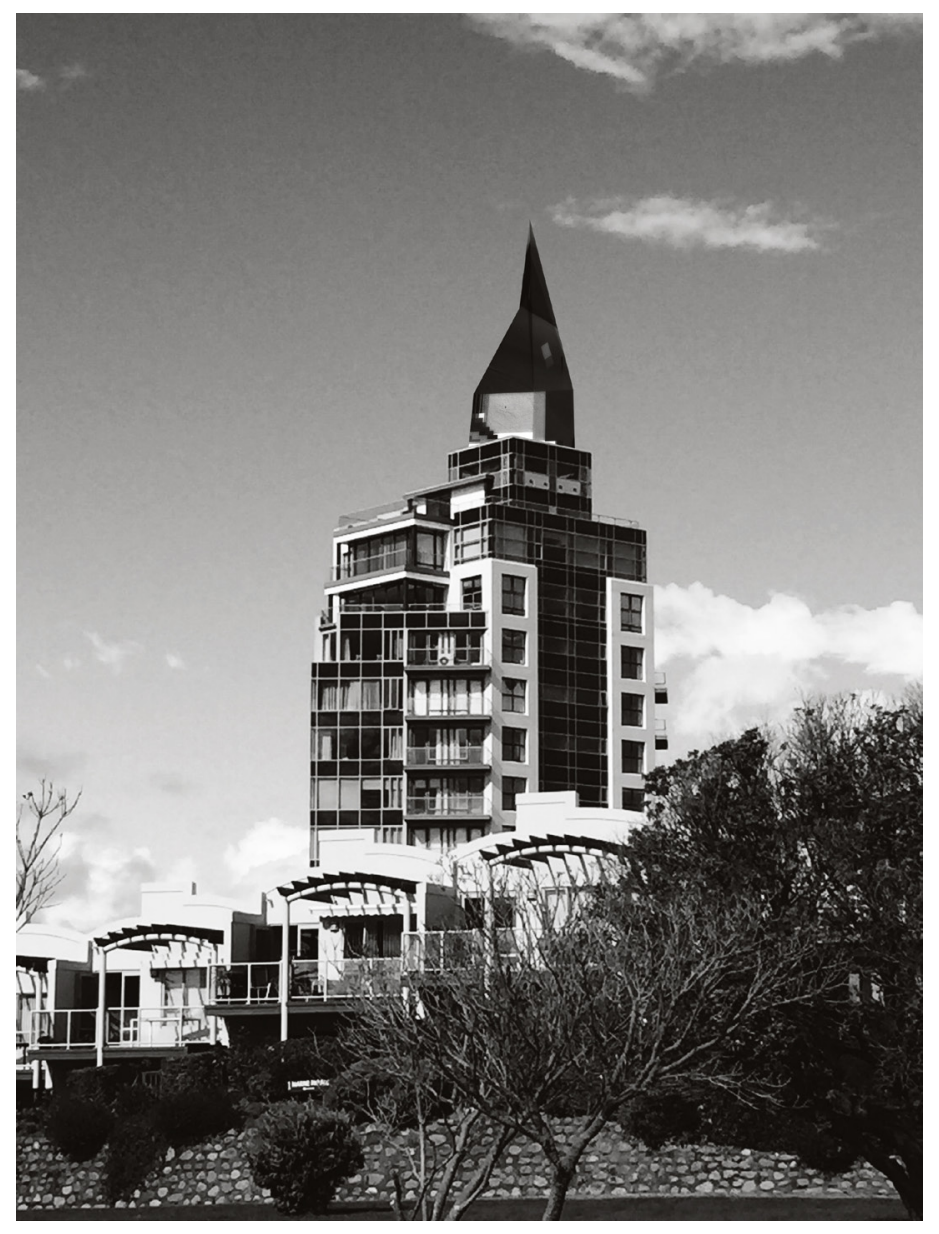

$\wedge$ Figure 54

Friend Two perched on an existing Paraparaumu apartment building, creating havoc 


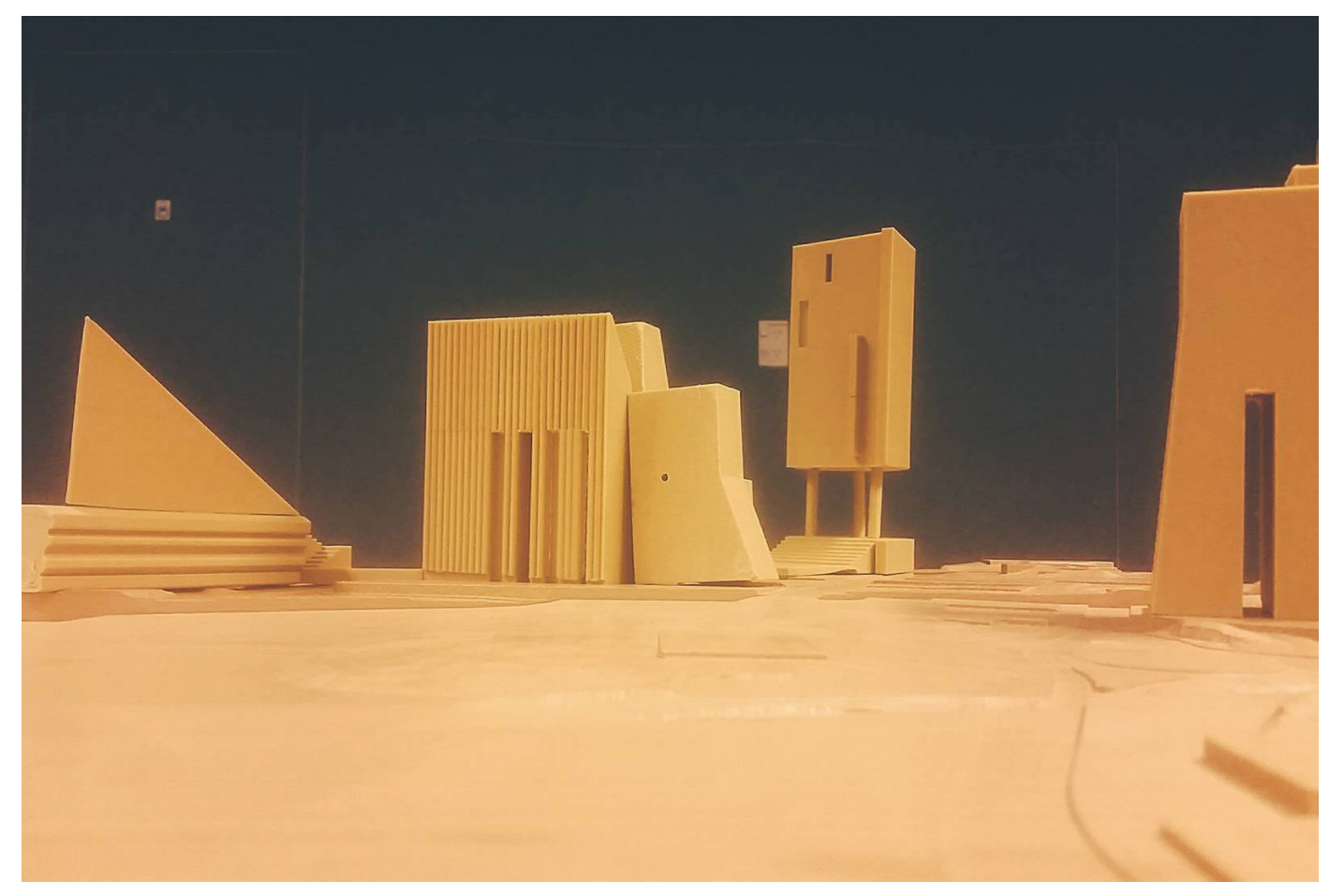




\section{POSITIVE DESTABILISATION}

In a presentation in May, one reviewer described these experiments as 'terrifying'. These figures in the Kapiti Coast context are shocking and confusing, and to some a ghastly and offensive intervention, provoking opinions on the nature of what a public building should look like in New Zealand. Slipping disruptive elements into projects can consciously provoke uncomfortable situations, following the injunction of Pablo Picasso: "You must wake people up. Overturn their way of identifying things" (Boudet 33).

\section{$<$ Figure 55}

The presence of Friends 

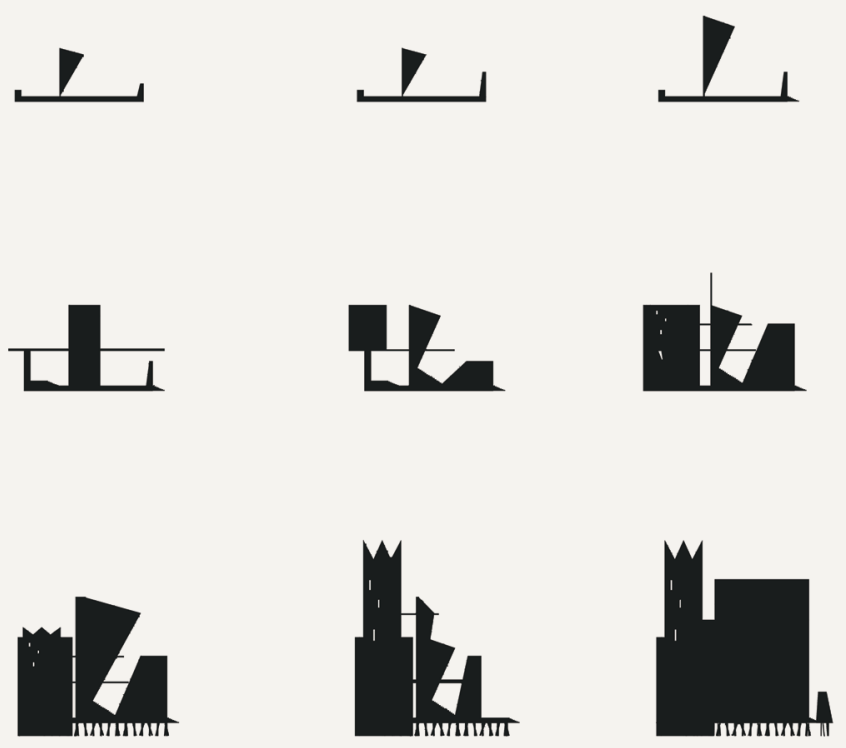

Figure 56

Evolution of the waka 
PART 2

\section{THE WAKA VISION}

EXPERIMENT TWO 


\section{THE WAKA VISION}

Metaphors in architecture use analogies between two entities, where the design's appearance, form or function is symbolic of a particular context or reference. The reference is reflected upon the building, as in Te Wharewaka by Architecture Plus on Wellington's waterfront, which uses the korowai (cloak) as a concept for the building- the roof drapes over as the outer layer, giving protection to the building, similar to how the korowai protects the human body. More literal in appearance is the Waka Mãori on Auckland's waterfront, which was built for the Rugby World Cup 2011 as a cultural venue and events base.

In an early meeting with a Kapiti district council member, they envisioned an upside-down waka as the bio-security centre. This set of experiments uses this vision as an investigation into generating form, seeing if the process leads to a successful or unsuccessful outcome. The experiments are done consciously, knowing the outcome will be a building tethered to the waka as a referent. The process takes principles, forms and characteristics of the waka to drive the building's figure, including the protruding sails, the long boat, the mast and operational cues. The process slowly evolves, emphasising certain features like the large building for a mast and the entrance at the back of the building, reflecting the ritual of entering a waka from the back, not the sides.

\footnotetext{
$<$ Figure 57

Maori Waka with Sail, Miss E Richardson

$<$ Figure 58

Te Wharewaka, Architecture Plus (2011)

$<$ Figure 59

Waka Māori, TOA \& Opus Architecture (2011)
} 


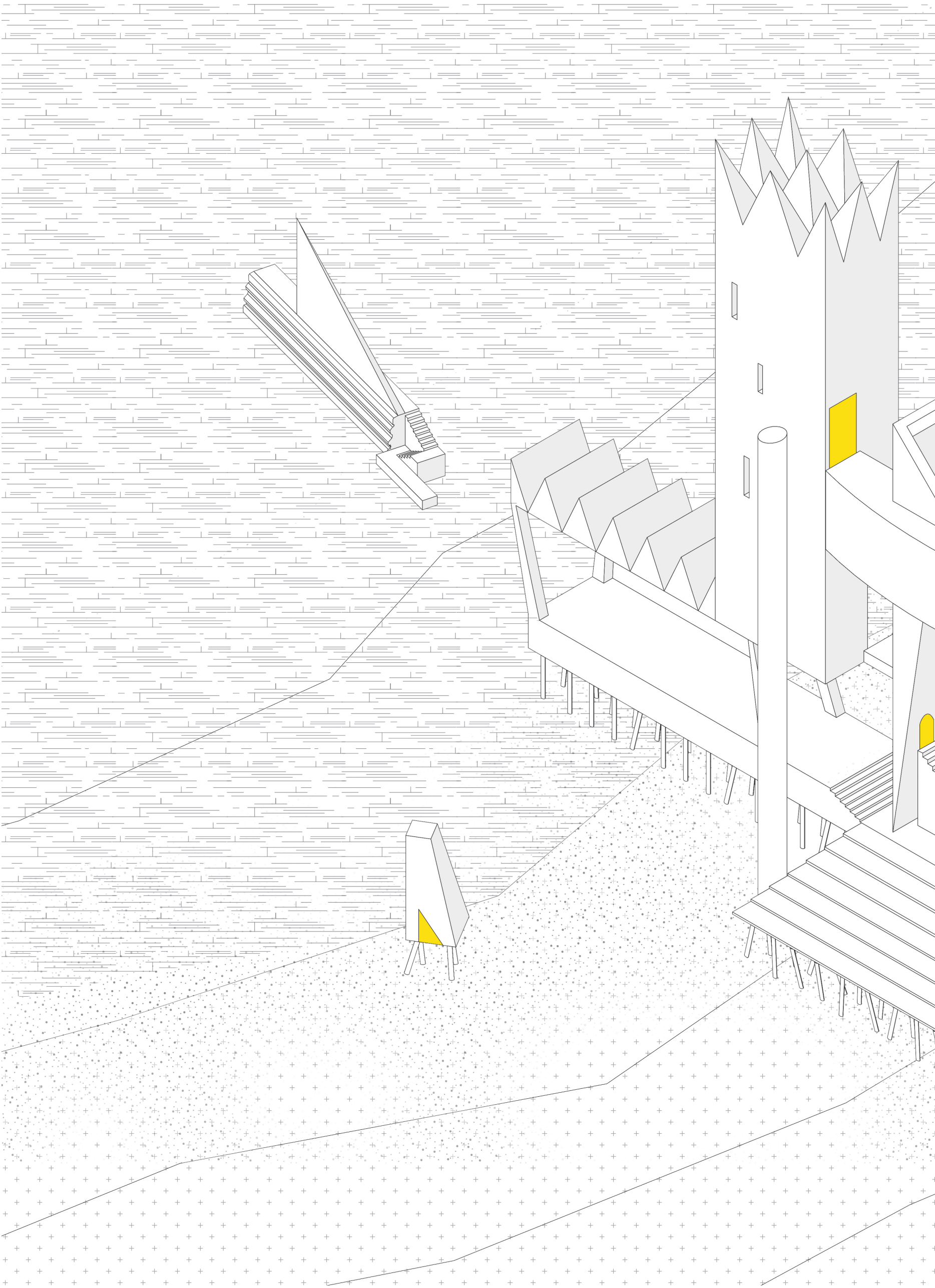




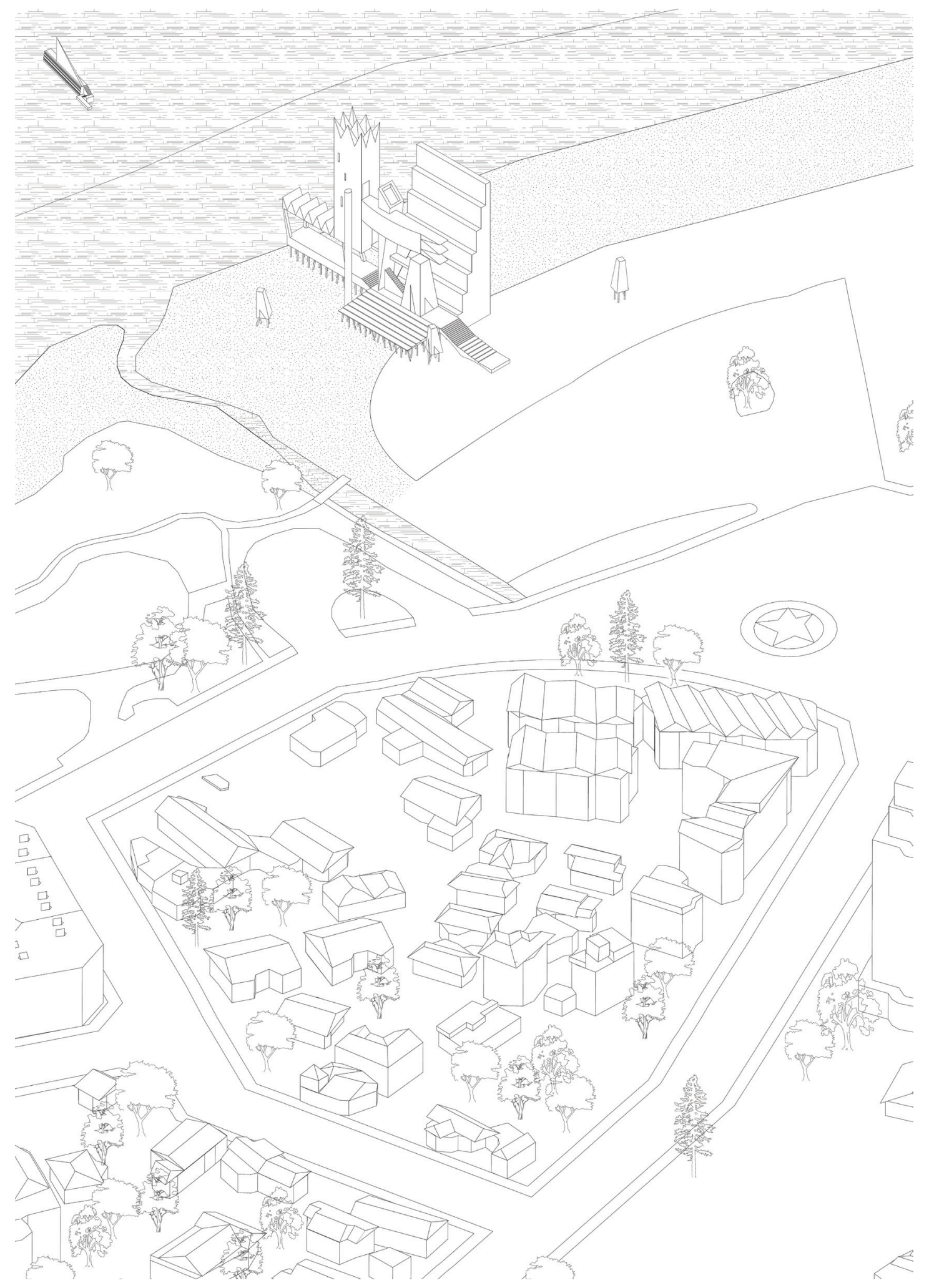

Figure 61

Waka building in the township 

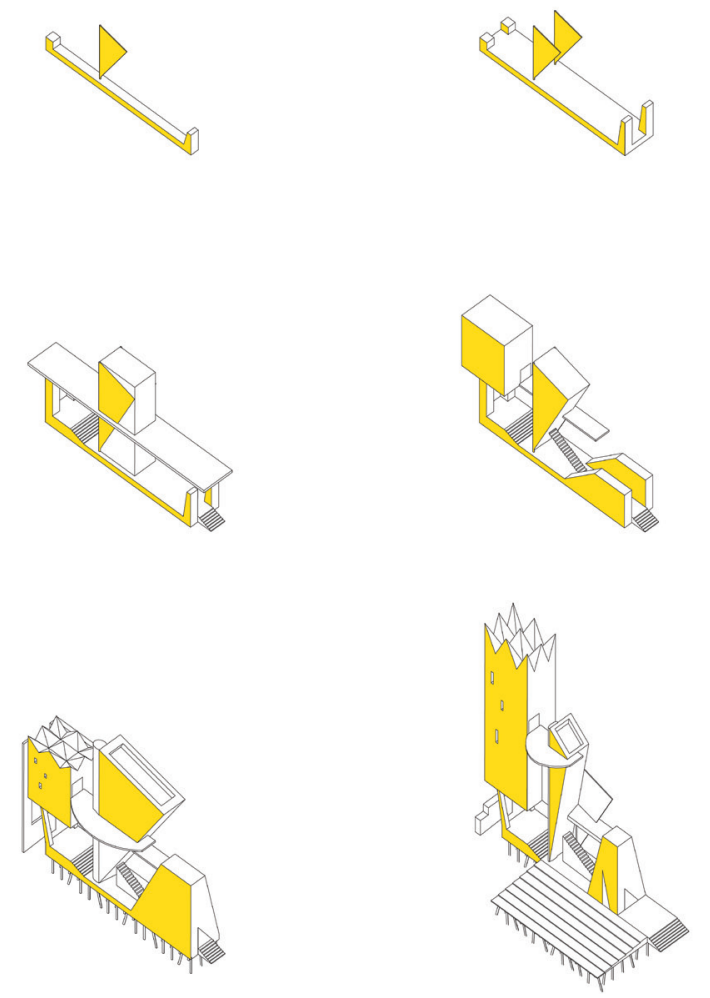

Figure 62

Formal explorations. Figuration of the Waka building
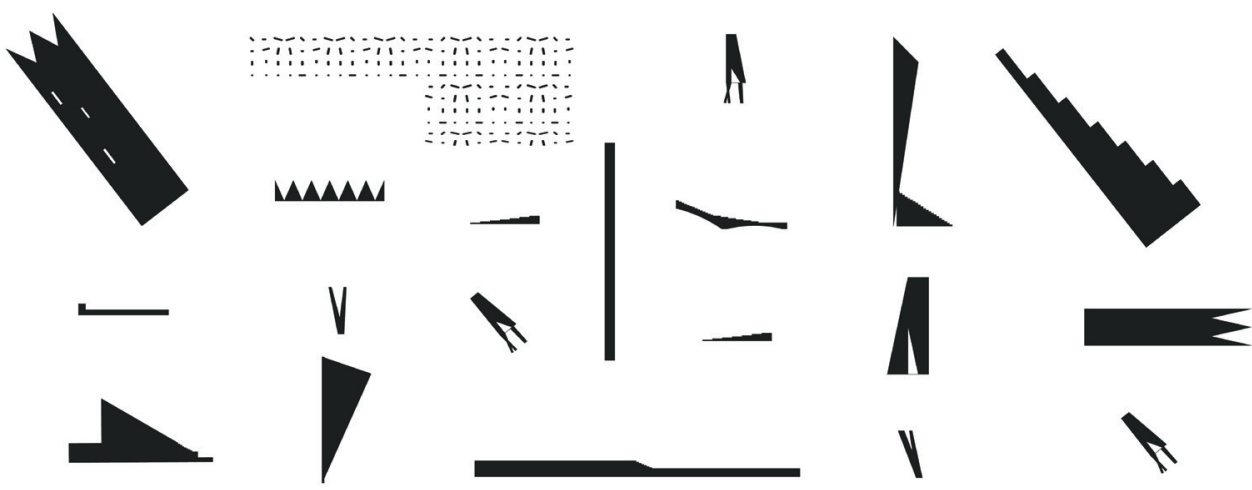

Figure 63

Waka components fragmented 


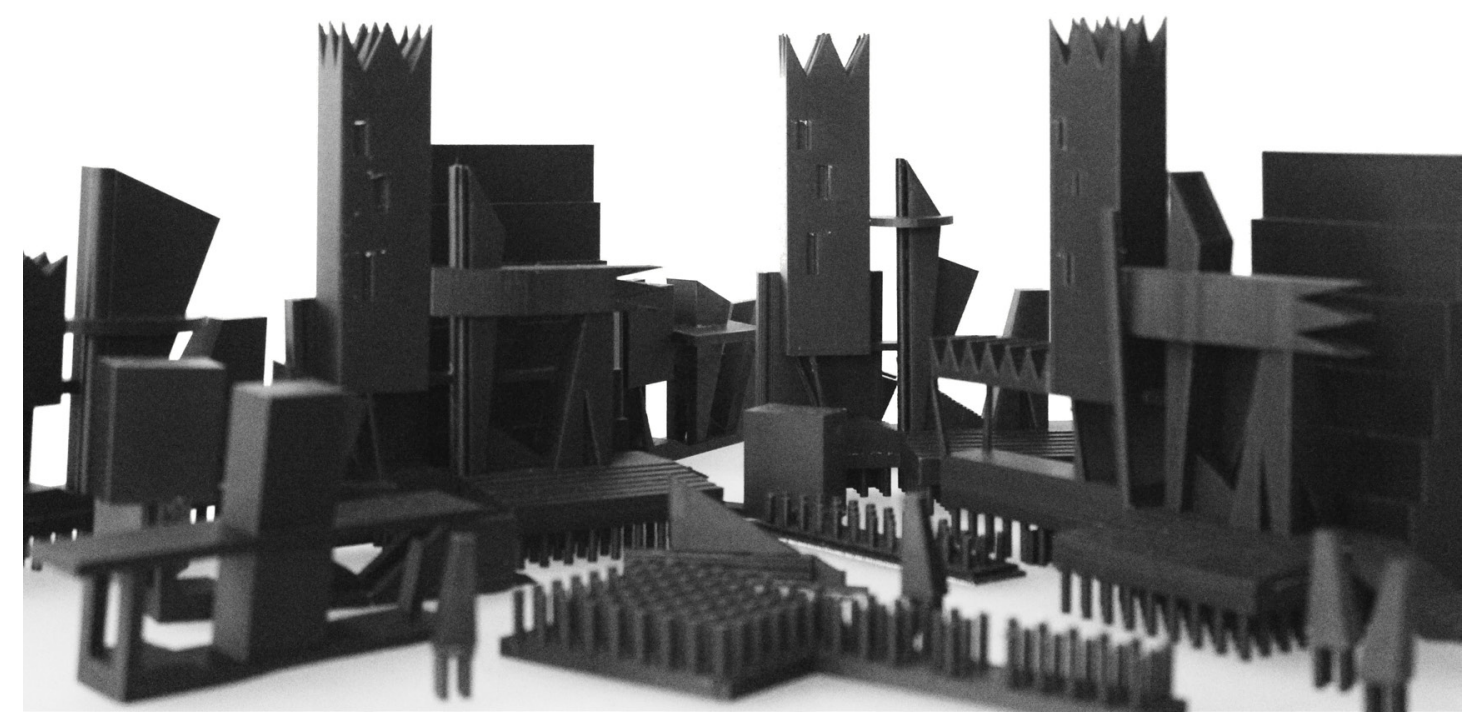


This process leads to a playful composition of forms, continuing on from the same language as Friends where the architectural language of Hejduk and other architects still have a presence. There are hints at how the bio-security operates within this abstract compilation of forms symbolising the waka- visitors enter from the rear staircase, heading through forms which house other programmes and eventually exiting using the pier that points towards Kapiti Island.

The result is messy and clumsy with no thought to appropriate requirements regarding the bio-security facility and other needed programmes. The surrounding site has not been addressed and forms are illegible with no clear hierarchy to the shapes. 

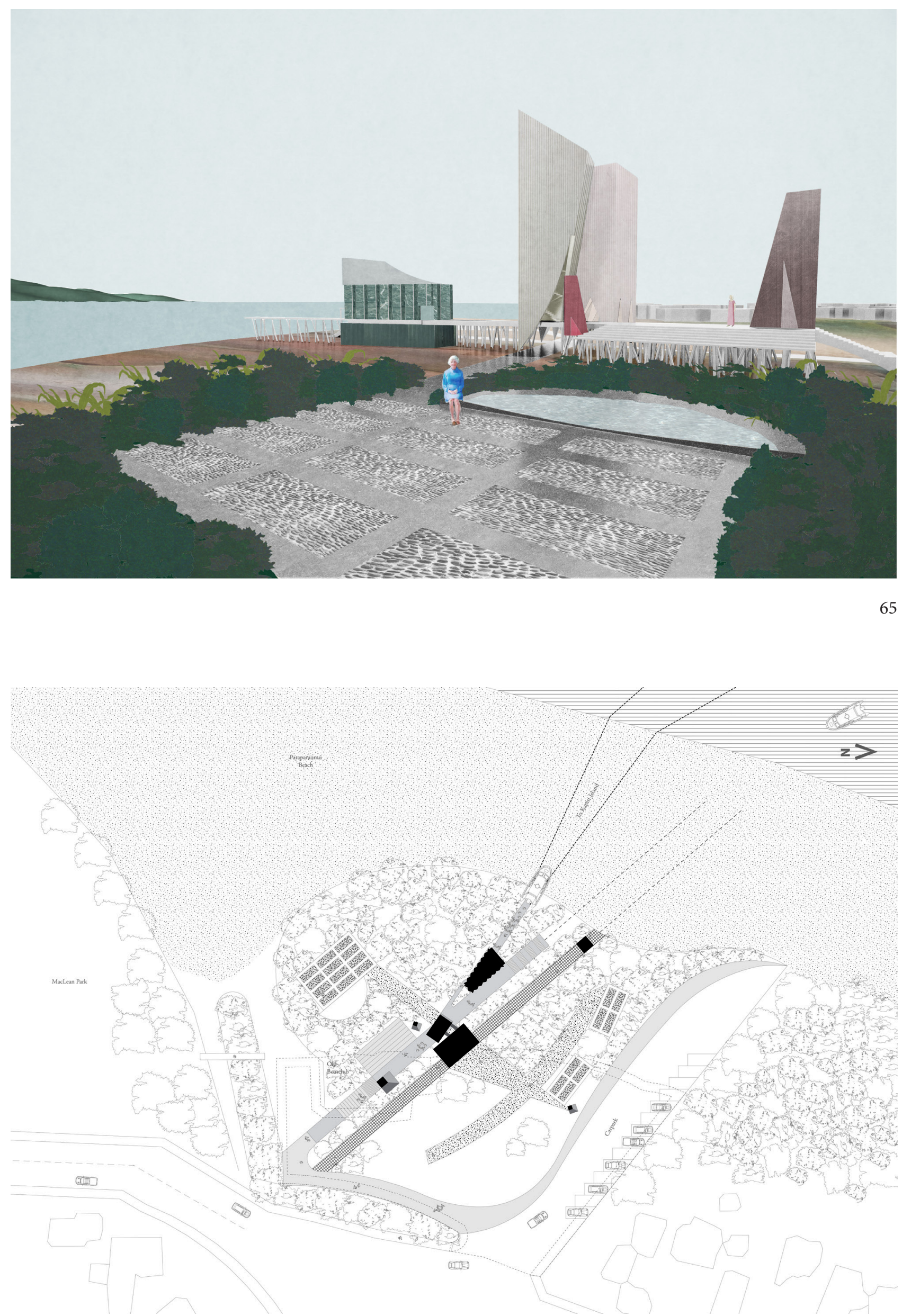


\section{REFINEMENT}

The building is developed and refined (see figure $65 \& 66$ ).

The design is more convincing as a composition on the site and addresses the intended programmes the forms would house.

The hierarchy of components are simplified to read more legibly and defined in stature. The main tower houses a gallery space, a learning facility, bathrooms and office spaces for the tour guides. This tower adjoins another, which serves as a circulation tower. Down the pier is the bio-security facility which screens visitors and then allows them to board a boat, which picks them up at the end of the last floating pier.

The design however still lacks a concern for materiality, pragmatic features such as balustrades and apertures, accurate land contour representation and a development of form.

Figure $65^{*}$

$<$ Perspective of the reflexology park with the developed Waka building behind

$<$ Figure 66

Reflexology park and building masses in plan 


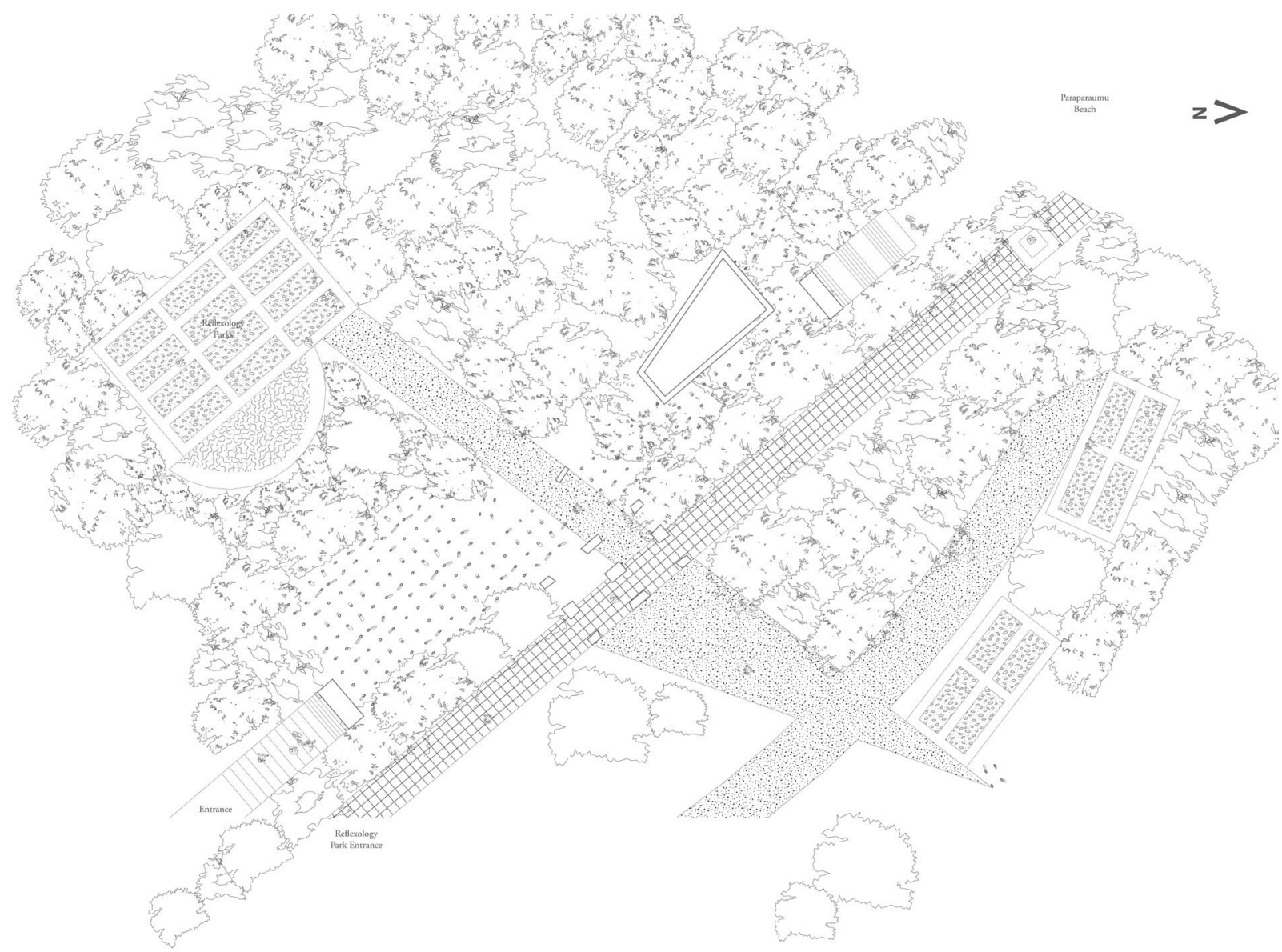

Figure 67

Ground floor plan showing the park amongst foliage

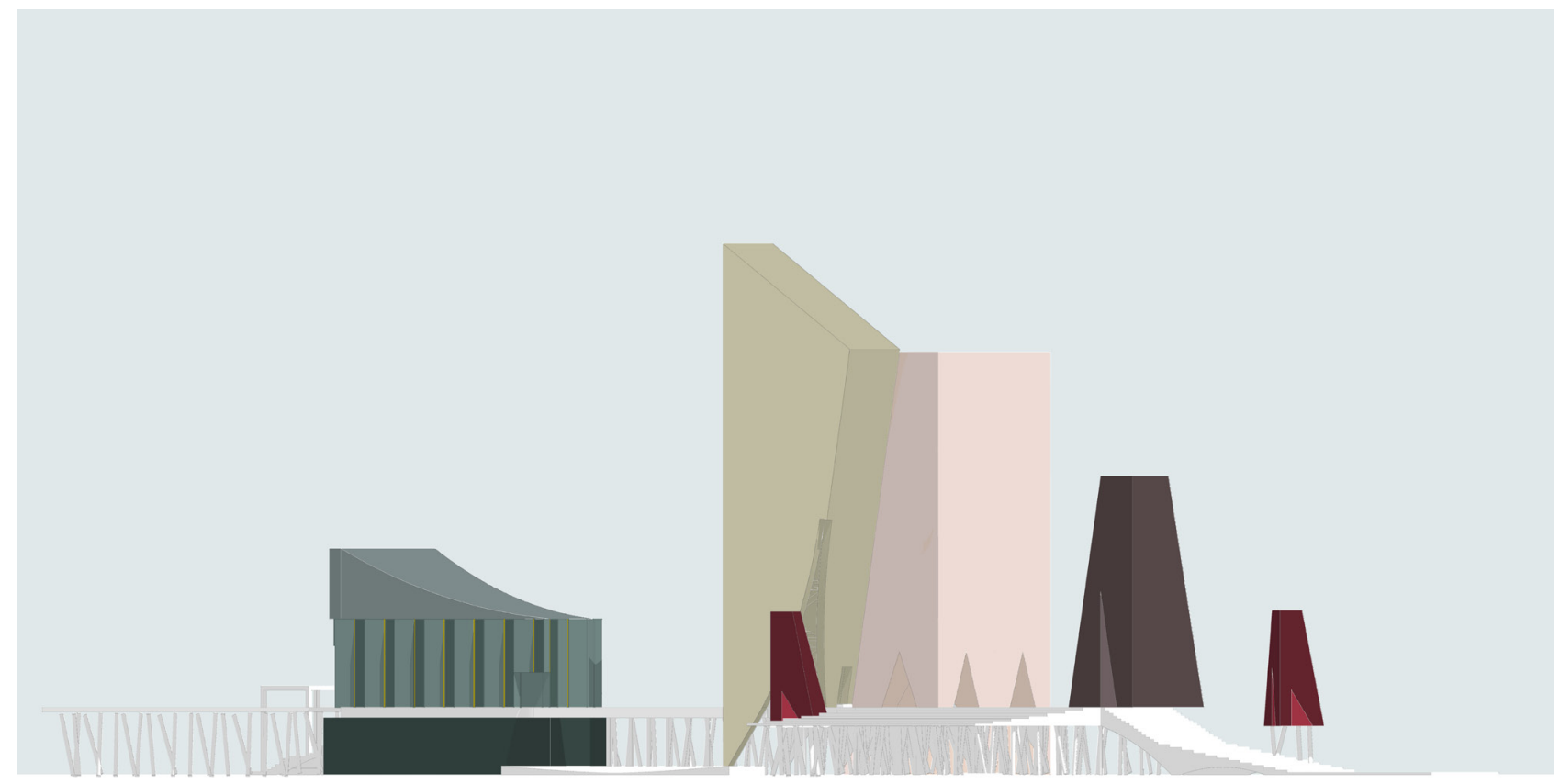

Figure 68

Elevation of the Waka building forms 


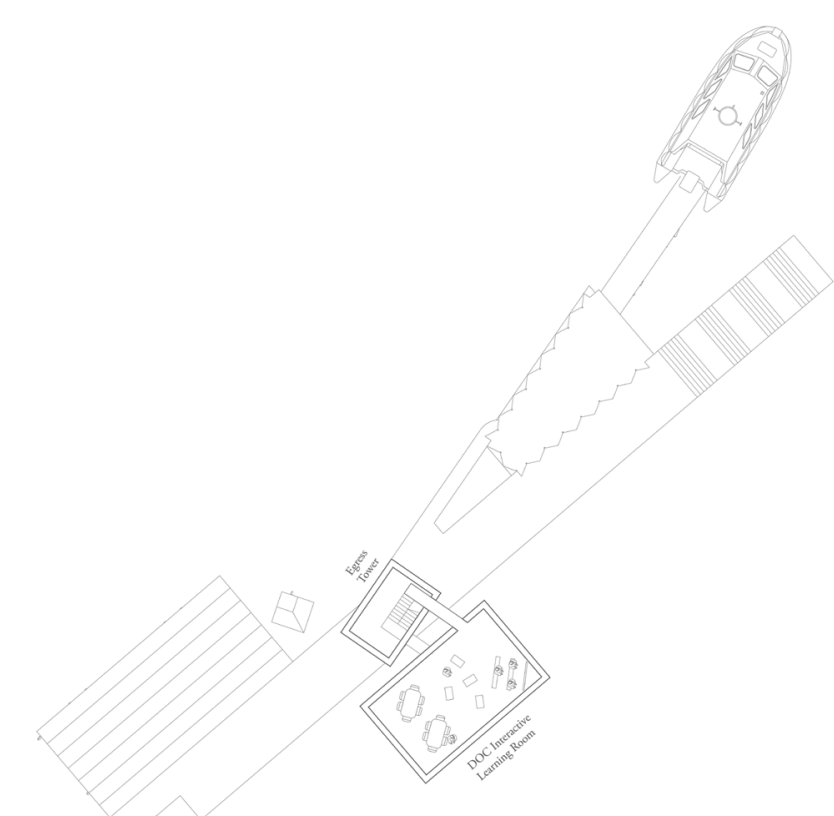

$$
z>
$$

Figure 69 Third floor plan cut through the central towers

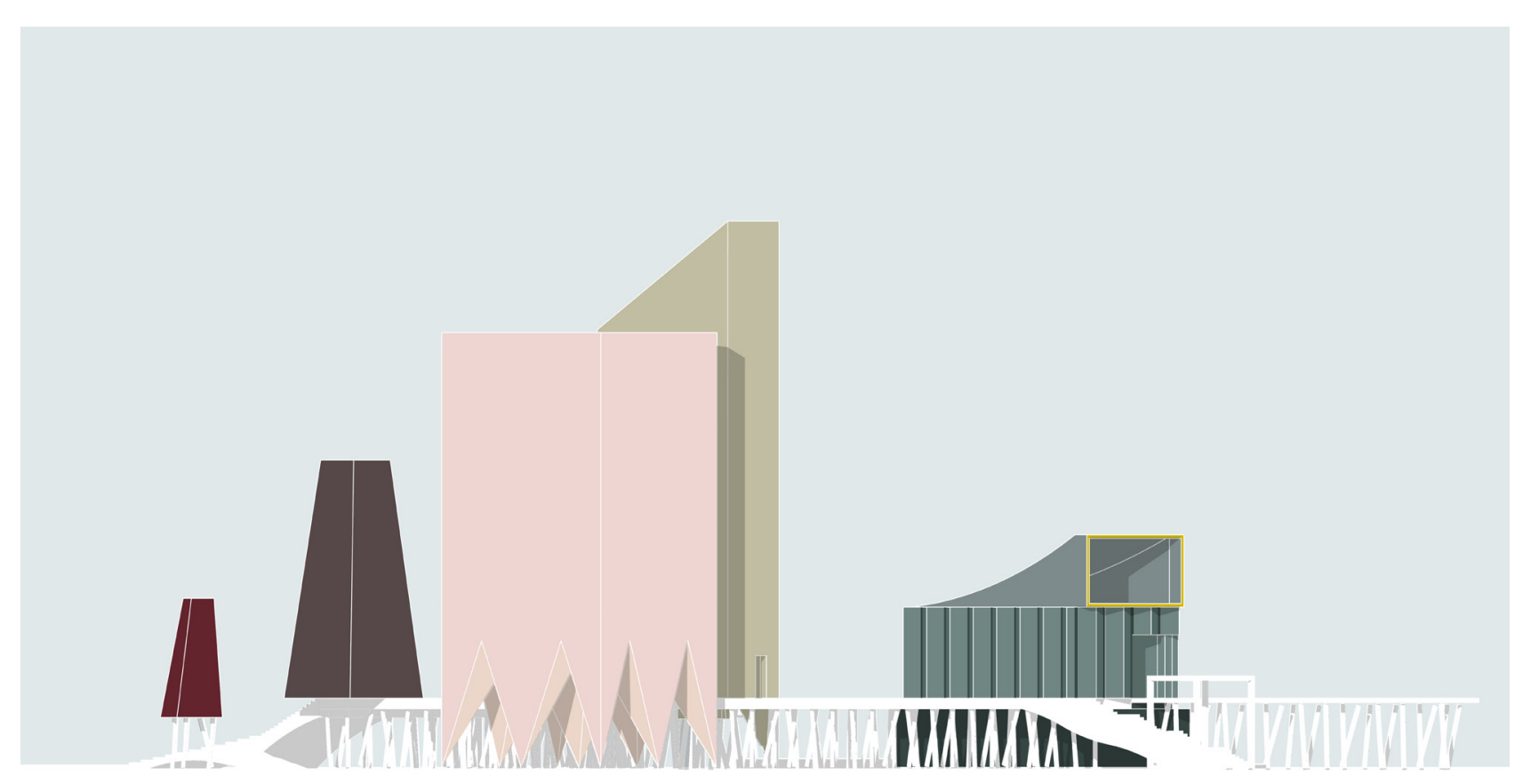

Figure 70 * Elevation of the Waka building forms 


\section{CROSS-PROGRAMMING}

This experiment introduces the strategy of cross-programming. The bio-security and visitors centre is met with a reflexology park, expanding the site's facilities and linking to MacLean Park. A reflexology park is a set of stones embedded into the ground for users to walk on, applying pressure and stimulating neurological reflex zones in the foot to create health and wellbeing (Lallouslab). This is targeted towards elderly people, as integrating the elderly works with Kapiti's growing numbers of residents aged 70 and above. Rem Koolhaas' Downtown Athletic Club in his publication 'Delirious New York' depicts a mixeduse skyscraper with visitors "eating oysters with boxing gloves, naked on the nth floor" (Koolhaas, 155) ((see figure 71)). The unconventional nature of the arrangement is deliberate in choreographing a new dynamic interaction between different spatial formal qualities, as well as human tendencies and perceptions.

The gesture of a reflexology park in conjunction with the visitors centre sets up a scene, a theatrical theme to the building, where users of the park meet tourists. The slow-walking users on the reflexology stones at ground level contrast with the fast, bumbling tourists shooting down the elevated pier outward to Kapiti Island. The elevated pier consists of stands and viewing platforms for the 'performance' below, while the park consists of pathways meandering around and under the building, leading users to sheltered areas with views of the beach. This idea of slow and fast movement mimics the scene from Mad Max: Fury Road where the fleeing truck zooms pasts swamp walkers in the foreground.

The plane of the park uses textures and physical characteristics to dictate slow movement, inspired by Caruso St John's project to renew the town square in Kalmar, which uses a range of rock textures suitable for different purposes, such as walking, biking or slower walking (see figure $72 \& 73$ ). Similarly, Lina Bo Bardi's SESC Pompéia consists of a boardwalk streaming through the site (see figure 74). The wooden texture attracts sunbathers, affecting the speed and motion of the path.

$<$ Figure 71

Downtown Athletic Club, Rem Koolhaas (1994)

$<$ Figure 72

Kalmar Square, Caruso St John (2003)
$<$ Figure 73

Kalmar Square, Caruso St John (2003)

$<$ Figure 74

SESC Pompéia, Lina Bo Bardi (1977) 


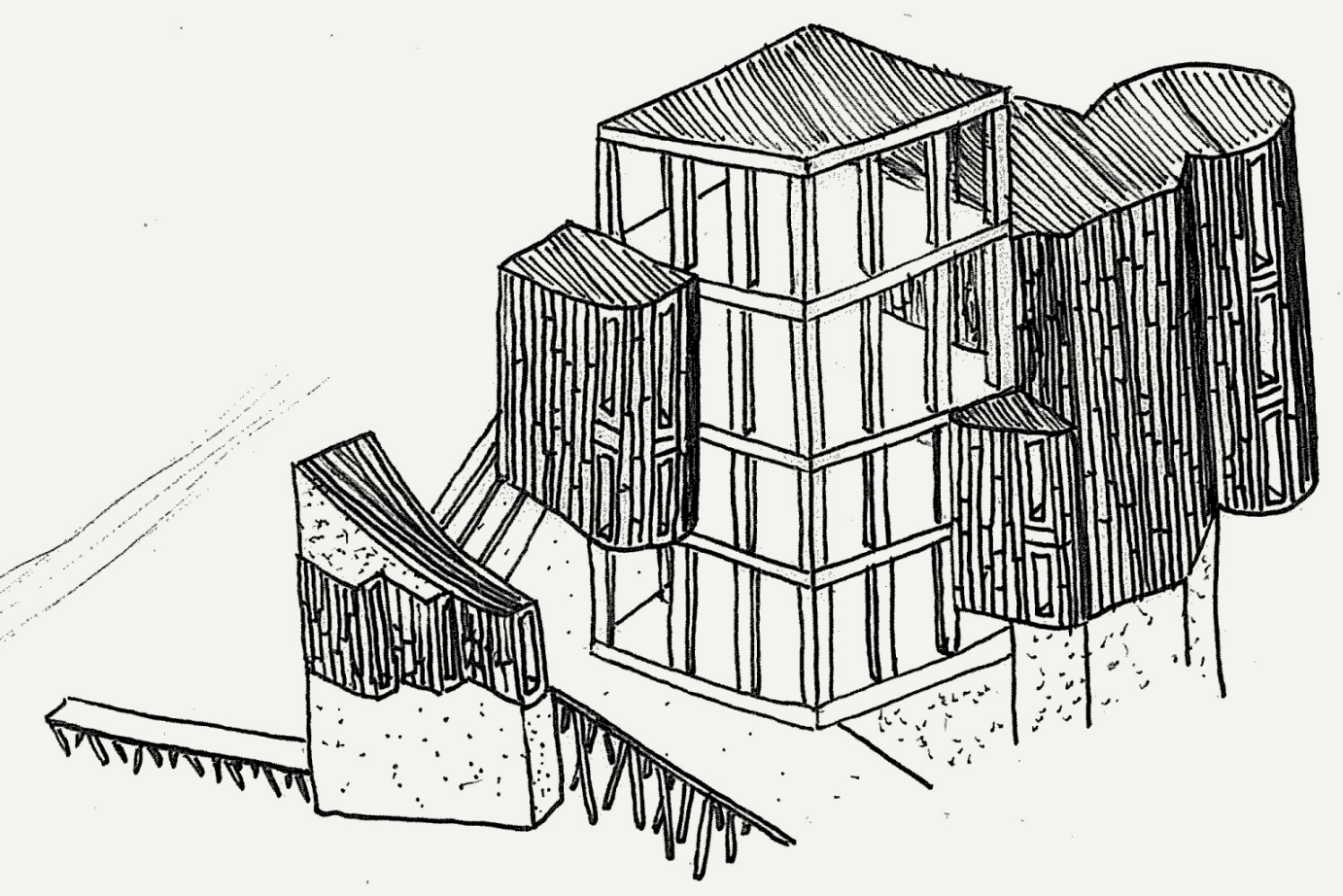

Figure 75

Skin ideas - Overlapping timber shingles 
PART 2

\section{ANTHROPOMORPHISM}

EXPERIMENT THREE 


\section{BEACH CREATURES}

These experiments use anthropomorphism to generate form, following on from Hejduk's caricatures of zoomorphic and anthropomorphic forms explored in Friends. Architectural critic and theorist Jeffrey Kipnis talks about how buildings would make him feel existentially better if he saw another building leaning on another for support, rather than walking through a city with buildings upright and strong (Kipnis, 2013). Kipnis argues that perhaps buildings should reflect imperfections which humans have, rather than the symmetrical and proportionate qualities often associated with the human body (Leonardo da Vinci's Vitruvian Man or Le Corbusier's Modulor). Peter Cook and Colin Fournier's Kunsthaus Graz-also known as 'The Friendly Alien'- is a museum with an organic form containing a performative skin that displays information and interacts with users (see figure 76). The technology and material shaping the curvaceous foreign form becomes part of the figure as an 'intruder' within the urban context.

These experiments look at imperfections and inorganic shapes, interpreting the building of the bio-security and visitors centre. These experiments, bridged on from the Waka Building, break the design down into elements, with each element teased out and tested by asking questions.

Legs - How tall? How fat or skinny? How crooked?

Face - How punctured? Apertures? How flat? How pointed?

Skin - How transparent? How repetitive? Patterns?

Head - How big? How tilted?

Guts - How exposed? How clustered?

The experiments also develop into another series of drawings, breaking free from the computer and allowing the drawing to generate inorganic forms in the view of elevation (see figures 77). These Dr. Seuss-esque drawings exploit a different set of ways of looking at legs, face, skin and so on. There is again this sense of looking at the form and not seeing a reflection of ourselves, but instead seeing another thing looking back, watching.

\section{$<$ Figure 76}

Kunsthaus Graz, Peter Cook and Colin Fournier (2003). Outer skin and facade lights up displaying different moving images as an exhibition itself 

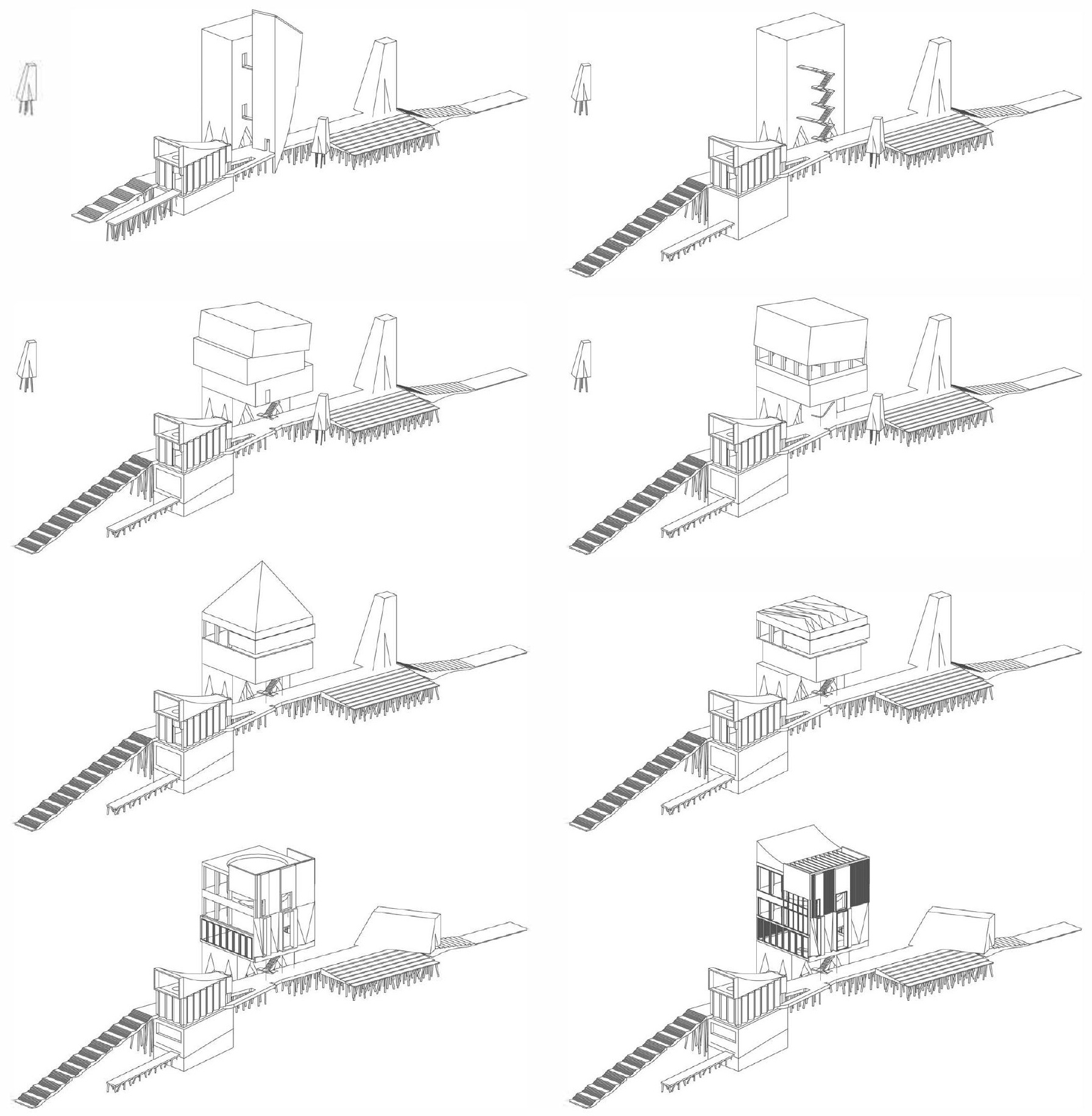

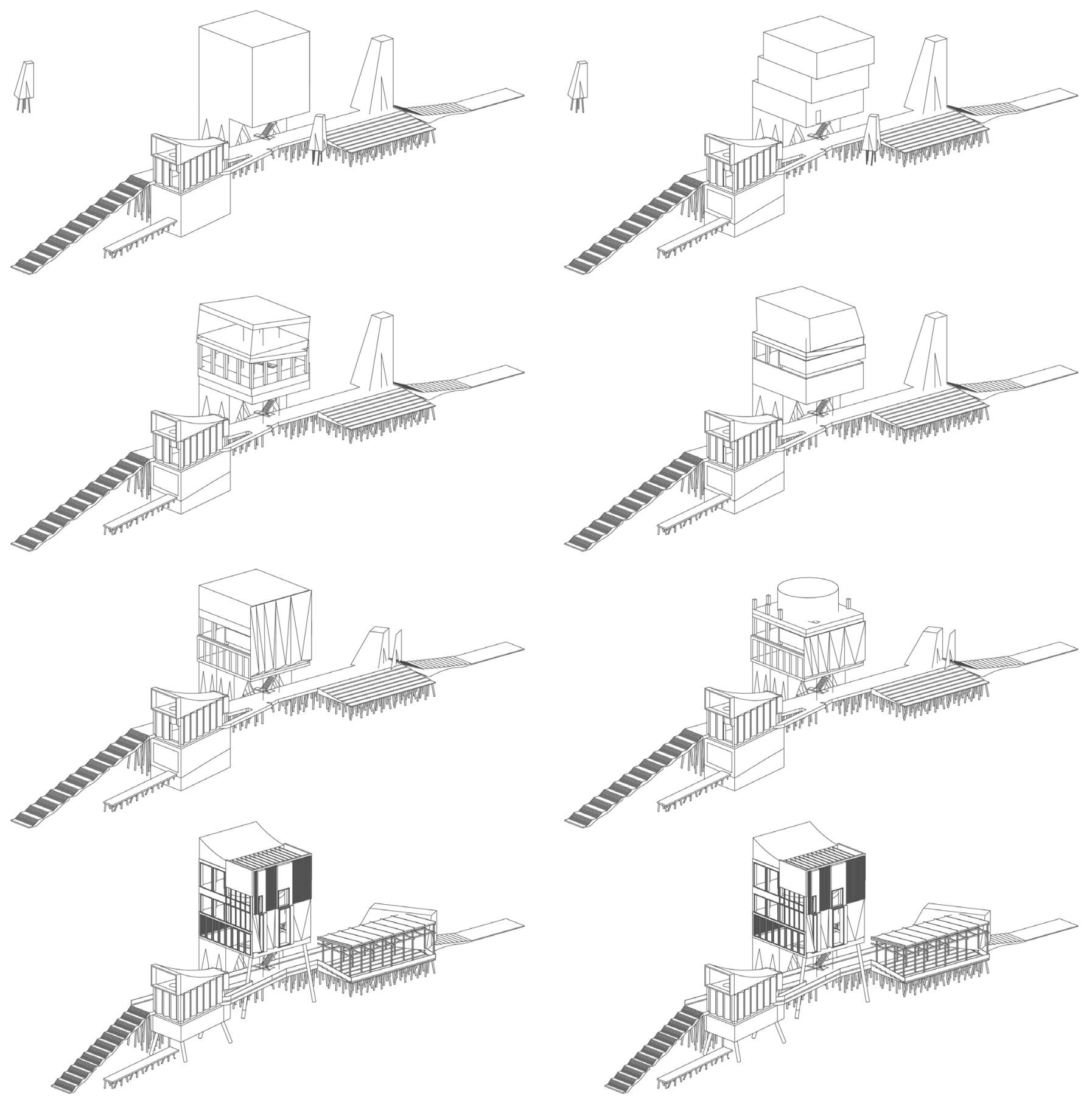

Figure 77 *

Developing from the Waka Building 

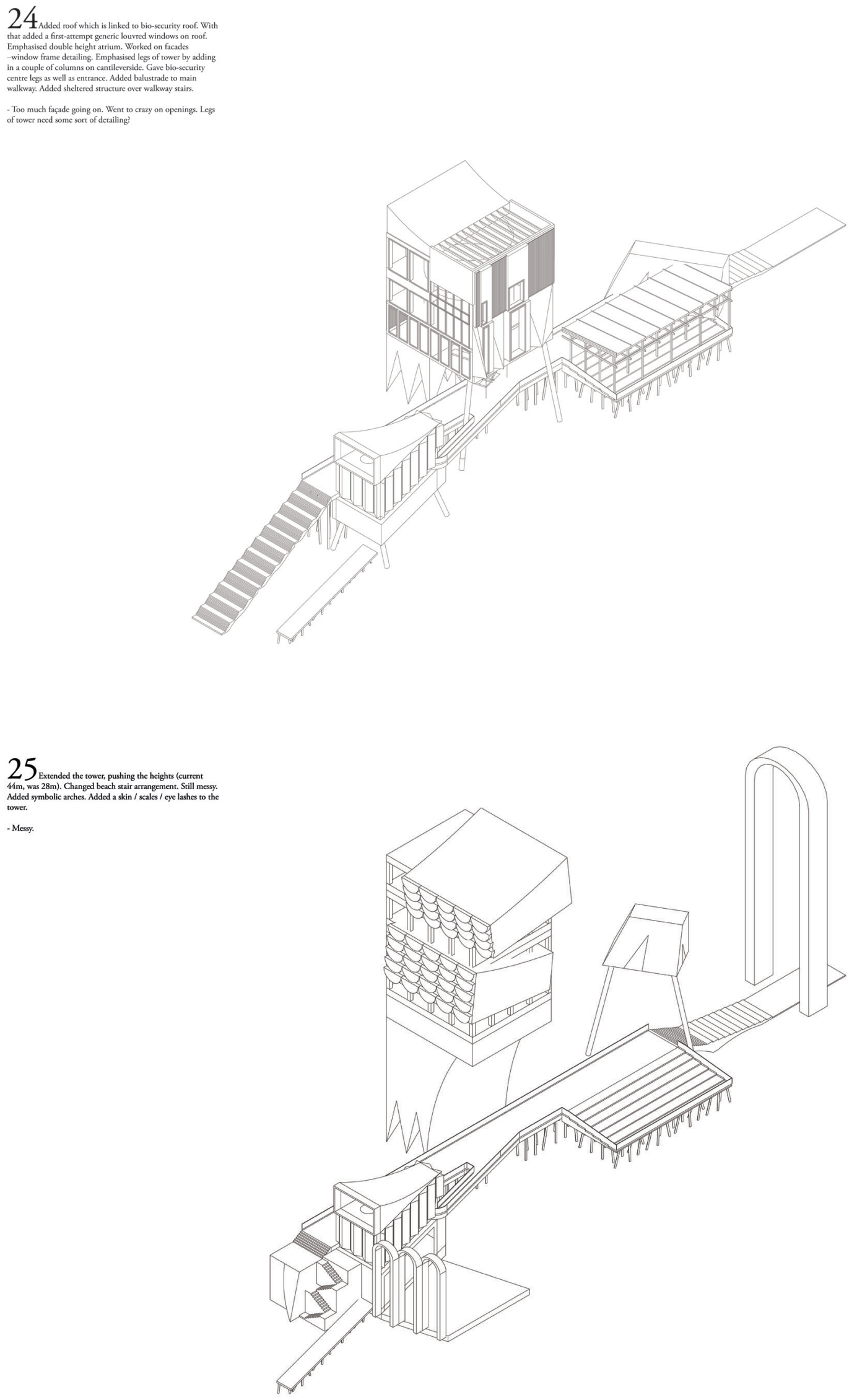

Addd long legs for the canti-levered tilted head. - Messy and still not legible. No link between main tower and
cnerance tower with circulation not quite addressed. Elevared
viewing saircsen needs refinement if idea is ro carry on

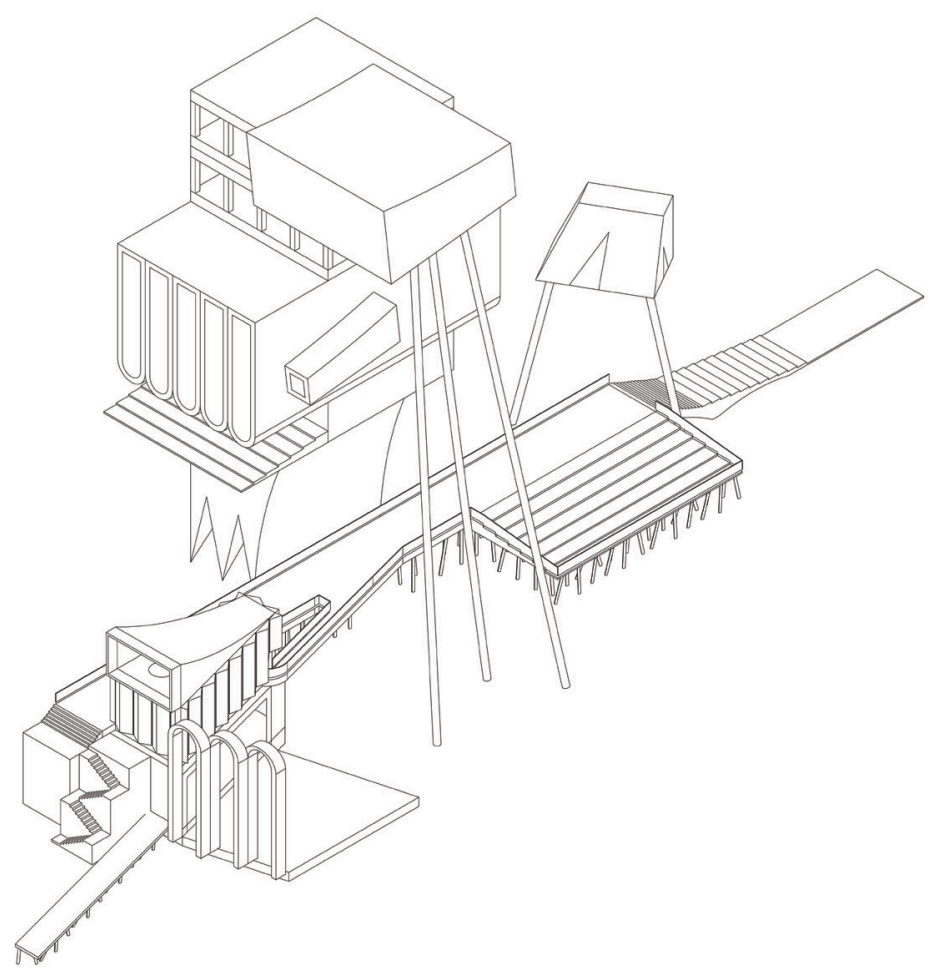

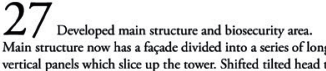
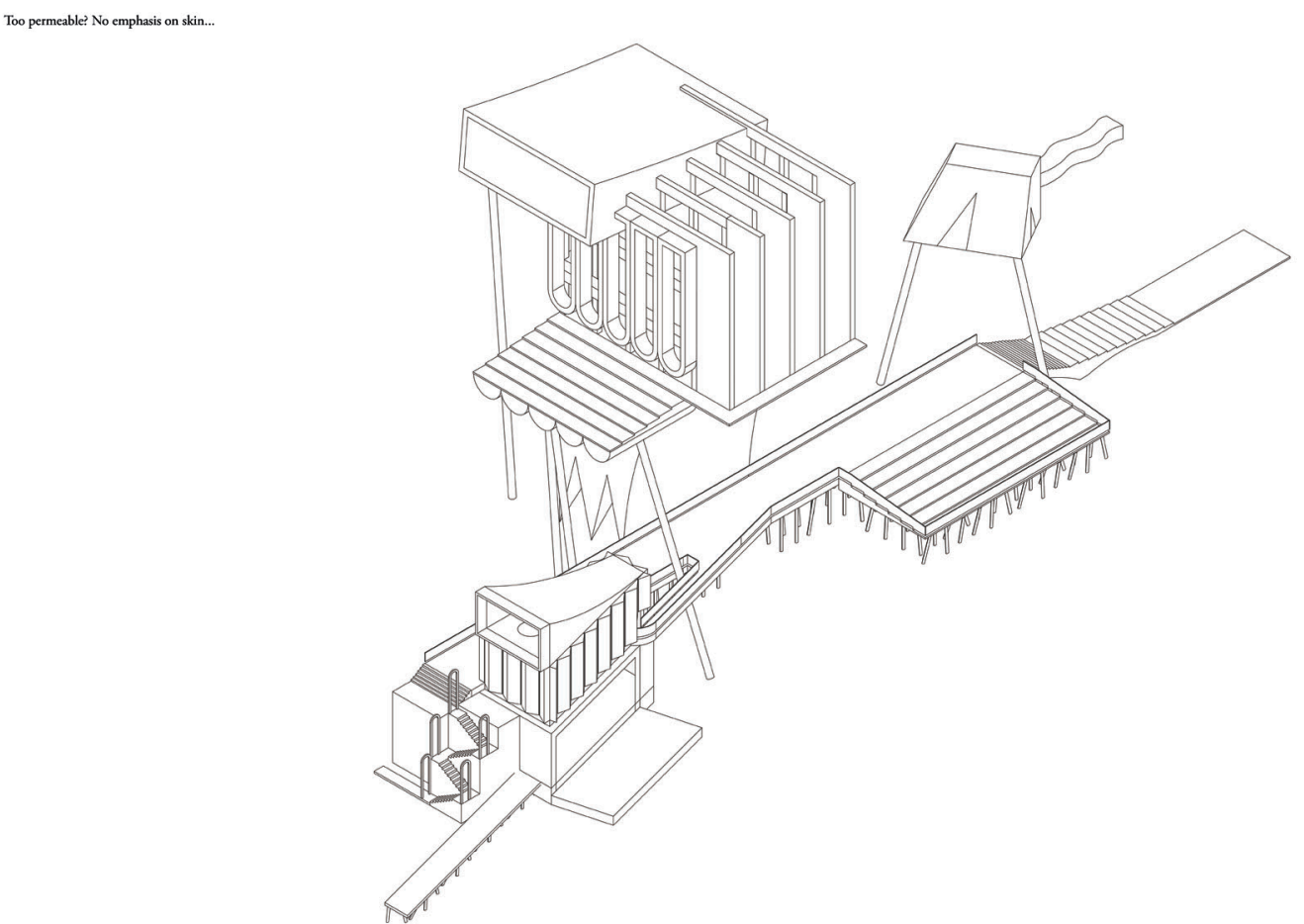

Figure 78 

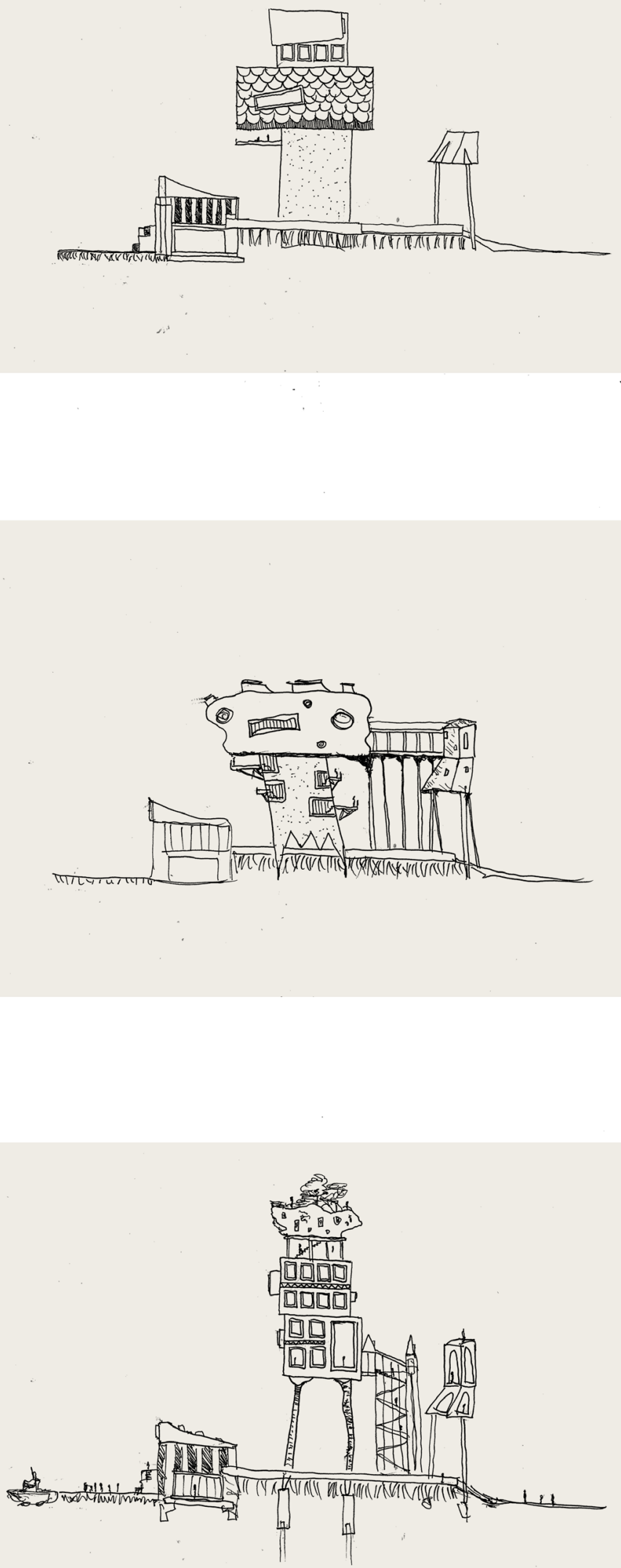

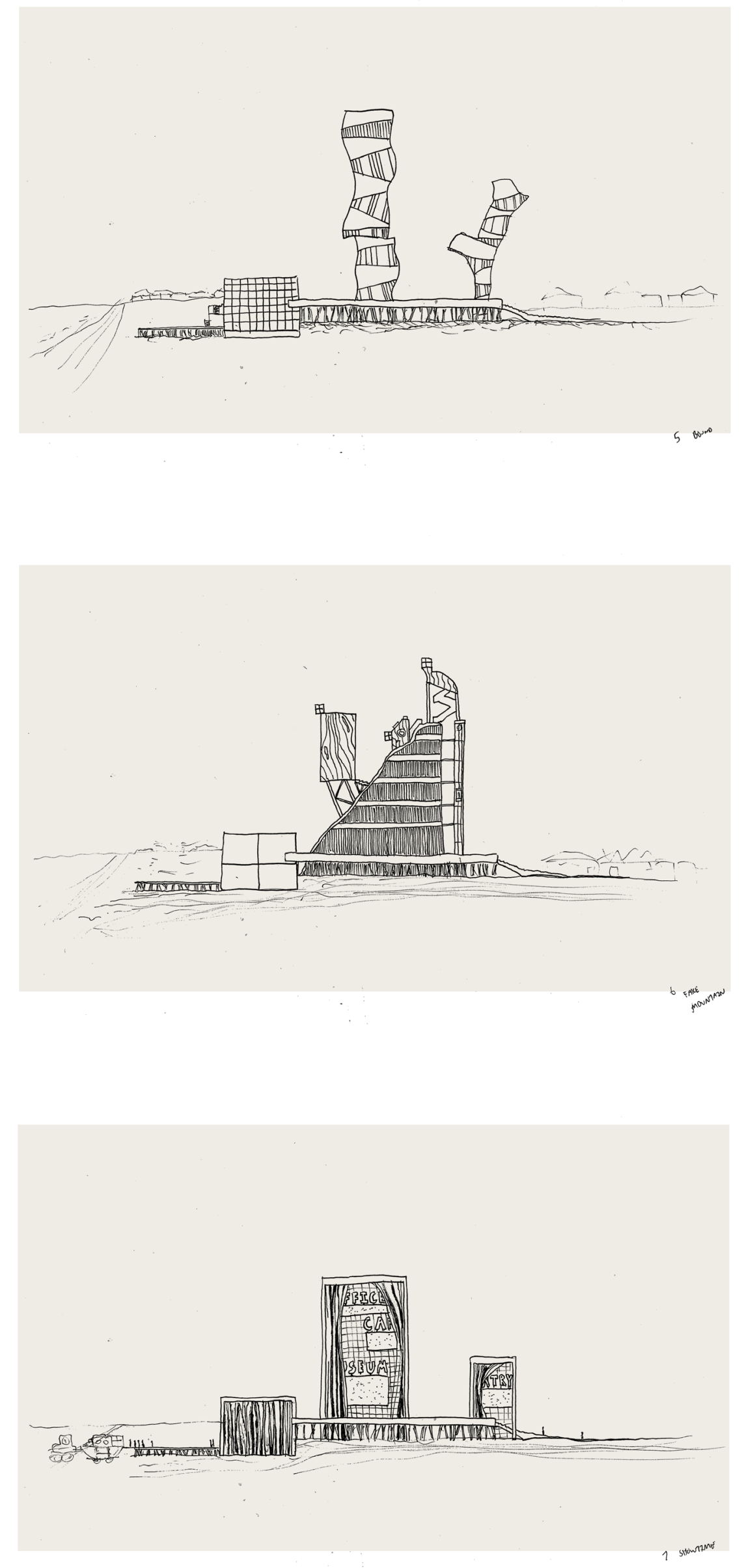

Figure 79

Whimsical elevation drawings breaking free from the computer 

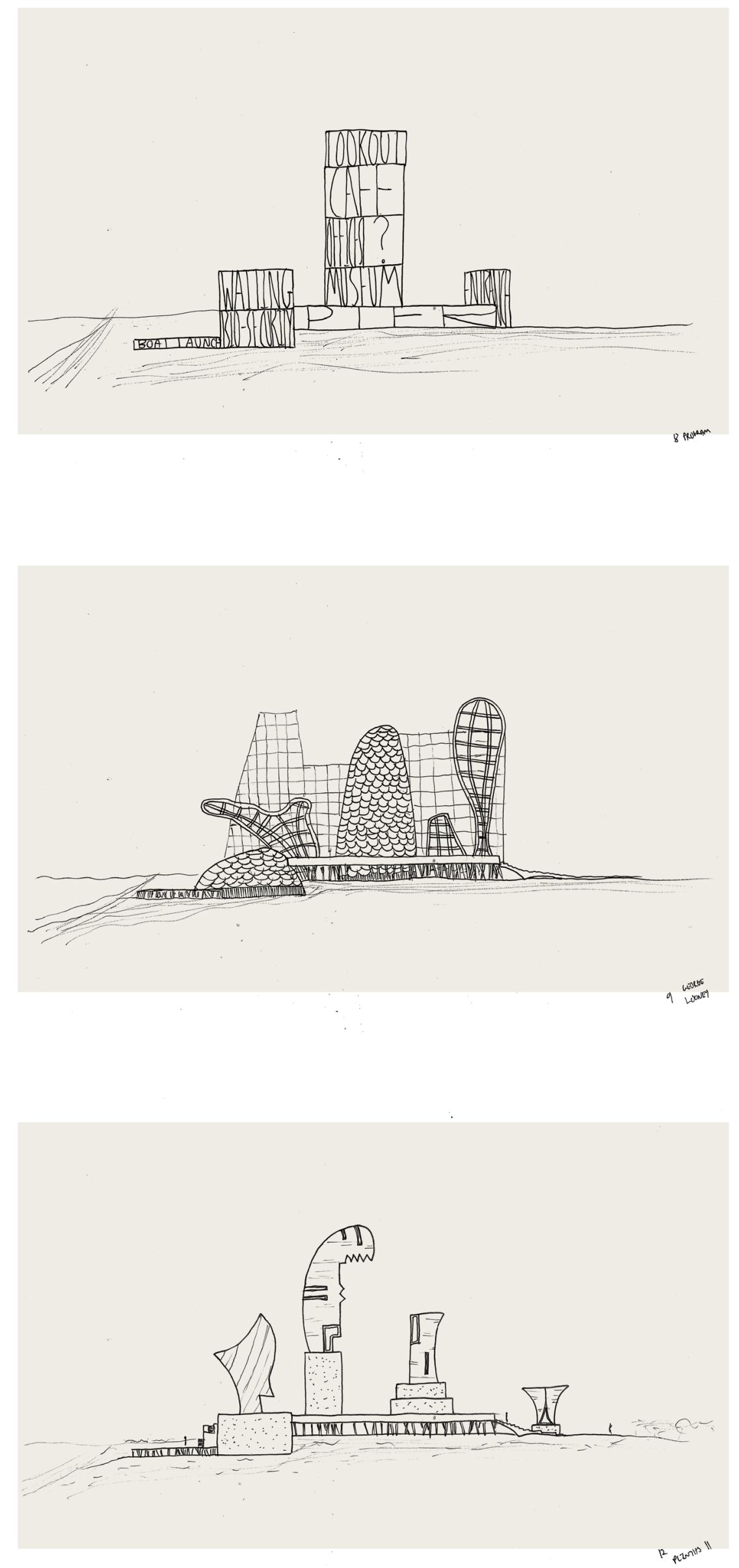

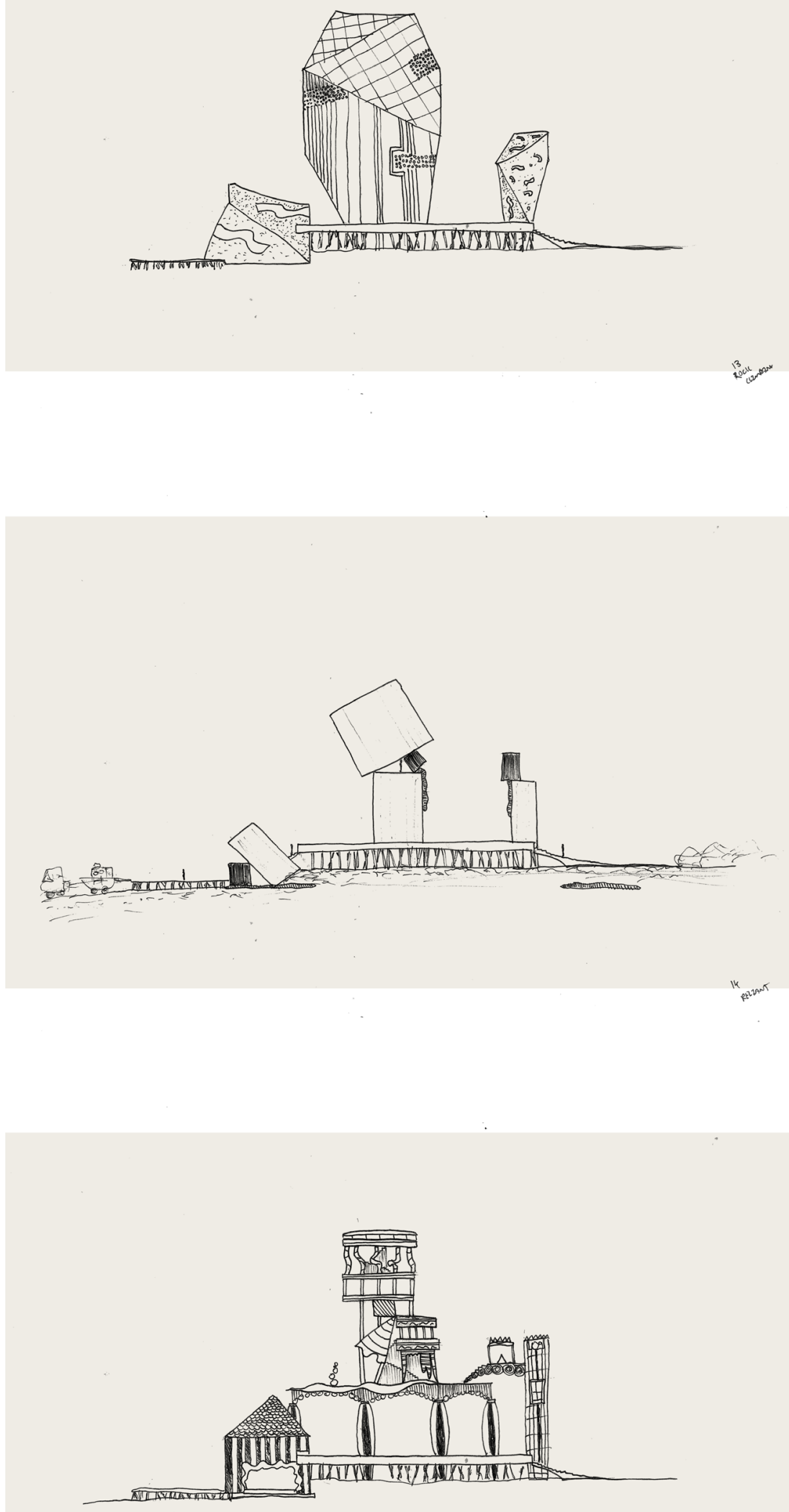

Figure 80

Drawings continuted 

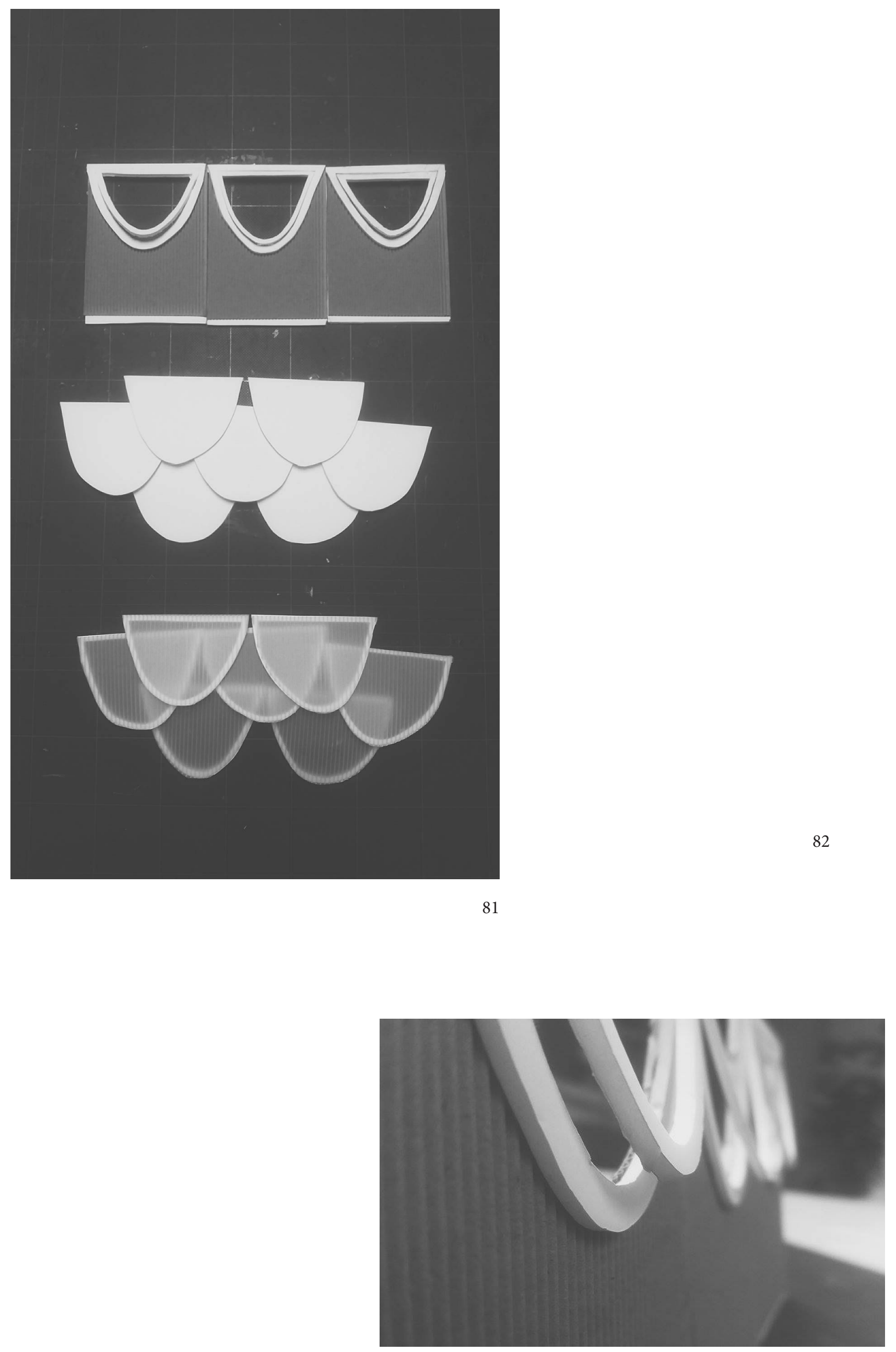


\section{APPENDAGES}

The façade and skin of the building is developed by looking at possible materials and patterns (see figure $81 \& 82$ ). The experiments move on to designing and drawing at plan and axonometric. The appendages or fragmented spaces are tested into pushing beyond a central tower or core. Rooms and spaces are latched on parasitically, independent from the structure, offering different housing to different programmes. The plans reveal a beginning to working with circulation and space in conjunction with structure or the thickness of structure.

$<$ Figure 81

Model making with scales

Figure 82

Clear corrugate scales and glazed window scales

Figure 83

Scale as an awning window 

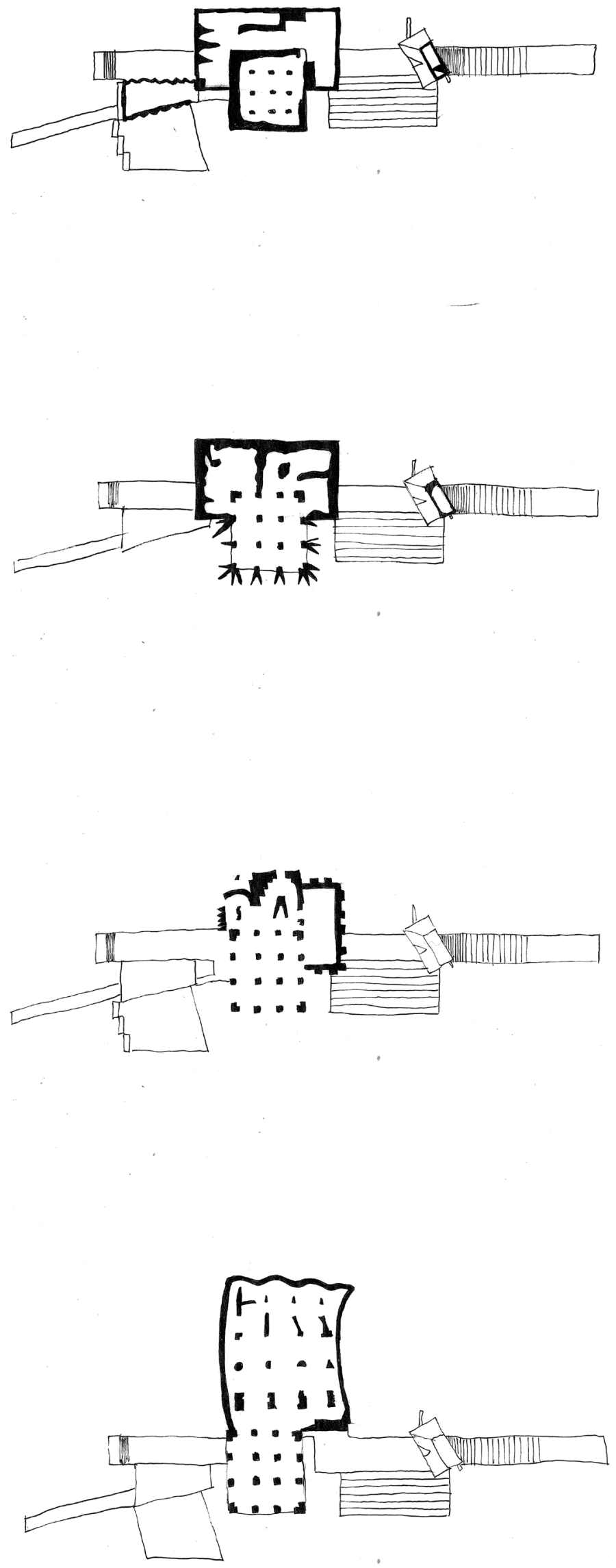

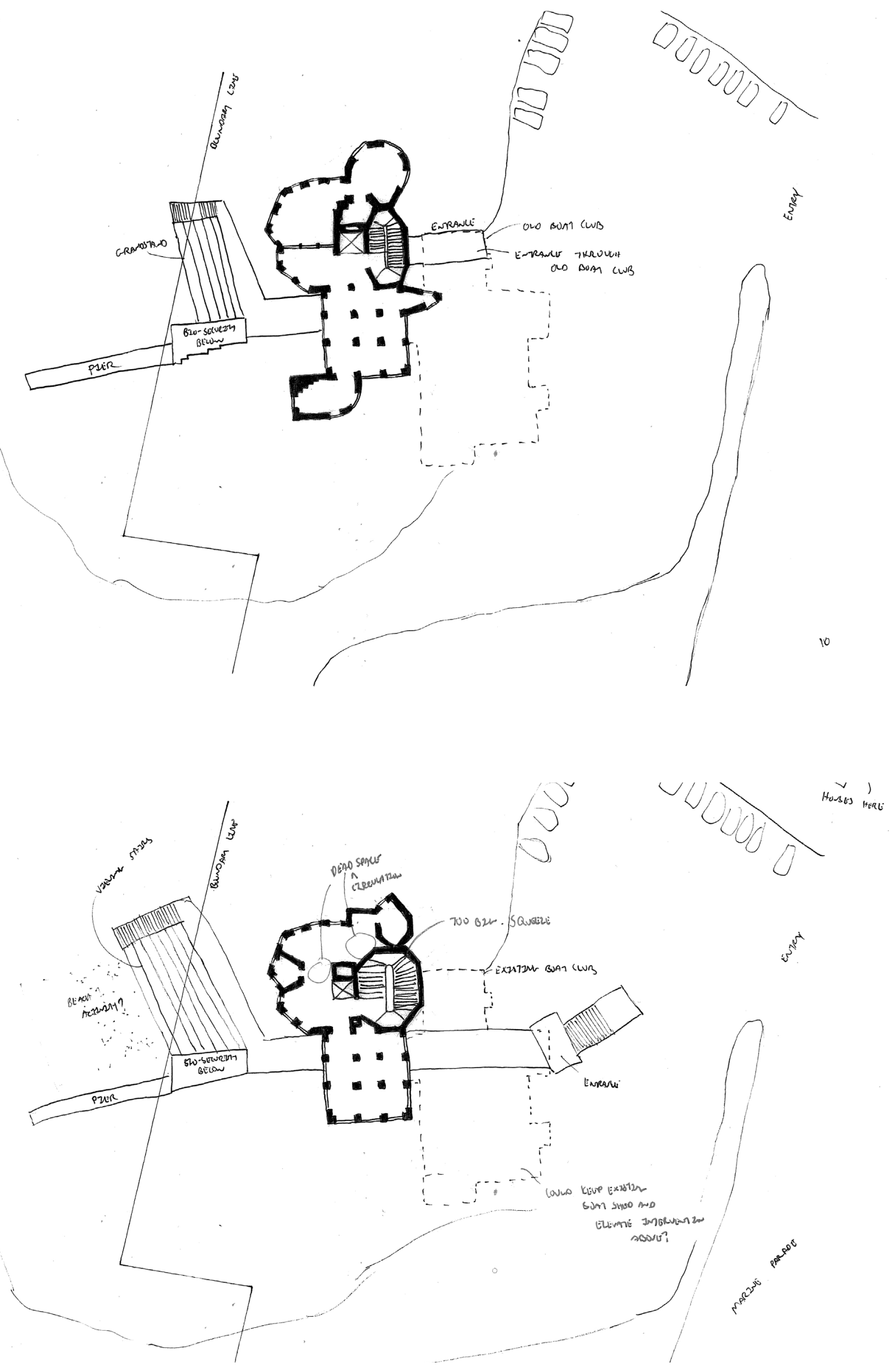

Figure 84 

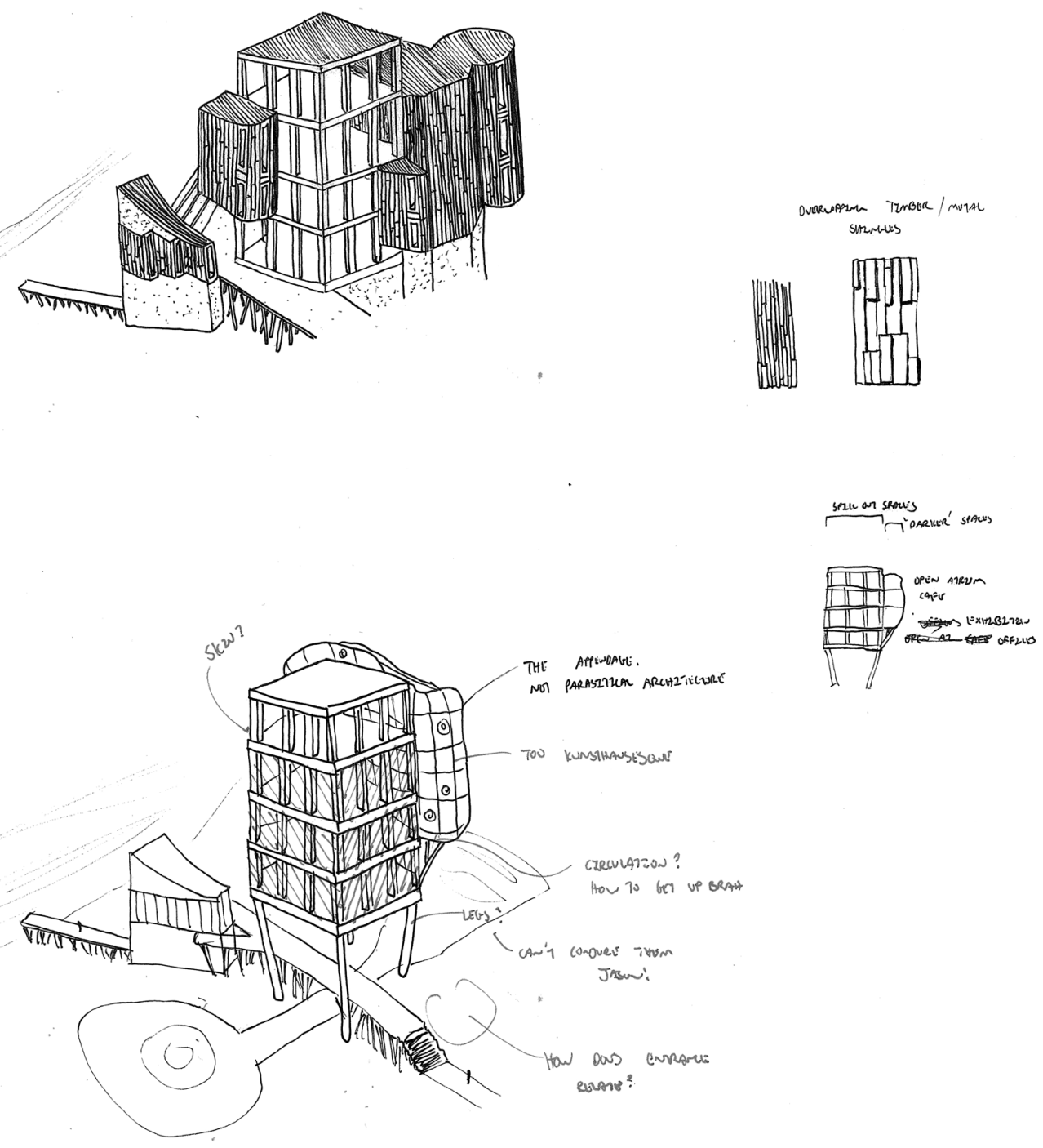

Seluar spanc's

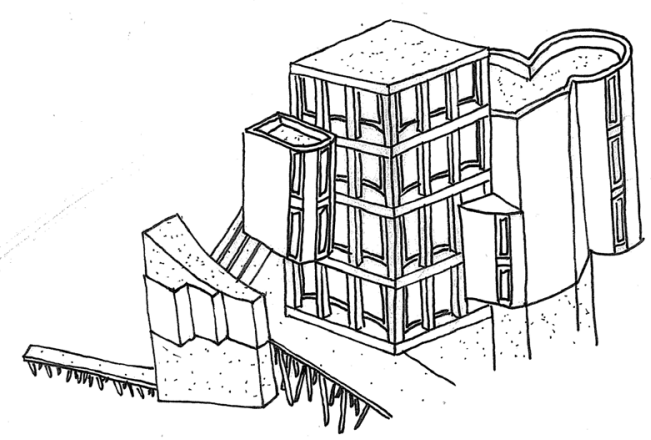




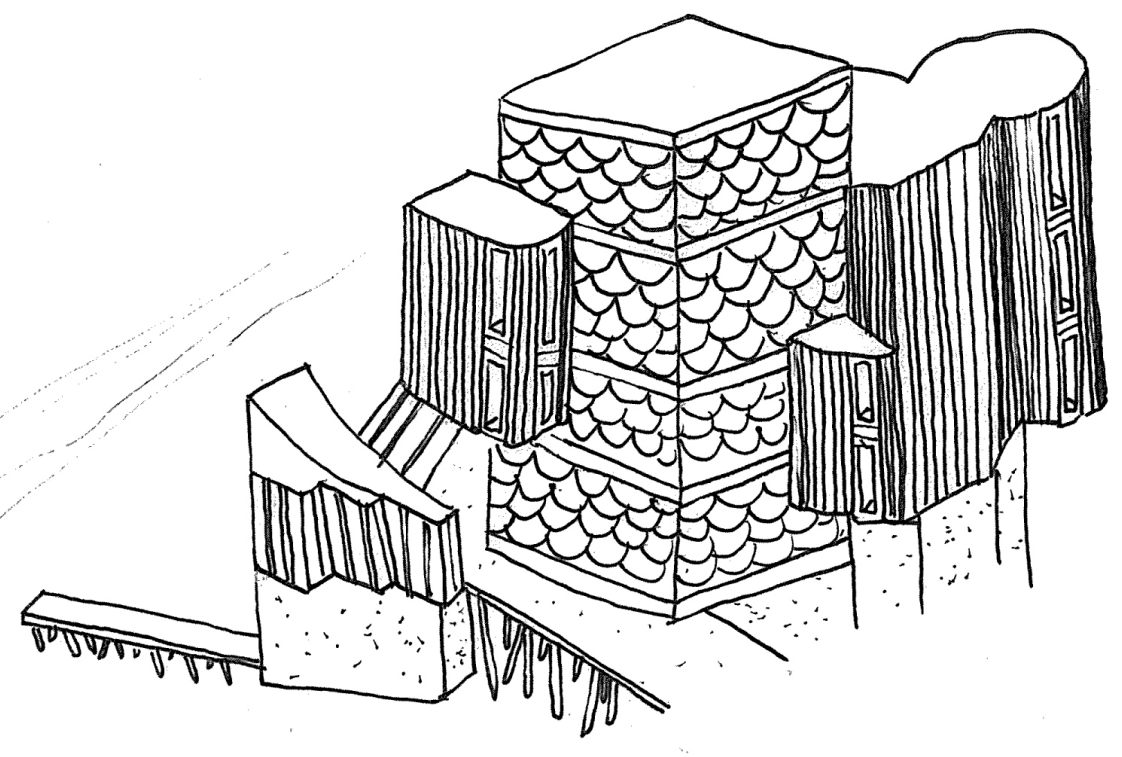

Figure 86

The tower is simplified into a series of slabs and columns referring Le Corbusier's Dom-Ino House. The skin is then overlayed on top experimenting with materiality and its patterns 
ABANDONING THE ABSTRACT... 


\section{IN SEARCH FOR THE NON-REFERENTIAL.}




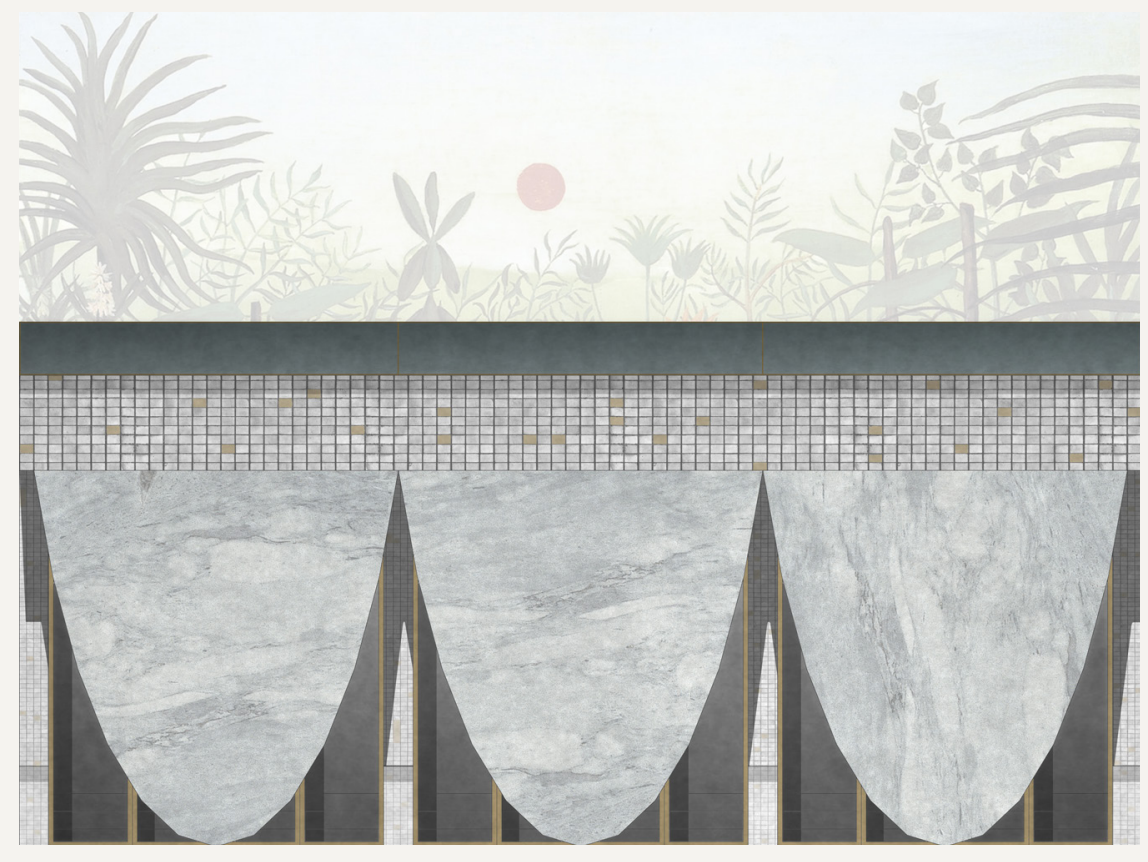

Figure 87

Elevation study 'Scales' 
PART 3

\section{THEORETICAL CONTEXT}

ADRESSING THE REFERENT 


\title{
NON-REFERENTIAL ARCHITECTURE
}

\author{
"The Greek temple is an abstraction of a house, dome structures \\ are an abstraction of heaven, and Asian temples are abstractions of \\ mountains..." " \\ Valerio Olgiati 17 \\ Architect Valerio Olgiati talks about the 'non-referential' and \\ the 'abstract'. He likens the non-referential to the Mayan \\ temple Tikal in Guatemala, and sees the temples as inventions, \\ as they have no ancestry or genealogy to them and no clear \\ trace of how the forms were produced. On the other hand, he \\ calls the temple of Angkor Wat in Cambodia an abstraction, \\ as the design's form emulates the mountains and peaks of the \\ Himalayas, the seat of the gods. What we see at Angkor Wat \\ is the abstraction of that image, while the Mayans do not \\ depict anything and the origin of their forms are unknown \\ (Olgiati 16). As Olgiati points out, invented forms and \\ shapes are captivating, more interesting and less trivial, and as \\ such the idea of a non-referential artifact with no origins or \\ representational references is the aim for this design proposal.
}

\footnotetext{
$<$ Figure 88

Tikal, Guatemala 600 B.C

< Figure 89

Angkor Wat, Cambodia 12th century
} 


\section{IT IS WHAT IT DOES}

Brussels-based architecture firm Dogma look at a rearticulation of the relationship between architecture and city. Dogma's projects are seen to be projections of an idea of the city through autonomous architectural forms. All their projects share the same geometry of a square form.

"All of our projects start from the figure of a square. We simply use it and thereby skip the humiliating moment for architects when they have to desperately search for some interesting form. We avoid that moment and use preconditions to explore something that goes beyond the choice of forms."

Ramones (see figure $90 \& 91$ ) is a design of a linear bridge within a park. As a landscape form or a mega-form, a definition paraphrased by Kenneth Frampton, the bridge would contain programmes that allowed the park to be free of structures. As a generic and abstract structure, the bridge does not allude in any way to its context. Its architecture stubbornly avoids any figurative reference, any metaphor: it is what it does (Aureli and Tattara 66).

Pier Vitorrio Aureli and Martino Tattara, of Dogma, beliefs allows them to focus on their pursuit of an agenda of political, cultural and social engagement with the city without the need to invent new forms. The purpose of a simple square form allows ideas and other motives to take place. This doctrine set by Dogma lends itself to a self-disciplinary inquiry and a questioning of the intentions of form-finding and figuration.

$<$ Figure 90 Ramones, Dogma (2011)

$<$ Figure 91 Mega-form 


\title{
SECRET LIGHT
}

\begin{abstract}
painting looks for qualities within paint itself; colour, viscosity, fluidity and shape rather than the image depicted like a countryside landscape. Pierre Soulages's Painting (see figure 92) is composed of black acrylic on canvas. Soulage does not use brushes as his method of painting, but uses tools and wooden blocks. What interests Soulage is working with the material of black, the surfaces of black and the light created. He calls this light the 'secret light' (Soulage, 2015). Can designs be started by experimenting with light? What sort of architectural elements and methods can be used to generate designs?

Architect Peter Eisenman's House IV uses transformational methods (shift, rotation, compression, extension) as a way of form-making. These are a series of iterations under a limited set of rules, and are autonomous, like Soulage's work, where the finished product is a result of the self-referential process and properties, and not of social context or external references.
\end{abstract}

\footnotetext{
$<$ Figure 92

Painting, Pierre Soulages (2008)
} 


\section{GO FIGURE}

"Bad figures are stars. Good figures constellations - Bad figures are filled. Good figures are pregnant."

Ron Witte 81.

So how can we produce good figures? Architect Ron Witte observes in architecture today a new wave of figures that are good and bad: the fold, metaphor, pattern and blob (Witte 77). The bad figures are often laced with representation and reliant on narration, whilst the good figures are void of their representational obligation, providing resonance. Witte further suggests that a good figure is comprised of a cross-fertilisation of programme, technology and form to give its density.

The Seattle Central Library, built in 2004 by OMA and LMN Architects, has a distinctive form in which its shape is dictated by the library's various programmes, arranged across five platforms with four flowing 'in between' planes (OMA, 2017) (see figure 93). The clustered programmes become the driver for form with the cross-fertilisation of technology, with a curtain wall glazing system wrapping the entire building in a continuous layer of transparency (see figure 94). The mixture of stacked programme and wrapped façade gives this figure its resonance. More importantly, the spatial qualities experienced inside become valued in the design process. Being void of any representation simply allows the building to function creatively.

$<$ Figure 93

Seattle Central Library,

OMA \& LMN (2004)

$<$ Figure 94

Form informed by

program 


\section{INNOVATION OR DERIVATION?}

"Abstraction did not kill figuration in art."

Adam Caruso, 2017.

Architect Adam Caruso argues that novelty is nonsense. He explains that in discussions with his art friends, he learned that they would not use novelty as a value in their work and that they have a clear relationship with the history of their discipline. Caruso argues that "to say that something is new is not credible. Even if it was new, why would that make it good? The tragedy of architecture is how stupid architects are whilst artists are too smart to think in that way" (Caruso, 2017).

Winy Maas of MVRDV also shares the same view on the derivation around design, noting that "instead of mocking the culture of copycats, design could learn better how to make good fakes" (Maas, 2017). Maas compares architecture with science, where progress in research builds and stacks on the work of others. Maas points out the need to deepen architectural analyses, improving on the exploration of predecessors and being open and honest about the references made. (Maas, 2017).

These forthright remarks form a stance which this proposal looks to experiment and test: a way of embracing an open approach to design in the abstraction of sources. Abstraction used here is different to abstraction of the waka or mountains. In this context, abstraction of sources relates to deriving knowledge from the discipline and from historical architectural references to generate form.

\footnotetext{
$<$ Figure 95

Winy Maas's Generator, tracing forms to their origins
} 


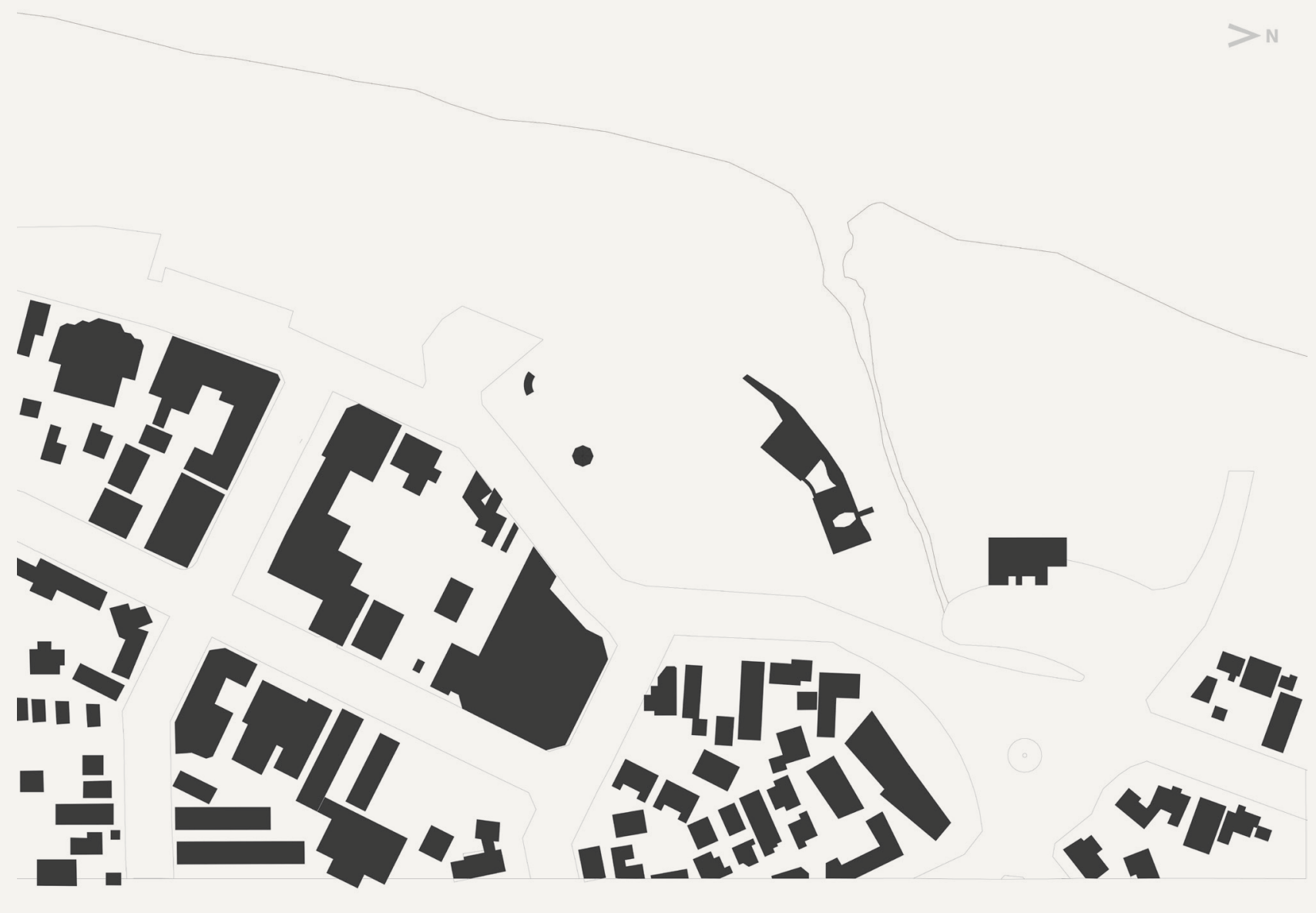

Figure 96

Figure-ground plan of proposal in Maclean Park 
PART 3

\section{BUNKERS}

DESIGN PROPOSAL 


$$
P A R A P A R A U B \text { B } E_{A} C_{H}
$$

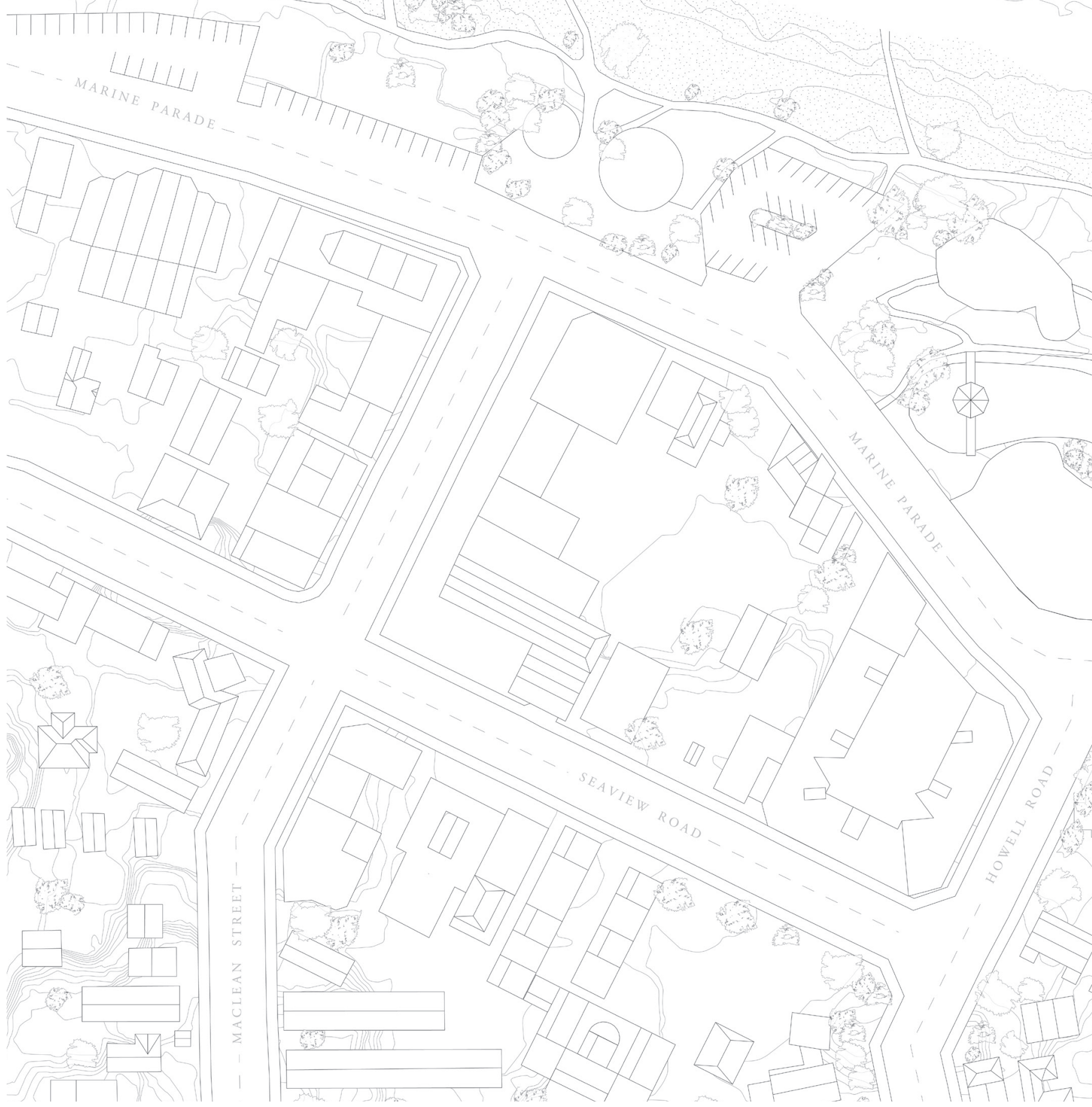




\section{(8)}

$>-N$

1 स०

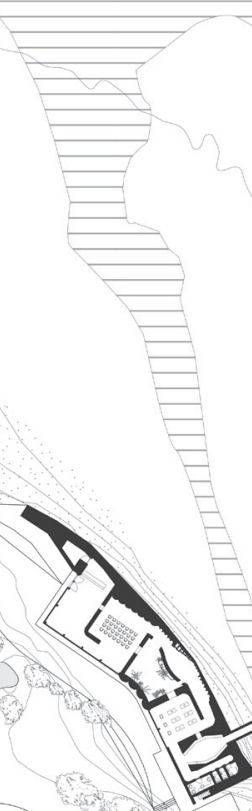

,

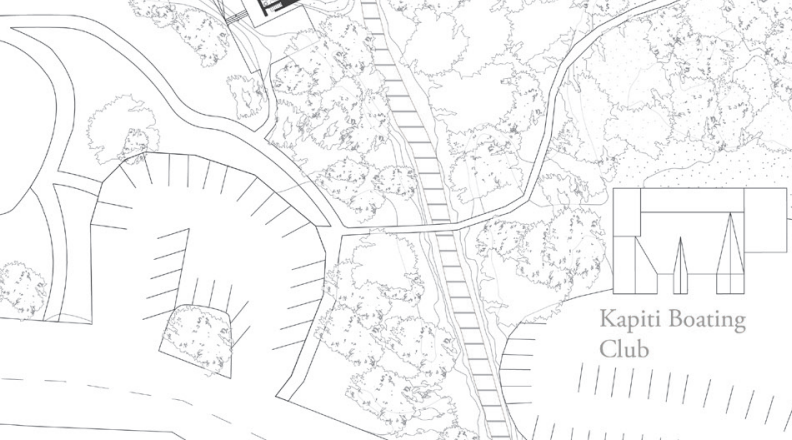

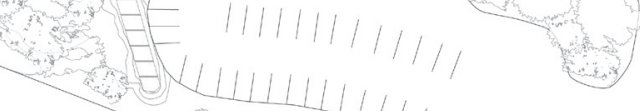

目

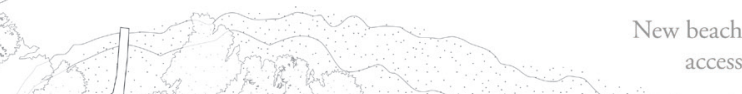

3
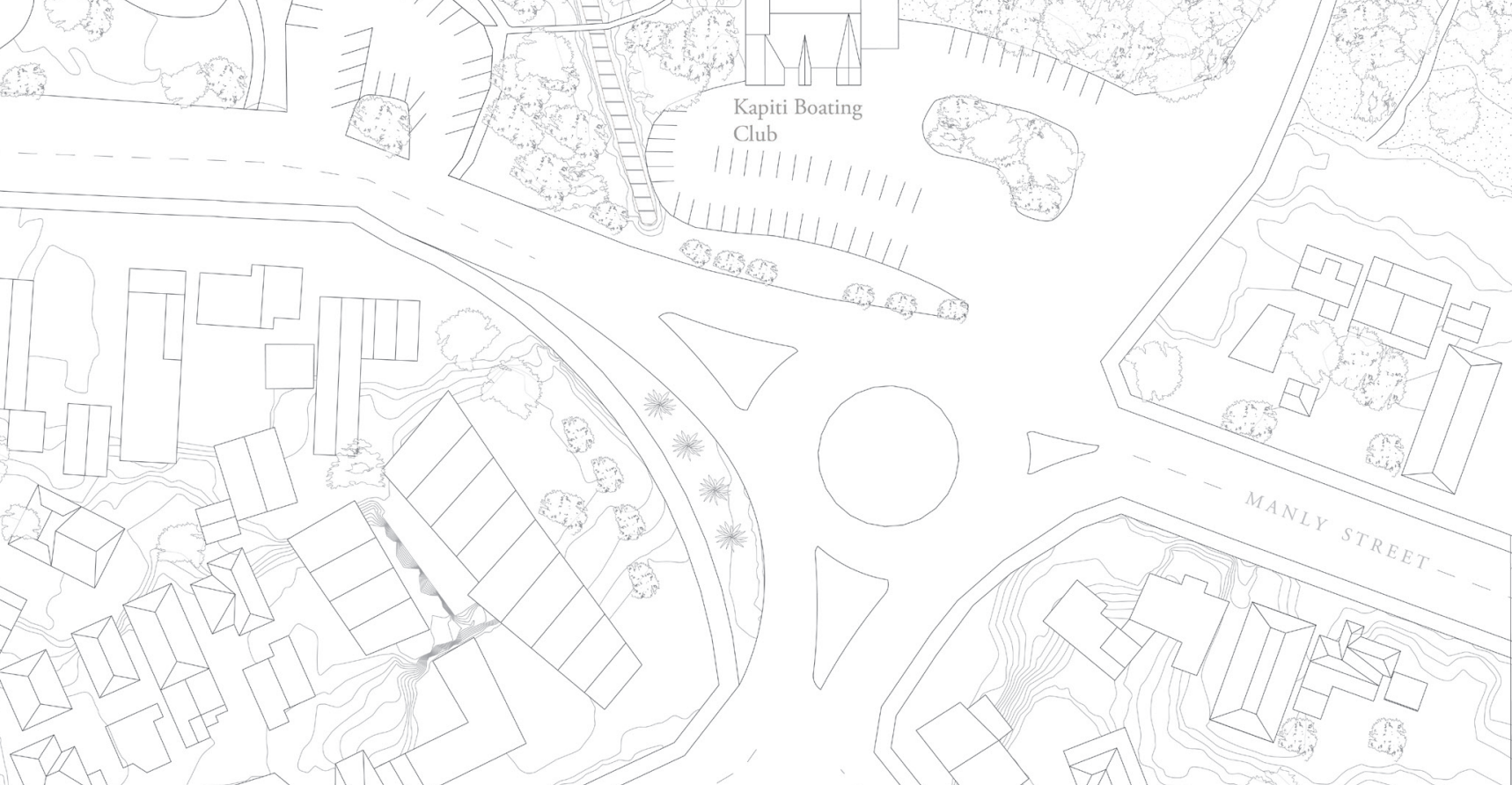

$\wedge$ Figure 97 *

Site plan 


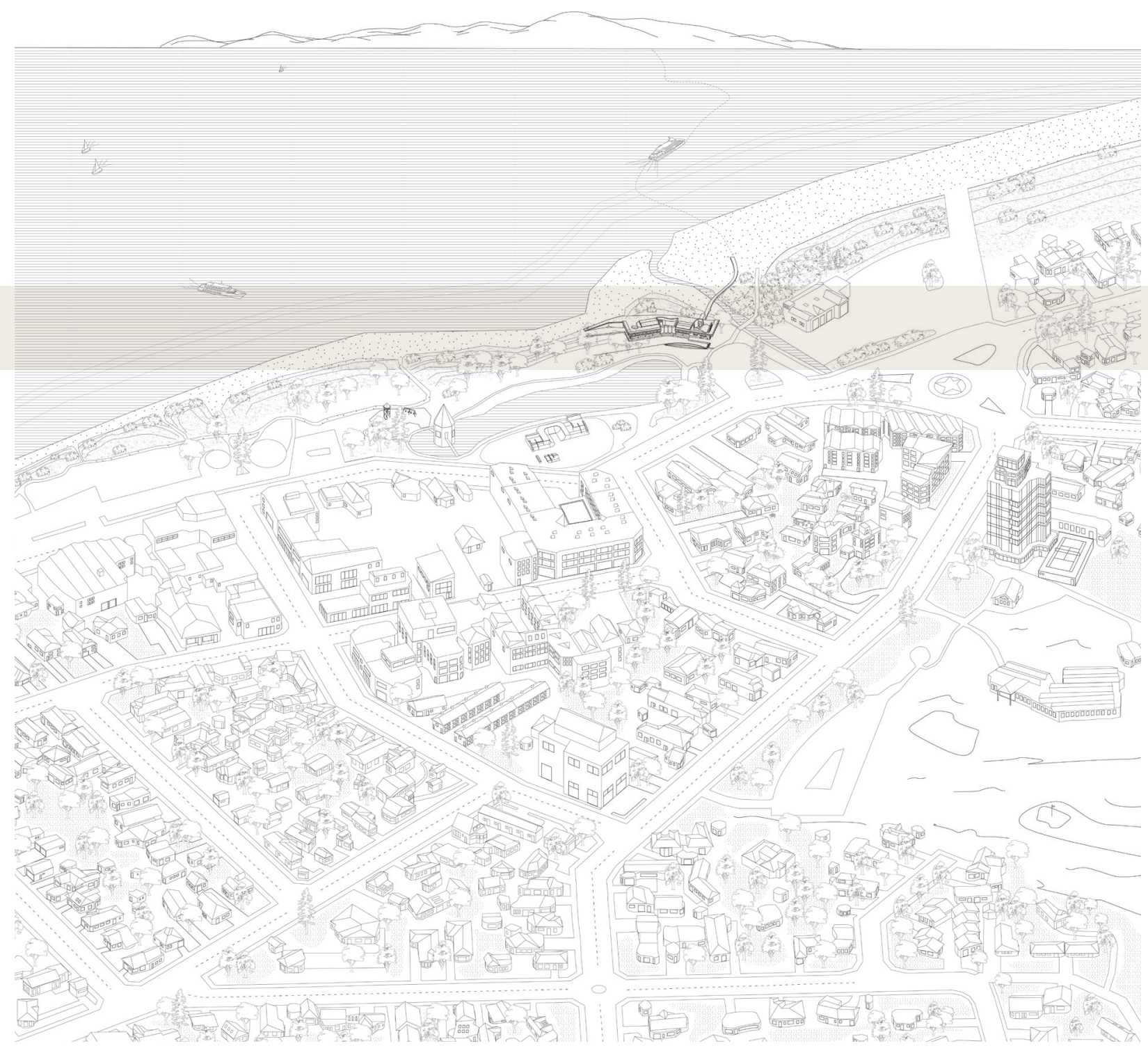




\section{DESIGN PROPOSAL}

This design proposes a building embedded and buried among the existing dunes. The dunes are extenuated to create a sheltered park space featuring a reflexology park and terraced seating at the front side of the building, facing away from Kapiti Island (see figure 98). The park is connected to the existing MacLean Park amenities (children's playground, skatepark, lake and public toilets) to form a harmonious relationship with them, developing the park's configuration (see figure 97).

All of the visitor centre programmes are buried underneath the dunes, concealed and experienced through a guided sequential journey (see figure 99). The programme defines this playful maze, which is choreographed specifically to allow the tour guides to take visitors through to Kapiti Island. The building stretches 60 metres long and roughly 14 metres across, emphasising this journey (see figure 102).

\section{$<$ Figure 98}

Proposal on site amongst existing context 


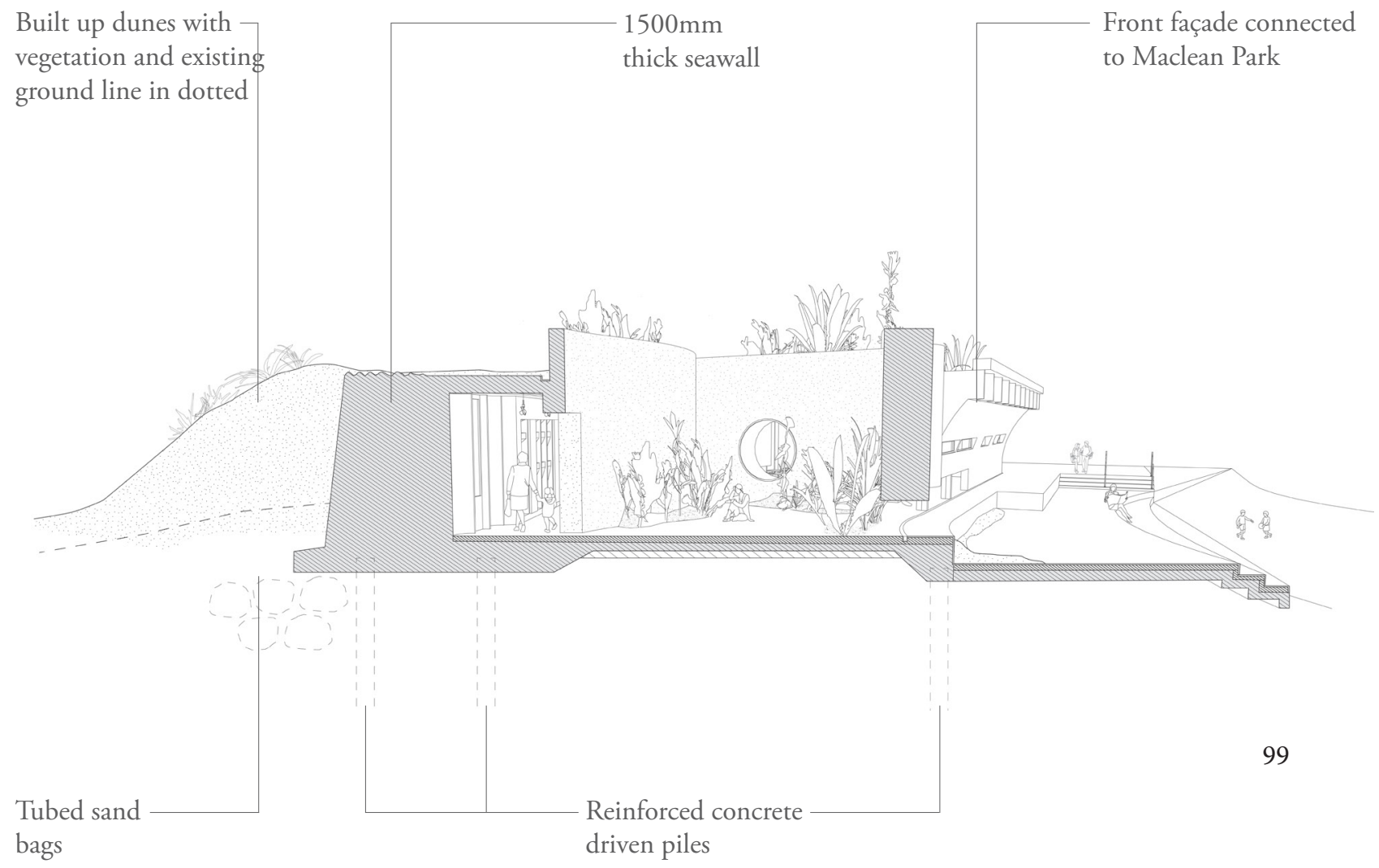


The structure of the building is concrete, responding to the dynamic landscape- changing tides, shifting dune lines, sea level rising, future storms and the nearby stream. It consists of a thick $1500 \mathrm{~mm}$ seawall banked at the back as the spine and structural anchor of the building. The wall consists of two reinforced concrete driven piles every $9000 \mathrm{~mm}$ down the wall, as well as tubed sandbags that stop the foundations from being overturned and eroded by sea water (see figure 99). This was used effectively at the recent ACENZ (The Association for Consulting and Engineering Professionals) 2016 winner Sumner Surf Life Saving Building (see figure 101). Internally the walls range from $250 \mathrm{~mm}$ thick to $500 \mathrm{~mm}$ thick.

Vertical timber formwork is used throughout the sculpted interior and is contrasted with a smooth curved façade connecting to the park. The concrete façade is emphasised with 'garnet' pigmentation applied to the exteriority of the building (see figure 105). This subdued colour accentuates the essence of the bio-security, a sober reminder about the serious implications of visiting the nature reserve on Kapiti Island. The colour also amplifies the building's setting, being buried and enveloped by the park and the dunes, as well as extenuating the materiality of the concrete and the building's distinct shape and form.

$<$ Figure 99

Cross-section through exposed uncovered internal courtyard

$<$ Figure 100

Galveston Seawall, Texas (1903)

$<$ Figure 101

Sumner Surf Life Saving, Wilson Hill Architects (2016) 


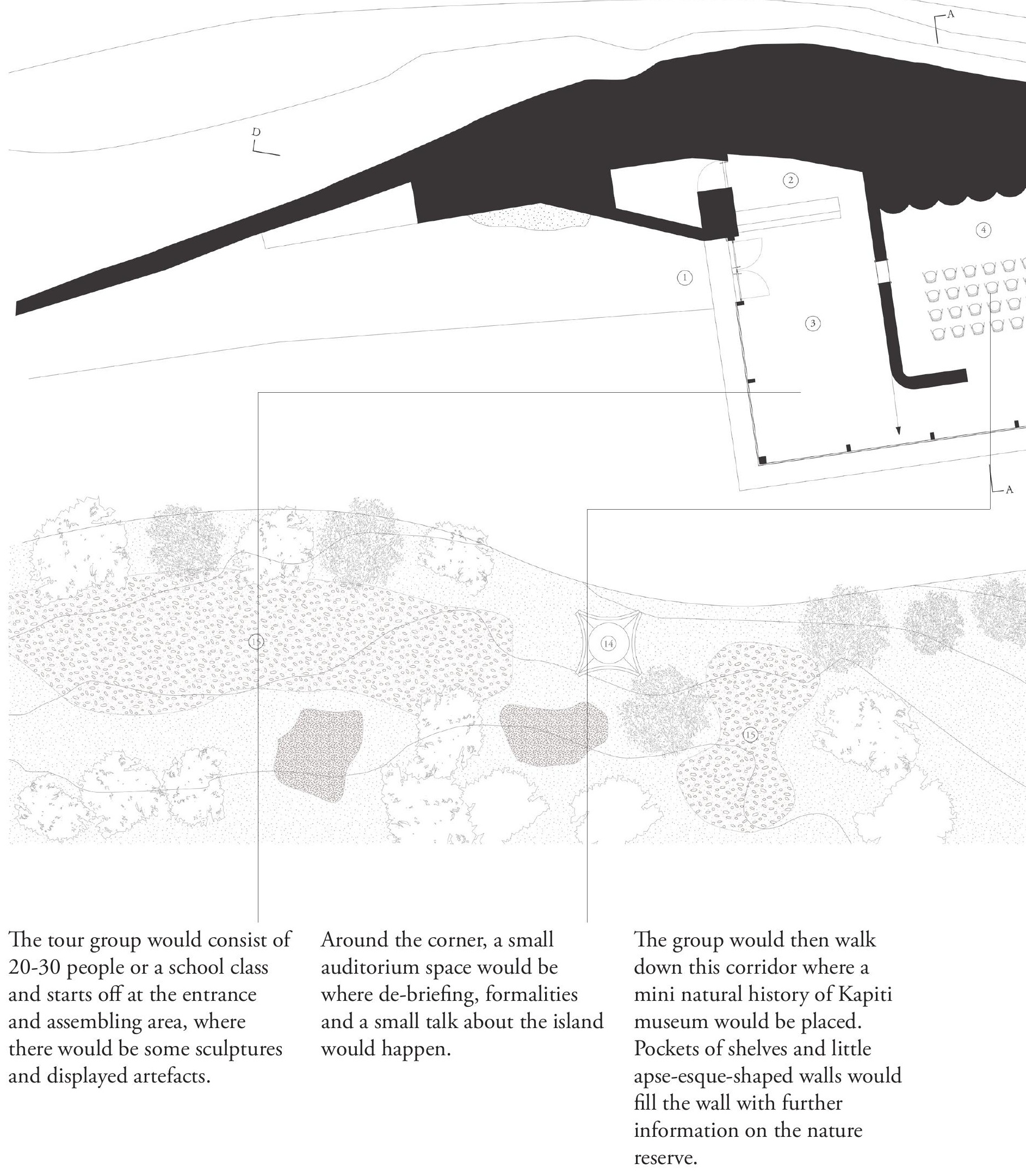




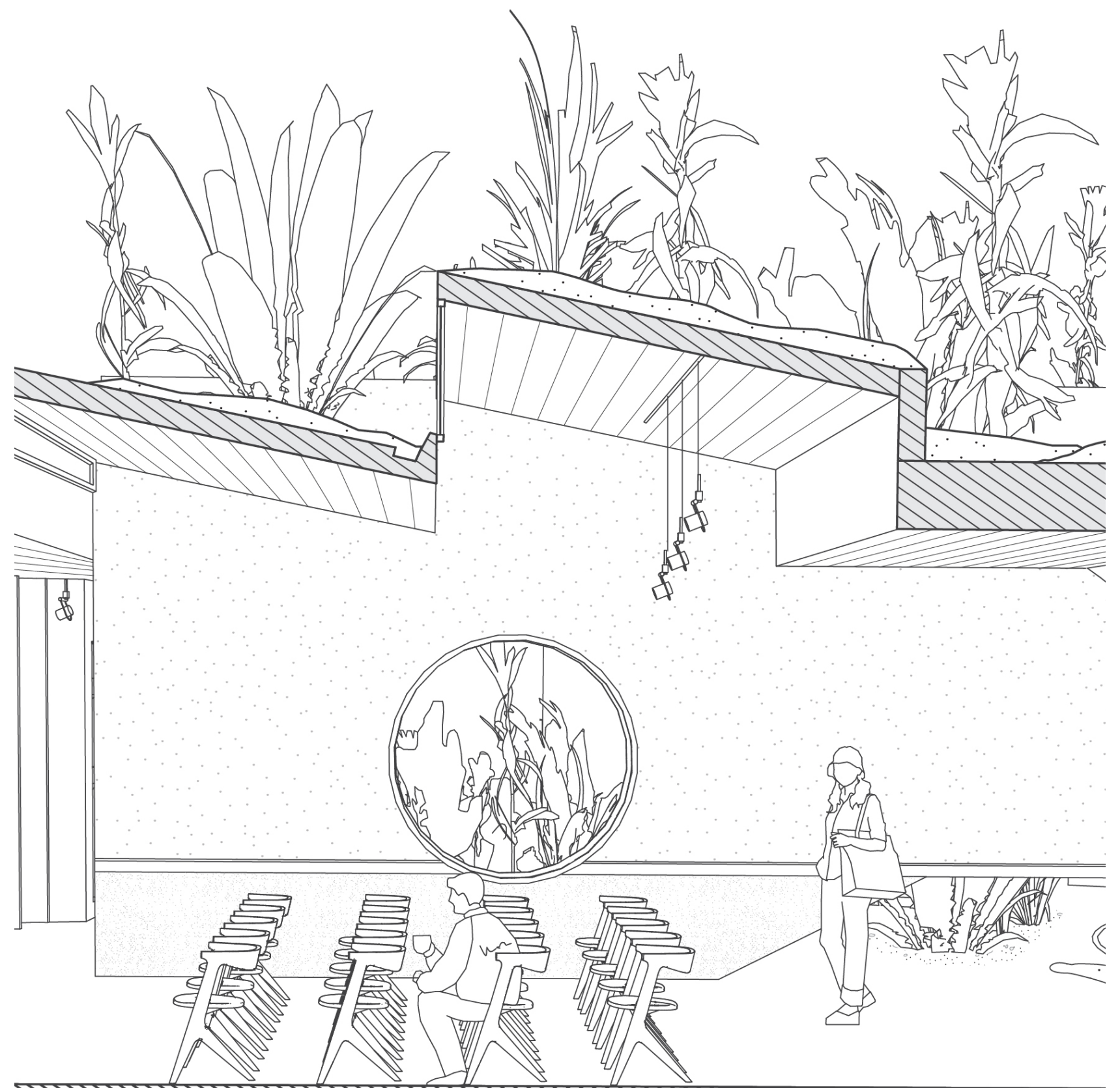

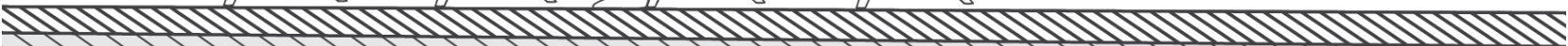

Figure 103

Close-up cross-section through small auditorium close-up 


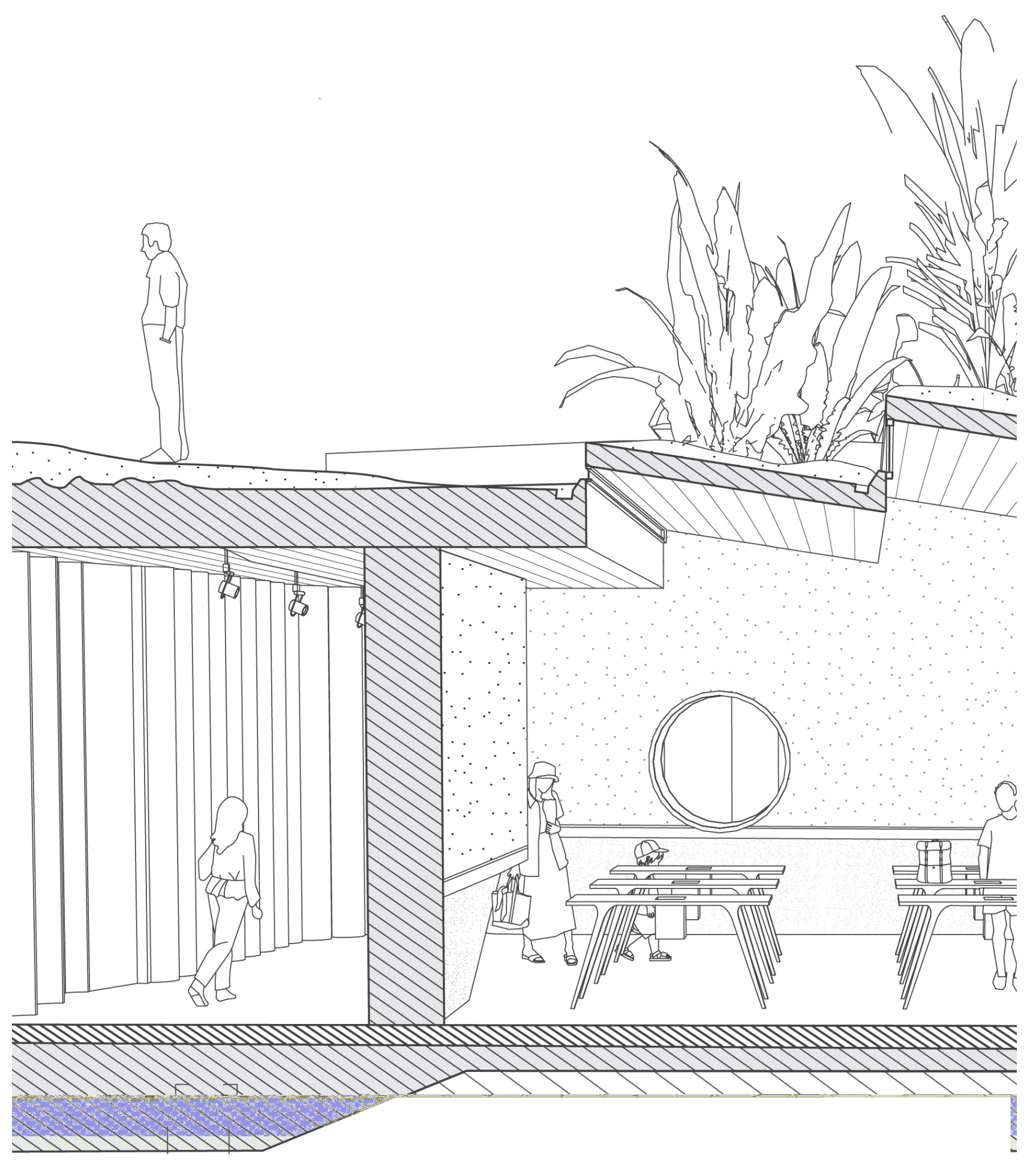

Figure 104

Close-up cross-section through corridor and bio-security chamber 


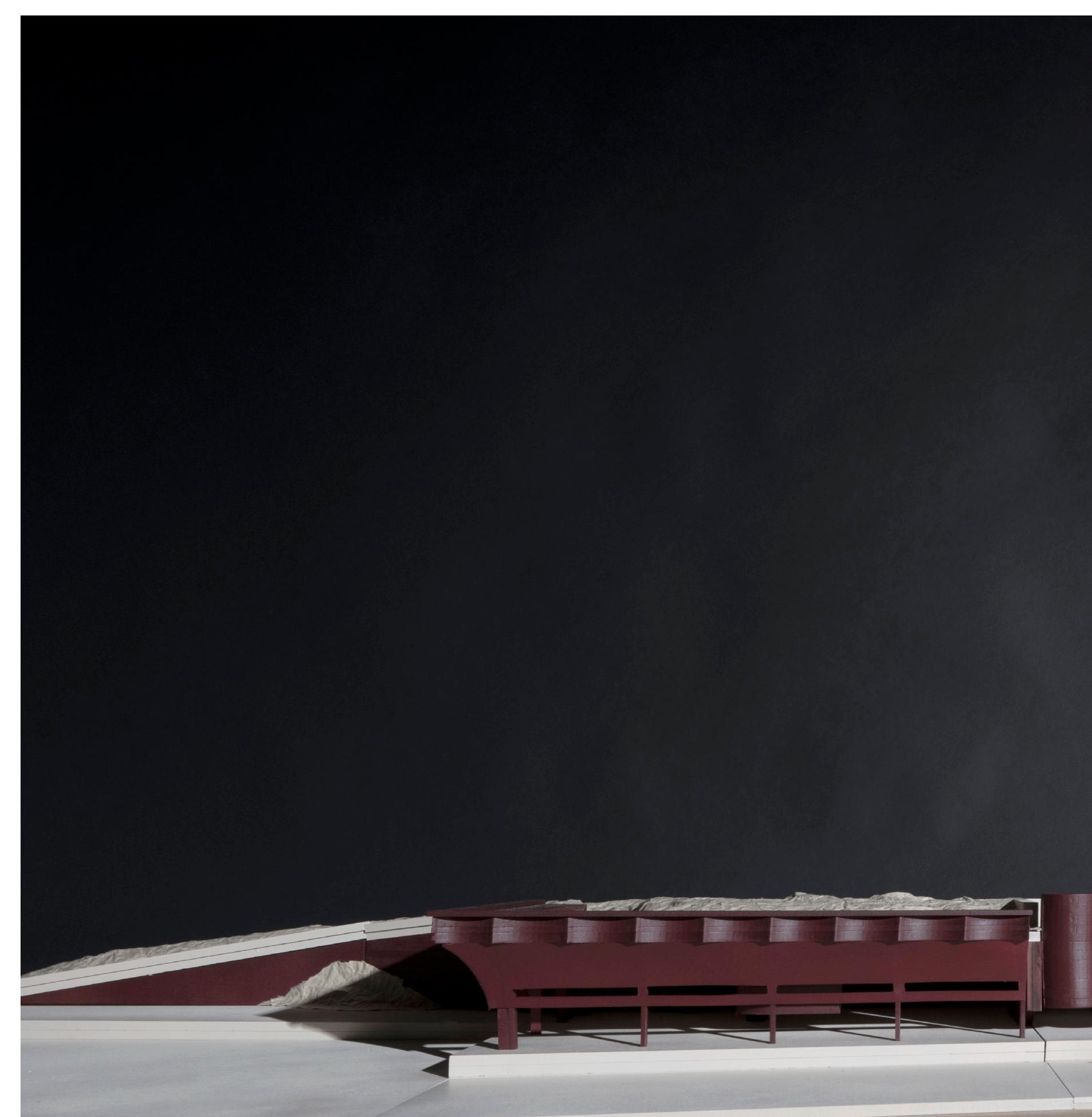




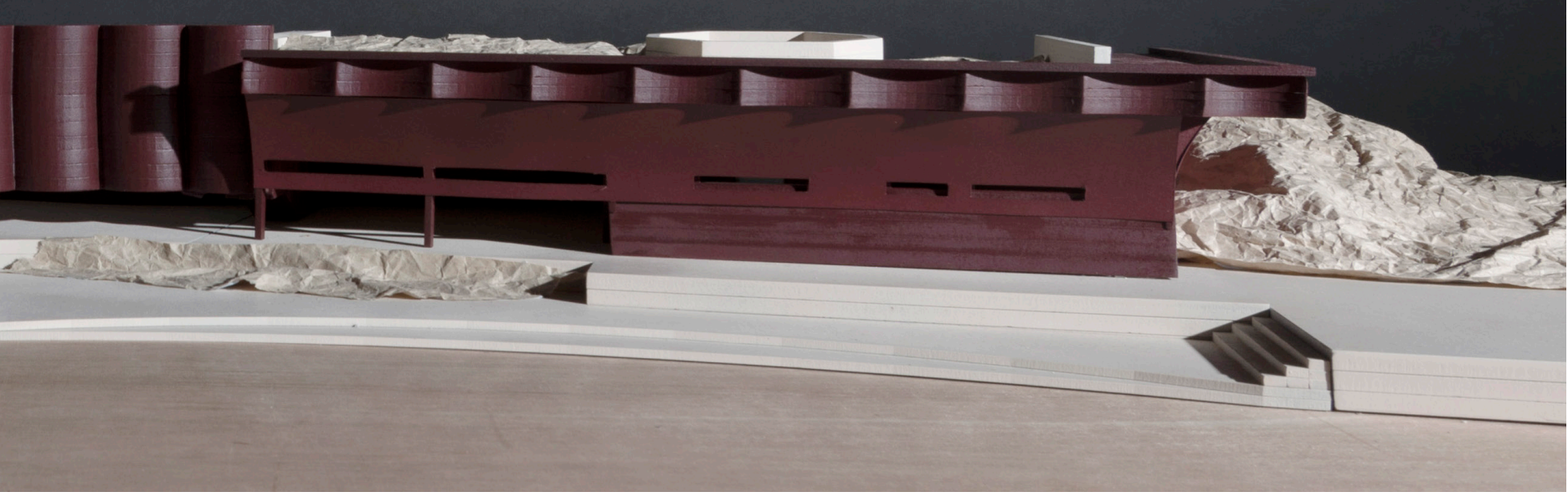

$\wedge$ Figure 105

1:50 Model - Dunes forming the rooftop 


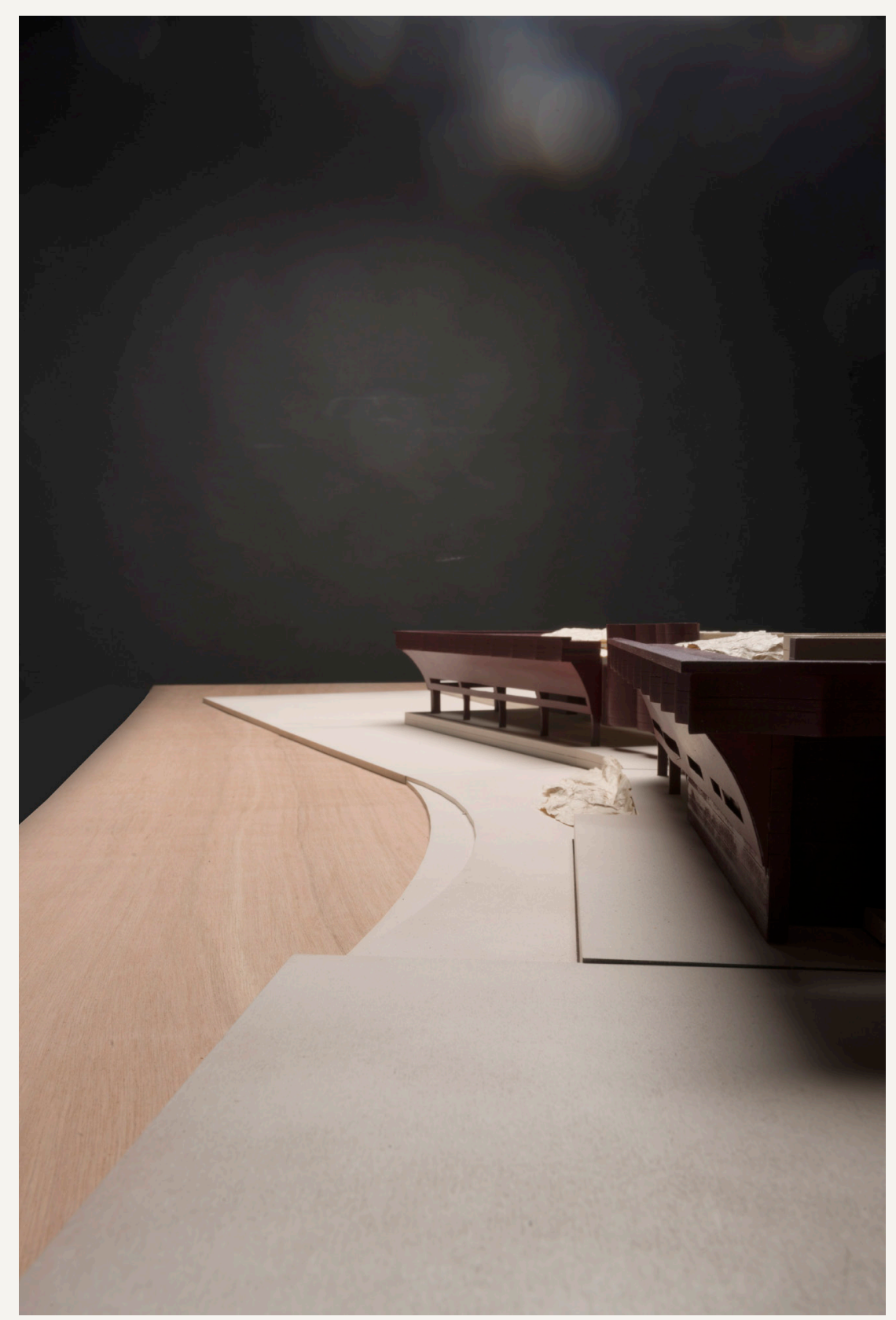

Figure 106

1:50 Model - Curved and disjointed façade 


\title{
PART 3
}

\section{CURATING ARCHITECTURAL PRINCIPLES}

\author{
DISCUSSION on: Fat Structure \\ Circuitous Plan \\ Buried Building \\ Clean Form \\ Anchor Points \\ Major and Minor Geometry
}


Six design principles shape and order the design of the building's architectural language. These principles drive a technique, a modus operandi . These principles are: 
Fat structure - Carving out space where programme is independent from structure

Circuitous plan - A sequential journey looking at a playful arrangement of circulation

Buried building - Landscape becomes a form of expression

Clean form - Using repetition and continuity

Anchor points - Nodes and moments where programme re-orients visitors

Minor and major geometry - Components of the building which provide tectonic expression, atmosphere and function 


\section{FAT STRUCTURE}

\section{Poché}

/'pofeI/

Noun
The method or result of representing the solid part of a building
(as a wall, etc.) by a darkened area on an architectural plan; (
occasionally) a pen for doing this.
Verb
(with object) To darken or fill in (walls, columns, etc.) with
shading on an architectural plan.
Oxford Dictionary

The programme is independent from structure. Starting from a mass of concrete, poché becomes the referent where spaces are carved from the inside. Forms and spatial arrangements are now experienced through the interiority of the building using concrete as a means of experimentation.

By working in section, the form shifts from a blatant elevational figure to looking at developing spatial qualities through section and plan (see figure 107). This shift in working from the inside out rather than outside-in or a top-down approach presents a clearer opportunity to explore a richer understanding of how fundamental architectural conventions like programme, light and shadow, texture, materiality and so on can work. Unlike previous experiments with image-driven compositions based on references and metaphors, starting off with the existing landscape, a mass of concrete and programmes as components produces a richer approach to understanding how figure can work when tethered to a different set of references. These references are inherently based in architecture- an internal referent as opposed to an external referent.

$>$ Figure $107 *$ Cross-section through small auditorium showing roof aperatures and expressing the prominence of the use of concrete as the building's structure

$>$ Figure 108*

Perspective of the small auditorium space. Concrete form and strategies of dealing with natural and artificial light expressed through interiority of the building 

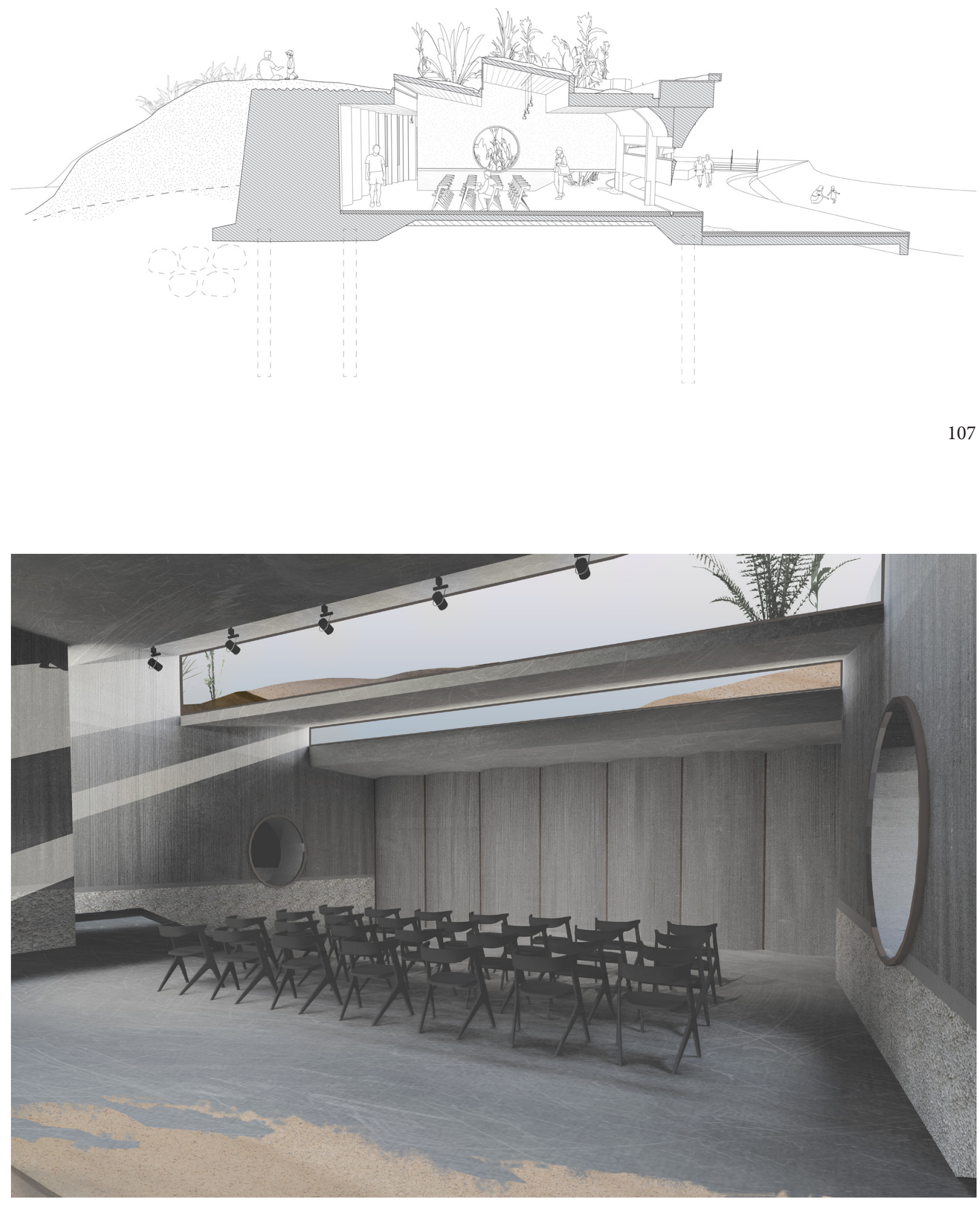

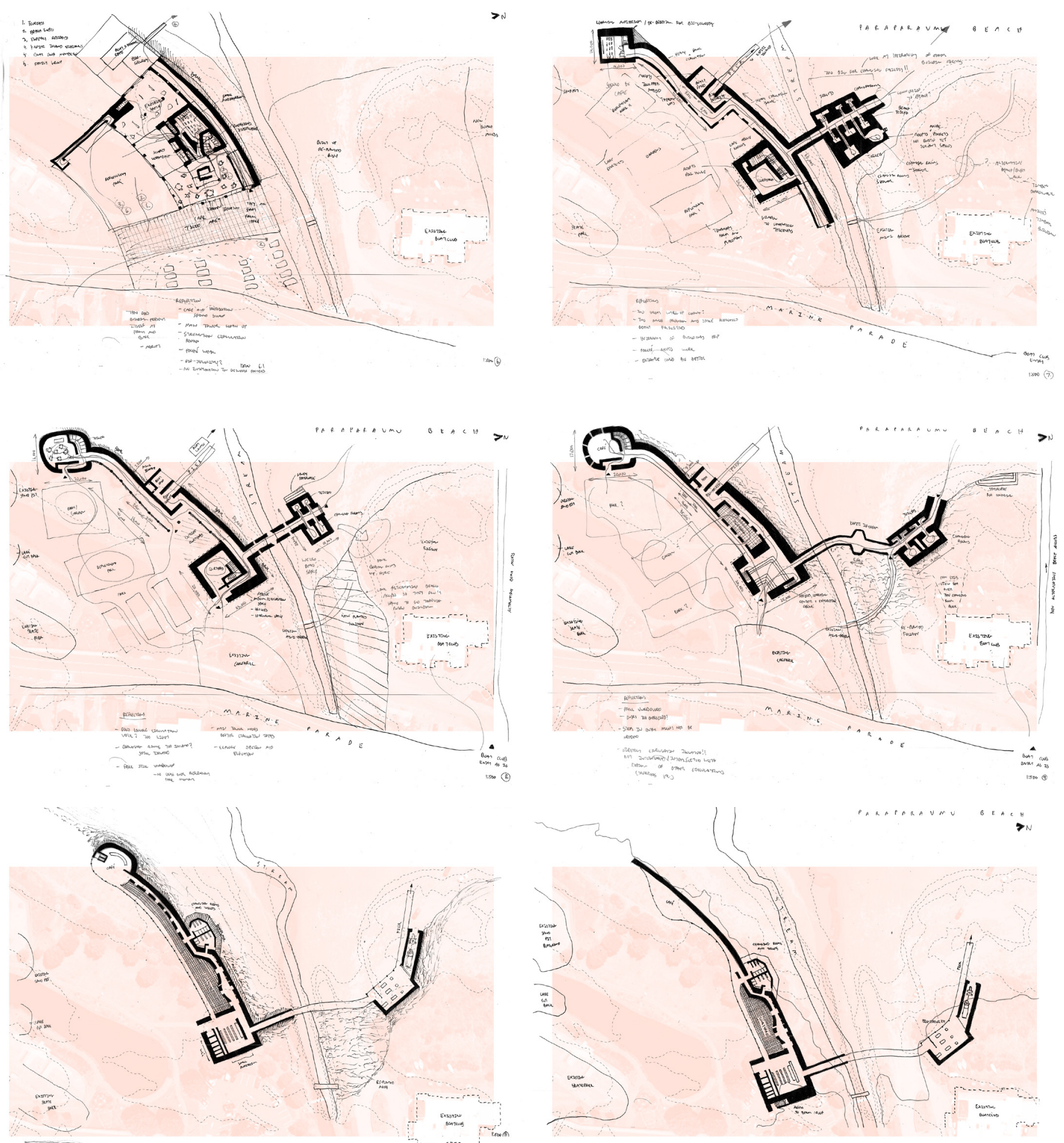

$\wedge$ Figure 109

$>$ Figure 110

Early iterations - ink pigment liner pen on tracing paper.

Rough testings of different programs sprawled on site. Early on the gesture of curling around the site with the placement of the retaining wall as the spine of the building. Programmes were then positioned on or off axis in relation to the spine and landscape

Figure 111

Iteration where the façade looks like a solid front façade. No programmes penetrating through so as to not break the spine of the building

$>$ Figure 112

Final current plan. Façade is lighter and programmes are given more space for circulation. Geometry of walls developed 


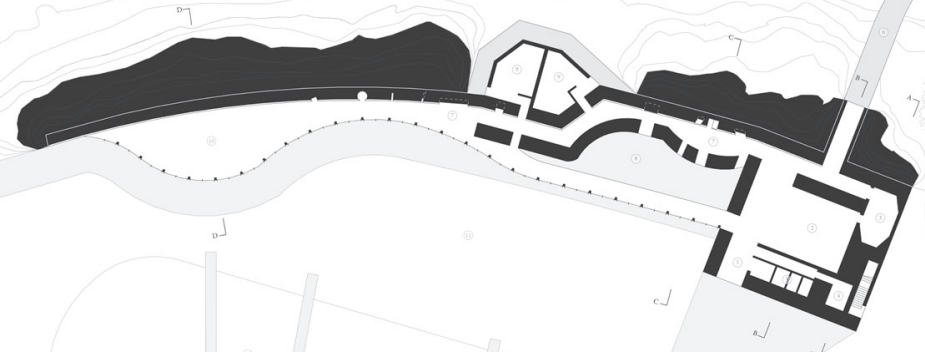

110
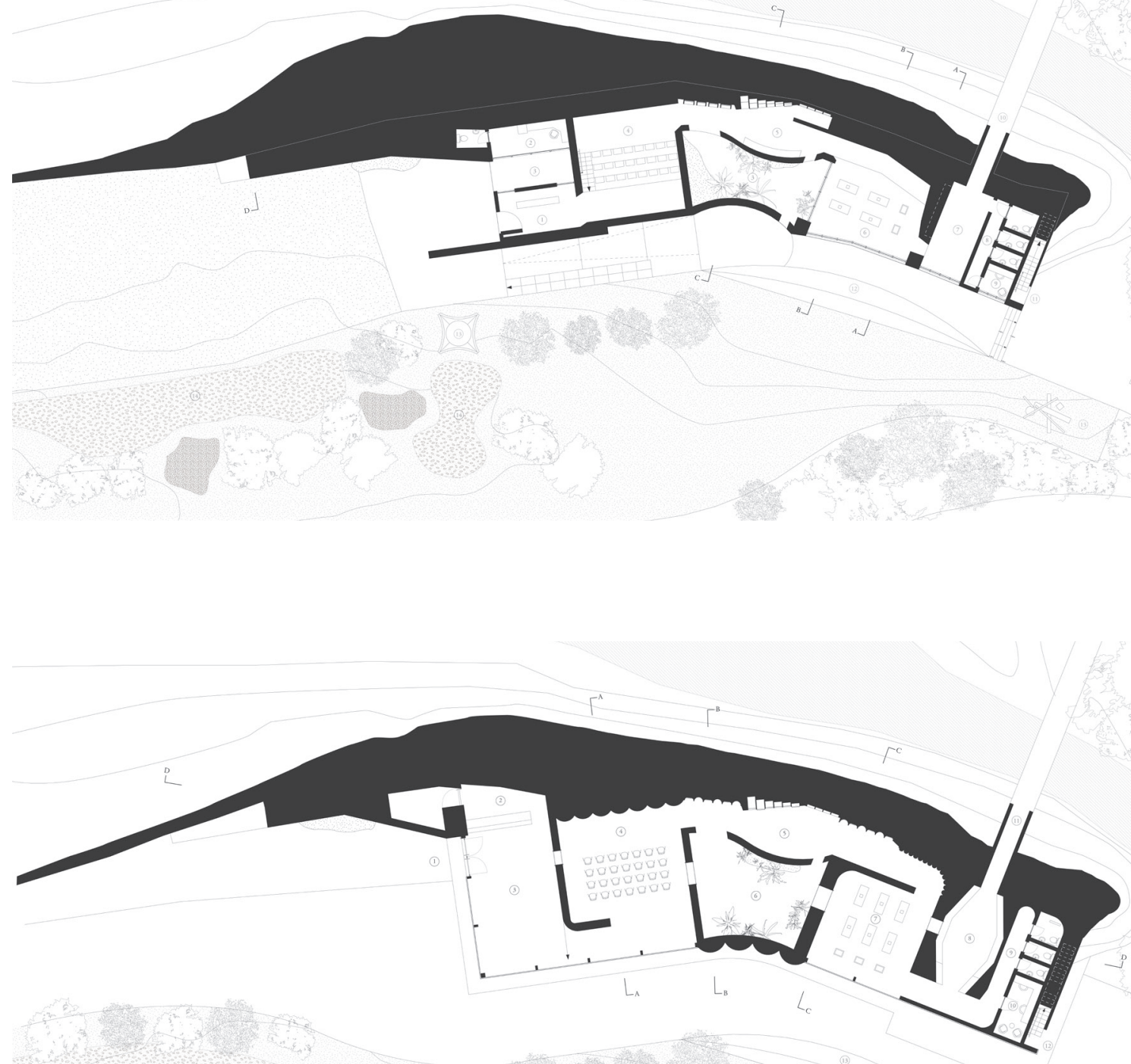
Aspects of playfulness, previously experimented with, are now implemented through the organisation of programme planning. The playful operations of carving and sculpting and working with the positive of concrete to form the negative of space are an iterative process worked in plan (see figure 109). Each programme is sculpted away differently from a solid mass to give different spatial indications, giving each programme its own way of being inhabited. The waiting room becomes an elongated hexagon, bio-security a square and other spaces rectangles with the courtyard taking its own unique shape.

The process of working in plan is key to generating the building's form; it is only later that the design is developed through section. This is due to the shape and proportion of the building being one storey high and stretching longitudinallythe length becomes an opportunity to work with the long site of MacLean Park as well as the shorefront of Paraparaumu beach. Experimenting with poché in plan in this format generates an outcome that is unlikely to have occurred with a tall, protruding building that was short in length.

Sculptor Richard Serra's list of operative architectural verbs and contexts (see figure 113) becomes crucial for design decisions which manipulate the form of concrete in a way that means the action becomes physically visible in the finished form. 'To split', 'to shave', 'to rotate', 'of tension', 'of grouping', 'of location', 'of equilibrium' and so on are used throughout the process of this design. Using these operations, a clearer referent for form-making is established. Each verb and its result has a measurable effect on the treatment of concrete, working with its physical and spatial qualities. In comparison to this, using representational cues like the abstraction of a waka makes it harder to understand how concrete can work as form. 


\begin{tabular}{|c|c|c|c|}
\hline to roll & to curve & to scatter & to modulate \\
\hline to crease & to lift & to arrange & to distill \\
\hline to fold & to inlay & to repair & of waves \\
\hline to store & to impress & to discard & of electromagnetic \\
\hline to bend & to fire & to pair & of inertia \\
\hline to shorten & to flood & to distribute & of ionization \\
\hline to twist & to smear & to surfeit & of polarization \\
\hline to dapple & to rotate & to compliment & of refraction \\
\hline to crumple & to swirl & to enclose & of tides \\
\hline to shave & to support & to surround & of reflection \\
\hline to tear & to hook & to encircle & of equilibrium \\
\hline to chip & to suspend & to hole & of symmetry \\
\hline to split & to spread & to cover & of friction \\
\hline to cut & to hang & to wrap & to stretch \\
\hline to sever & to collect & to dig & to bounce \\
\hline to drop & of tension & to tie & to erase \\
\hline to remove & of gravity & to bind & to spray \\
\hline to simplify & of entropy & to weave & to systematize \\
\hline to differ & of nature & to join & to refer \\
\hline to disarrange & of grouping & to match & to force \\
\hline to open & of layering & to laminate & of mapping \\
\hline to mix & of felting & to bond & of location \\
\hline to splash & to grasp & to hinge & of context \\
\hline to knot & to tighten & to mark & of time \\
\hline to spill & to bundle & to expand & of cabonization \\
\hline to droop & to heap & to dilute & to continue \\
\hline to flow & to gather & to light & \\
\hline
\end{tabular}

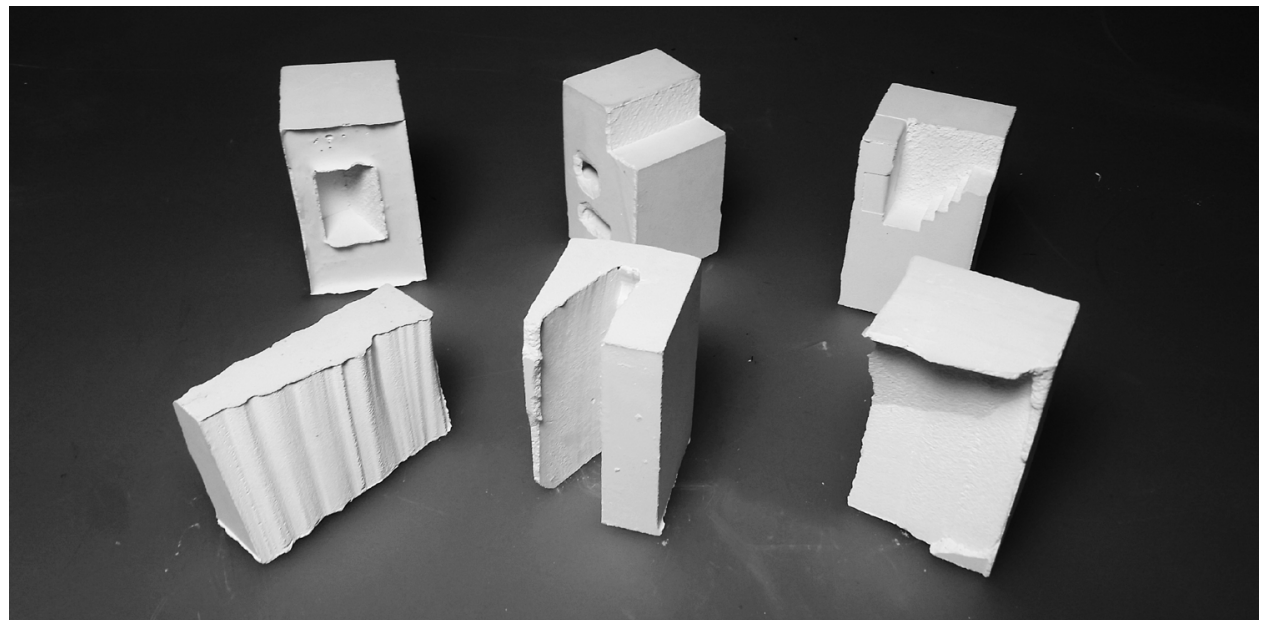


Why are the carved interior walls so thick? What would the argument be for justifying the cost of a $500 \mathrm{~mm}$ thick wall? 'Rawlinsons New Zealand Construction Handbook 2011' estimates a cost of $\mathbf{\$ 5 3 0}$ per square metre for $400 \mathrm{~mm}$ thick in situ concrete walls with reinforcing. There is a $\mathbf{6 7 \%}$ cost difference when specifying $150 \mathrm{~mm}$ thick walls at $\mathbf{\$ 3 5 4}$ per square metre (Rawlinsons, 80).

What justifies this differentiation? How thin is too thin?

Firstly, the fat interior structural walls are to celebrate the materiality of concrete and to over-emphasise the expression of concrete and its strength. These structural walls complement the even fatter seawall (the spine of the building) and contrast with the light curved façade at the front side. The use of concrete in this vast size is similar to its use in a bunker. In a similar sense, this building operates like a bunker in its strength and endurance, but against the environment. This emphasis on the building's strength reinforces the value of building resilient structures on the shorefront, acting as an architectural precursor for other buildings that will be erected on the coastline in the future.

Secondly, as a public building with impact on the town's tourist growth, the building must take up a role beyond the usual typical I-site buildings: it needs to attract tourists internationally for its architectural merit. In a similar context, the provincial town of New Plymouth's Len Lye Centre by Patterson Architects consists of a large 14 metre high concrete colonnade façade (see figure 116). The total project amounted to 11.5 million dollars with the building being roughly double the size of this proposal. That building, however, helped grow its local tourist industry, reaching 151,000 visits in the opening year and solidifying itself as a national attraction (Shaskey, 2017). This proposal for the visitors centre as a gateway to Kapiti Island also seeks to achieve the same results.

Figure $115^{*}$

Perspective of the mini natural history of Kapiti museum. Information and artefacts are embedded within the walls

$>$ Figure 116

Govett-Brewster Art Gallery/Len Lye Centre, Patterson Architects (2015) 

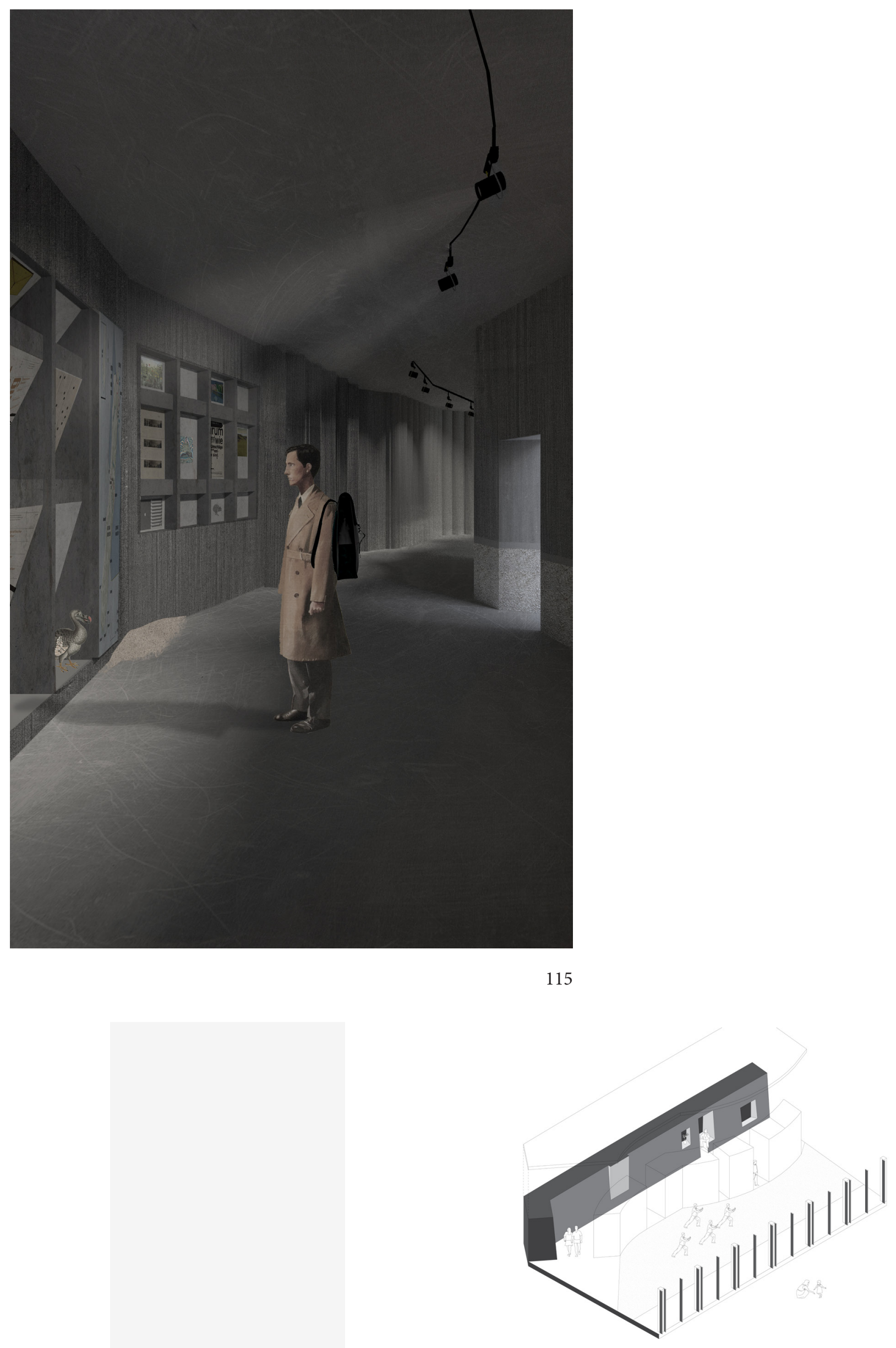
Thirdly, the atmosphere of the building is considered. Light bounces around the space and the thick walls, providing different visual moments, some darker than others. Circular windows are set into the $500 \mathrm{~mm}$ thick walls, penetrating between the rooms and offering view shafts, yet still partitioning each space.

"The room is the beginning of architecture. It is the place of the mind. You are in the room with its dimensions, its structure, its light responds to its character, its spiritual aura... Structure, I believe is the giver of light."

Louis Kahn, 263-264

The thick walls also intensify the acoustic qualities of the interior, providing solemn spaces as part of the whole experience of the nature reserve. The $500 \mathrm{~mm}$ thick walls are capable of providing 72 STC ratings (Insul) where a rating of 60 and beyond is deemed excellent soundproofing (Soundproofing).

Lastly, the walls absorb programmes when experimentation with poché is further indulged with an inhabitation of the walls. The mini natural history museum of Kapiti Island displays information and artefacts using recesses, shelves and apse-esque shaped pockets (see figure 102). This is prompted by Architect Louis Kahn's interest in Scottish castles, which is due to their use of circulation and programmes inhabiting the walls. Kahn observes, "Thick thick walls. Little openings to the enemy. Splayed inwardly to the occupant. A place to read, a place to sew... Places for the bed, for the stair... sunlight." (Kahn). These nestled spaces, each arranged sporadically within the castle's structure, prompt compositional and layout strategies for the secondary spaces of the visitors centre. The office and bathrooms are placed around a corner from the larger hexagonal waiting room (see figure 118). The external staircase which accesses the roof is also embedded within this mass, adjoining the side of the secondary spaces. These decisions work with the thickness of the wall and how it operates in order to shape each particular space. 


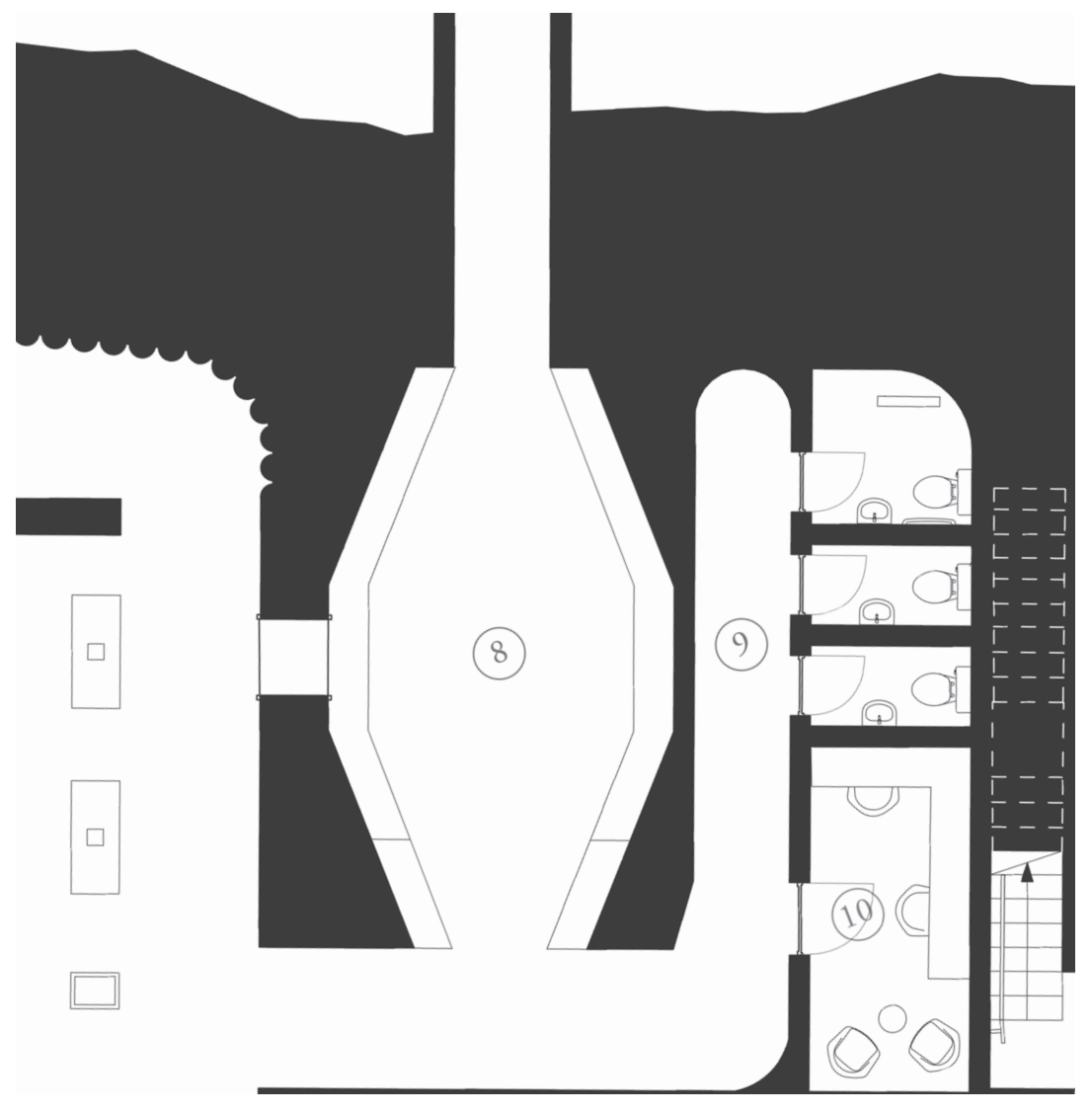




\section{GIRCUITOUS PLAN}

"A labyrinth is a spatial system built in order to lose orientation, to lose the notion of a beginning and an end... It is a machine that creates the impression of an infinite, endless space within a restricted, maybe even modest, area."

Christian Kerez, 19

Architect Christian Kerez comments on the labyrinth as a spatial device which describes the structure of the design's spatial layout. The interaction between the user and the building is experienced through playful shapes devising a mazy circuitous journey, not a direct route. The journey is in fact linear, but not visually so as corridors twist and bend, revealing different spaces to pop in and out of (see figure 120). Visitors aren't completely abandoned, however; the maze has a purpose and logic to it as they follow Kapiti tour guides through the building. Each programme builds upon the next and is sequential for the purpose of a creating an experience. The experience of the gateway centre has been fashioned to reflect the experience of a shrine or temple, with its own set of conditions, rules and rituals in place. This plays into the relationship of honouring the nature reserve on Kapiti Island, starting a connection immediately from the building itself as soon as visitors set foot inside. The building and its specific programmes set the tempo for the trip out to the island. The seriousness and solemnity of the bio-security procedure can be likened to how an airport departure zone operates and is perceived.

The programmes are ordered in the following:

- Entrance / Reception

- Small auditorium - De-briefing and information session

- Mini natural history museum of Kapiti

- Internal courtyard - nature

- Bio-security chamber

- Waiting room in conjunction with

bathrooms and the tour guide's office

- Exit out onto pier to board boat 


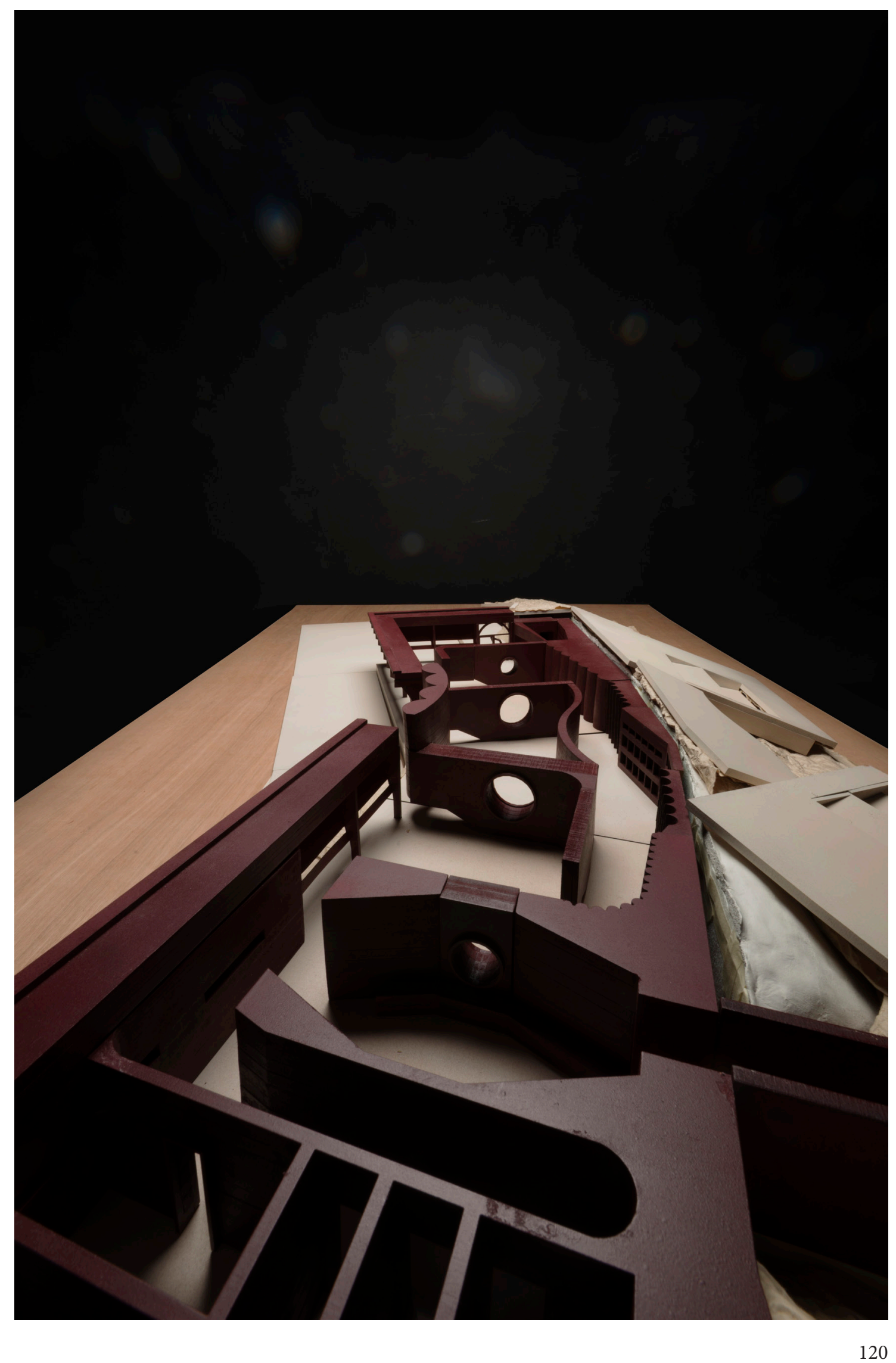


These initial tests of circulation schemes are also inspired by Kahn's studies of Scottish castles. Each experiment tests different interactions between the inhabited programmes with circulation routes within a mass of poché. These initial experiments were useful for understanding how the thicknesses of structure could be arranged and composed to accommodate programme and dictate circulation.

$>$ Figure 121 Scattered and isolated programmes. Circulation is non-linear

$>$ Figure 122

Mazy and unordered circulation

$>$ Figure 123

Internal courtyard, with circulation wrapping around

$>$ Figure 124

Layering on from the internal courtyard embedding progammes in alignment with the wrapping stairs

$>$ Figure 125

Collective 'cells', inward facing 


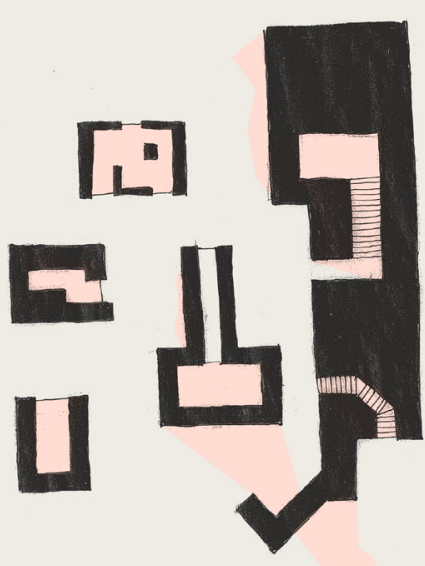

[ [
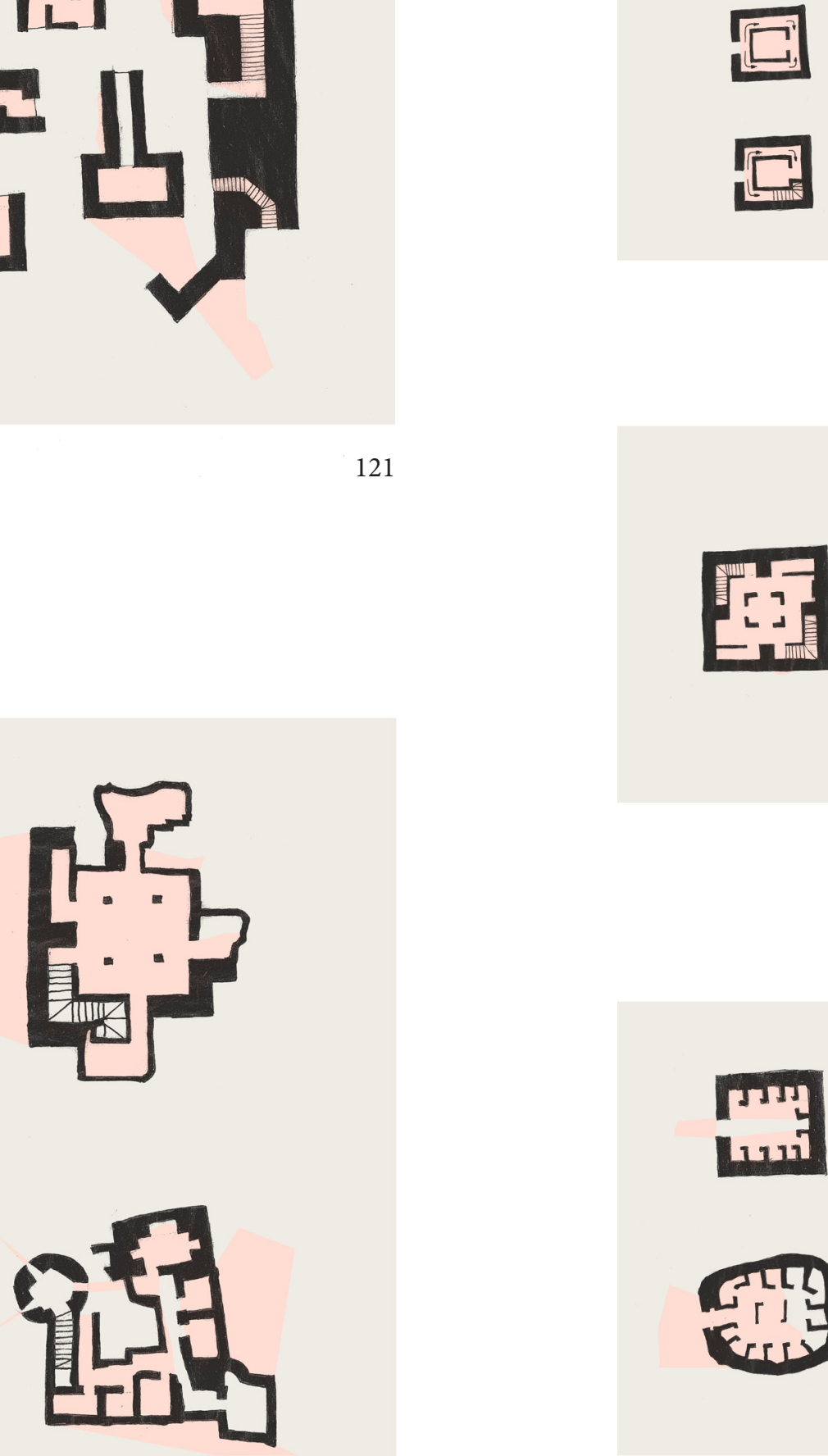

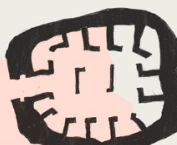


An earlier design iteration incorporated height (multiple storeys) with the expression of the circuitous plan (see figure 128).

Different buildings were also spread out along the coast (see figure 126). This however began to overcomplicate things, losing the emphasis of structure and hierarchy. Visitors would become too isolated and a sequential journey was not clear. It became too circuitous. The design, lastly, was less theatrical as the spaces carved out when inhabited became quite generic, as seen in the section and plan (see figure 127).

$>$ Figure 126

Scattered building masses to separate key programmes

$>$ Figure 127

Section showing relationship between internal courtyard and programmes

$>$ Figure 128

Different floorplans showing how visitors can travel to rooms and then back track the way they came to the main stair egress. Spaces and corridors became too tight to manage groups of 20-30 visitors wandering through

$>$ Figure 129

Worms-eye axonometric 

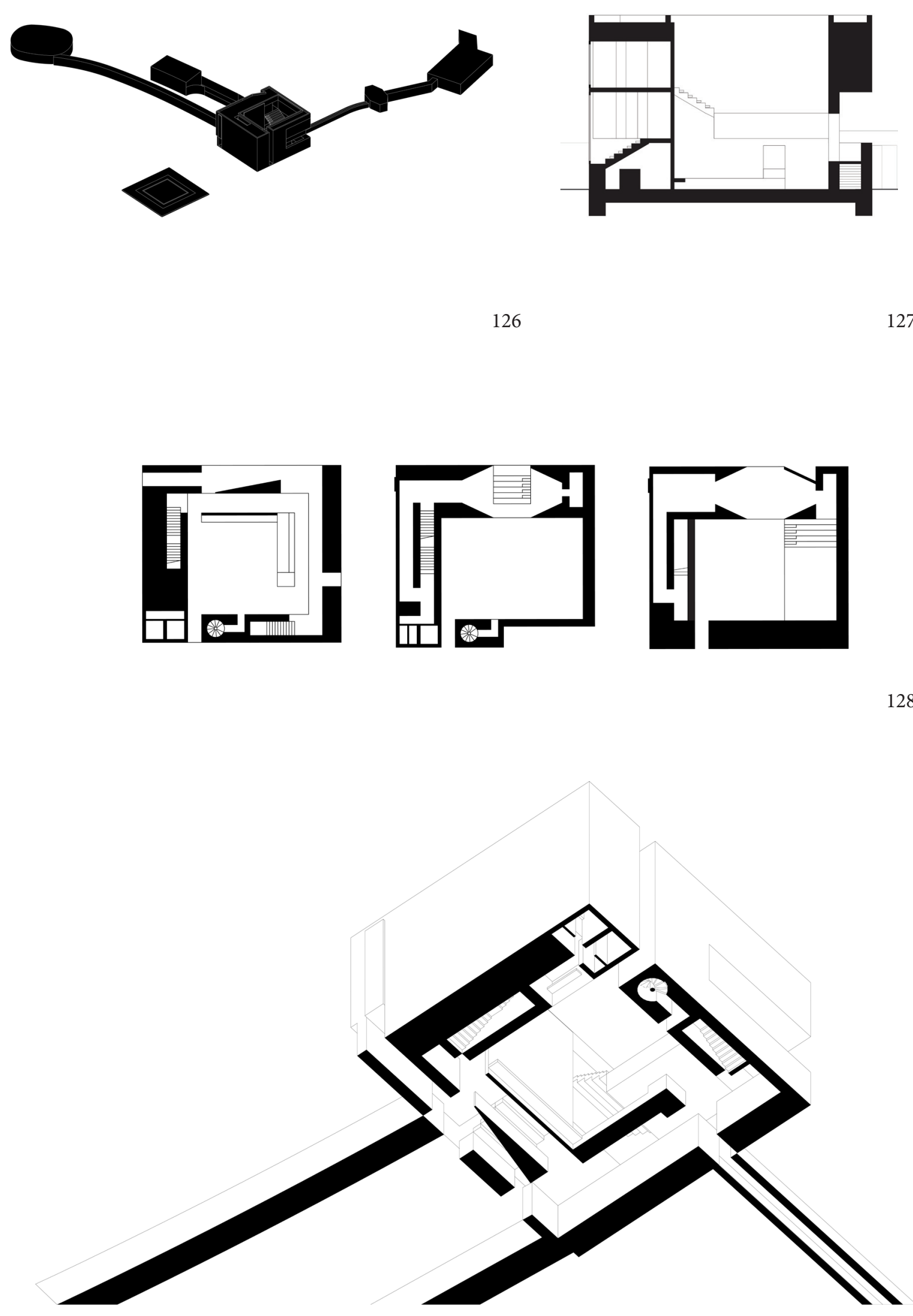
Why can't these rooms be placed in a straight line? Why does it need to be laid out in this way? Giambattista Nolli's 1748 Nolli Map (see figure 130) depicts Rome as figure and ground, showing the intense relationship between the positive and negative of the private and public spaces of the city. The representation of public spaces shows how those spaces can provide unique moments where no street and corner seems the same. This plan can be contrasted with other urban cities like Barcelona's Eixample city extension and even the gridded city of Manhattan, New York, both of which are affected by transportation and the priority of the road. The building favours an overlay of a compressed city's circulation rather than a systematic circulation. The dense engagement of activity and tightly knitted user experience is what the design looks to emulate, but on a smaller scale.

Contemporary practice Sergison Bates' Hamstead Housing for older residents (see figure 131) has a distinct floorplan where programmes are interconnected and intertwined with each other. The mosaic of tessellated geometries and their connections dictate the circulation between the spaces. The shape of each space is clear and legible. "What is noticeable are the lack of corridors. As Jonathan Sergison notes, "even circulation space was considered more as a room than a functional passageway" (Sergison 7). The Kapiti design proposal uses this cue, incorporating the main passageway at the spine of the building with a built-in wall museum. 


\section{BURIED BUILDING}

All of the programmes are buried underneath a newly shaped landscape (see figure 132). The form of the existing landscape is used to shape where the building bends and tapers off. The building doesn't become an obstacle in the landscape, but rather accentuates the existing dune lines and provides shelter at the front of the building.

The landscape is architecture. Users can walk up the ramp or take the stairs on the side. The roof is accessible as a green roof with vegetation and reflexology spaces with views out to the island and Paraparaumu beach. The rooftop becomes an extension of this existing park adding more activities to the shorefront.

As the building forms into its own figure, a referent becomes the landscape which it sits in. The landscape informs the design instead of becoming a representational symbol. The building operates in conjunction with the sand dunes as opposed to being designed to look like sand dunes. This principle of burying the building and working with the landscape becomes key in allowing the figure to work internally rather than externally. 


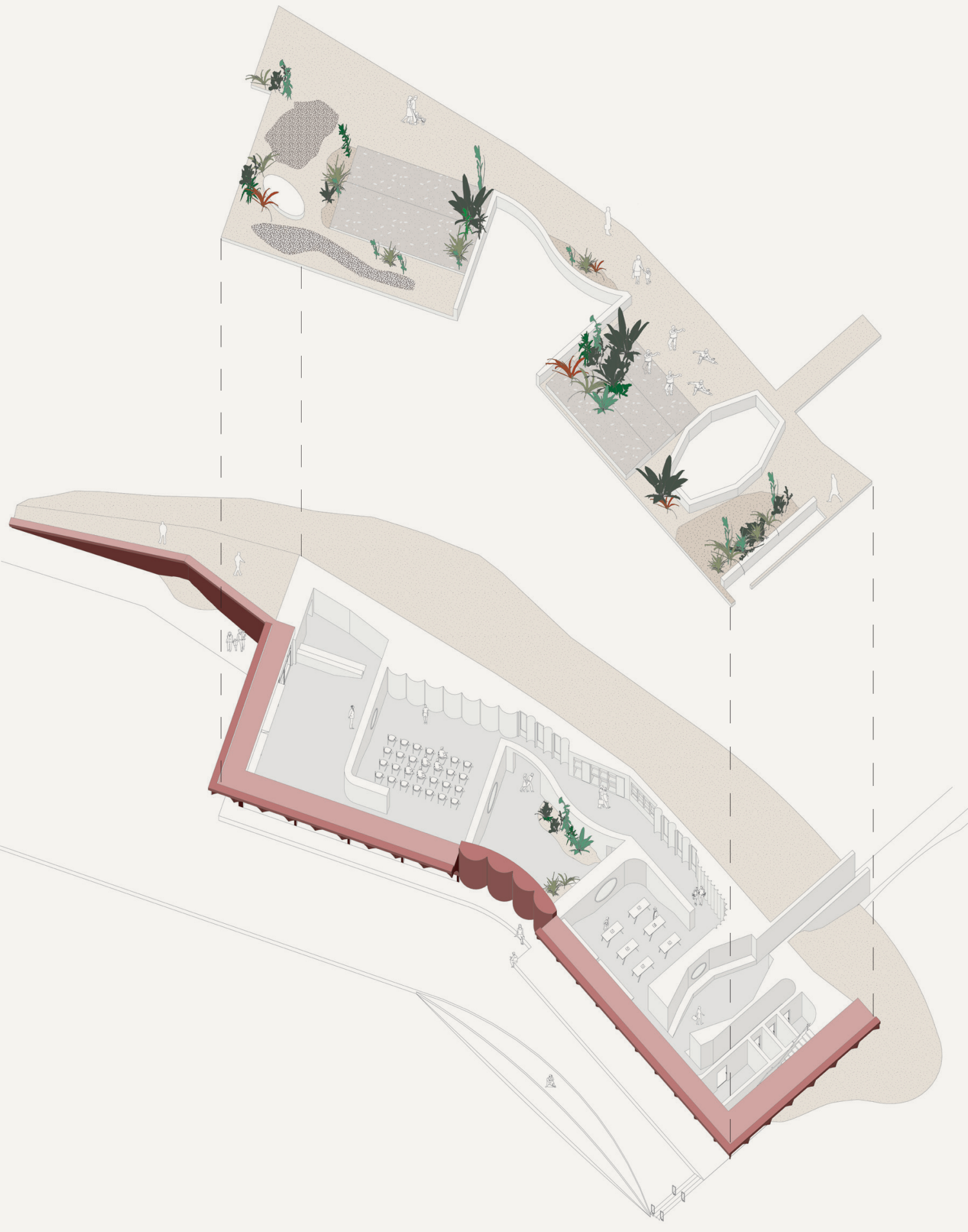


Art critic, Rosalind Krauss describes a shift in the understanding of sculptures and their conventional site or pedestal with the emergence of un-categorical sculptures in the 1960s. Krauss describes new categories in her adapted version of a Klein group (see figure 134). The diagram provides a different structure of possibilities in which a sculpture can be assimilated.

Robert Smithson's Partially Buried Woodshed (see figure 135) is an example which shares the same aspects to the design in Kapiti. It is an abandoned woodshed covered in dirt to be an earth sculpture and left to decay and just simply be; an illustration of entropy. In Krauss' diagram, it sits in between 'architecture' and 'landscape' or referenced as 'site construction'. 'Axiomatic structures' for example, sitting between 'architecture' and 'not-architecture' would feature works from Robert Irwin, Sol LeWitt, Bruce Nauman, Richard Serra and Christo (Krauss 41). Using this diagram is useful in understanding the relationship between the other fields exploring the possibilities of sculpture or figure not dictated by the conditions of a particular medium (Krauss 43). In this instance, the design in Kapiti also shares a crossover between landscape and architecture exposed to environmental factors using the dunes and newly added vegetation as the land to cover and create the figure (see figure 133).

$>$ Figure $133^{*}$

Cross-section through bio-security chamber showing relationship between rooftop park and ground floor 


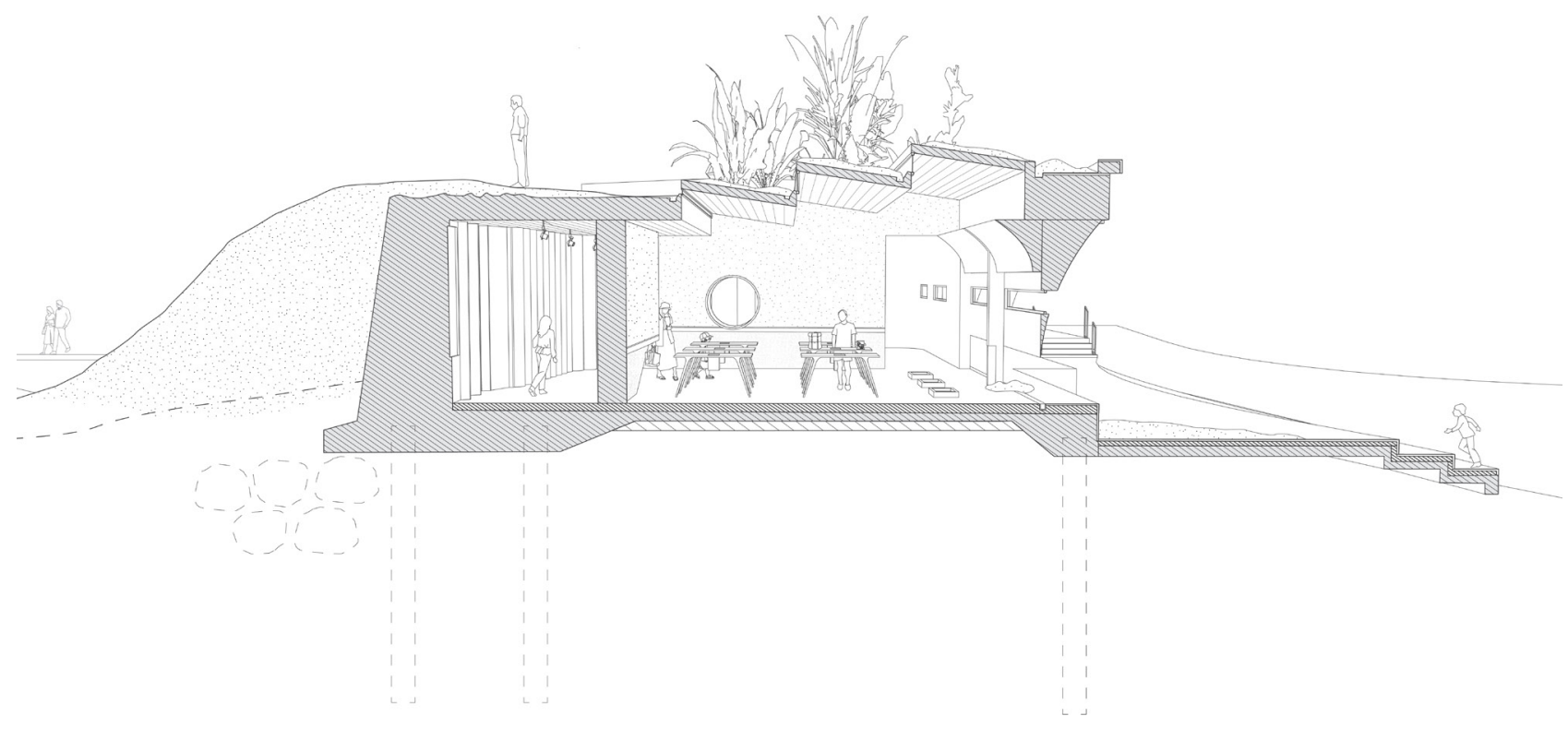


This building's relationship with the sand dunes can be seen in many other emerging contemporary buildings, which also mix architecture with landscape. To an extreme extent, Édouard François' Tower Flower in Paris with window planters arrayed on each floor of a residential tower (see figure 136), and Diller \& Scoffida’s New York Highline, which mixes existing infrastructure with green space, both express a desire for nature in the city. In New Zealand, too, there are opportunities to integrate the existing landscape with architecture to create a relationship between land and building. Nationally awardwinning buildings like Patterson Architect's Seascape Retreat (see figure 137) or Fearon Hay's Te Kaitaka or 'The Cloak' (see figure 4) are some examples.

Snøhetta's International Cave Art Centre in Lascaux, France (see figure 138) sits as an incision in the landscape, a horizontal fault that accentuates the line between the valley and the hill. "The form and materiality of the museum have a monolithic, sober expression, speaking to the surrounding nature and the massive rock formations embedded in the hill, with a new public, agricultural landscape unfolding around it" (Snøhetta). In a similar manner, the design in Kapiti looks to encompass the use of the sand dunes with the existing MacLean Park, offering a new public space as well as reconnecting users with the shorefront. This integration becomes a destination or a node in the park where visitors can gather and enjoy the newly provided shelter and added amenities. 


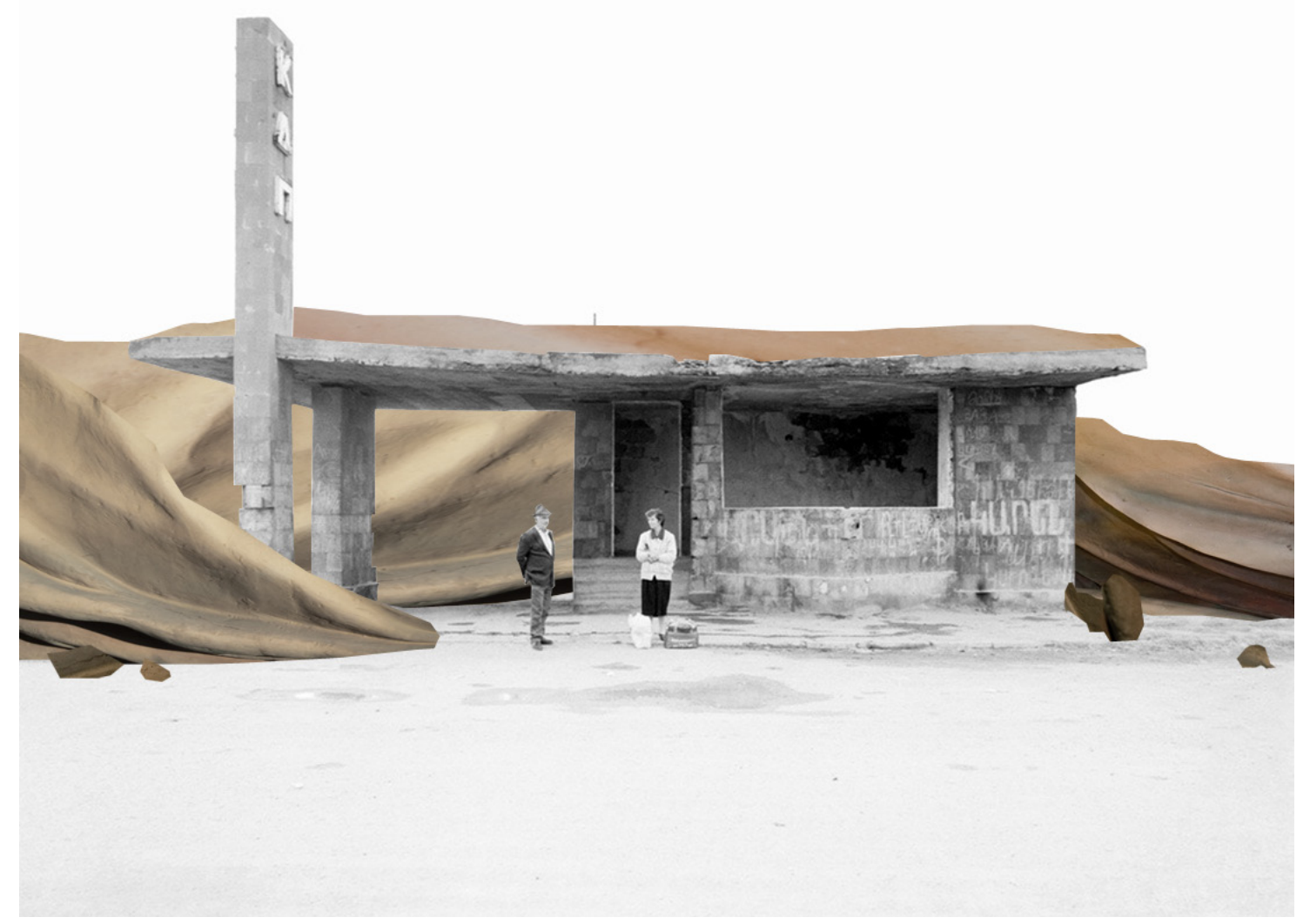

Figure 139

Drawing one

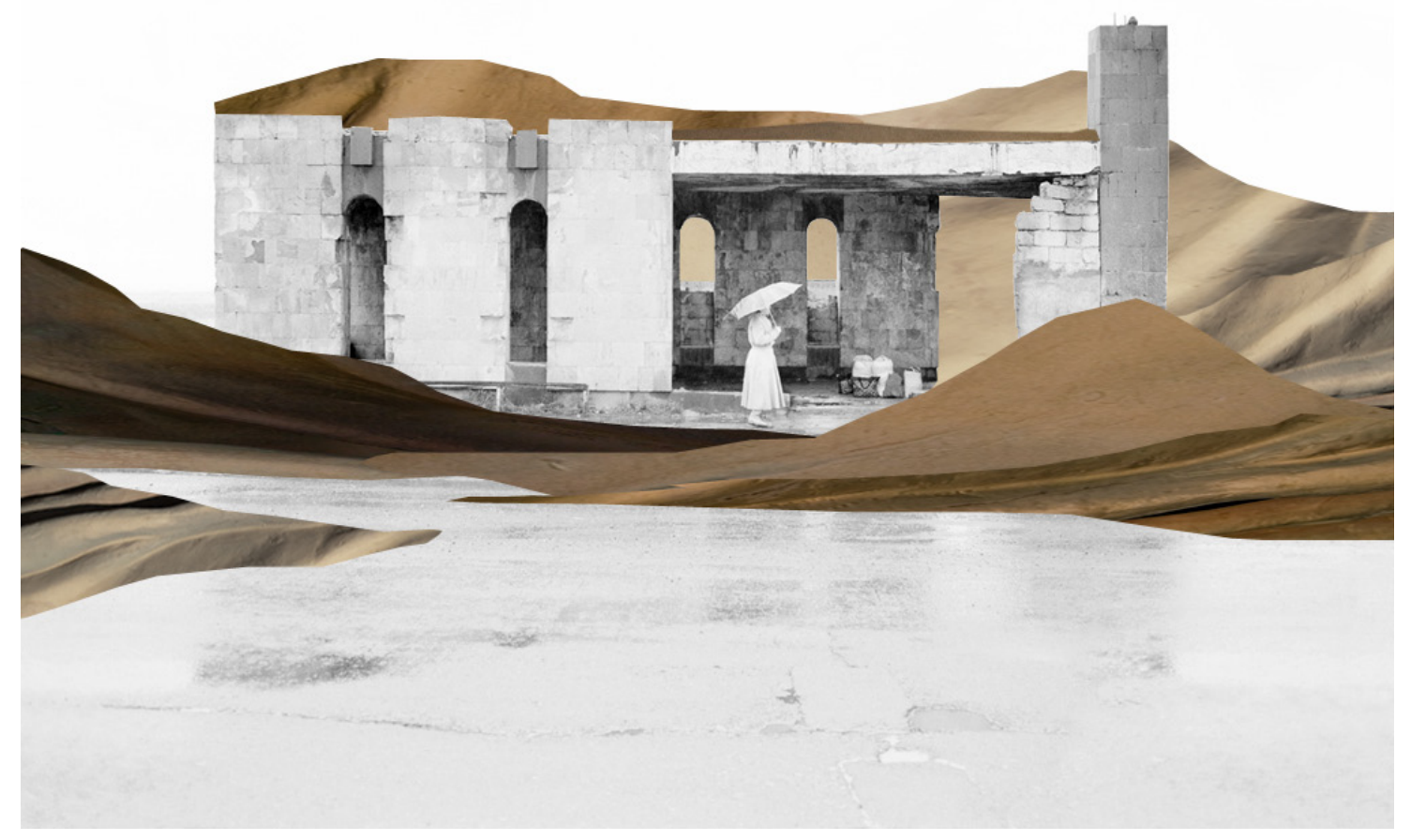

Figure 140

Drawing two 


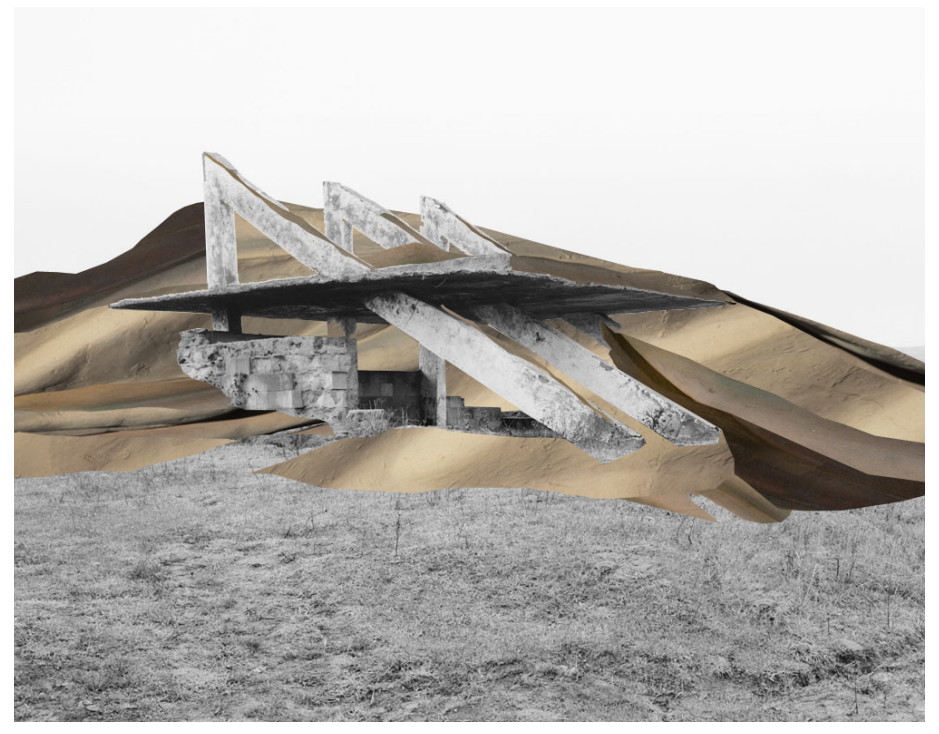

Figure 141

Drawing three

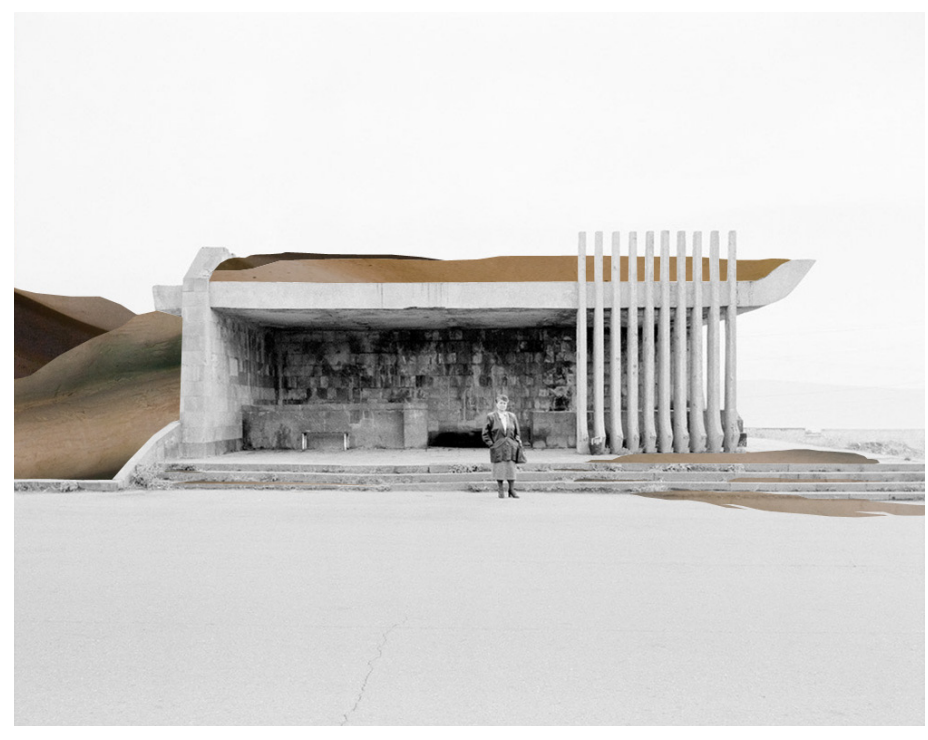

Figure 142

Drawing four

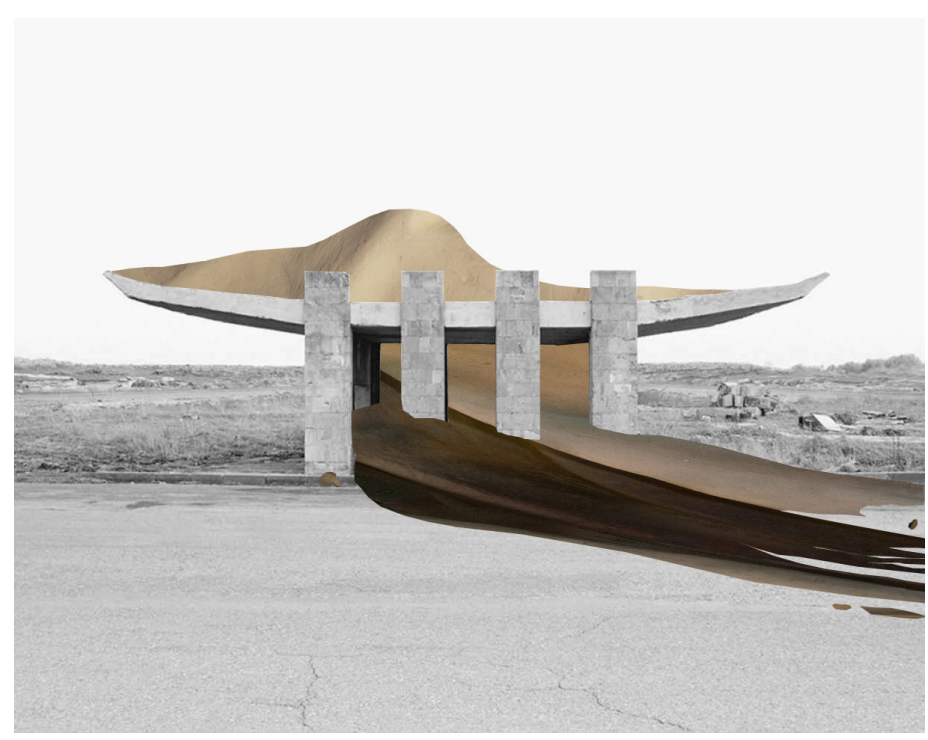

Figure 143

Drawing five 
There is also a temporal aspect to the use and function of the building. With climate change and frequent storms the sand dunes will build up and then get washed away revealing and exposing parts of the building form buried underneath. The building only operates during fine weather when visits to Kapiti Island can occur. When storms have passed, the sand blown around and fallen through down inside the internal courtyard of the building can be swept and cleaned out using the gap under the façade. By not being fully shut and waterproof this is a stance the design takes in accepting and succumbing to superior forces. The choice of concrete, 'bunkering' down and lack of exposed glass is part of this design strategy. The building takes the approach to endure than to outright resist.

The previous page depicts some visualisations using Ursula Schulz-Dorunburg's Armenian Bus Stops taken from 1997-2001 (see figures 139-143). These drawings try and capture the bus stop structures being engulfed yet still intact and operational. This temporal aspect using the sand dunes as a visual reminder and illustration of entropy is very much like Smithson's buried woodshed. This poetic aspect to the design highlights movement, time and decay. 

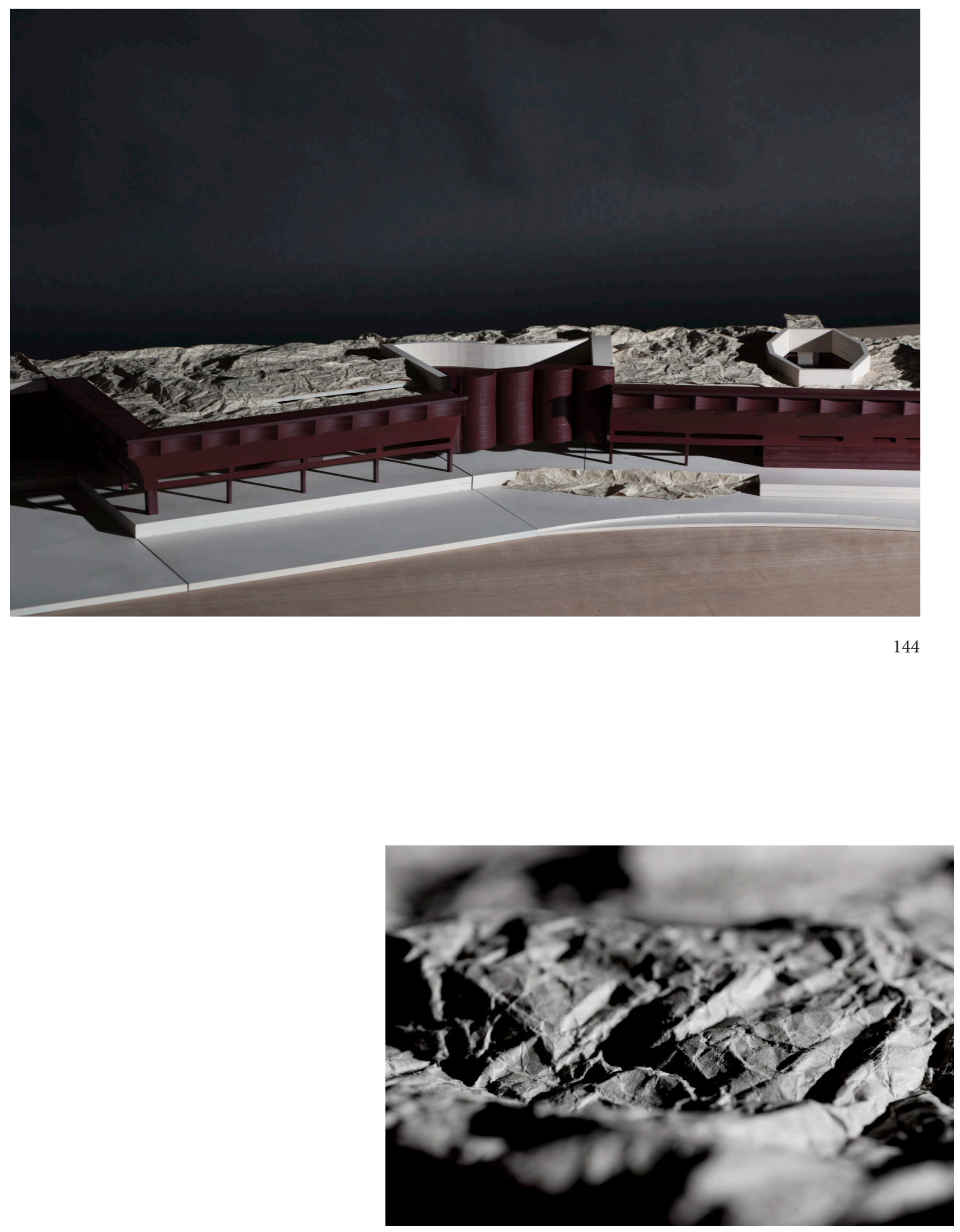
War can be seen as the mother of invention. "Invention does not consist in creating out of void, but out of chaos" (Shelley). The typology of the bunker as a war-made creation is now adopted to 'fight' the landscape- with the sea level rising, burying and bunkering down will reinforce the coastline. This design, taking up the bunker typology, acts as a precursor for other models to be established on the coastline of Kapiti (see figure 147). These structures will range in scale and size, consisting of different programmes all working to endure and react to the changing environment. 


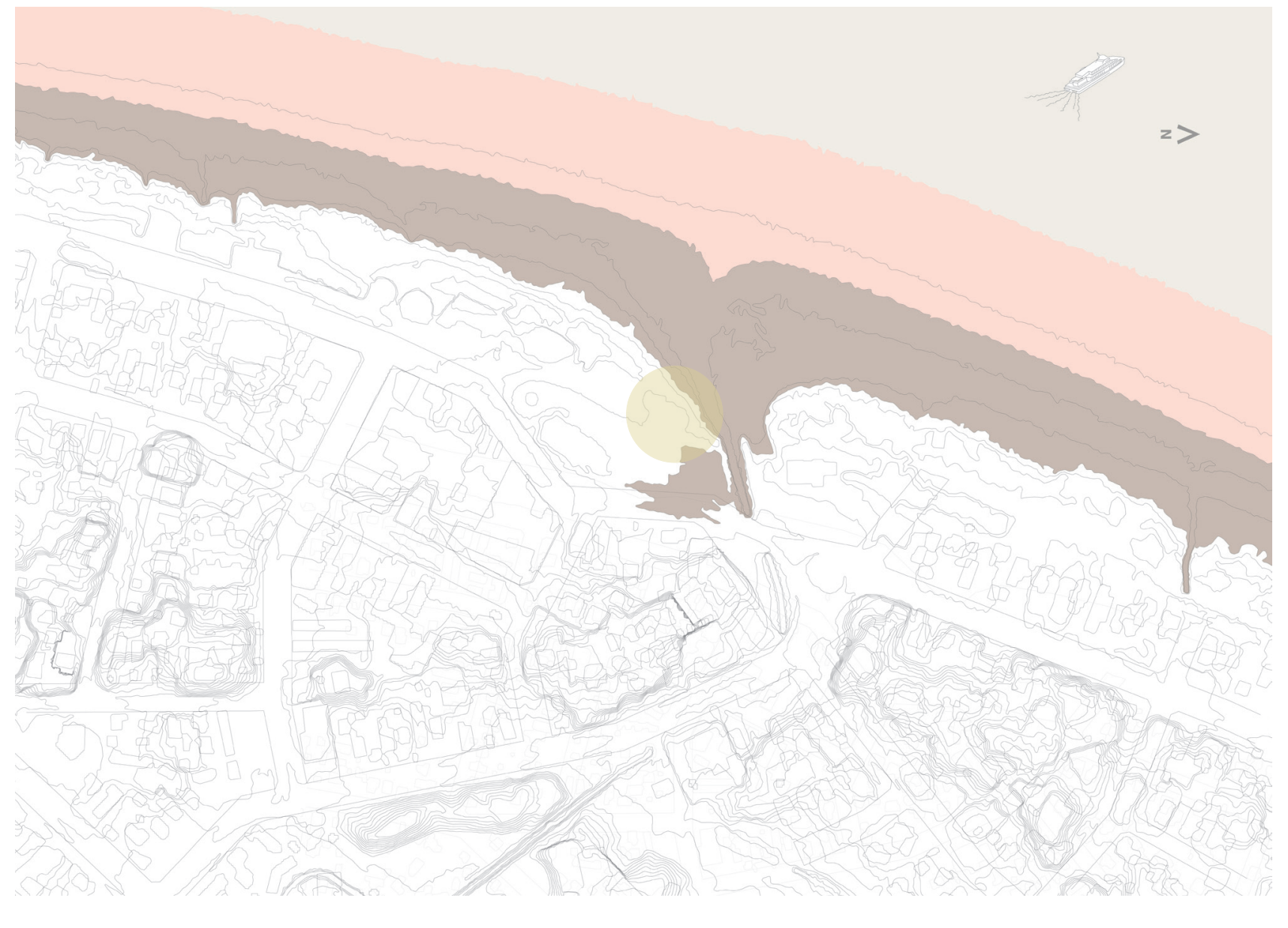




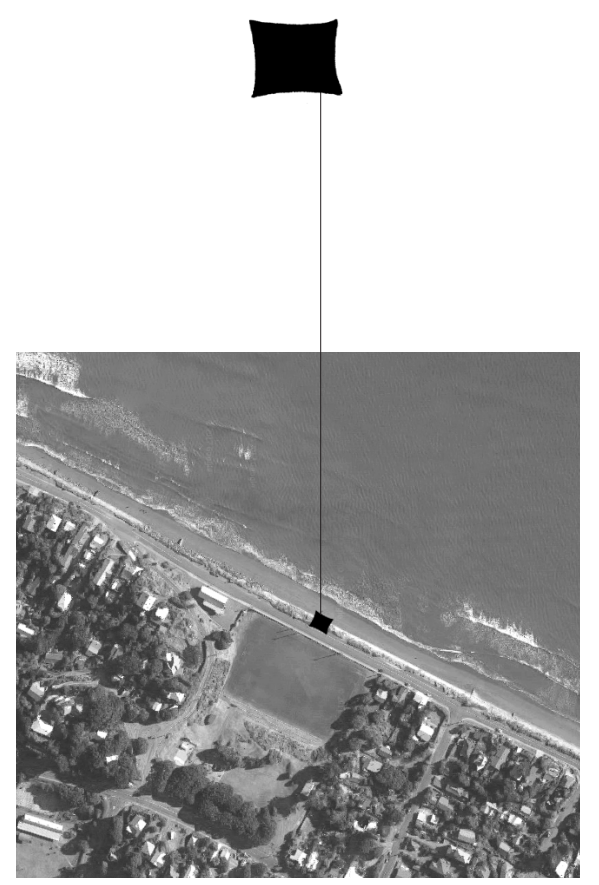

Paekakariki Memorial Hall

- Sculptural /

Memorial Extension

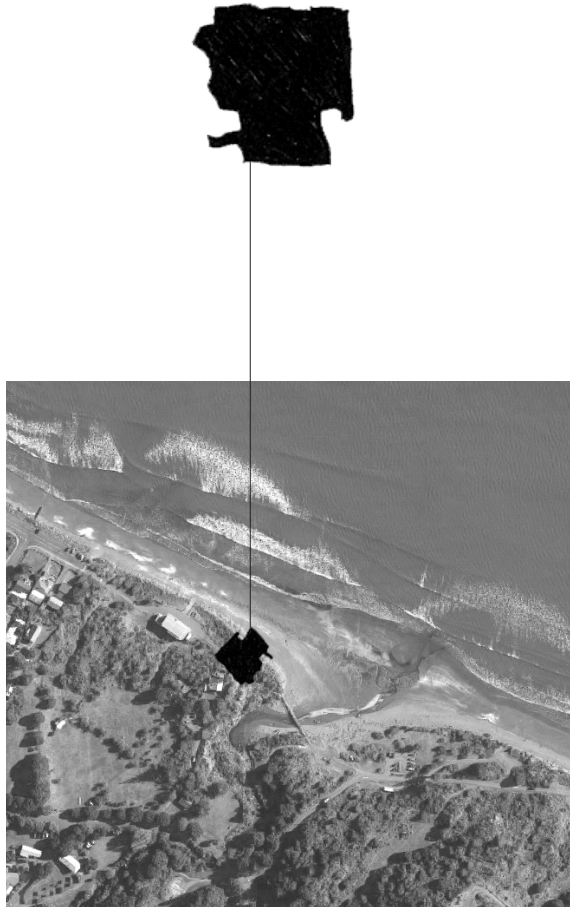

Paekakariki Surf Lifesaving Club

- Changing rooms, function space or clubrooms

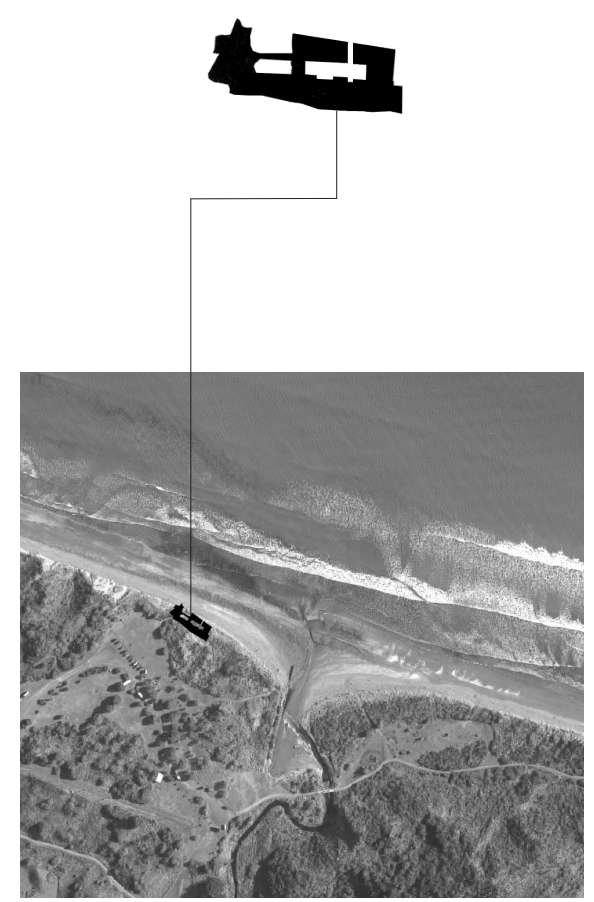

Queen Elizabeth Park

- Reflexology park (going through bunker)

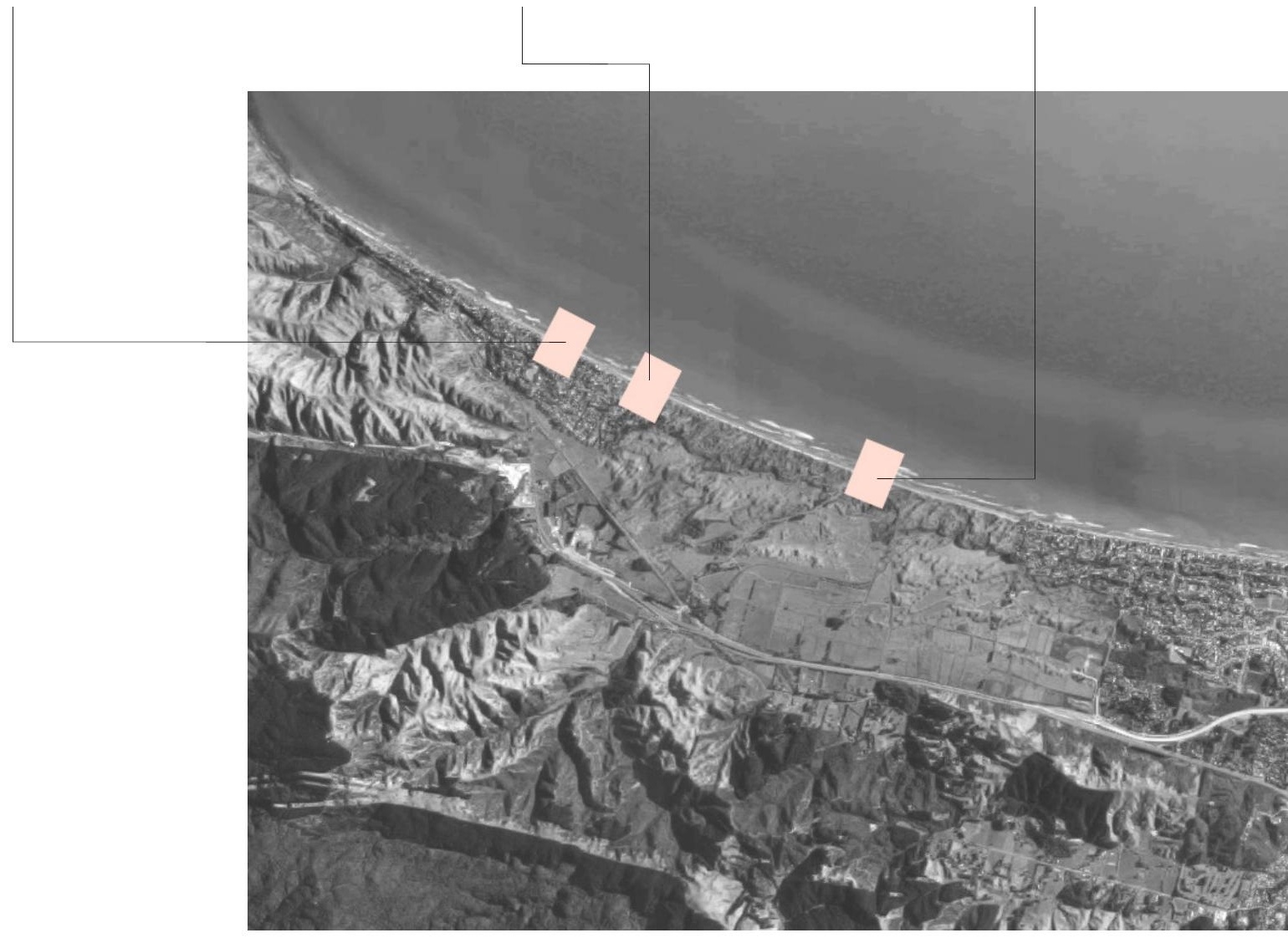




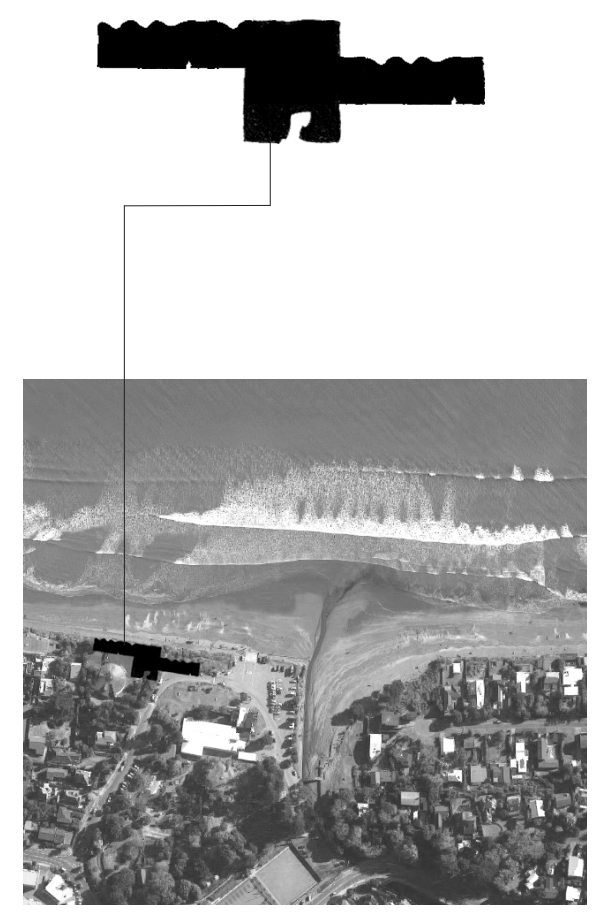

Raumati Beach

- Changing rooms, cafe, function space

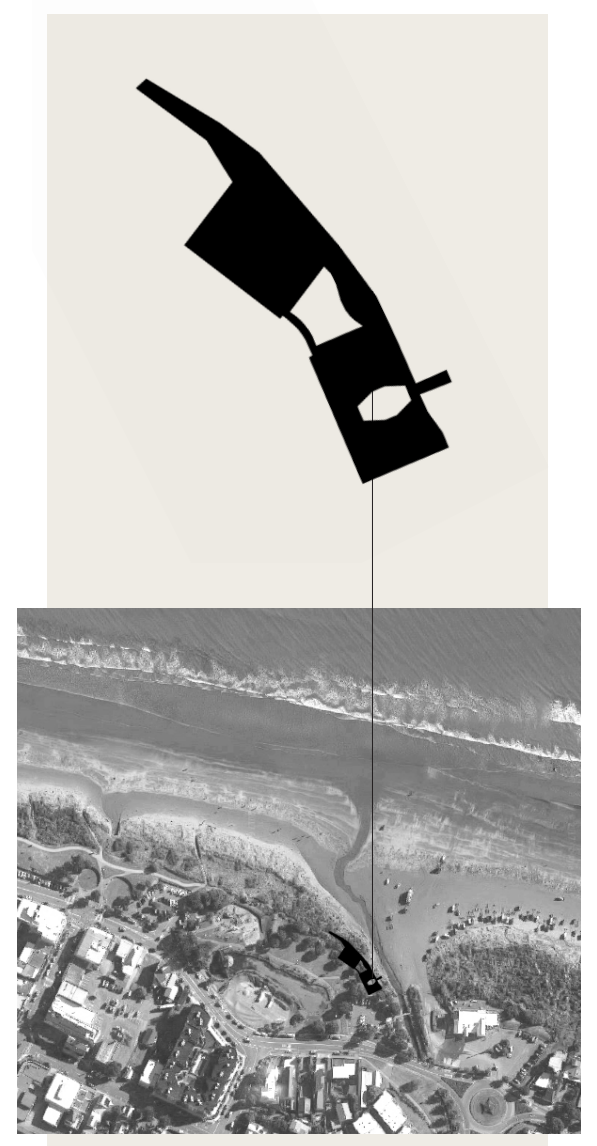

Paraparaumu Beach

- Bio-security, Kapiti Tour Guide $\&$ DOC offices \& mini-museum

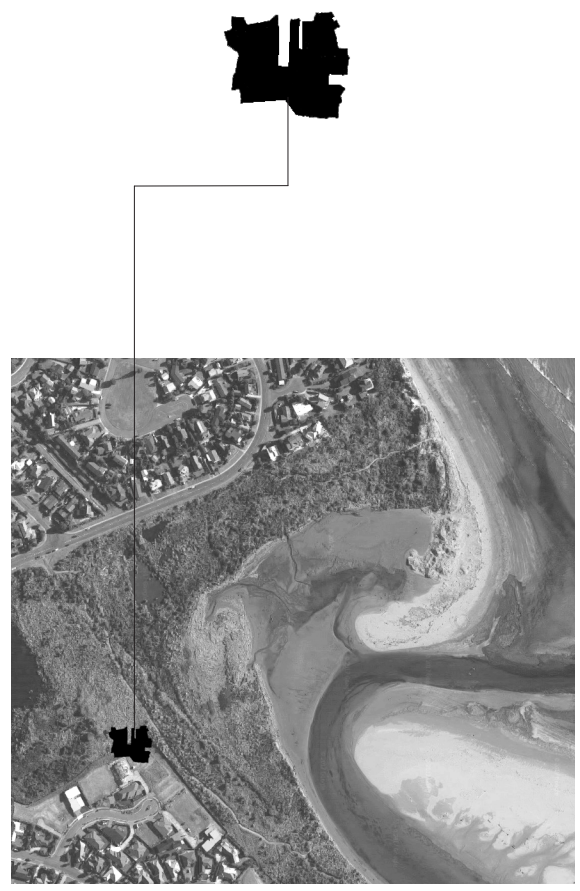

Waikanae Estuary Scientific Reserve

- Science research offices (DOC) 


\section{CLEAN FORM}

"We don't expect films, novels, sculptures or paintings to be pretty, so why should we expect buildings to be pretty? There are other qualities we seek."

Jonathan Meades.

Bunkers can be perceived as bulky and raw in their concrete form, as well as being inelegant. The design takes up the characteristics of the bunker, but alters the aesthetic impression with a 'clean' formed façade facing the park. The 'clean' form is generated through the process of initial experimentation, producing five iterations (see figure 148). These tests tease out a different series of shapes and forms built up of motifs and different compositions of ornamentation. These experiments use repetition and continuity to break down the long 40 metre façade which faces the park. Each iteration explores the entryway, the lightness or heaviness of the colonnade, the shading, aperture sizing and also internal light shafts that penetrate through from the buried roof (see figure 150). Each experiment in the drawing of cross-section looks at the relationship between the façade and the building's interiority. There are opaque compositions pointing inwards or heavier compositions pointing outward and away.

At this stage, it became apparent that these experiments were being produced based on the synthesis of different sources like Valerio Olgiati, Christian Kerez, Caruso St John and Sergison Bates. This synthesis of sources was an experiment in whether these iterations could be designed without looking solely at referential images and aesthetics, and instead at a different understanding of the precedent: materiality, scale, light, hierarchy and form. Previous experiments were derived from Hejduk caricatures; this set now looks at a different curation of sources and their play with types of motifs, typologies and disciplinary conventions. 

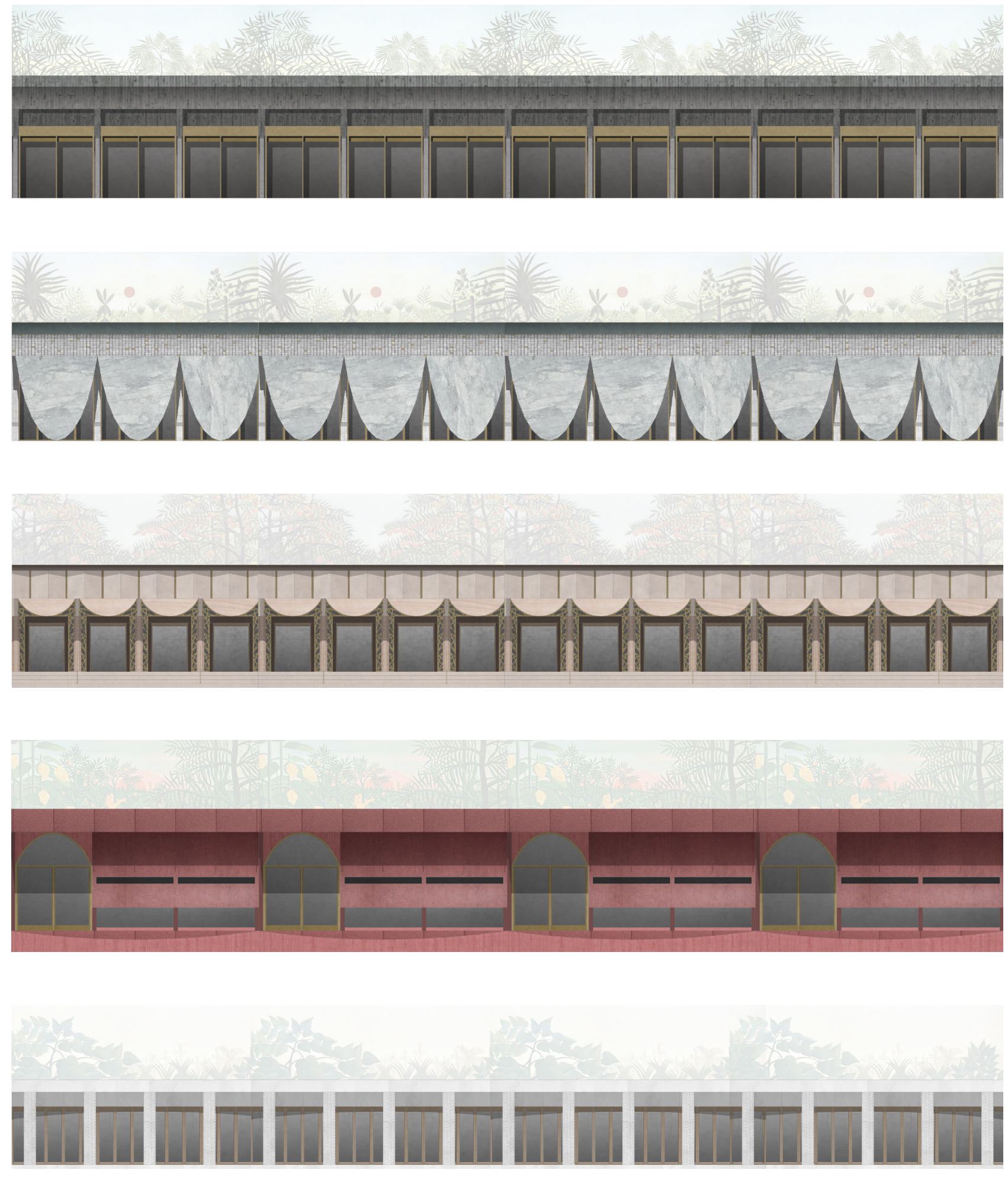


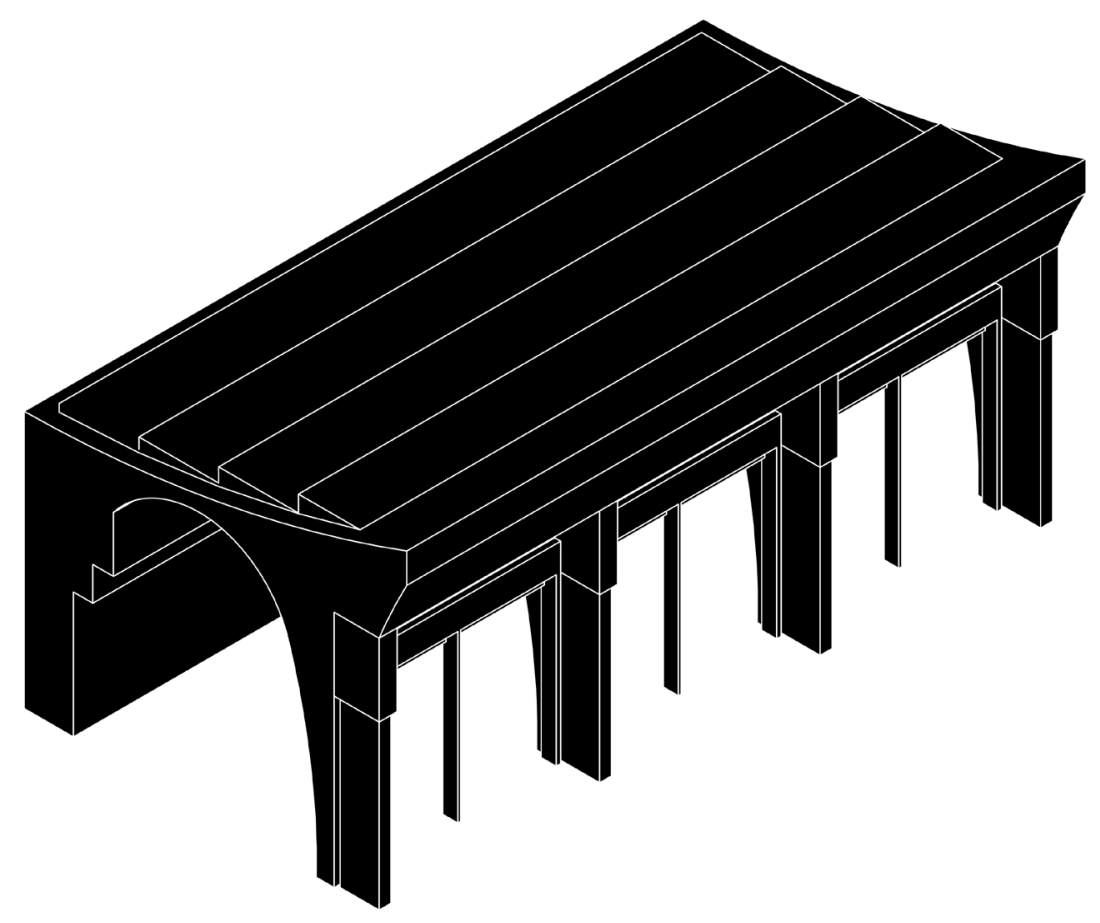

Axonometric

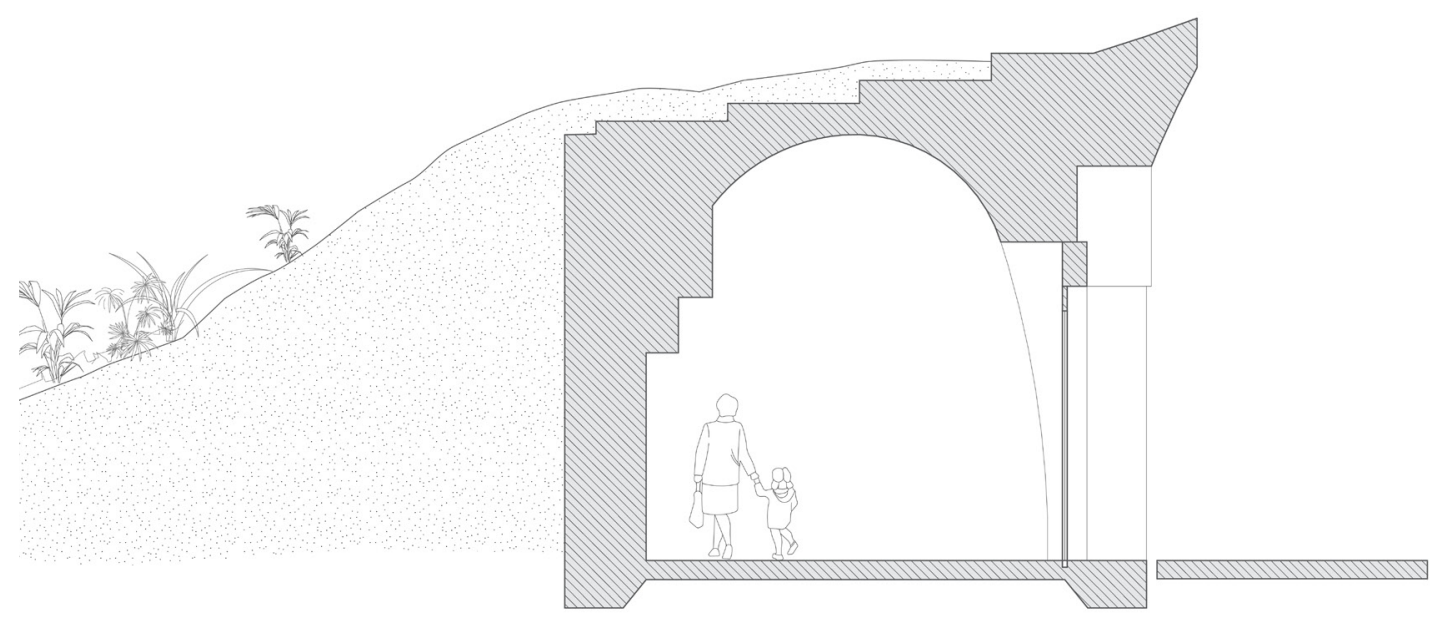

Cross-section 


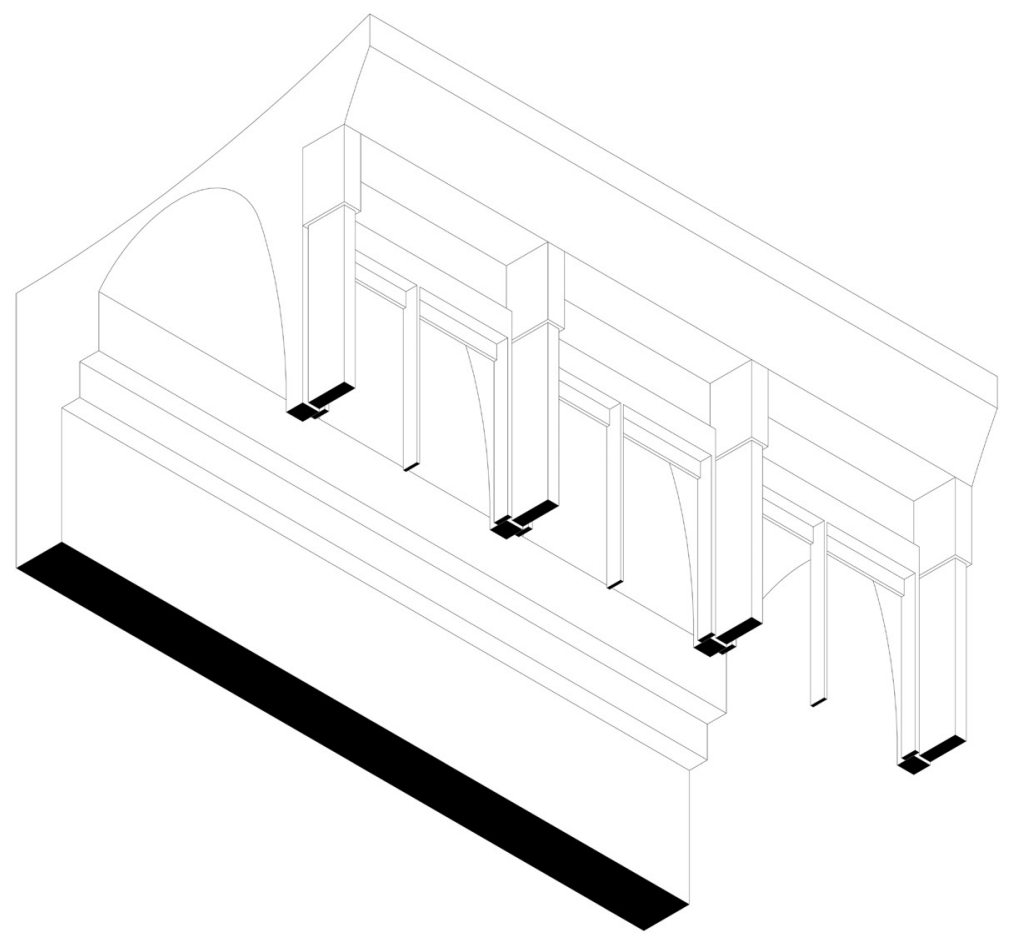

Wormseye Axonometric

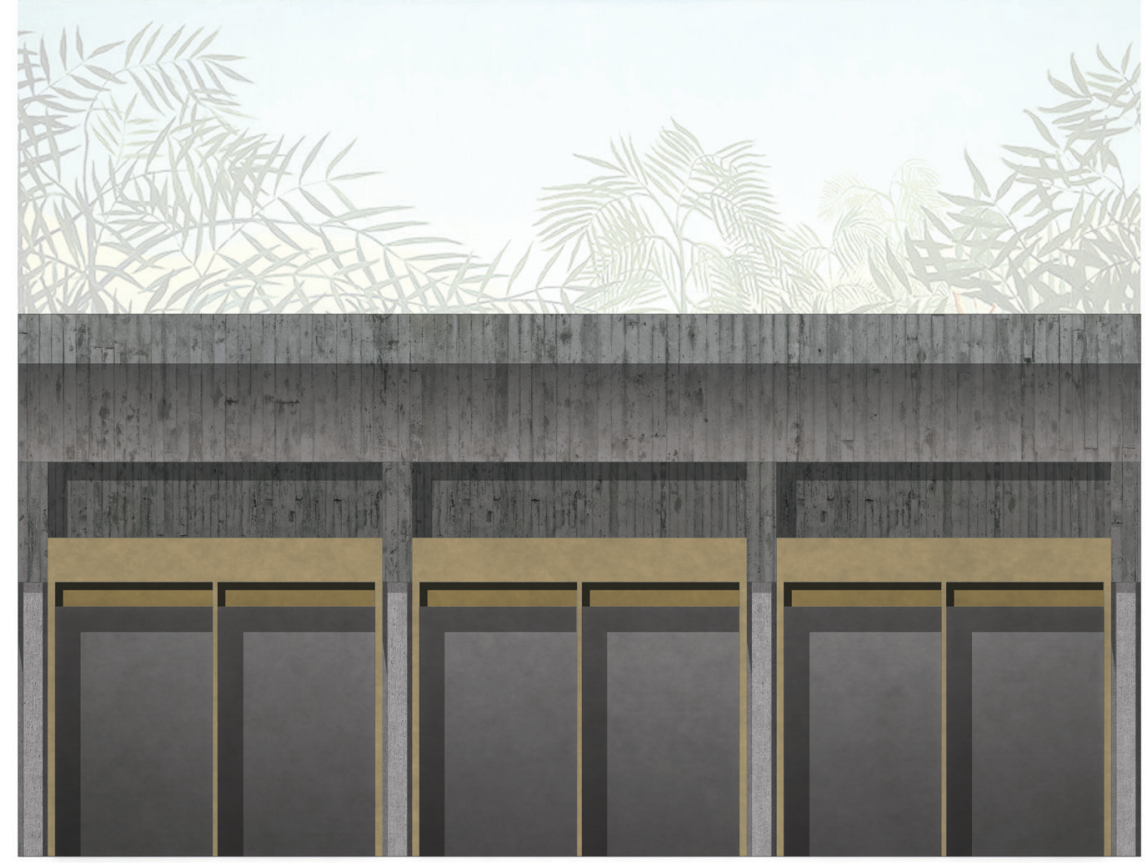

Elevation 


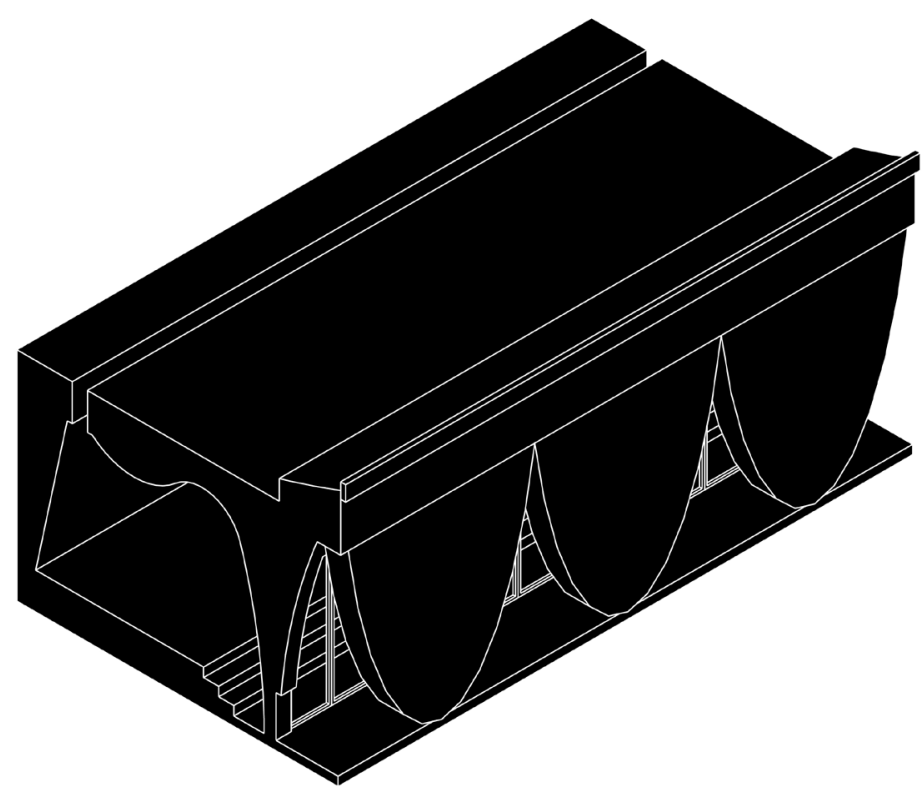

Axonometric

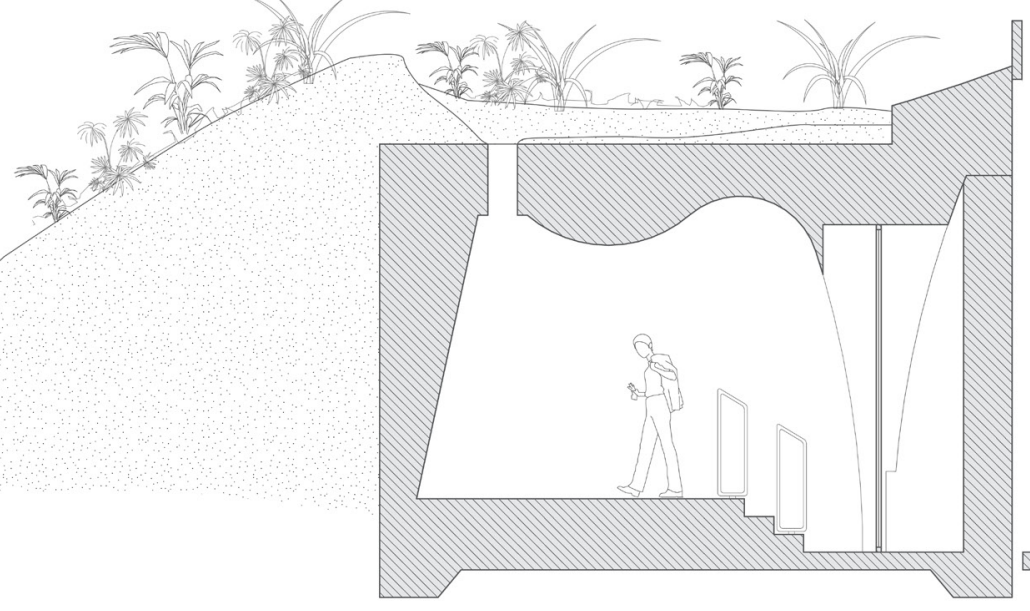

Cross-section 


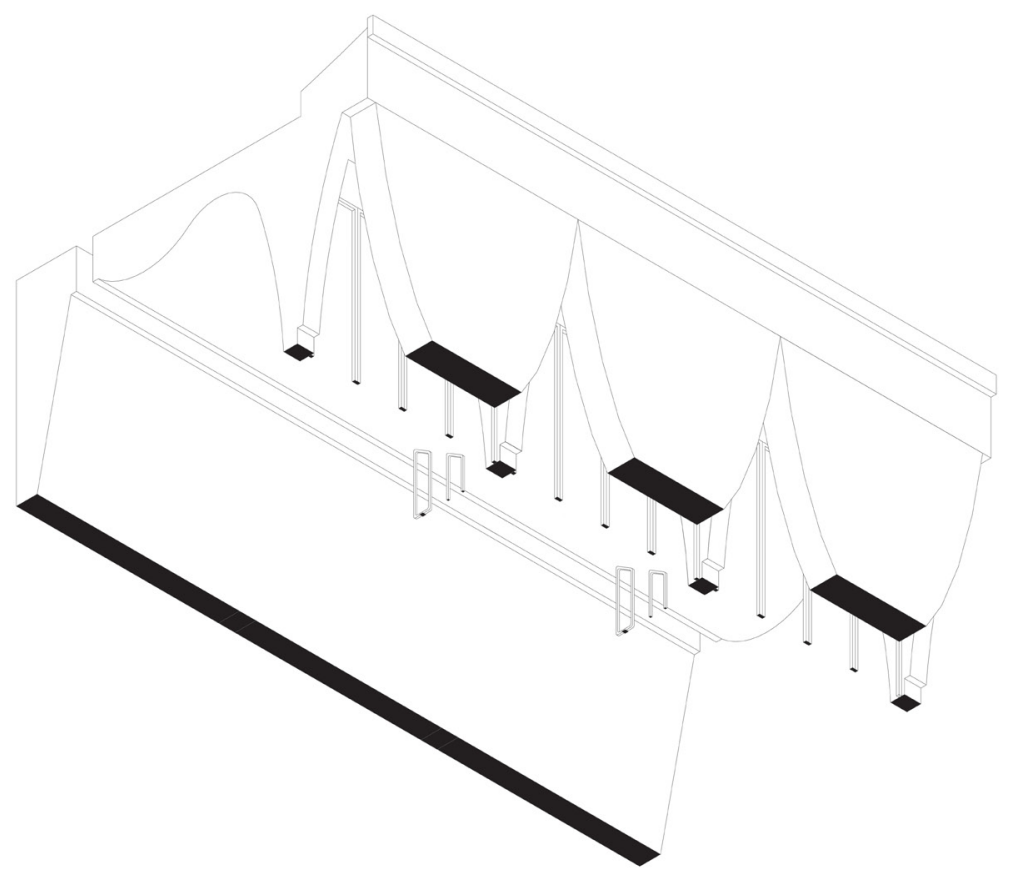

Wormseye Axonometric

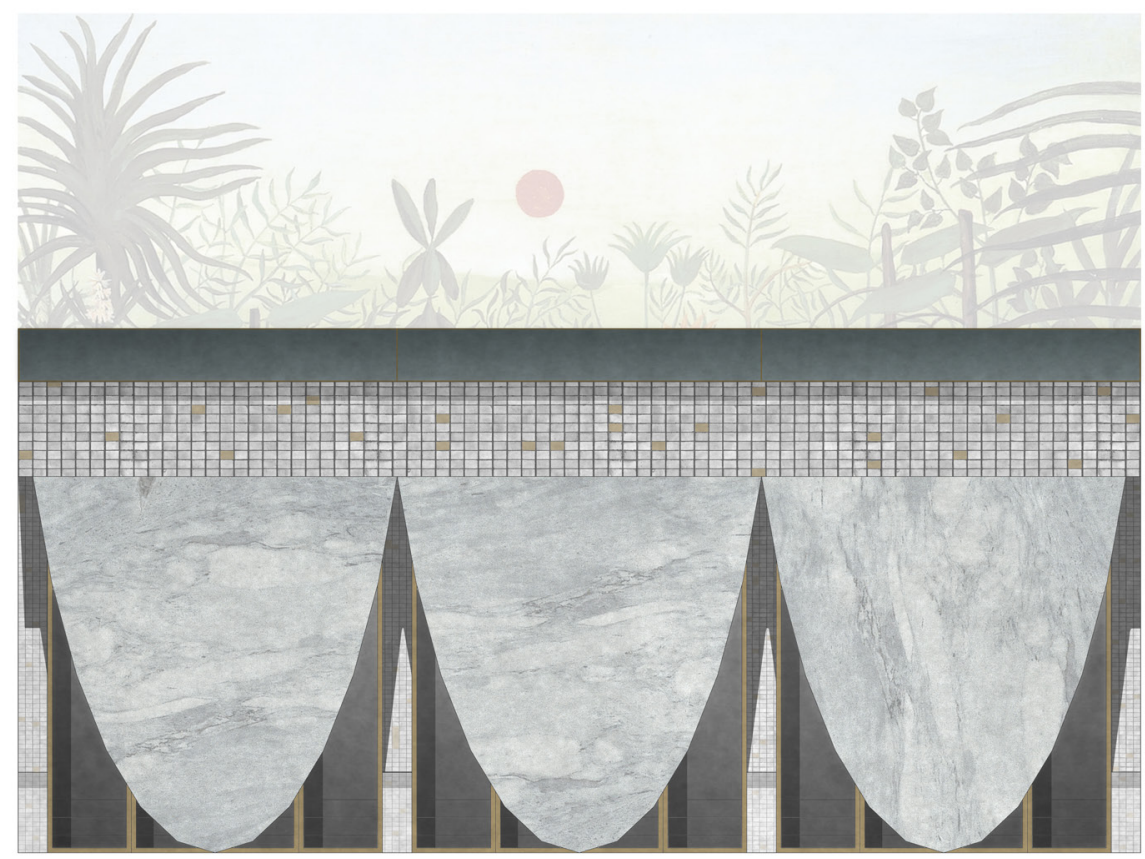

Elevation 


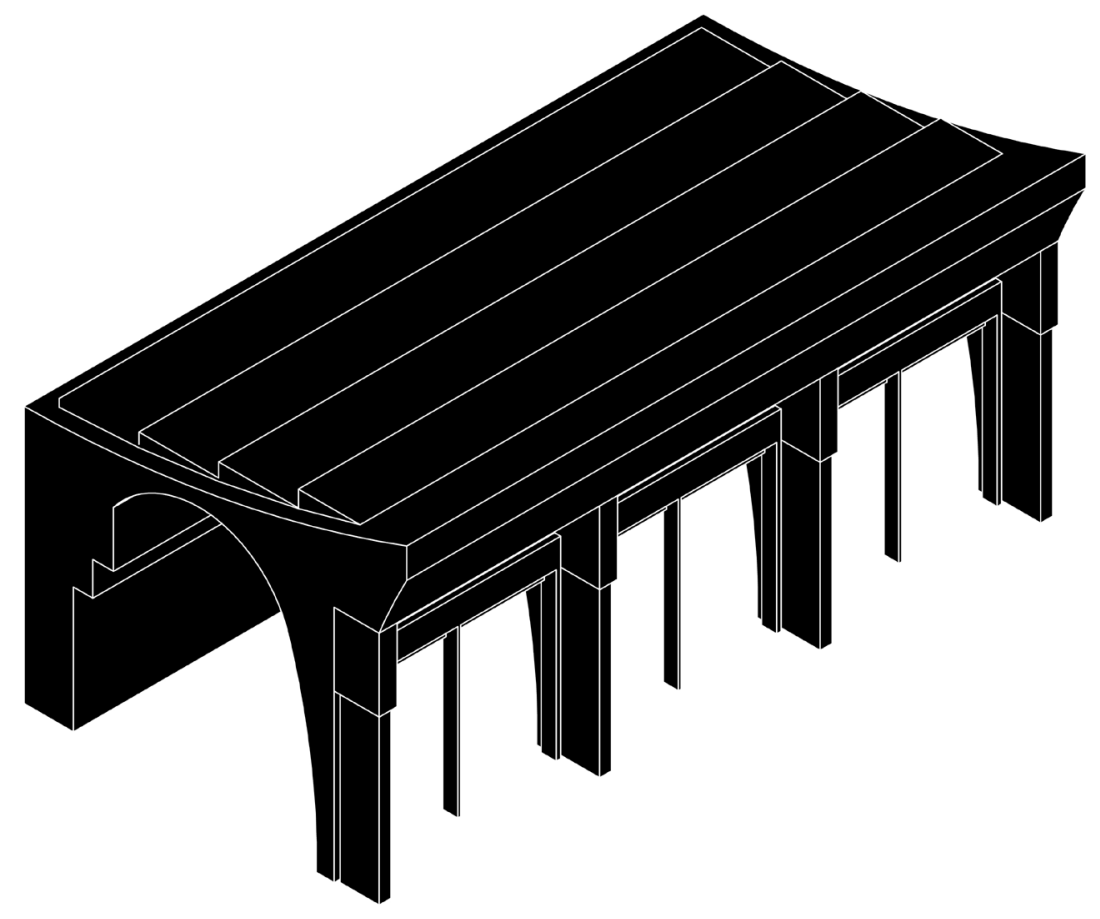

Axonometric

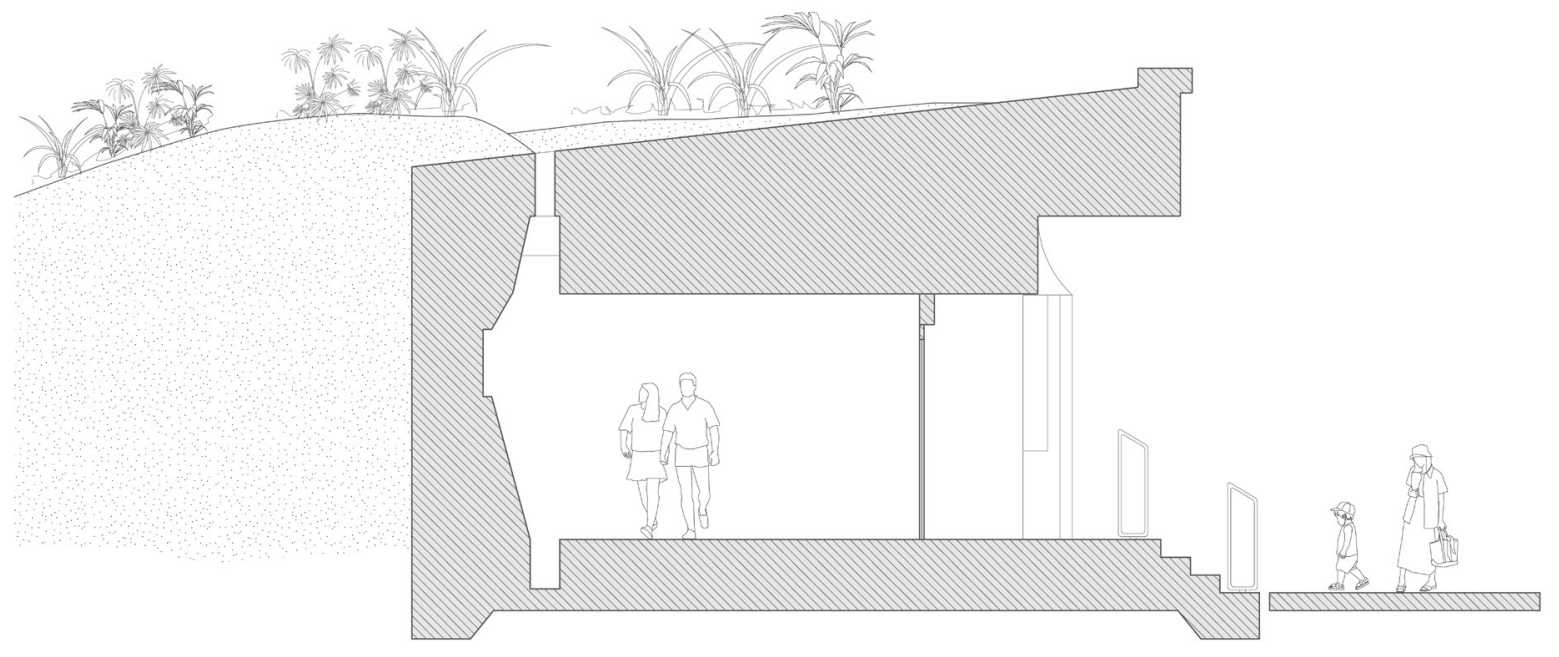

Cross-section 


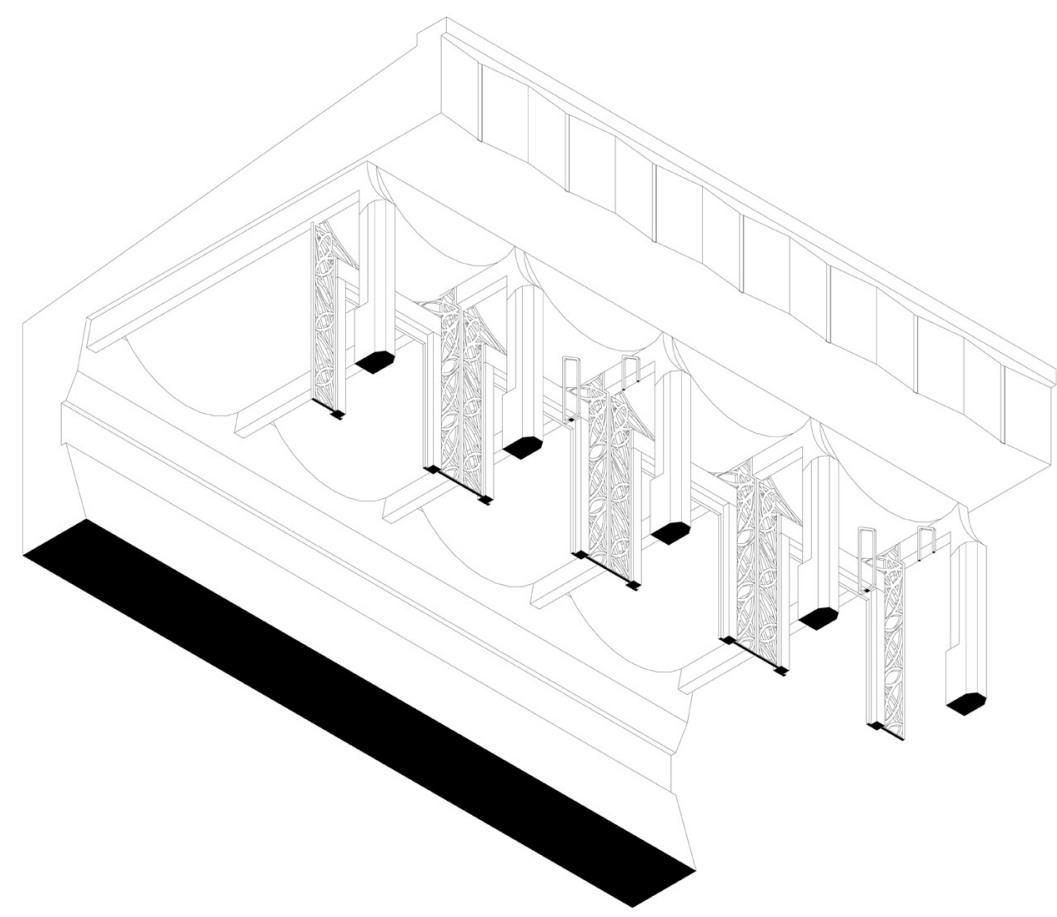

Wormseye Axonometric

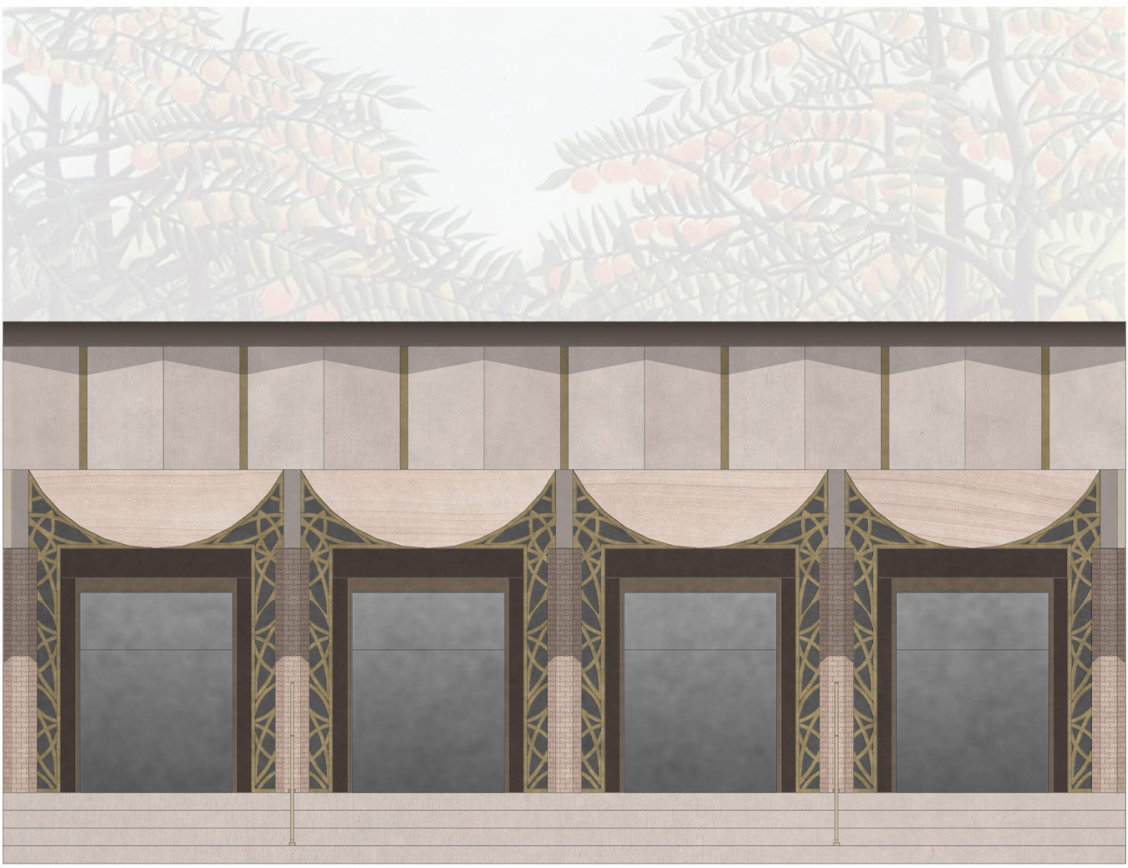

Elevation 


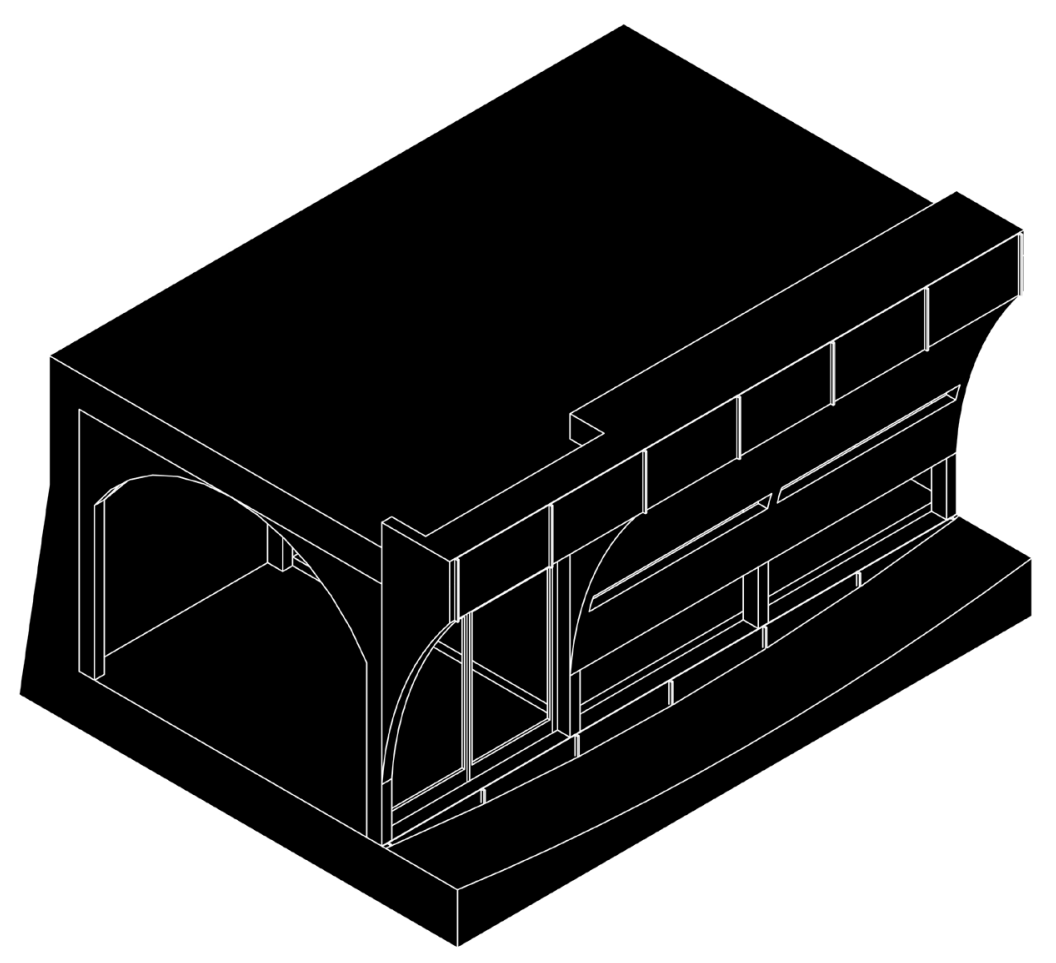

Axonometric

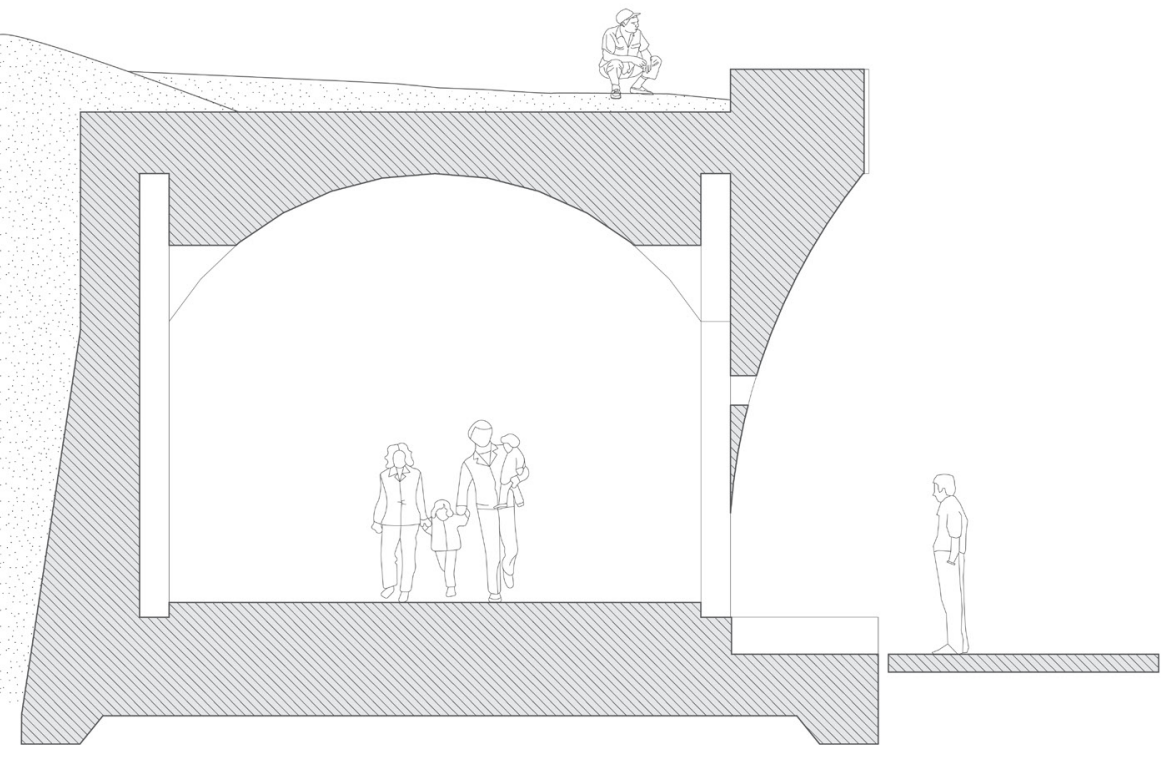

Cross-section 


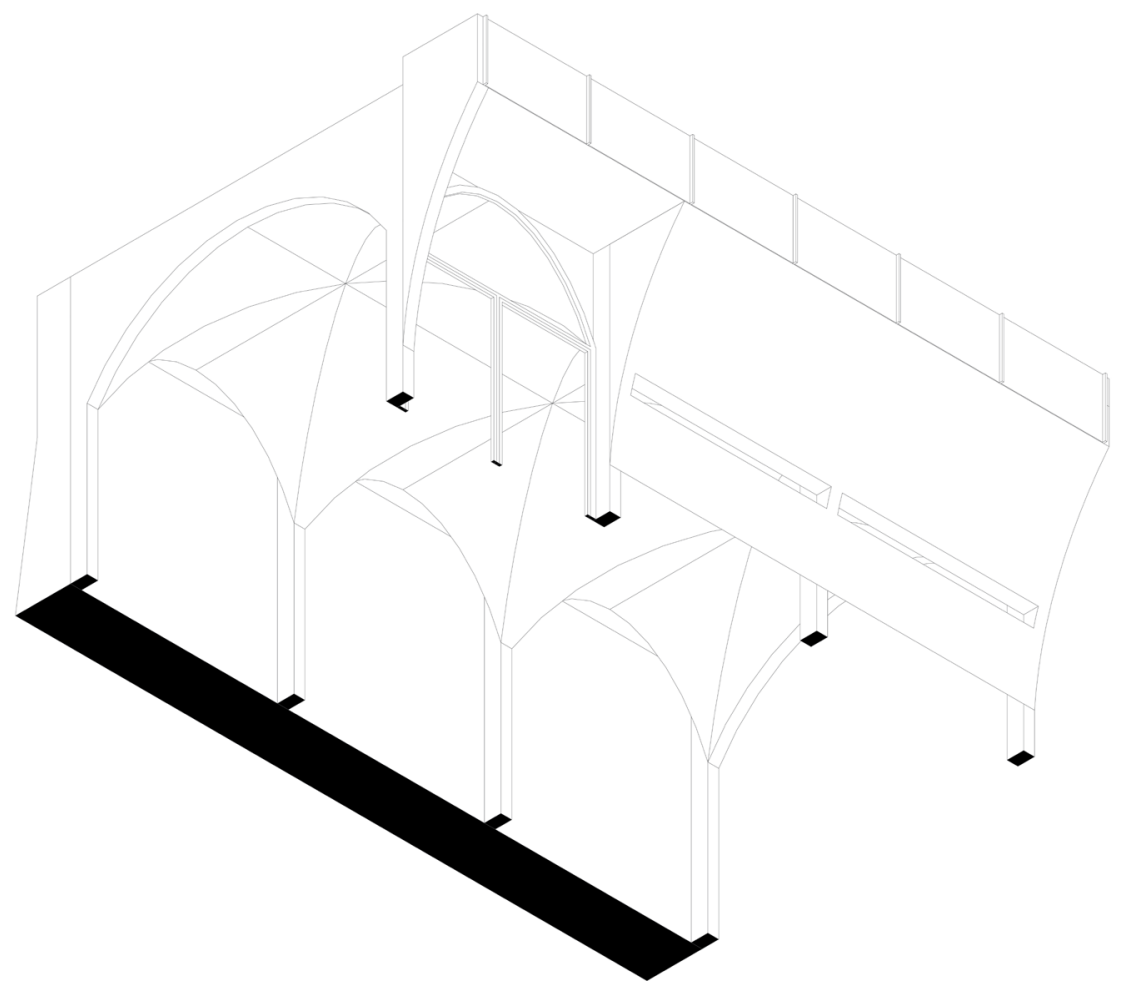

Wormseye Axonometric

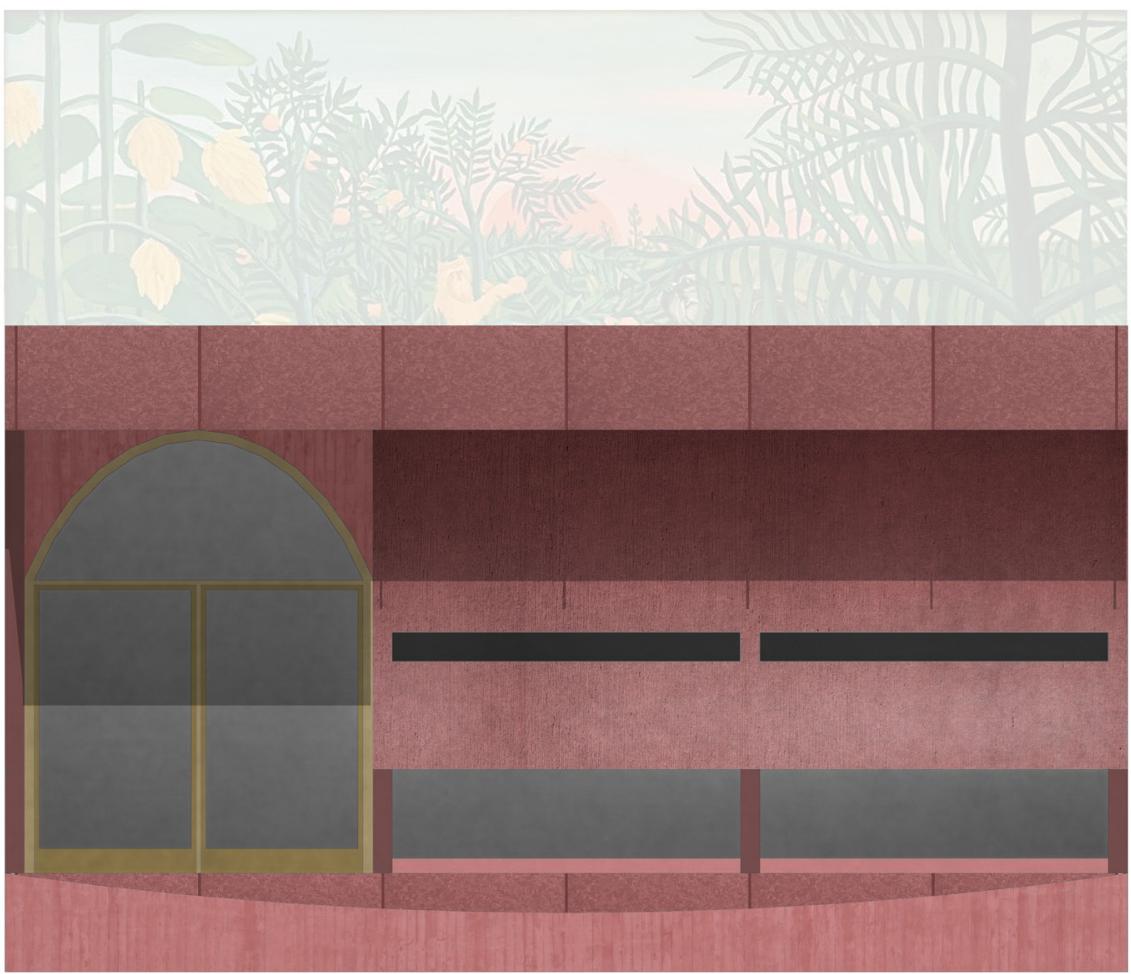

Elevation 


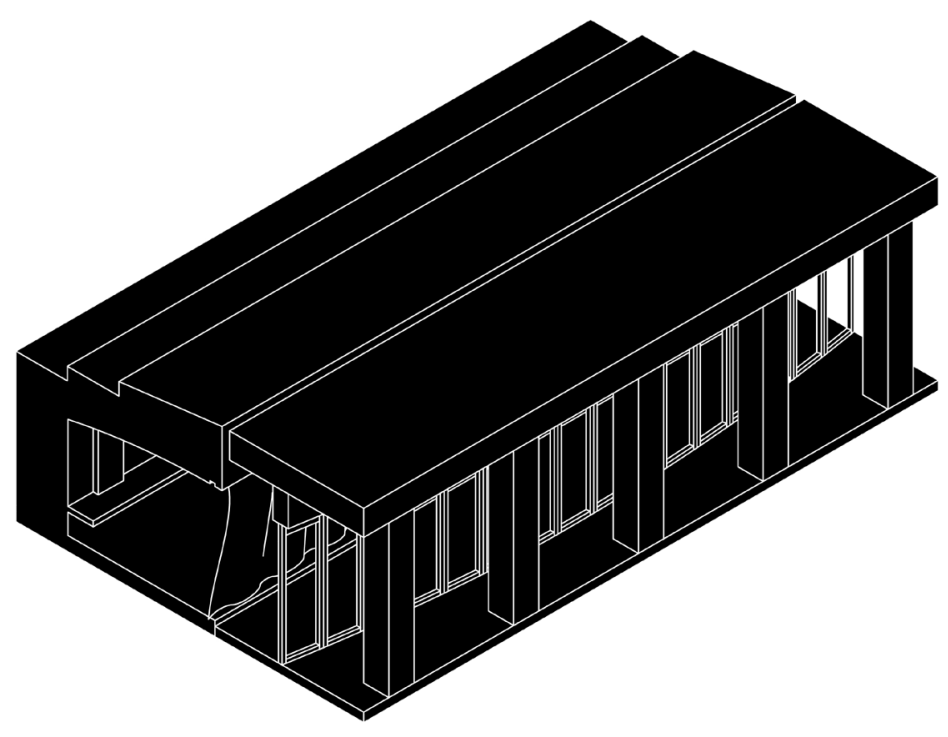

Axonometric

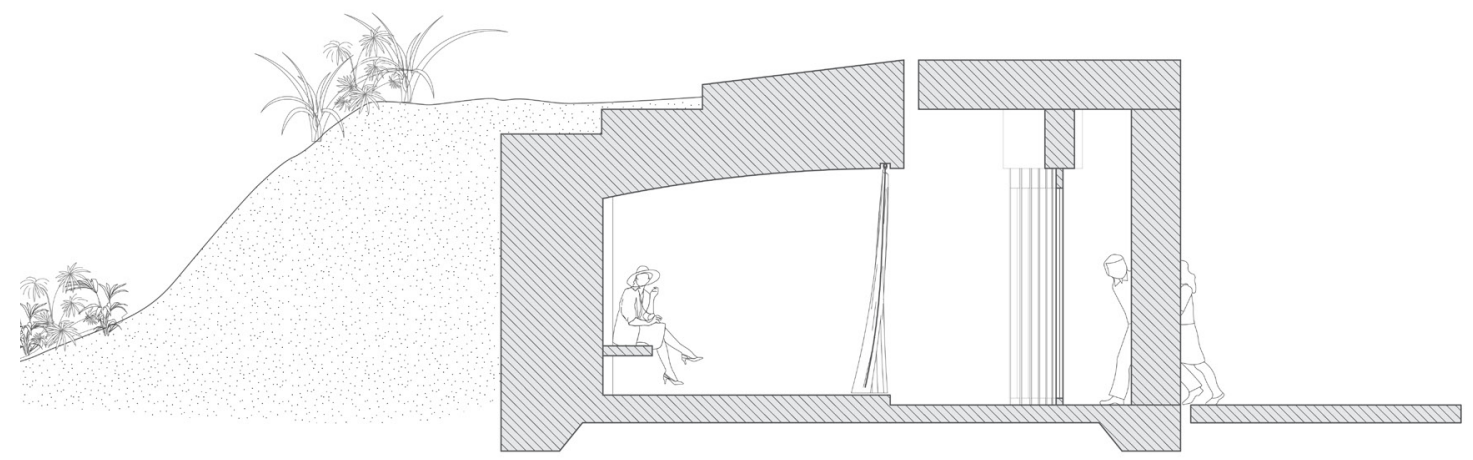

Cross-section 


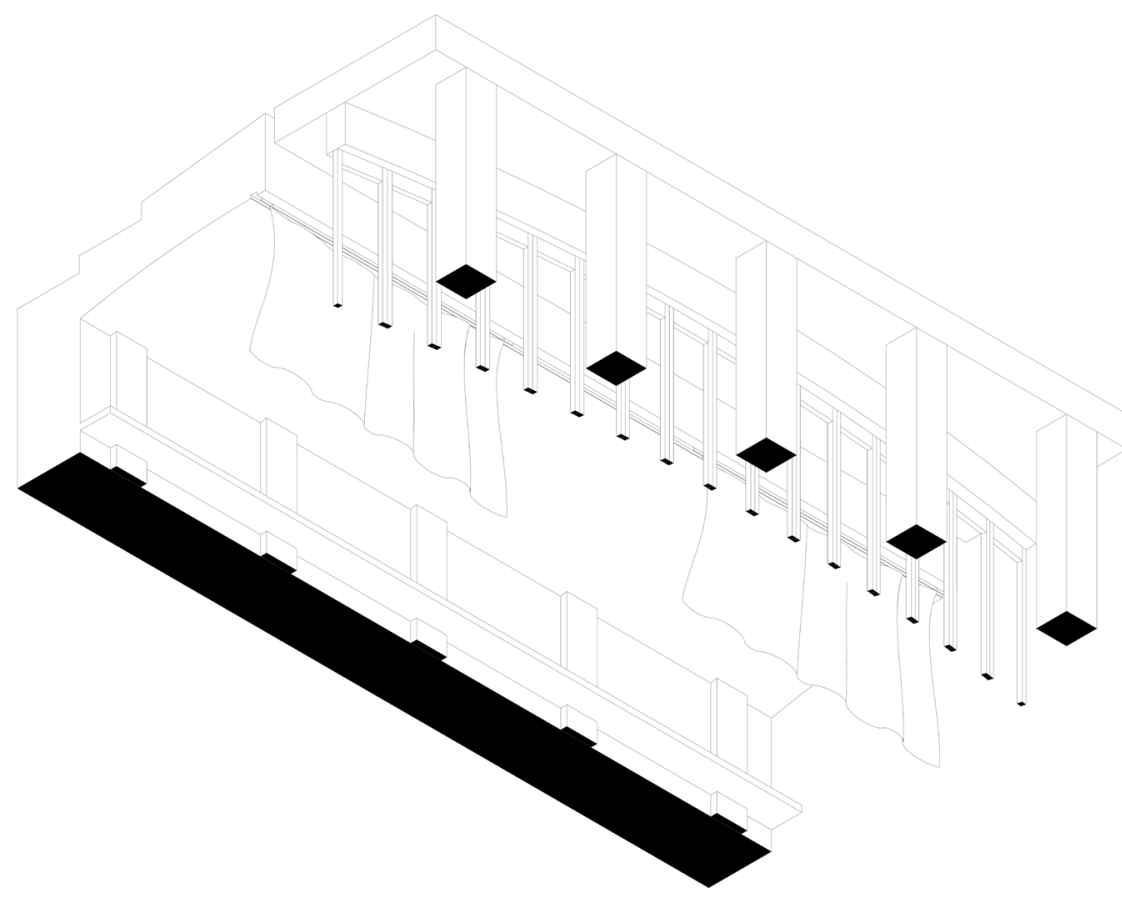

Wormseye Axonometric

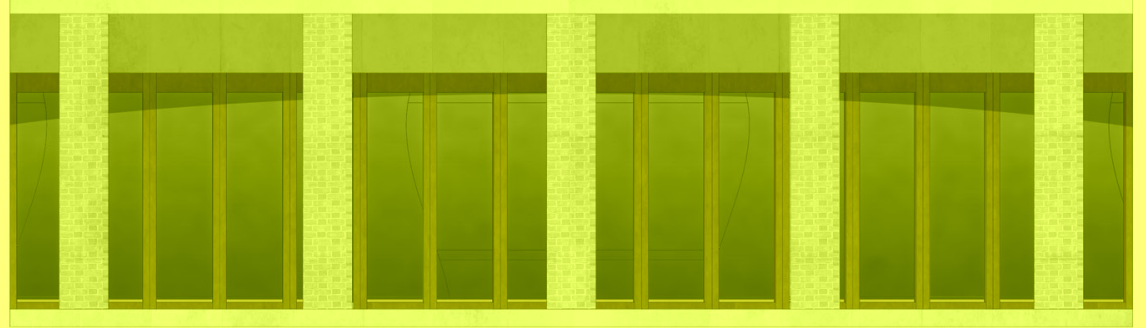




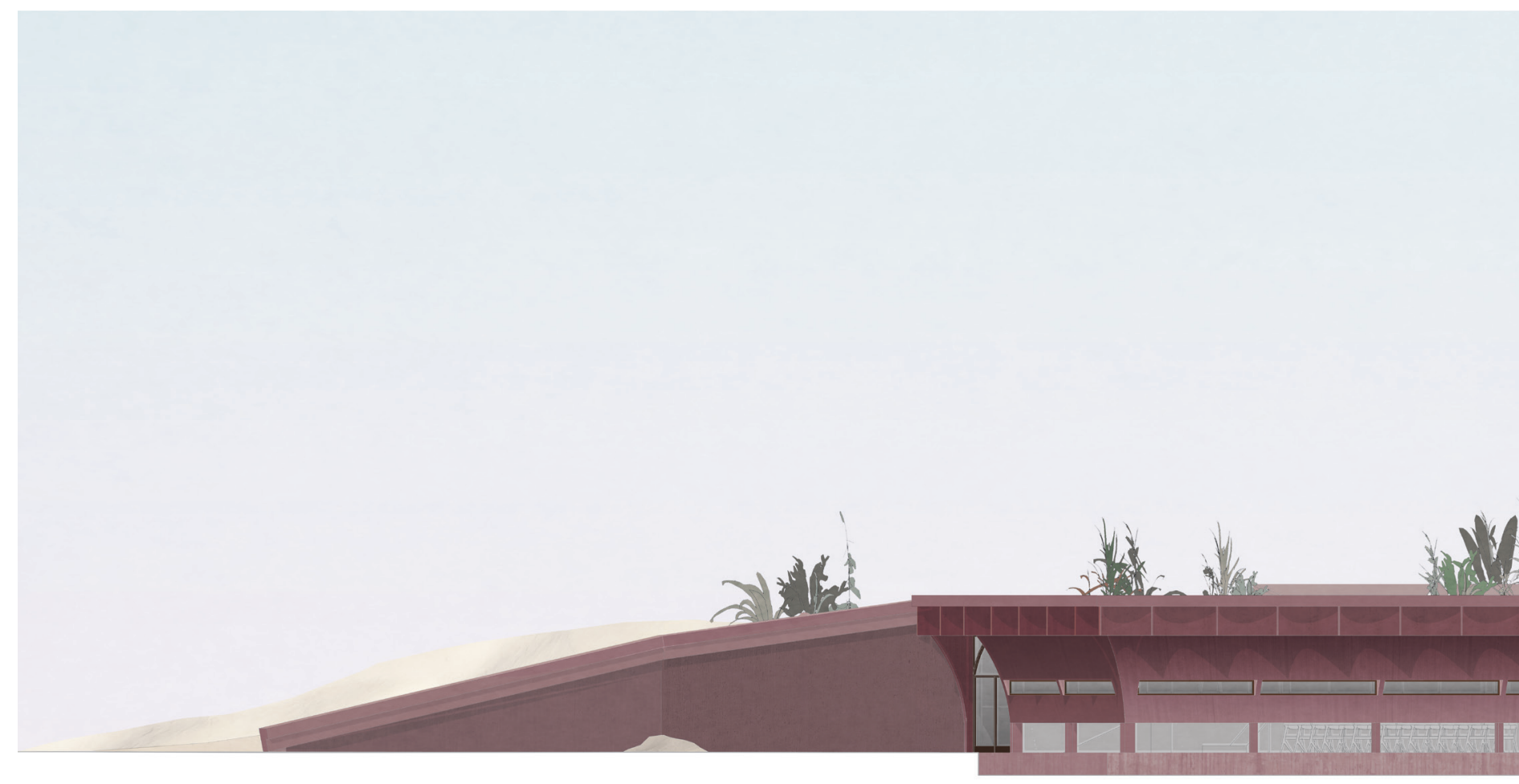

The result is a development of iteration four, a curved concrete-panelled façade which has thin slotted penetrations at eye height and gaps at ground level to allow for cleaning out sand, topped off with a repeated scalloped form at the lip and top (see figure 154). The concrete is emphasised with a 'garnet' pigmentation, which is applied to the exteriority of the building to give it character and contrast with the sand dunes and vegetation. The concrete is smoothly finished, but over time the material reveals itself as the environment wears it away with exposure to the sea, scratching of the sand and so on. This gives the clean form a textured, rough aesthetic, changing its character over time.
The façade also responds to the interior of the building and its programmes. The five previous iterations only looked at a corridor as the interior. This façade takes the interior programmes into account by adjusting the length of the slotted window to match the programmes, covering up the bottom opening when appropriate, such as in enclosed rooms such as offices and bathrooms.

The final 'clean form' is void of any 'loud' or visible ornamentation. The scallop-shaped arrangement at the lip of the roof and the central wall shielding the internal courtyard are the only repeated motifs that can be seen as symbolic. 


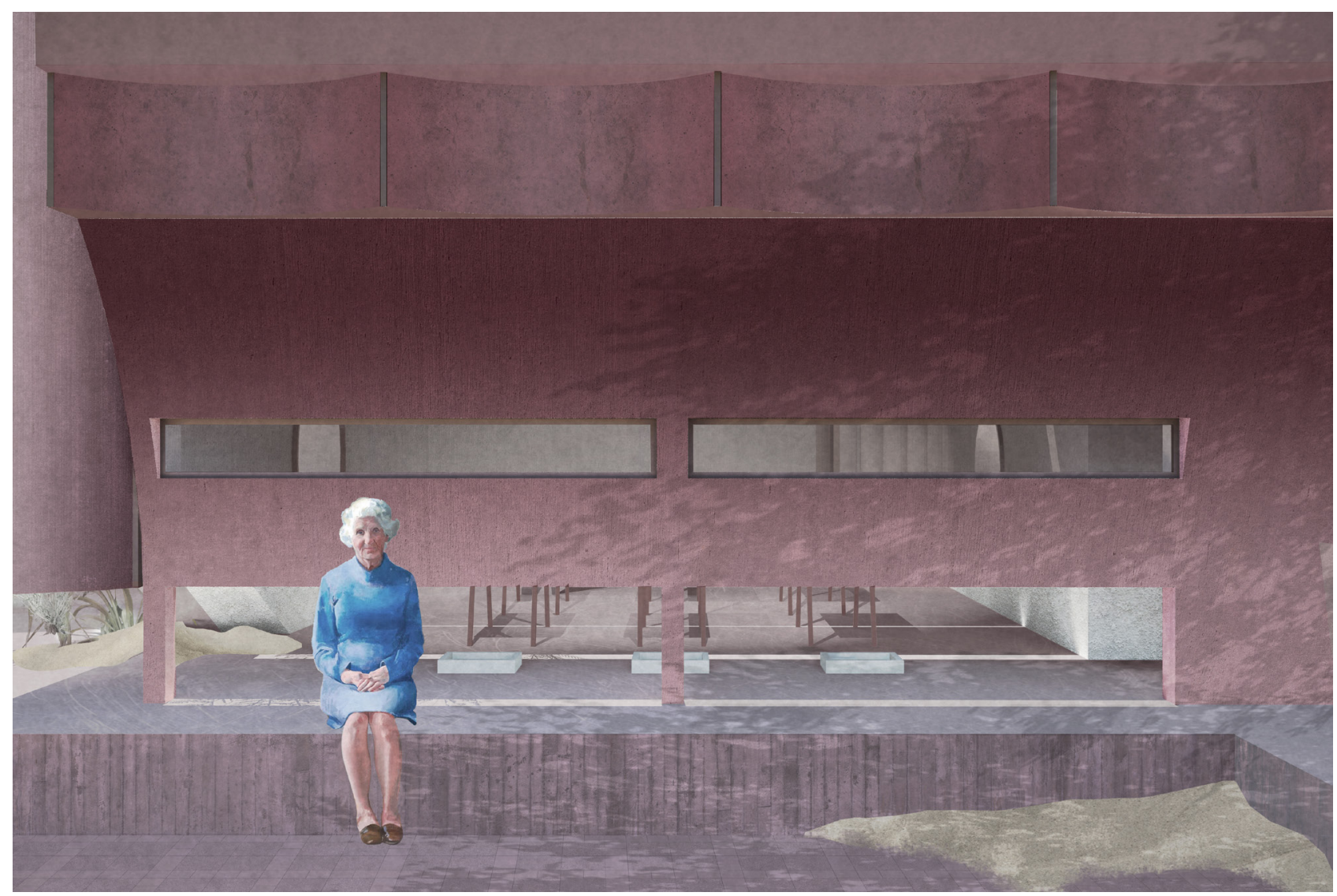

$\wedge$ Figure 155* View of the façade into bio-security chamber

$>$ Figure 156 1:50 Model - Southern Elevation

$>$ Figure 157 Scallop shaped motif

$>$ Figure 158

1:50 Model - Slotted windows 

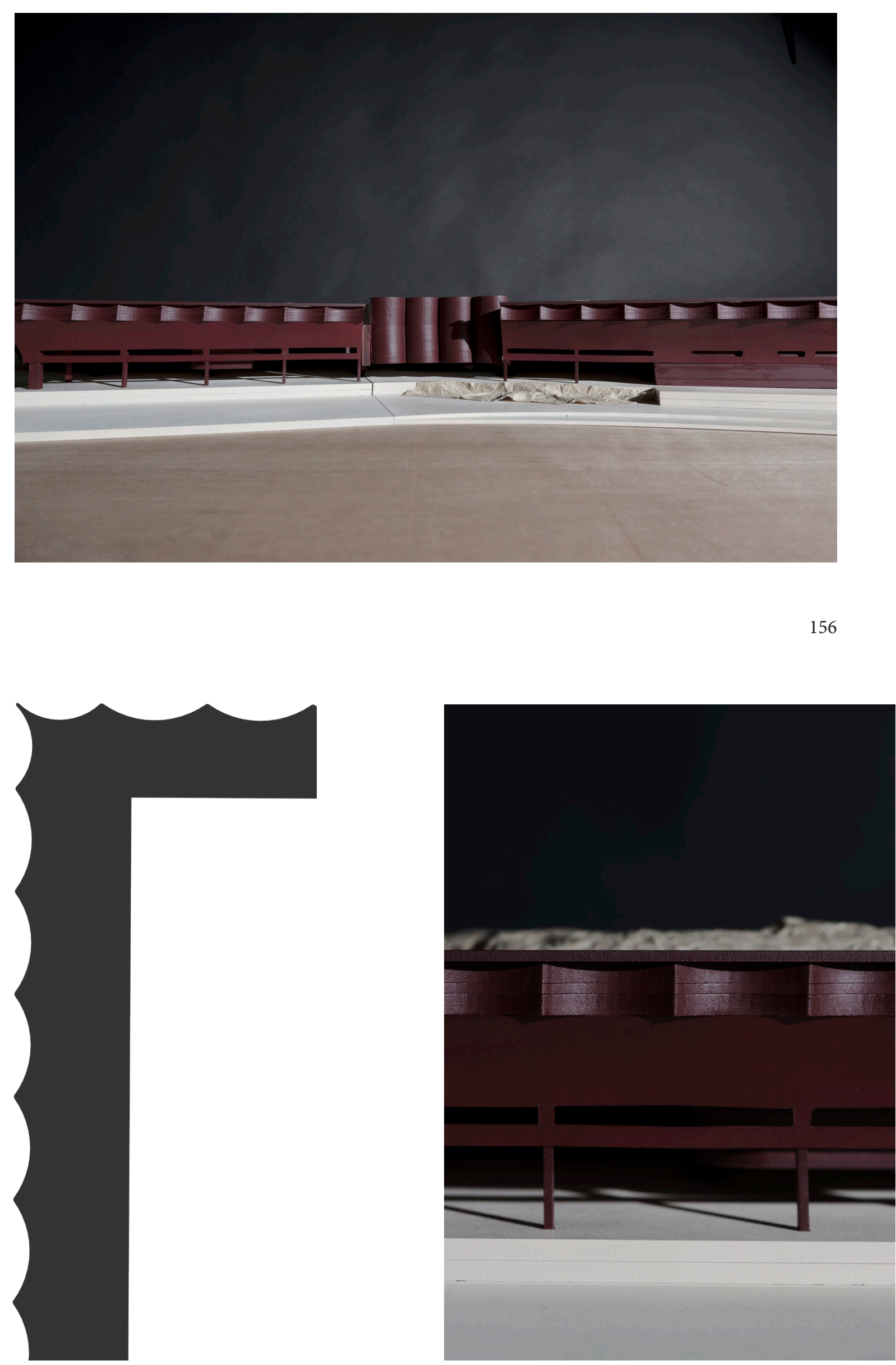


\section{ANCHOR POINTS}

Anchor points are nodes in which the programmes become central to reorienting the visitors. This strategy is driven by the building's horizontal form. The building's form operates on a longitudinal axis rather than a vertical one, generating spaces and programmes that aren't stacked but are splayed out. The anchor points respond to the arrangement of the circuitous plan. These moments complement the playful maziness of the journey by offering hierarchy and clarity in way-finding. These points are sized to retain intimacy if visitors are few in numbers and yet still accommodate larger groups of 20-30 visitors. The entrance, courtyard and bio-security room and waiting area become these points (see figure 159).

The internal courtyard is the most influential anchor point. All of the other programmes are concealed and buried while the courtyard is open from above. This particular moment releases the tension of being underground. It provides a feeling of weightlessness with this internal courtyard by being surrounded by concrete walls without the roof. It is also at this segment of the building that the form gets 'pinched', with the other segments arrayed at either side. This transforms the whole experience of the building as well as the figure of the design seen on plan. The elevation also responds to this pinch as well, revealing its shape through the building's façade. The pinch accentuates how the building's spine is shaped to the landscape of the dunes. It is a gesture that acknowledges the formation of the existing landscape. 


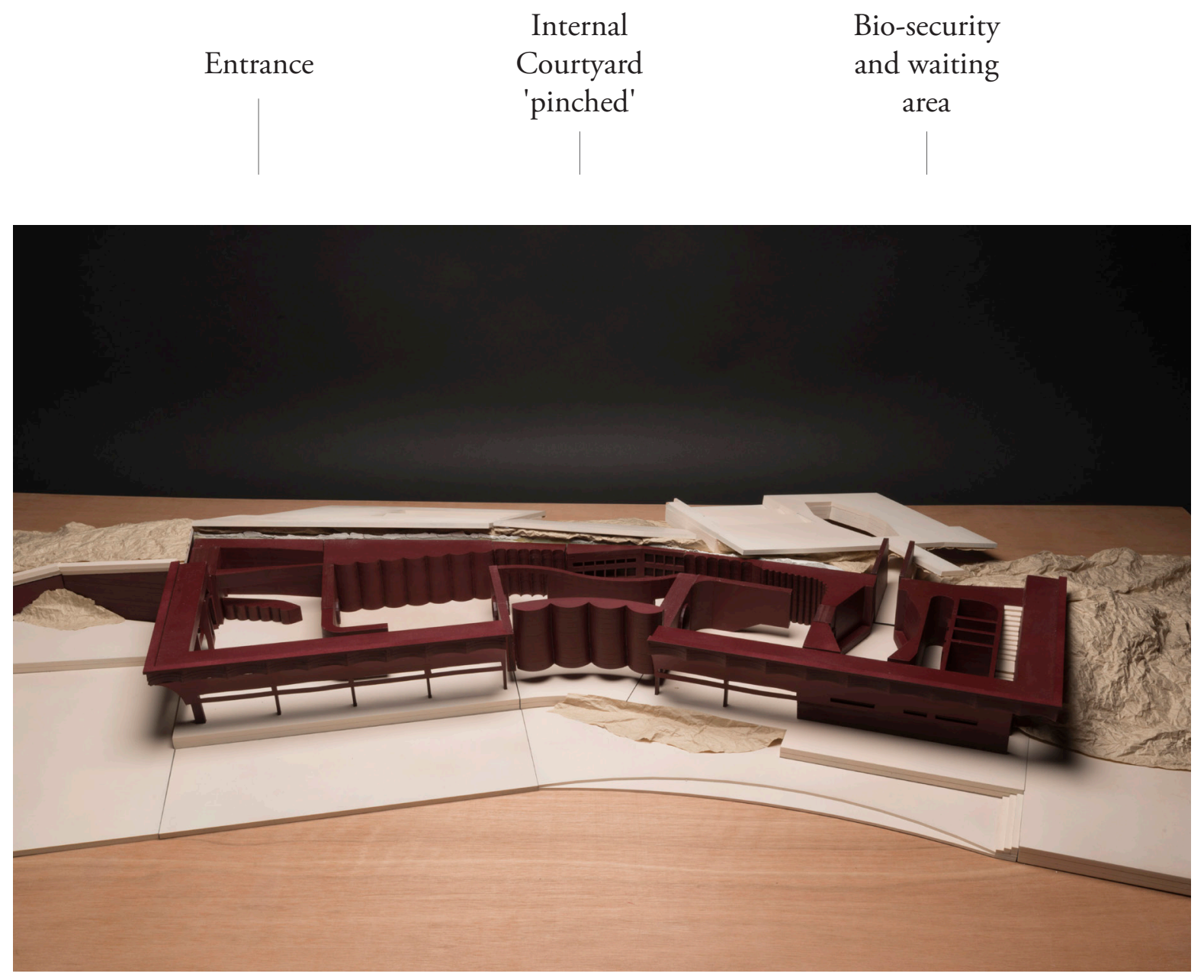




\section{MINOR AND MAJOR GEOMETRY}

The minor and major geometry consist of architectonic elements composed together throughout the building. The minor geometries of the building are smaller elements which look into detailing, while the major geometries have more influence on the spatial quality and expression of the interior.

The major geometry consists of the heavy concrete structure, particularly at the back wall, which is the spine of the building. The spine's playful sculpted form, as discussed in 'Fat Structure', is relayed and echoed through the carved scalloped form under the lip of the roof. This minor geometry discussed in 'Clean Form' provides rhythm as a repetitive motif, teasing out the expression of concrete in the interior.

The heavy back wall is complemented by the light façade, which is thin in comparison. The geometry of the façade, however, experiments with the idea of weight, contrasting with the heavier structural elements. The thick layered roof sits perched on top of a curved panel which tapers down to thin posts. The gaps under the curved panel also isolate the posts, exaggerating this tapered form. This tectonic strategy plays with the typical impression of a bunker being buried and connected to the ground and foundations, flipping it around instead so that lightness starts from the bottom, which is holding up a heavy top.

Circular windows which penetrate through the building longitudinally offer a sense of openness as another set of minor geometries (see figure 160). As the programmes are sequential in journey, these windows puncture through to allow visitors views to the next room (see figure 162 long section). 

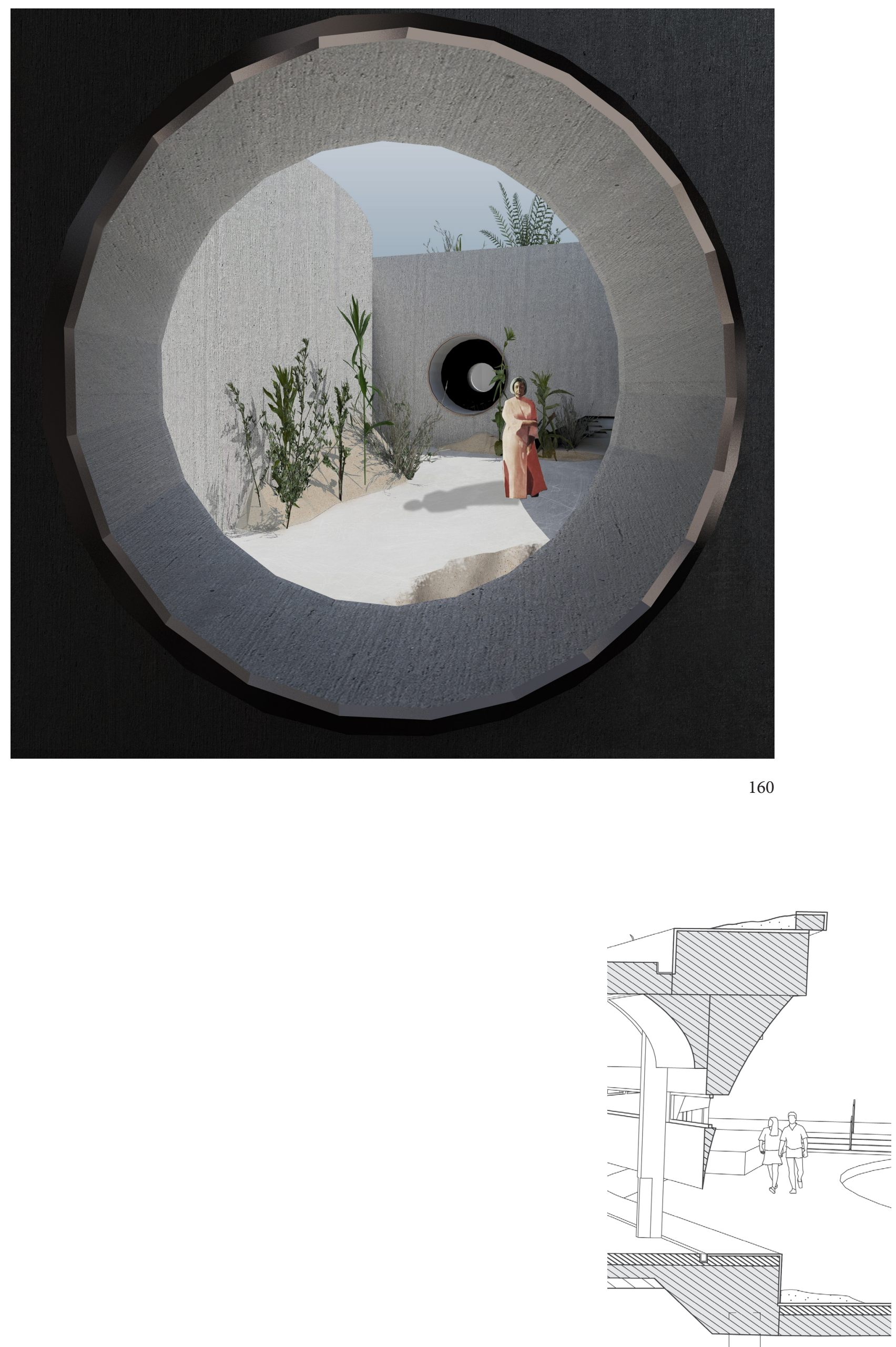
Ramp

Entrance \&

Small

reception

auditorium

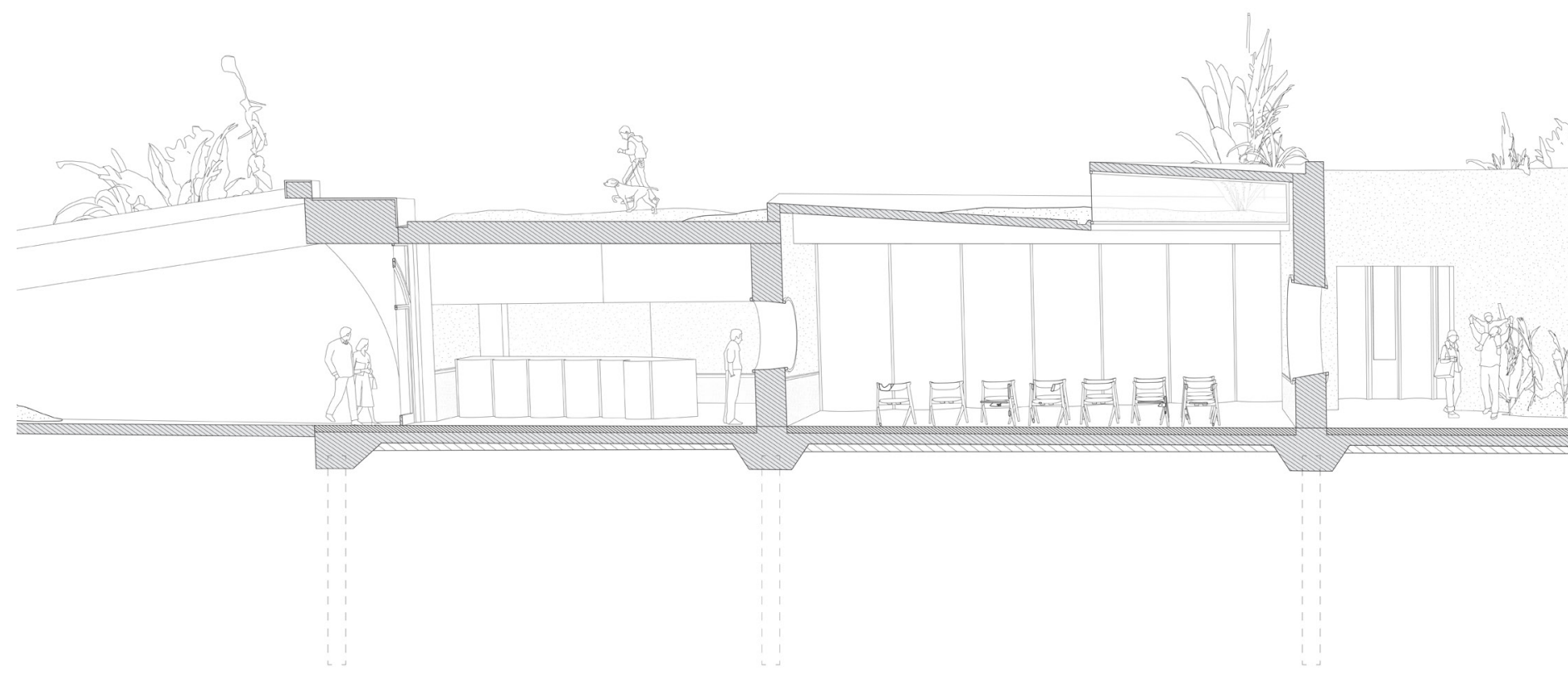




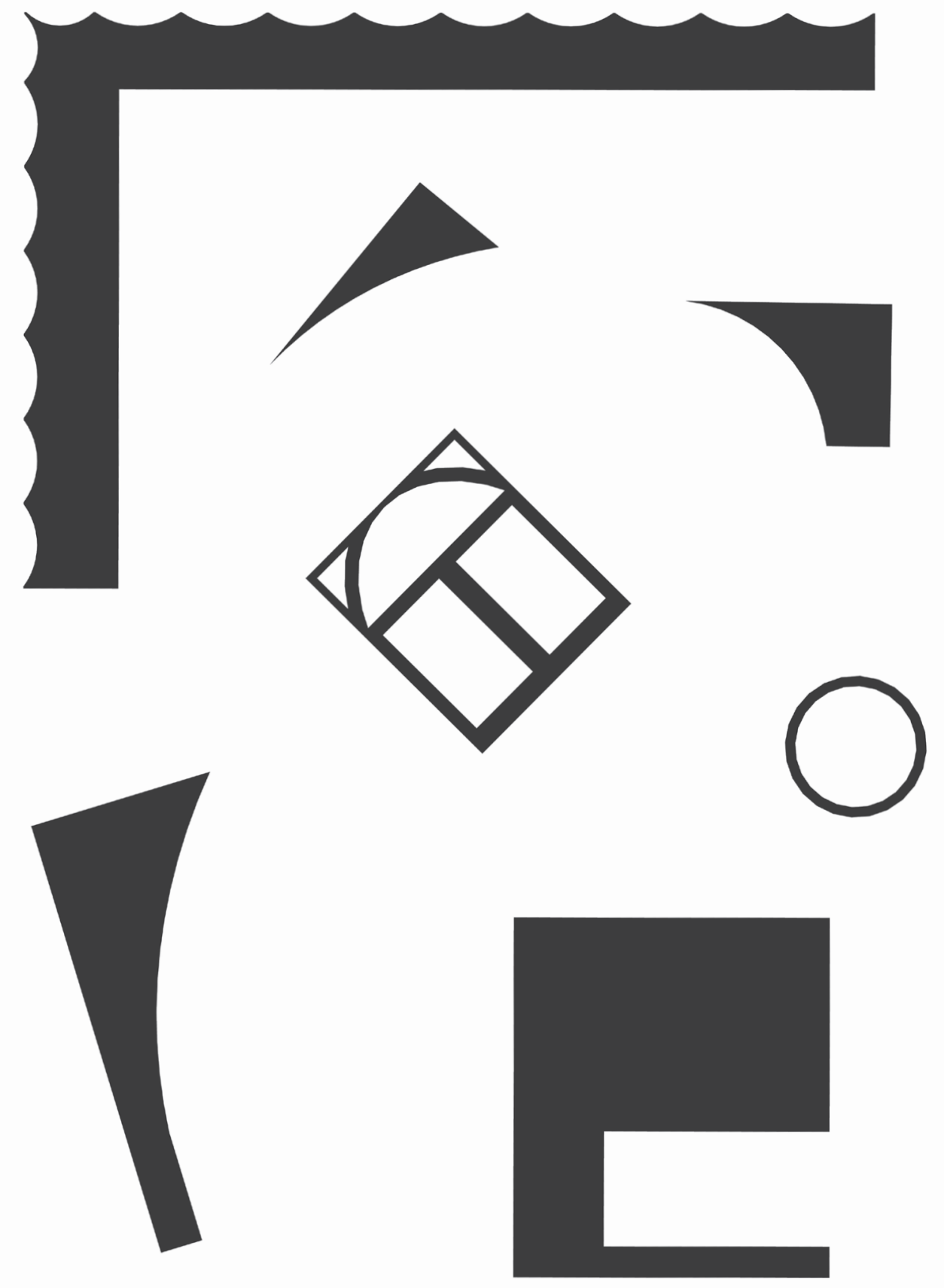




$$
\text { की? }
$$



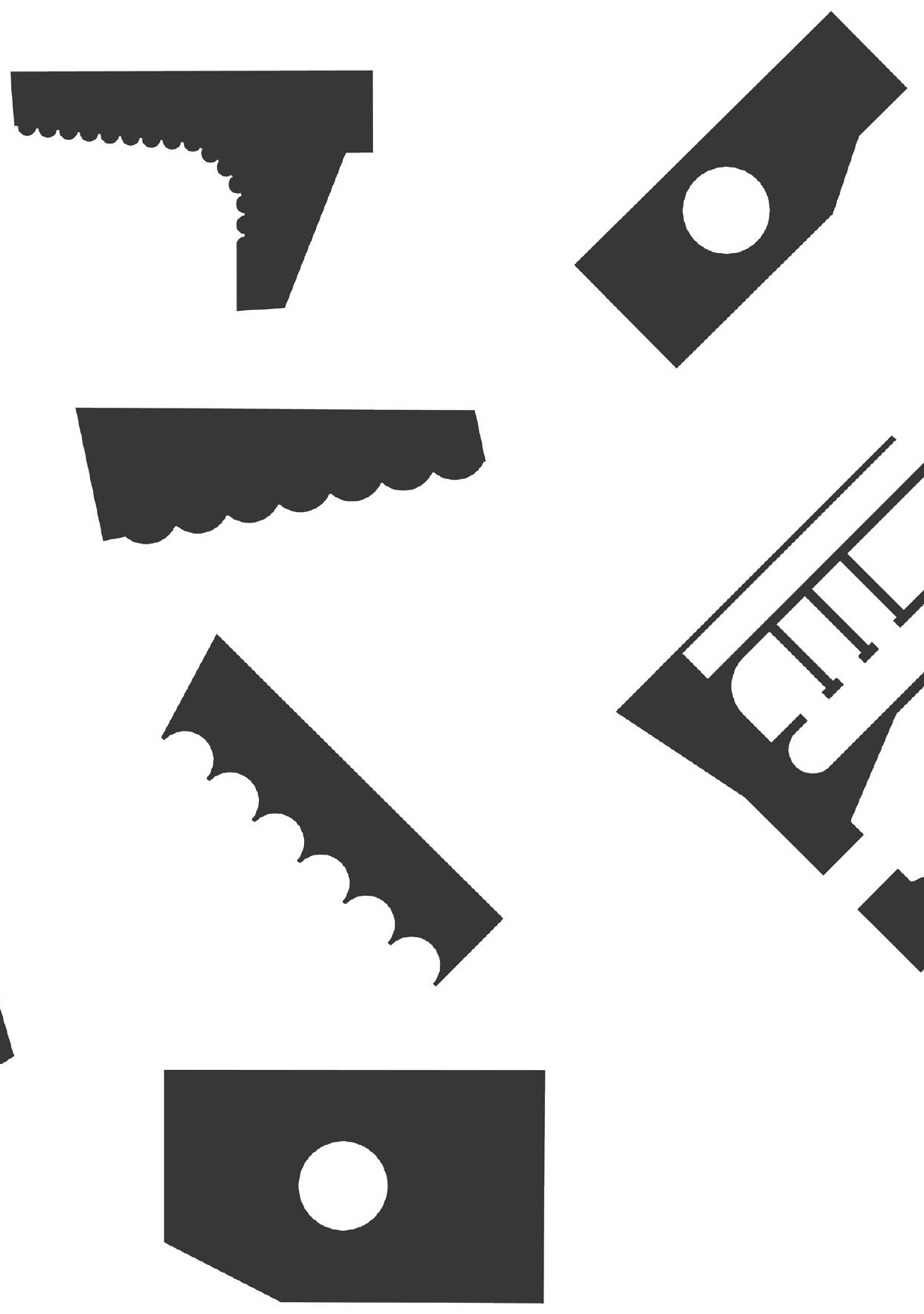

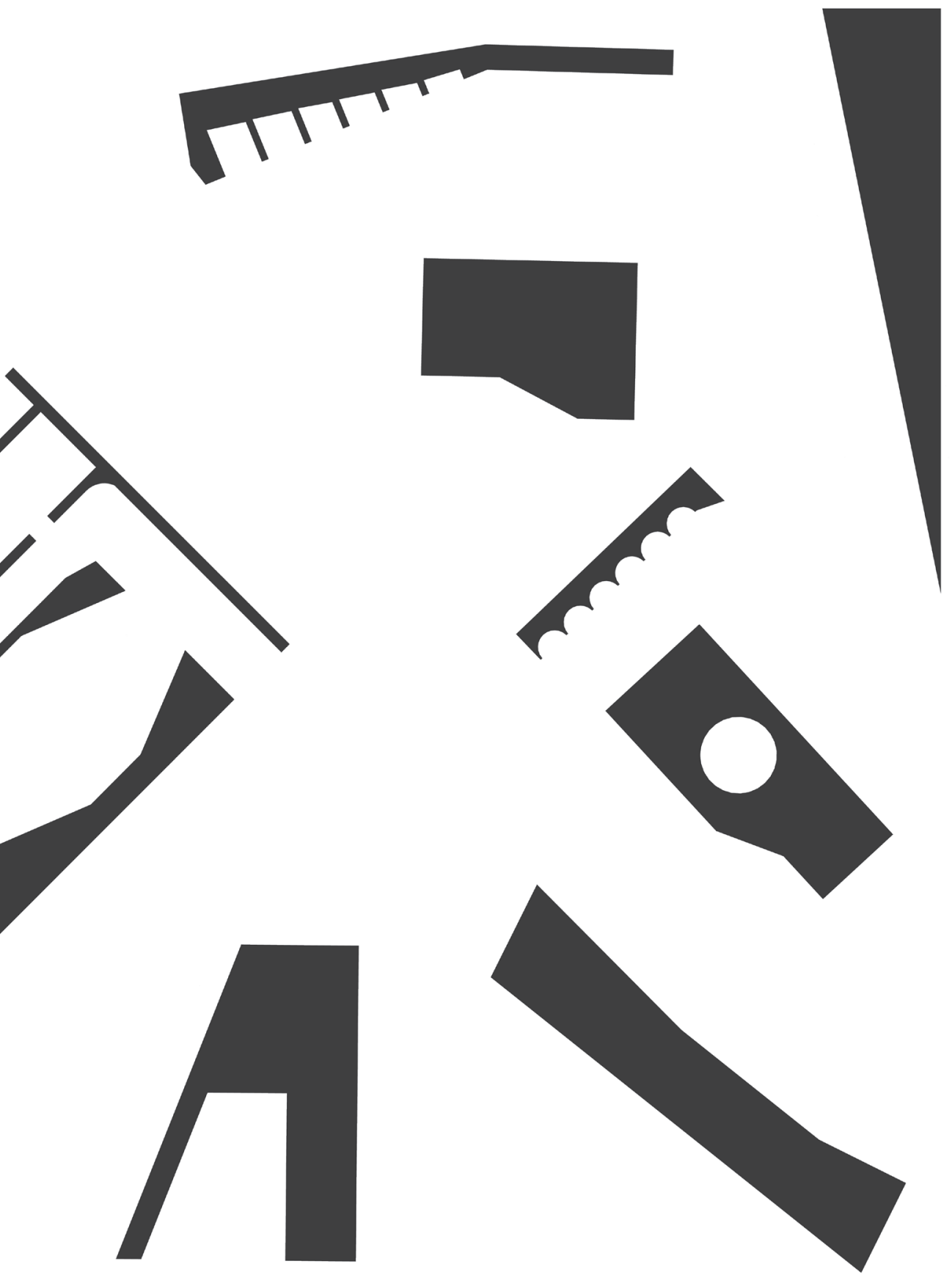

Figure 164 


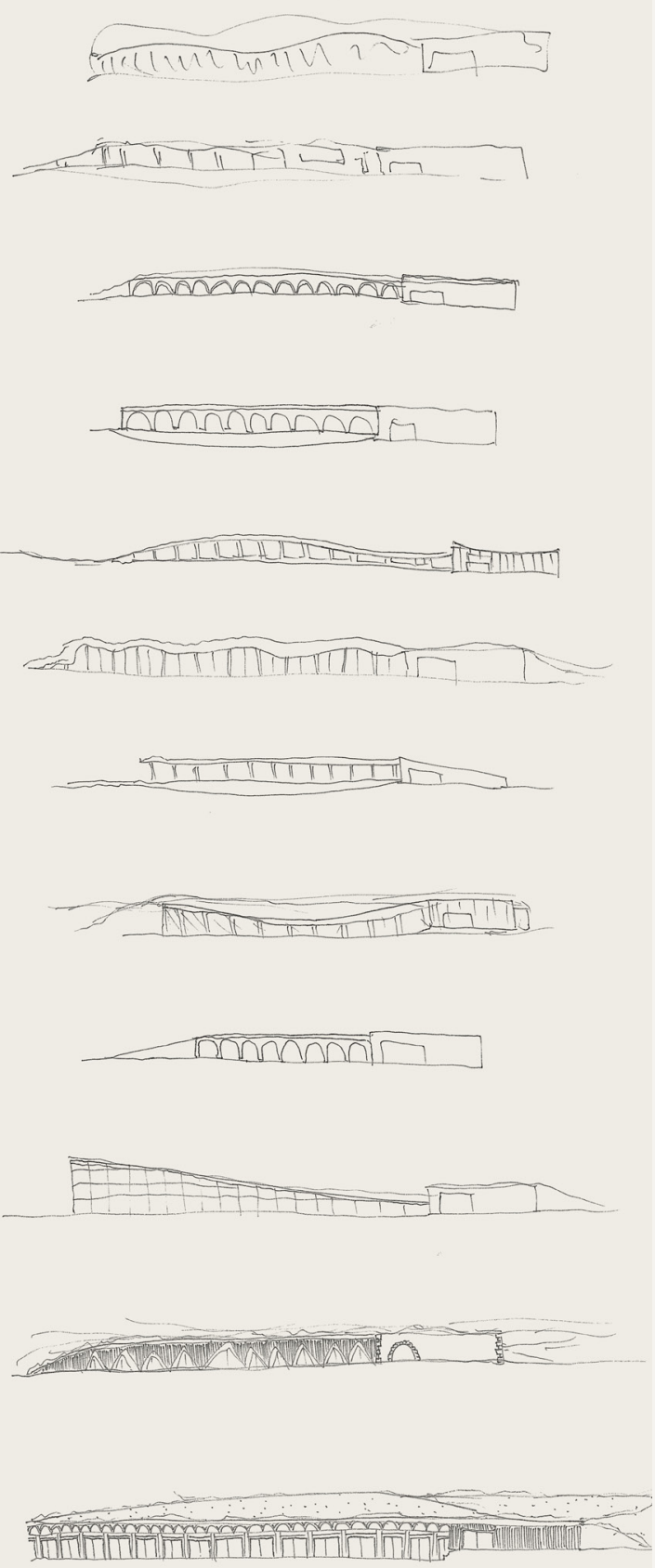

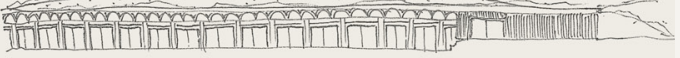

Figure 165

Rough elevational sketches 


\title{
PART 4
}

\section{REFLECTIONS and CONCLUSION}

\author{
REFLECTION on: Body of Work \\ Bridging the Gap - Transitioning to the Design Proposal \\ Design Process \\ The Future of the Referent \\ Synthesis - Dealing with Precedents
}




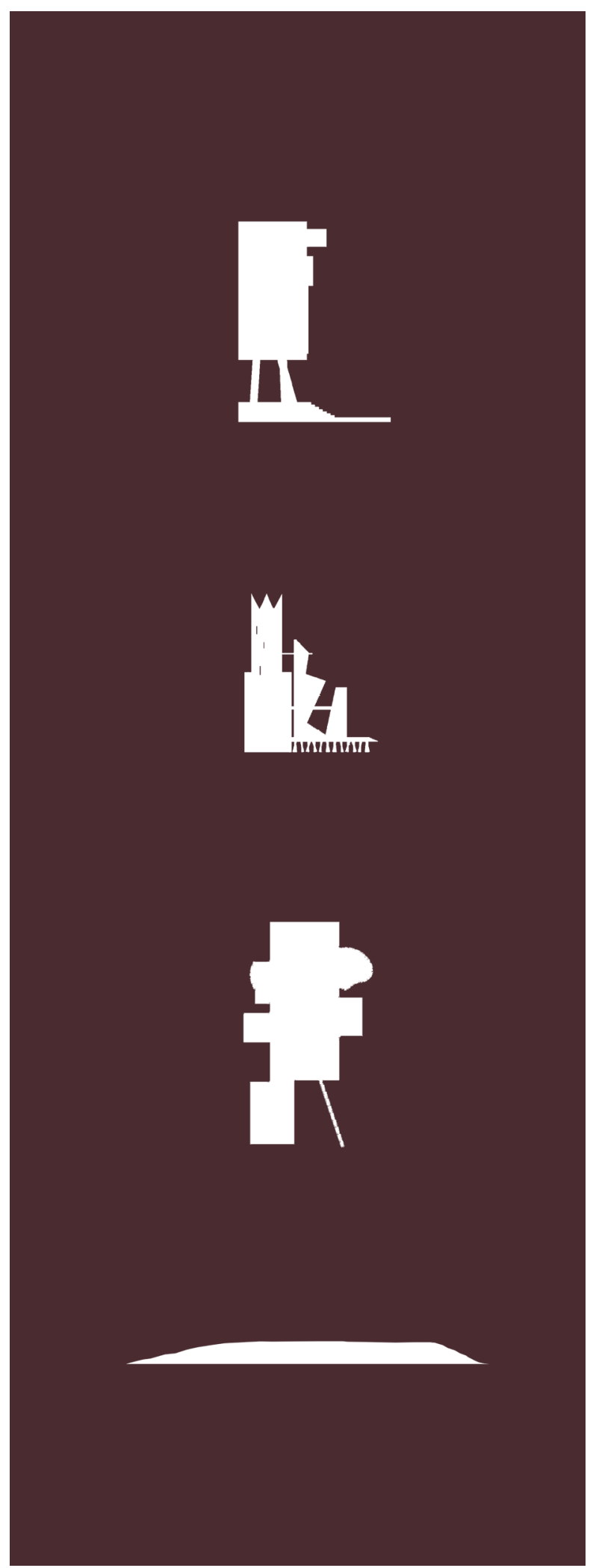




\section{BODY OF WORK}

The three experiments and final design proposal were framed around different inquiries around the referent questioning how figure works. Each set of experiments looked at different aspects around the referent; internal and external. This section will summarise and critically reflect on each experiment and design proposal.

\section{EXPERIMENT ONE}

\section{- FRIENDS}

Friends looked at synthesising sources from other architects with the architectural language of Hejduk to generate forms and figures. Site, programme and context were not involved in the process, resulting in a collection of produced forms in a playful language. Anthropomorphism or zoomorphism became clear when Friends were superimposed on site in Kapiti, creating havoc and interfering with the urban context. The forms and poetic language generated here can be seen in the subsequent experiments. In hindsight, not setting any parameters led to a more playful interaction with form, but also led down a path where image was more of a concern rather than any practical investigations of site, program, materiality, circulation and so on. The emphasis was more on imagery, disconnected and distant from a scheme of a building and visitors centre.

\footnotetext{
< Figure 166

The figure and its changing state
} 


\section{EXPERIMENT TWO}

\section{- THE WAKA VISION}

The design used the waka consciously as a metaphor to generate form and as a way of interpreting program. The entry to the building was at the back, not the side, the central tower was a mast and the elevated pier and elongated form mimicked the attributes of the waka. This was in response to a Kapiti Council member's vision of an upturned waka as the visitors centre, and the experiment was clear on the referent being the waka. The result was a cluster of forms, which were amalgamated and eventually refined to singular objects, but there was a lack of understanding and interrogation of the site. The design, however, started to look at internal cues like circulation with the inclusion of cross-programming, looking at the texture of surfaces to dictate movement. This became a successful aspect of the experiment and one that would be carried through to the design proposal.

\section{EXPERIMENT THREE}

\section{- ANTHROPOMORPHISM}

The design followed on from the waka building, looking at anthropomorphism as a referent. The impetus was to look at the imperfections of humans, reflecting them onto the building. Elements (the legs, face, skin, head and guts) of the building were accentuated and disfigured. This experiment overall was unsuccessful. The anthropomorphic elements led to questions like 'how tall should the legs be?' or 'how tilted should the head be?', but I realised it was difficult to produce a tangible building with these parameters. I struggled to find links or resonances between these elements and any architectural inquiry, such as light, materiality, atmosphere or construction. The Dr. Seussesque drawings explored the exteriority of the figure through elevation, leading to an array of images and depictions untranslatable to building. Drawing in plan however started a positive conversation on how the building could work in relation to its exterior form. It was here that the plan became essential in defining the form rather than the elevation. The plan became a hybrid of architectural elements as well as an expression of anthropomorphism. 


\section{THE DESIGN PROPOSAL}

The design proposal achieved a self-referential understanding of architecture. The building was what it was without trying to represent or be anything else, and it used programme, technology and form to give it density (Witte 80). Site also became an important condition for the design. The site itself became the referent, motivating how the building form would respond to it. This process led to a bunker as the visitors centre, buried under the sand dunes of MacLean Park. Six aspects or principles were also used to frame the design: the operational cues of Richard Serra's 'verb list compilation' became more central to the way design was approached, 'Fat Structure' looked at poché and carving from concrete, 'Circuitous Plan' looked at a labyrinth, 'Buried Building' looked at the landscape and building and 'Clean Form' looked at ornamentation with Adolf Loos as an influence for the façade. These principles were highly useful in framing the design with the internal referent in mind.

These principles could have been pushed further, however. For example, with 'Fat Structure' the sculpting of the concrete structure could have been explored using Serra's 'verb list compilation'. The current proposal is just an extruded form of a motif. What would happen if 'weaving' and 'tightening' were applied, along with 'carving'? I suspect the result would dramatically change the concrete form and its structure as well as how the programme interacted with it.

The design proposal opened an inquiry into how figure could work with an internal referent rather than an external referent, and through successful and unsuccessful tests, the progression of experiments led to a greater understanding of how the referent fundamentally informs figure. 


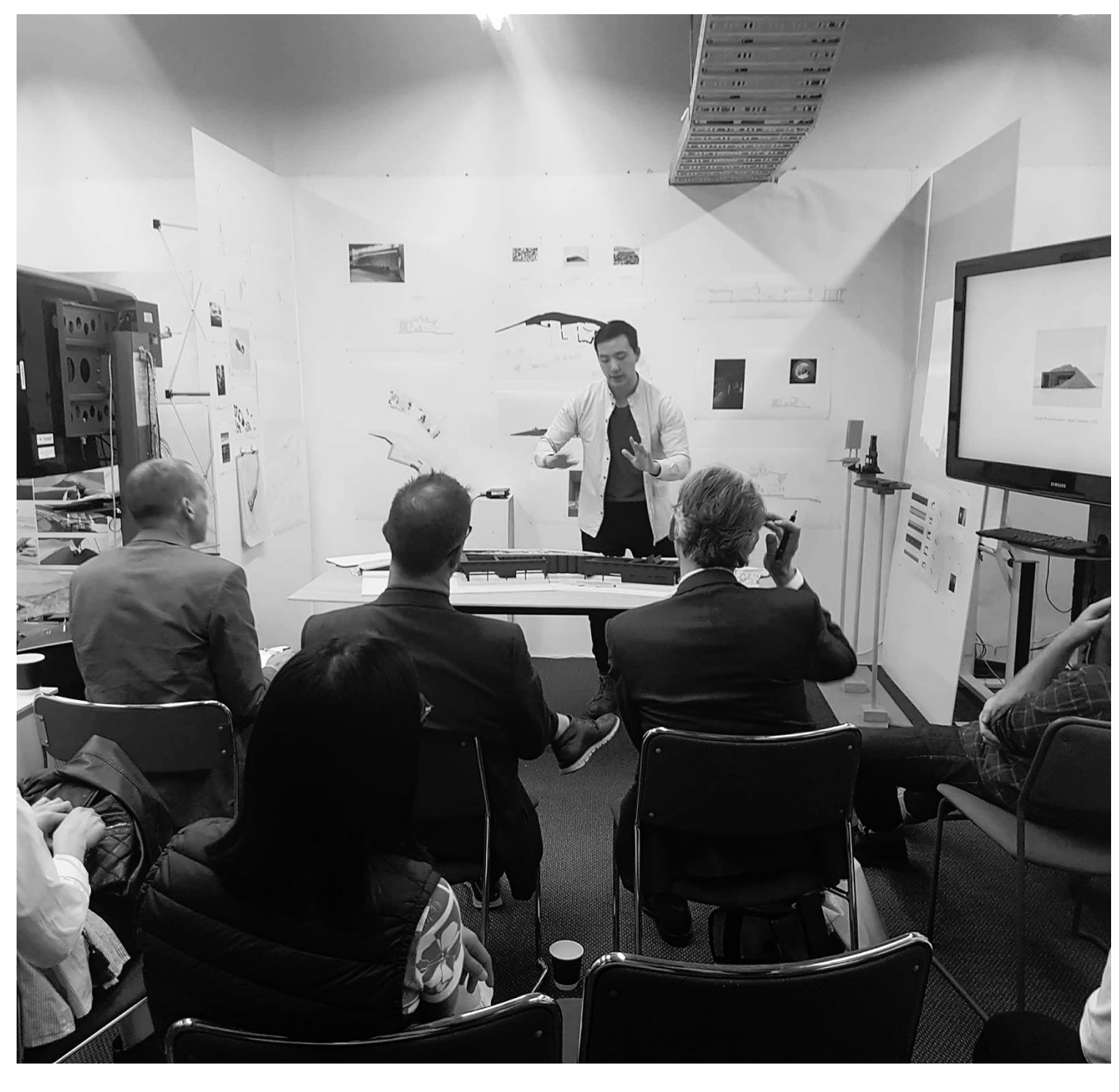




\section{"Did you betray form? Did you}

become afraid of it?"

"Bold forms suddenly become landscape, an opposite approach to how you started. How do you combine these two positions?"

\section{"Why did it become a landscape building?"}




\section{BRIDGING THE GAP}

There is an obvious jump from the initial three experiments to the design proposal. The reception of the design proposal raised questions about my sudden transition into exploring form and figure, noting that it was unclear how the experiments were connected with the design proposal, and that this work could seem like two different sets of projects, each designing a visitor bio-security centre. Were the experiments wasted time? Did I evade the problem of figure and representation?

In my opinion, the design proposal emerged through a learning process and through a series of experiments. There was no pre-conceived scheme or answer to form-making; these three experiments helped build up a tension and struggle, eventually leading to a realisation and point of discovery about how influential the referent is. I therefore do not see it as wasted time, but as time valuable for discovering a refreshing way of thinking. These three key ideas help frame this transition and sudden shift in the design from quirky to solemn.

PRIORITISING SITE

$$
\text { - BURIED NOT SUFFOCATED }
$$

My early work was driven by an interest in imagery linked with the elevation, mass and stature of the form on site. Could I have pushed on with these schemes, exploring elements of a technology-driven skin like Cook and Fournier's Kunsthaus Graz? Yes, but instead I decided to abandon the creatures created and to firstly prioritise and re-centralise the importance of site. This led to scaling the proportions down completely, reducing the height of the building. Abstract forms were finally confronted with the constraints of the site, like the nearby stream, shifting sand dunes, wind and so on. However, the building still sits as an alien in the landscape in comparison to the urban context, and I believe that I did not betray form. The figure has been buried, not suffocated. There is a combination of what was once fluid and excessive with what is now rigid and practical. 


\section{ARCHITECTURAL OPERATIONS \\ - FOCUSING ON THE SELF-REFERENTIAL}

Using Serra's 'verb compilation list' provided operational cues to inform design. This approach led to a more rigorous and clear process in designing without looking at representation or a narrative. The cue was no longer looking to imitate the imperfections of a human form or a waka. The design instead used principles to explore a different kind of formmaking, one that was more self-referential.

\section{RETAINING PLAYFULNESS \\ - WORKING WITH PLAN}

The playful nature of form-making has still been retained, expressed in the interiority rather than the exteriority of the design. With each principle ('Fat Structure', 'Circuitous Plan', 'Buried Building', etc.) there is a sense of playfulness. The visitors centre and bio-security becomes almost a ritual and performance before heading to Kapiti Island.

Working with plan internally was essential in connectingthe two stages. The playful plans in experiment three were carried on through to the design proposal (see figure 168). The intent shifted from designing appendages as an anthropomorphic building to looking at circulation with Kahn's study of Scottish castles. Playfulness was contained in the form's interiority and not expressed through the outside. It gives the building a sense of mystery and intrigue, rewarding visitors as they wander through. Previous upright forms on the beach revealed playful forms and shapes. Those forms were extrovertedly expressed, while the design proposal sits as an introverted building.

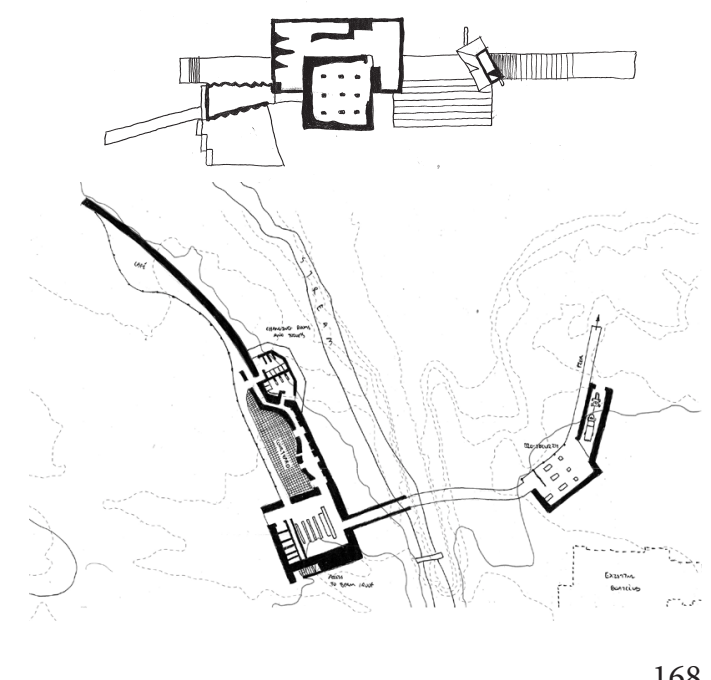




\section{DESIGN PROCESS}

The computer tools and programs used also shaped and defined the building design. The method of using SketchUp as the $3 \mathrm{D}$ modelling tool was prominent in the design process (see figure 169). SketchUp's operational cues are very much limited to 'extrude', 'copy', 'rotate', 'shift' and 'place'. SketchUp is different to Revit, which uses components like walls with preset thicknesses, often aligned to a grid, or Grasshopper, which uses parameters, algorithms and variables to generate dynamic forms. Unfortunately, my limited skillset and competency with these other programs pushed me down the path of using SketchUp. A future challenge which this current proposal lacks is to explore how concrete poché can be pushed beyond just a limited command or operation. Preston Scott Cohen's Taiyuan Museum of Art (see figure 170 \& 171) takes material and form beyond this with different operational cues, specifically 'to twist' and 'to fold', which generate a different and complex form that reflects the modern technology of computer and construction techniques. Though this example experiments wildly with form, the operations used in the design proposal in Kapiti feel conventional, plain and almost predictable. 

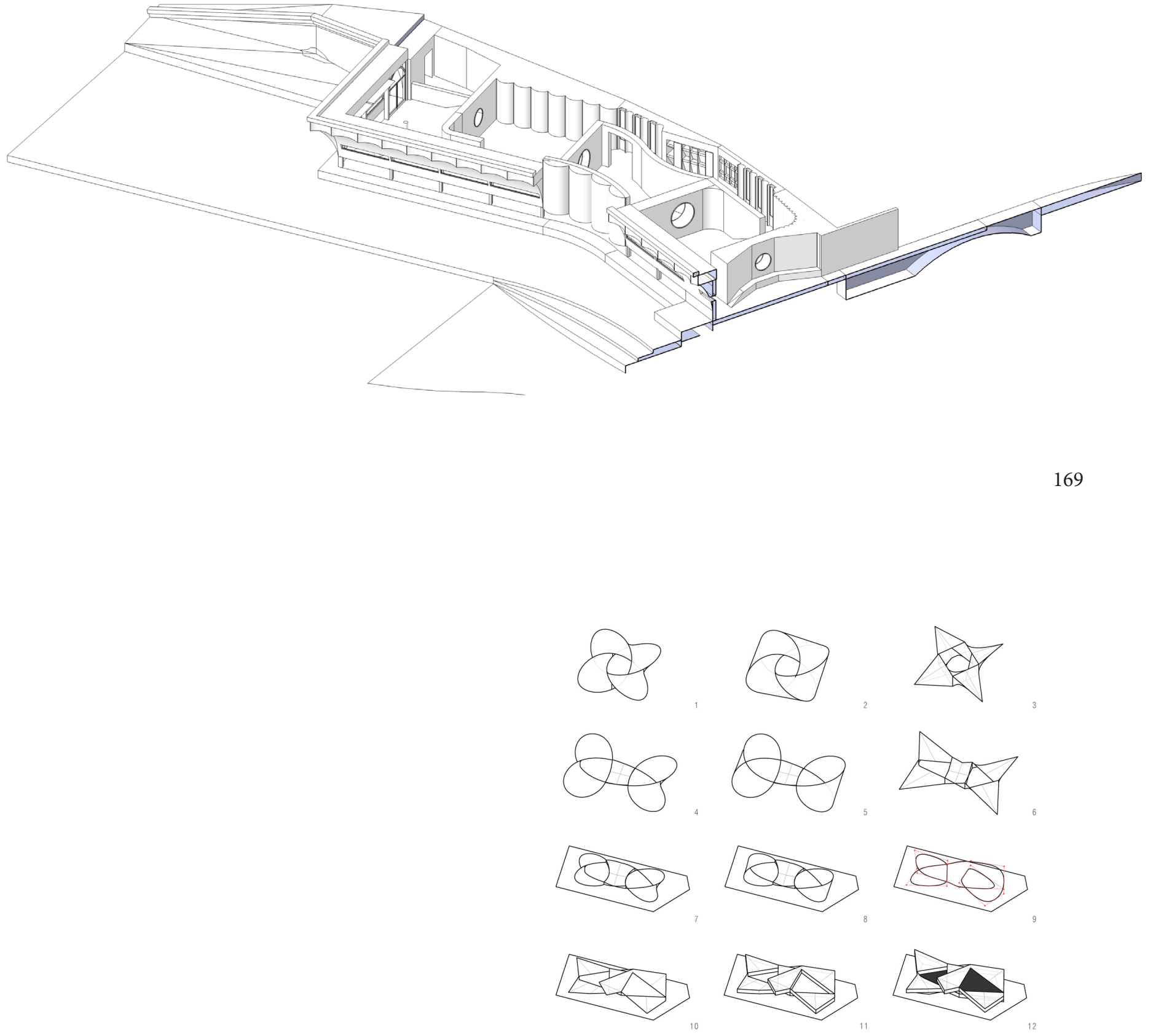


\section{THE FUTURE OF THE REFERENT}

The design proposal in Kapiti is stuck between being an 'invention', using site and materiality to dictate form, and 'abstraction', still attached to references. Valerio Olgiati admits himself that no works are completely non-referential buildings. They are still some sort of abstraction, but are not in the same vein as Angkor Wat and its representation of mountains. Can there be a balance between invention and abstraction when using a referent? 13 th century grotesques perched on top of buildings were used as decorative ornaments (see figure 172). Gargoyles were used for the function of diverting and draining water away from the building's masonry walls (see figure 173). The gargoyle operates with specific functions, yet still represents animal forms or caricatures fending off evil spirits. Gargoyles lie between abstraction and invention. Does form always have to be invented? 


\section{SYNTHESIS - \\ DEALING WITH PRECEDENTS}

Caruso and Maas's statement about building upon past references, where 'new' does not always mean good, challenges this stance on invention. Caruso and Maas accept the idea of references, but are conscious of how references are used. This is where image plays a part in this idea of building upon predecessors and the use of precedent.

There is a growing issue helped by the efficient accessibility of the internet with the use of image and precedent in architecture, particularly in architecture schools. The fast-paced, time constrained projects often lead to designs and projects that are strong in image, but lacking in any design rigour. These images are often not new and are déjà vus tethered to a vast collection of existing designs. Quite often, designs are inspired by Pinterest and Archdaily, the usual suspects. Architectural theorist and Professor Sarah Whiting challenges her students to answer the question, "what five projects do you like and why? Articulate why? It's easier to consume information than to consider it" (Whiting 110). Eisenman also states that "students today don't know precedent because they are in touch with media, and if an architect isn't featured in the media, he or she doesn't matter. How are they capable of describing anything about Rem if they don't know Mies, Corbu, and Venturi? In other words, if they don't know the history of ideas, not the history of facts" (Whiting 110). Precedent and image often overtake formmaking. Image often becomes a selling device and information gets lost. 
Throughout my work there is a common theme of appropriation from a particular group of architects. Entrepreneur Gary Vaynerchuk reiterates that nothing is written for the first time, and that the only thing we are doing is synthesising it for 2017 (Vaynerchuk). With this synthesis there is the danger of what we are taking in and using. My own work is evidence of different sources collected and synthesised to generate form (Sergison Bates, Caruso St John, Valerio Olgiati, Christian Kerez and so on). Motif, patterns and architectural language are where these sources have influenced my process in form-making, where I admit often image becomes the driver. Being aware of this, the six design principles helped me to frame and find reasons for why decisions were made and why certain sources were chosen. It was a challenge to look beyond image and to analyse sources for their content. Learning beyond image became fascinating, and I believe led to a richer understanding of how form can work. The result was reasoning that was linked to something pragmatic, yet still playful and experimental. 


\section{GONCLUSION}

This research explores how form-making can work, how a referent is used in design and how it affects form. Experiment one looks at form-making through the derivation of 'heroes'. Experiment two focuses on abstracting and using the metaphor of a waka. Experiment three explores anthropomorphic and zoomorphic figures through the architectural language developed by John Hejduk.

The design proposal buries these figures in the site's sand dunes, offering a different kind of architectural form-making. This proposal presents an appropriate bio-security facility with additional programmes, fit for the importance of a national reserve. The building interlinks with the site of MacLean Park, reinforcing the berm and sheltering the park as well providing a line of strength against sea level rise and future storms. The design is both a response to the environment and its harsh conditions, as well as a response to how form is generated in a public building. This response is shaped through a design process of experimentation with the external referent: friends, waka and anthropomorphism. The external referent in each is teased and stretched, producing forms that are quite obscure and unfitting.

The departure from the first three parts for the design proposal led to an inquisition at a design review. Was I afraid of my own figures? Did I eventually betray them? This point in the design process reinforced the idea that I was not abandoning the figures, but that I was abandoning their references. I was now designing through the non-referential, rather than through abstraction. Understanding the difference between operational cues like Serra's 'Verb list' and representational cues and their eventual disconnect from architecture was an important point of discovery and revelation. 
I also became self-aware of my own use of image and deriving from sources. My work began to be a synthesis of other people's work. It made me realise the ways in which we work with precedent and whether we use it for image or information. These findings I believe are useful in a wider disciplinary context, especially at a tertiary level where students produce work lacking in architectural rigour and understanding, placing priority on image over information. In response to the initial objectives and these findings, then, how can form-making and precedent be taught in a way where representation and abstraction are not as heavily relied on? Will they ever be abandoned? 




\section{WORKS CITED}

Aureli, Pier Vittorio, and Martino Tattara. Dogma: 11 Projects. AA Publications. 2013. Print.

Boudet, Dominque. 2003. No Barragan, No Cry Anri Sala In. 51N4E Double of nothing. Belgium. 2011. Print

Caruso, Adam. "Adam Caruso: Novelty is nonsense". Youtube [video file]. 28 February, 2017. $<$ https://www.youtube.com/watch?v=Jyfq7uL$\mathrm{NXg}>$. Accessed 8 December 2017.

Department of Conservation. "Kapiti Island Nature Reserve”. Web. 2018. <http://www.doc. govt.nz/kapitiisland>. Accessed 26 March 2018.

Fearon Hay Architects. “Te Kaitaka - 'The Cloak'. Web. 2017 <https://www.fearonhay.com/projects/ te-kaitaka-the-cloak>. Accessed 6 December 2017.

Gurunathan, K. (2016) Students to design Kapiti Island biosecurity hub. Kapiti News. Web. <http://m.nzherald.co.nz/kapiti-news/news/article. cfm?c_id=1503789\&objectid=11699327?

Hays, K. Michael. Sanctuaries, the Last Work of John Hejduk. Whitney Museum of American Art. 2002. Print.

Hejduk, John. Mask of Medusa. Rizzoli. Ed. 1. 1985. Print.

.Id Community - Demographic Resources.

"Kapiti Coast Population and Age Structure". Web. 2018. <https://forecast.idnz.co.nz/kapiti/ population-age-structure $>$. Accessed $26 \mathrm{March}$ 2018.

Insul 8.0. [computer software]. 2014. $<$ http://www.insul.co.nz/news/version-80/>

Kahn, Louis. Letter to Richard Demarco, August 28 1973, Box LIK 10, Kahn Collection, University of Pennsylvania.
Kahn, Louis. "Louis I. Kahn: Writings, Lectures, Interviews" edited by Allessandra Latour. Rizzoli. New York. 1991. Print.

Kerez, Christian. "Glossary: A Conversation with Christian Kerez” El Croquis. 2010-15. 17, 19. Print.

Kipnis, Jeffrey. Talk-Show: A Conversation on "The Piranesi Variations". Vimeo [video file]. 2013. <https://vimeo.com/61530314>. Accessed 7 December 2017.

Koolhaas. Rem. Delirious New York. The Monacelli Press. 1994. Print.

Krauss, Rosalind. Sculpture in the Expanded Field. MIT Press. 1979. Print.

Lallous's Lab. "The health benefits of 'Foot Reflexology Path'. Web. 14 November, 2014. <http://lallouslab.net/2014/11/14/health-benefitsof-foot-reflexology-path/>. Accessed 1 February 2018.

Loos, Adolf. “Ornament and Crime.” Programs and manifestoes on 20th-century architecture by Ulrich Conrads. MIT Press. 1970. Print.

Maas, Winy. "Architects are suffering from 'originality syndrome' and should copy more, says Winy Maas. Dezeen. Web. 20 October, 2017. <https://www.dezeen.com/2017/10/20/architectssuffering-originality-syndrome-says-winy-maasmvrdv-copy-paste/>. Accessed 3 November 2017.

Maclean, Chris. "Wellington region - Population, Te Ara - the Encyclopedia of New Zealand". Web. 2015. <http://www.TeAra.govt.nz/en/wellingtonregion/page-12>. Accessed 25 February 2018. 
Meades, Jonathan. "Bunkers, Brutalism and Bloody-mindedness Part 1". Kanopy [video file]. 2014. < https://vuw.kanopystreaming.com/video/ bunkers-brutalism-and-bloody-mindednessconcrete-poetry-jonathan-meades $>$. Accessed 19 January 2018.

Olgiati, Valerio. "Valerio Olgiati's Ideational Inventory”. El Croquis. 1996-2011. Print.

OMA. "Seattle Central Library". Web. 2004. <http://oma.eu/projects/seattle-central-library>. Accessed 7 December 2017.

Oxford Dictionary. Oxford University Press. Web. Various. <https://en.oxforddictionaries.com/>

Rawlinsons. "Rawlinsons New Zealand Construction Handbook" Rawlinsons Media Limited. Ed. 26. 2011. Print.

Sergison Bates. "Interview with Stephen Bates, Jonathan Sergison and Mark Tuff". El Croquis. 2004-16. Print.

Shaskey, Tara. "Len Lye Centre visitor numbers buck trend”. Stuff. Web. April 212017. < https://www.stuff.co.nz/taranaki-daily-news/ news/91793196/Len-Lye-Centre-visitor-numbersbuck-trend> . Accessed 18 December 2017.

Shelley, Mary. Frankenstein. 1831. Print

Soulage, Pierre. "Pierre Soulages : Outrenoir". Youtube [video file]. 27 January, 2017. <https://www.youtube.com/watch?v=azb6K-R_ $\mathrm{q} 8 \mathrm{M} \& \mathrm{t}=23 \mathrm{~s}>$. Accessed 6 December 2017.

Soundproofing Company Inc. "Understanding STC and STC Ratings". Web. <http://www. soundproofingcompany.com/soundproofing101/ understanding-stc/>. Accessed 18 December 2017.
Studio Pacific Architecture. "Airways Wellington Control Tower". Web. 2017. <http://www. studiopacific.co.nz/projects/2017/airwayswellington-control-tower/>. Accessed 6 December 2017.

Vaynerchuk, Gary. "Gary Vaynerchuk on Creative Live. Chase Jarvis Live. Chase Jarvis”. Youtube [video file] 2016. <https://www.youtube.com/ watch?v=LrJSjSy8Ymo>. Accessed 26 March 2018.

Whiting, Sarah. "I am interested in a project of engaged autonomy". LOG 28 Summer Stocktaking 2013, authored by Peter Eisenman \& Anthony Vidler. Anyone Corporation. New York. 2013. Print.

Witte, Ron. "Go Figure." LOG Spring Summer 2005, edited by Cynthia Davidson. Anyone Corporation. New York. 2005. Print. 


\section{FIGURE LIST}

All figures not attributed are author's own,

Figure 4

Figure 5

Figure 6

Figure 20

Figure 33

Figure 35

Figure 57

Figure 58

Figure 59

Figure 71

Figure $72 \& 73$
Te Kaitaka - 'The Cloak'

Source: <https://www.fearonhay.com/projects/te-kaitaka-the-cloak>

Airways Wellington Control Tower

Source: <http://www.studiopacific.co.nz/projects/2017/airways-wellingtoncontrol-tower/>

Museum of New Zealand Te Papa Tongarewa

Source: <https://www.wellingtonnz.com/discover/sights-activities/

museum-of-new-zealand-te-papa-tongarewa/>

Kapiti Island Photo

Source: <https://commons.wikimedia.org/wiki/File:Kapiti_and_

Paraparaumu,_New_Zealand,_6_July_2005_-_Flickr_-_PhillipC.jpg>

U.S Assault Troops landing on Omaha Beach, 6 June 1944

Source: < https://www.history.navy.mil/our-collections/photography/wars-

and-events/world-war-ii/d-day/SC-320901.html>

Victims

Source: Hejduk, John. Victims. Architectural Association Publications.

London 1986. Print.

Maori Waka with Sail

Source: <http://sixboats.co.nz/wakas-part-3/>

Te Wharewaka

Source: <http://architectureplus.co.nz/public/wharewaka/>

Waka Maori

Source: <http://toa.net.nz/work/waka/>

Delirious New York Muscle Bar

Source: Koolhaas. Rem. Delirious New York. The Monacelli Press. 1994.

Print. Page 159

Caruso St John's Paving

Source: Caruso St John. "Glossary: A Conversation with Christian Kerez"

El Croquis. 2010-15. 19. Print. 
Figure 74

Figure 76

Figure 88

Figure 89

Figure $90 \& 91$

Figure 92

Figure $93 \& 94$

Figure 95

Figure 100

Figure 101
Lina Bo Bardis SESC Pompeia

Source: <https://www.archdaily.com/623834/lina-bo-bardi-togetheropens-at-the-graham-foundation/55399484e58ece7357000204-lina-bobardi-together-opens-at-the-graham-foundation-image>

Kunsthaus Graz

Source: <https://www.archdaily.com/296275/media-architecture-oscarsawards-announced/3-782>

Tikal

Source: <https://www.belizehub.com/tikal-from-belize/>

Angkor Wat

Source: https://www.lonelyplanet.com/cambodia/travel-tips-and-articles/ angkor-what-getting-to-know-cambodias-most-iconic-temple/40625c8c8a11-5710-a052-1479d2779f60

Ramones

Source: Aureli, Pier Vittorio, and Martino Tattara. Dogma: 11 Projects. AA Publications. 2013. Print.

Painting

Source: Peinture 17 novembre 2008 by Pierre Soulages.

Seattle Central Library

Source: <http://oma.eu/projects/seattle-central-library>

Winy Maas's Generator

Source: <https://www.dezeen.com/2017/10/20/architects-sufferingoriginality-syndrome-says-winy-maas-mvrdv-copy-paste/>

Galveston Seawall

Source: <http://www.gthcenter.org/exhibits/seawall/Concrete/G-

5925.2FF1-15.htm>

Sumner Surf Life Saving

Source: <http://www.hawkins.co.nz/projects/sumner-surf-lifesaving-club> 
Figure 111

Figure 114

Figure 117

Figure 128

Figure 129

Figure 132

Figure 133

Figure 134

Figure 135

Figure 136
Richard Serra Verb List

Source: 1967-68. The Museum of Modern Art, New York.

Len Lye Centre

Source: <https://www.archdaily.com/771278/len-lye-centre-pattersonassociates>

Louis Kahn Castle Sketches

Source: British Castle Floor Plan Sketches by Kahn. Source: Brownlee, David B., and David G. De Long. Louis I. Kahn: In the Realm of Architecture. Los Angeles: Museum of Contemporary Art, Rizzoli, 1991, 68.

Nolli Map

Source: Nolli, Giambattista (1748) The Nolli Map.

Hamstead Housing

Source: Sergison Bates. "Interview with Stephen Bates, Jonathan Sergison and Mark Tuff”. El Croquis. 2004-16. Print.

The Expanded Field

Source: Krauss, Rosalind. Sculpture in the Expanded Field. MIT Press. 1979. Print.

Partially Buried Woodshed

Source: Partially Buried Wood Shed (1970). Image from Field Trips: Bernd and Hilla Becher / Robert Smithson. Porto: Museu Serralves, 2001.

Tower Flower

Source: <https://www.archdaily.com/245014/tower-flower-edouard-francoi s/501874b828ba0d33a8000e49-tower-flower-edouard-francois-image>

Seascape Retreat

Source: <https://www.archdaily.com/790107/seascape-retreat-pattersons>

Snoetta Cave Painting

Source: <https://www.wallpaper.com/art/snohetta-international-cave-artcentre-brings-lascaux-paintings-to-light> 
Figure 168 \& 169 Taiyuan Museum of Art

Source: <https://www.designboom.com/architecture/preston-scott-cohentaiyuan-museum-of-art-china/gallery/>

Figure 170

Grotesque

Source: <https://www.slideshare.net/guimera/gargoyles-and-chimeras>

Figure $171 \quad$ Gargoyle

Source: <http://twistedsifter.com/2013/04/gargoyle-and-grotesquesculptures-around-the-world/> 
